University of Rhode Island

DigitalCommons@URI

Open Access Master's Theses

1997

\title{
STRATEGIC PLANNING: A CASE ILLUSTRATION
}

Christopher Delvaille

University of Rhode Island

Follow this and additional works at: https://digitalcommons.uri.edu/theses

\section{Recommended Citation}

Delvaille, Christopher, "STRATEGIC PLANNING: A CASE ILLUSTRATION" (1997). Open Access Master's

Theses. Paper 378.

https://digitalcommons.uri.edu/theses/378

This Thesis is brought to you for free and open access by DigitalCommons@URI. It has been accepted for inclusion in Open Access Master's Theses by an authorized administrator of DigitalCommons@URI. For more information, please contact digitalcommons-group@uri.edu. 


\section{STRATEGIC PLANNING:}

A CASE ILLUSTRATION

BY

CHRISTOPHER DELVAILLE

A RESEARCH PROJECT SUBMITTED IN PARTIAL

FULFILLMENT OF THE REQUIREMENTS FOR THE DEGREE OF MASTER OF COMMUNITY PLANNING

UNIVERSITY OF RHODE ISLAND

1997 
MASTER OF COMMUNITY PLANNING RESEARCH PROJECT

OF

CHRISTOPHER DELVAILLE

APPROVED:

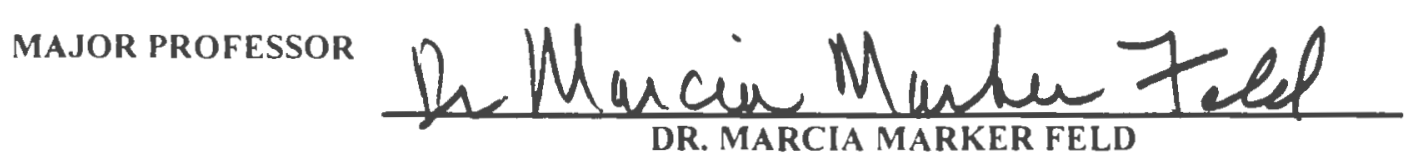

ACKNOWLEDGED: DIRECTOR

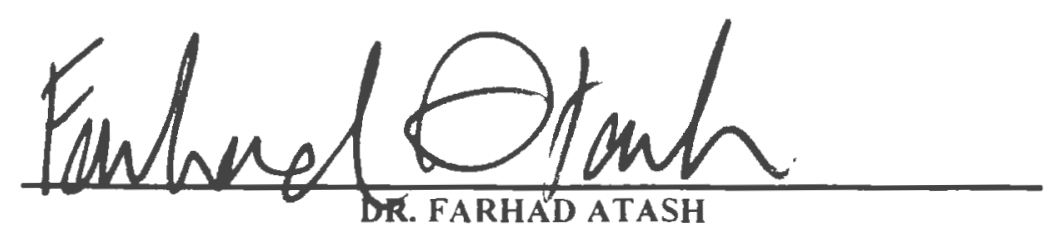




\section{ABSTRACT}

The following Masters Thesis Project is a case illustration exploring the strategic planning process as it pertains to public agencies, in this case a public housing authority. This paper has been written using the participant observation method in which the author served as the project manager for the Providence Housing Authority`s 1995 strategic plan entitled "Strategic Plan 2000."

The introduction includes a brief description of the housing authority, which addresses both its internal management structure, and resident population as it existed when the plan was written. The first chapter explains the political, and thus in some degree the social environment in which the plan was written. It explains why, for those in the public housing field, 1995 was a time of great consequence. It was a year when the entire foundation of the public housing program was seriously coming into question.

The second chapter outlines the strategic planning method employed by the Providence Housing Authority for this project. This method was developed fully by John Bryon in his book Strategic Planing for Public and Nonprofit Agencies. This chapter also explains how the PHA in particular administered this process.

The third chapter is the basic contents of Strategic Plan 2000. Two sections, the internal and external environmental scans, were not included in this chapter because of their length and because they were contextual in nature rather process centered. The fourth chapter illustrates the progress made by the housing authority in implementing the strategies developed in the plan for the period of approximately a year after the plan was put into operation.

The paper is briefly summed up and tied together in the conclusionary chapter which includes examples of where the process ran into road blocks, and what lessons have been learned during the process, and what lies ahead in the future of public housing. 


\section{PREFACE}

The following case illustration of strategic planning is based upon the Providence Housing Authority's Strategic Plan 2000. This document was completed in February 1996. I began working on the strategic plan as a graduate intern with the PHA. On February 17th, 1995 I met with Stephen O'Rourke, the Executive Director and was assigned to work on the internal and external stakeholder surveys. At that time I was working with Stacy Tobin, a graduate of the University of Rhode Island's Graduate Curriculum in Community Planning and Area Development, and a fellow intern with the housing authority. Her previous experience in strategic planning was extremely beneficial to me as we began to work on this project.

In June she left the housing authority and I began to take on a greater role in developing the plan such as instructing department directors and staff about the strategic planning process and directing major planning exercises with them. By September of that year I had been hired as a full time planner/policy analyst with the PHA and became the project manager and primary author of Strategic Plan 2000.

Chapter three of this document includes major sections of the Strategic Plan 2000 document, some of which I did not write. At this point I wish to acknowledge those responsible for these sections. The data for the mandates section were compiled by Stephen O'Rourke, the Executive Director. Marcia Sullivan, then Executive Assistant to 
the Executive Director and currently the Director of the Department of Special Projects, wrote the Vision of Success section. The Environmental Scans were written by the individual planning teams and have been included as an appendix to this report. Both Stacy Tobin and myself wrote the internal and external surveys as well as the resident survey. The remaining sections of Strategic Plan 2000 were written primarily by myself. The monitoring and evaluation system outlined in chapter four was also my design. It should be noted, however, that input from the Providence Housing Authority`s strategic planning teams (explained in chapter two) and the Executive Director was a critical ingredient for every section of the Strategic Plan 2000 document. 


\section{ACKNOWLEDGMENTS}

No masters research project is ever conducted in a vacuum; however those involving strategic planning in particular require the input and contributions from a vast number of people. I would thus like to thank the Providence Housing Authority's Strategic Planning Teams who helped make the Strategic Plan 2000 document a reality, and all of the PHA's staff members who have worked so hard in its implementation. In particular I would like to thank the Executive Director Stephen J. O'Rourke who continually has provided opportunities for me to expand my professional capabilities and responsibilities. His faith in my abilities and skills was often greater than my own. I would also like to thank Stacy Tobin, a fellow Connecticut College and CPAD alumni who helped to develop the foundation of Strategic Plan 2000.

Primary thanks go to my future wife Beth Lynn Schwab who set a clear deadline for me to complete this project and provided both the motivation and support to help me meet it.

I am also grateful to my professors at $\mathrm{CPAD}$ who provided me with a solid planning foundation. In particular I would like to thank Dr. Marcia Feld, my primary reader whose support for me has been unwavering. Thank you also to Professor Marjorie Jensen who supported my interest in the public housing field. I must also give special mention to Dr. Marsh Feldman who constantly provided me with a challenge and helped me to mature both academically and professionally. 
Finally I will echo the sentiments expressed by Professor Marvin Olasky in the acknowledgments section of his book The Tragedy of American Compassion in which he wrote "My greatest thanks are to God, who had compassion on me... and pushed me from darkness into light." 


\section{Strategic Planning: A Case Illustration}

\section{Contents}

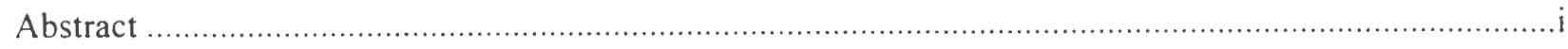

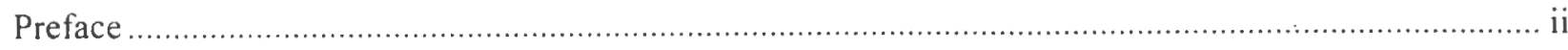

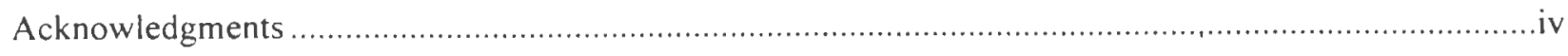

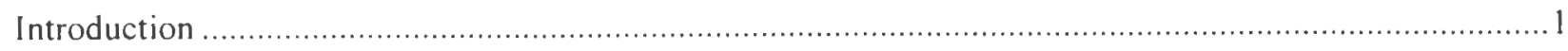

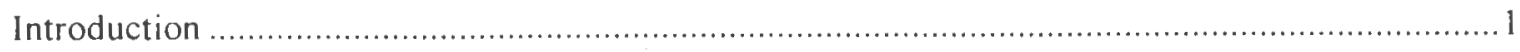

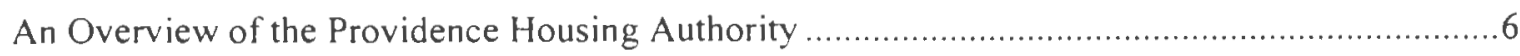

Chapter One: The Environment in Which the Strategic Plan Was Written ..........................................15

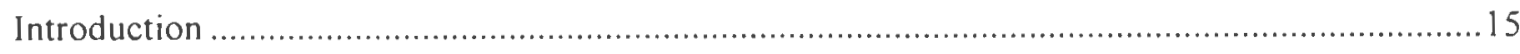

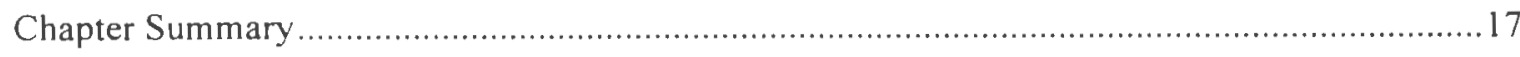

Political Environment: December 1994-December 1995 ....................................................22

Impact of Events Upon the Providence Housing Authority ................................................61

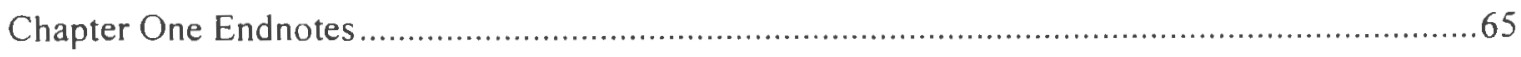

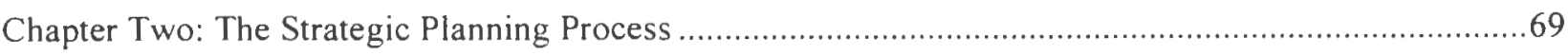

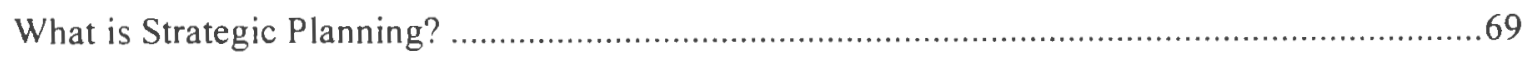

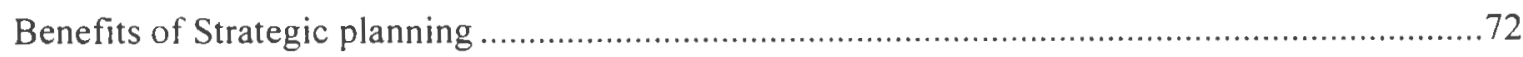

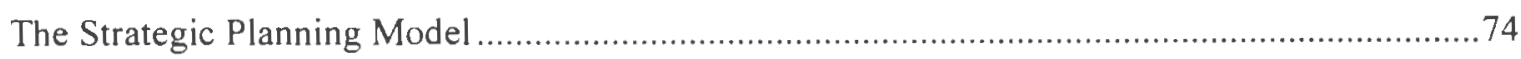

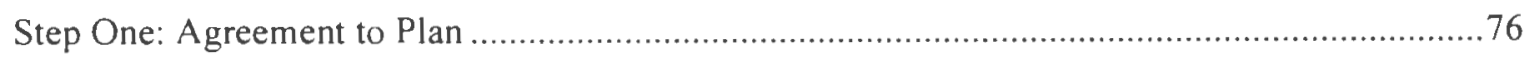

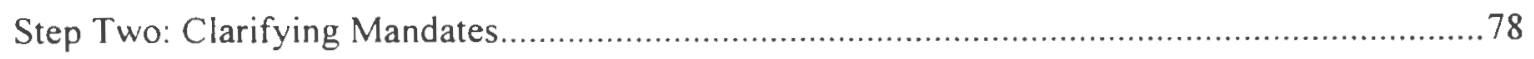

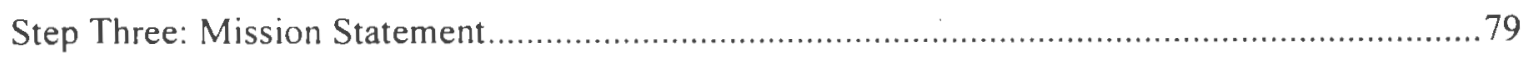

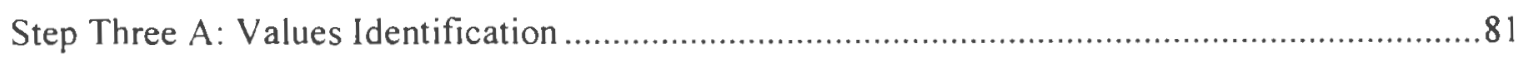

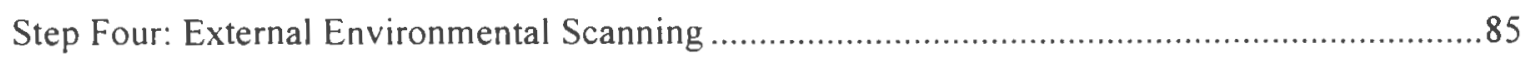

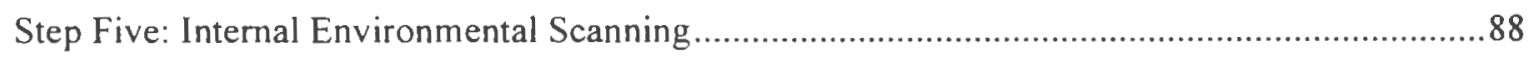

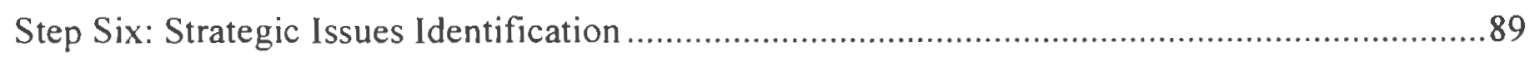

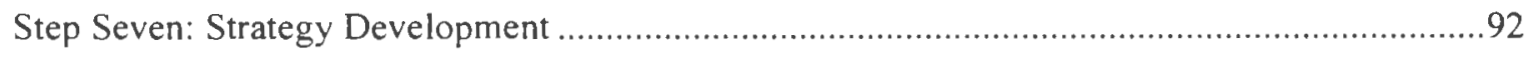

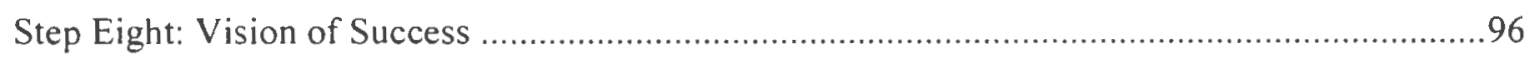

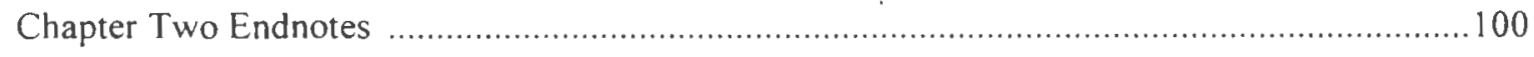

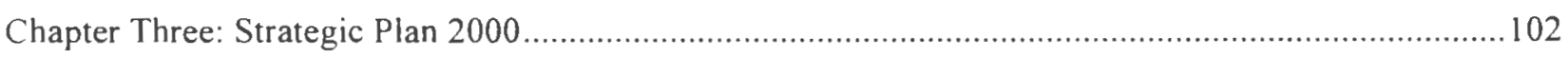

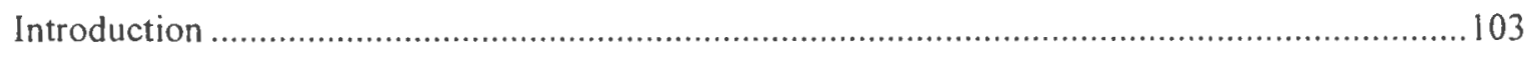

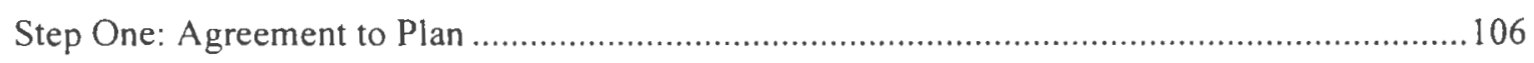

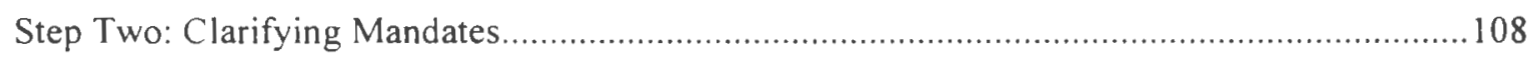




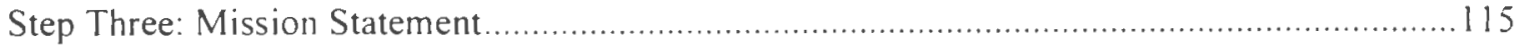

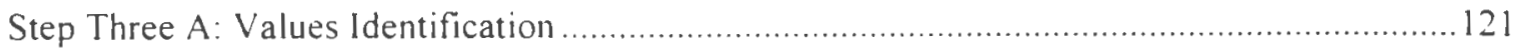

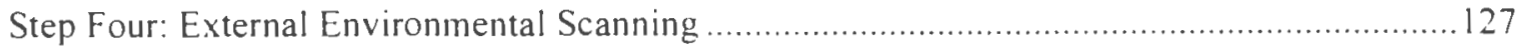

Step Five: Internal Environmental Scanning ................................................................... 154

Step Six: Strategic Issues Identification .......................................................................... 163

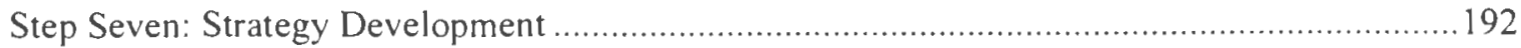

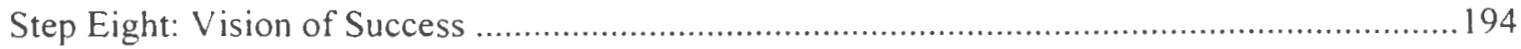

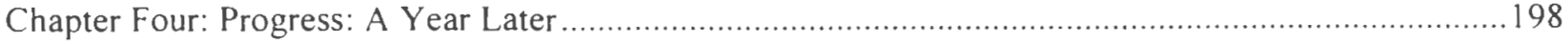

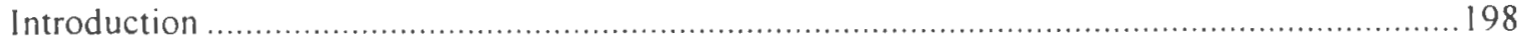

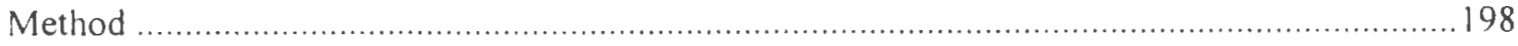

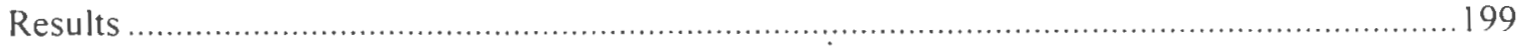

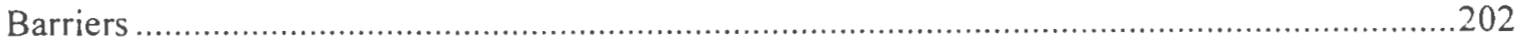

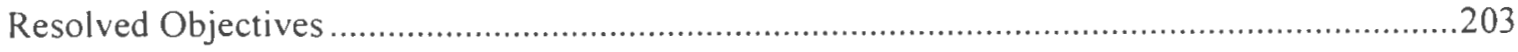

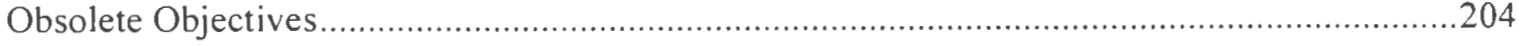

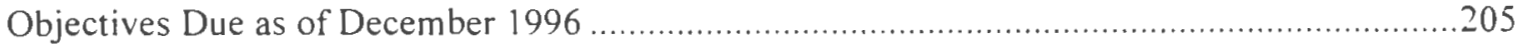

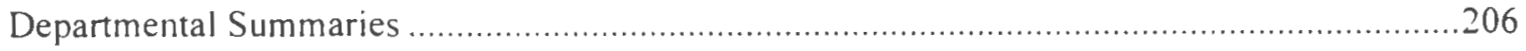

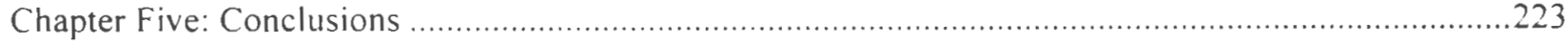

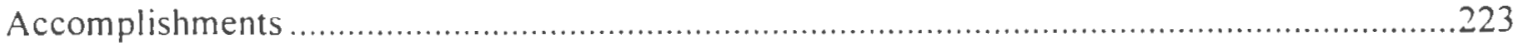

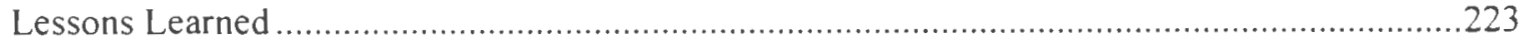

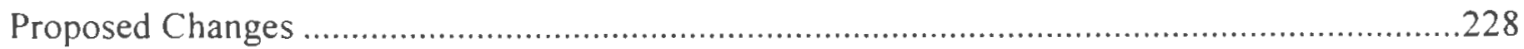

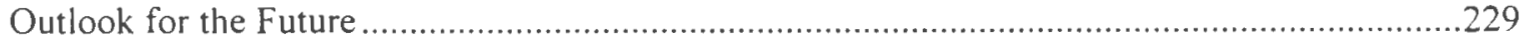

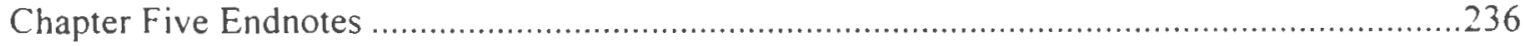

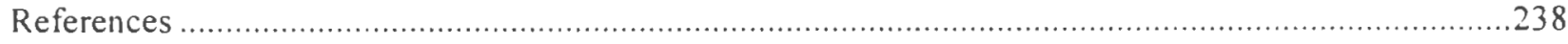

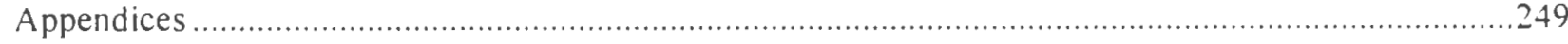

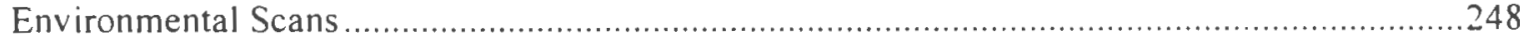

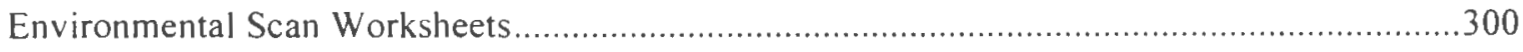

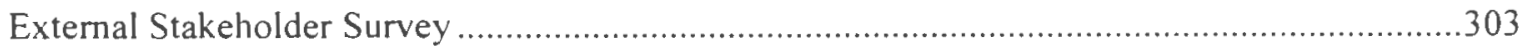

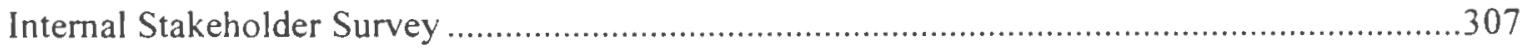

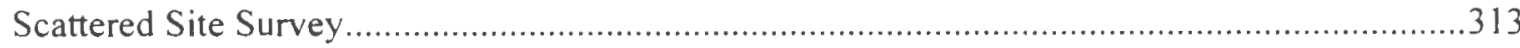

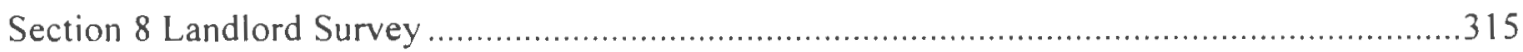

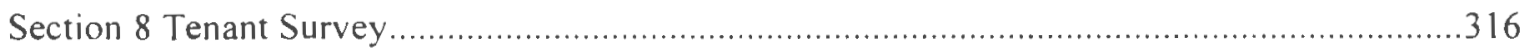

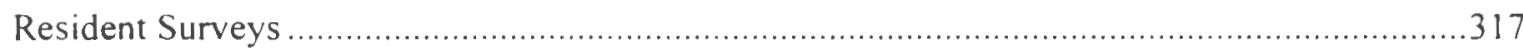




\section{Strategic Planning: A Case Illustration}

\section{Introduction}

Introduction

An Overview of the Providence Housing Authority 


\section{INTRODUCTION}

"So may a thousand actions, once afoot.

End in one purpose. and be well borne

Without defeat"

.. H'illam Shakespeare Henry l'

Social housing programs in America have always been controversial. The United States Housing Act of 1937 that authorized the creation of public housing was passed only with significant reservations from President Roosevelt. The argument has been made, and made well, that the President supported the bill more for its job creation and slum clearance aspects than for the provision of public housing. As the New Deal policies of the 1930s and 1940s expanded into the Great Society programs of the 1960s, the controversies grew. By the late 1970s however, federal spending began to outpace federal receipts. As this condition grew more serious and the extensive problems that social spending was supposed to alleviate grew more complex, more visible, and more institutionalized for a vast segment of American society, it became obvious that drastic change in the delivery systems of the nations social programs was inevitable. Throughout the 1980s and the early 1990s, government divided across party lines continued to debate the issues of social policy in America. Change began under the Reagan Administration and continued into the Bush years. But a stagnant national economy signaled the end of twelve years of Republican control of the White House. While the control of the executive switched to the Democratic Party, the shift came 
without the populist mandates enjoyed by Presidents Roosevelt or Reagan. Instead. the nation seemed ill at ease, primarily concerned with the condition of the national economy. Concerning social entitlement spending, then candidate Bill Clinton promised to change the welfare system as we know it. Much of the early year of Clinton's first term were spent debating the President's ill fated health care bill. While changes in entitlement programs always seemed around the corner, the Democratic majorities in the House and Senate combined with a Democratic President made it unlikely that drastic cuts in social programs would be at the forefront of the national agenda. Clearly the debate on healthcare showed that the democratic party at the time was interested more in expanding the reach of government than reducing it. All of this was about to change.

After the election of 1994 , when the Republican party captured the majority of the House and the Senate for the first time in forty years as well as the majority of the nation's State Houses. it became clear that social policy in America, particularly social welfare programs, would now be re-examined. Drastic change seemed imminent in the rhetorically charged atmosphere of Capitol Hill. Republican plans to end the perpetual budget deficits by the year 2002 fit well with an agenda of reducing the size of government.

One area in which this debate was to be particularly intense concerned the issues relating to public housing. Never a program with a powerful constituency, it was clearly an obvious place to cut federal spending. This was compounded by the fact that public housing programs are funded out the House and Senate Subcommittees on VA/HUD and 
Independent Agencies. These subcommittees oversee discretionary spending meaning spending which is vulnerable to budgetary cutbacks. This makes budget debates a very politically charged process. The vulnerability of housing programs is only compounded by the fact that public housing programs compete for funding with programs concerning NASA and space exploration. the EPA and environmental issues, and the VA and veterans" issues; all which have large powerful constituencies. In fact, at one point in the fiscal year 1996 budget process, the House rescinded a budget bill out of this Subcommittee which had been approved by conference committee and which called for significant cuts in housing programs, because it wanted to add more money for veterans' programs. Later, after the House added the funding for VA programs, the President vetoed the bill. Again, his objection was not that the bill drastically cut public housing programs, rather he objected to cuts in funding for the EPA and for his AmeriCorps program. That there would be large cuts in housing programs was taken as matter of fact by decision makers. Budget proposals on Capitol Hill included a $21.8 \%$ reduction in public housing operating subsidies, a $47.9 \%$ reduction in capital improvement funds, a nation-wide reduction of Section 8 funds of $\$ 2.7$ million with no new certificates and vouchers, and a $\$ 411$ million reduction nation-wide in Special Needs Housing. Other areas of concern for the PHA were the proposed elimination of Public Housing Development funds, and the zeroing out of the Youth Sports Program and the Senior Services Coordinators Grant.

For public housing authorities this was a time of great concern. In addition to inevitable funding cuts, major changes in the structure of housing programs were being proposed. 
In a pro-active measure designed to prevent the department from extinction, the Department of Housing and Urban Development, which is the primary funding source and regulator for the 3,200 public and Indian housing authorities, proposed a reinvention blueprint which would dramatically change the manner in which funding for public housing would be administered. Under this plan, funding would no longer go to housing authorities, but rather to tenants, who would be free to use their subsidy to stay in public housing or to find housing in the private market. Fearing an inability to compete with the private market, many housing industry organizations predicted that large numbers of housing authorities would simply fail to remain in business.

In Congress, both the House and Senate prepared bills to rescind billions of dollars from funding that had already been approved for the 1995 fiscal year. This rescission was based upon a disproportionate cut in housing and community development activities and was a great concern for those in the housing industry. There were also several major pieces of housing legislation in the works during 1995, all of which proposed major changes in federal housing programs. Some went so far as to call for the elimination of the Department of Housing and Urban Development. Yet another bill was designed to replace the Housing Act of 1937.

These problems were exacerbated by the poor public perception of public housing. Today public housing is considered by some to be the housing of last resort. Many residents, due to their lack of education and job skills, remain for longer periods of time. Some families are multi-generational residents of public housing. Housing authorities, 
particularly the large urban authorities, are seen as being mismanaged, severely deteriorated and crime ridden. This is the image of public housing projected to the public every day by the news media. While housing authority professionals are aware that this depiction of public housing is not an accurate portrayal of the program. efforts to educate the general public have not been successful. Of the approximately 3.200 public housing authorities in the United States, only 100 are considered distressed, that is, not well managed or suffering from the effects of irregular funding. The Providence Housing Authority (PHA) had its dark period when funding was not adequate to sustain its most basic operations. As 1995 began, housing authorities faced great uncertainties about their futures.

In response to these threats, the Providence Housing Authority conducted a formal strategic planning process beginning in the spring of 1995. It is this plan, the Providence Housing Authority's Strategic Plan 2000 which serves as the center of this paper: A Case Study of Strategic Planning: The Providence Housing Authority's Strategic Plan 2000.

This paper is divided into four main sections. The first section explains in greater detail the changes occurring in the public housing industry at the time the PHA's Strategic Plan $\underline{2000}$ was being written. This chapter will cover changes in budget allocations, the debate on HUD's reinvention blue print, major housing legislation, and other matters concerning housing on a national level. The chapter will end with a brief description of some of the affects these changes have had on the Providence Housing Authority. 
The next section of this paper will explain the basic principles and benefits of strategic planning and the model chosen by the Providence Housing Authority. This section will be followed by the plan itself for which the author of this paper served as the primary author and project manager. Material contained in Strategic Plan 2000 which was written by persons other than the author of this paper is noted in this section.

This paper will end with a section detailing the progress made by the Providence Housing Authority in implementing the plan looking back after one full year. This section will track the completion of objectives stated in the plan and will explain changes which were made in the plan after a year of implementation. This section will also explore barriers to completion for objectives which were not met.

\section{The Providence Housing Authority}

\section{An Overview}

The following overview of the Providence Housing Authority has been provided to illustrate the composition of the agency, its operations, and its residents at the time the $\underline{\text { Strategic Plan } 2000}$ was being written. Several changes have occurred since these data were originally prepared. This is to be expected, however one change must be noted. In accordance with goals and objectives contained in Strategic Plan 2000, a new department was created. The Department of Special Projects was created to facilitate the transition of residents from public housing to self-sufficiency. The main responsibilities of this department are to oversee the Family Self-Sufficiency Program and to operate the newly 
created Family Investment Center, where residents receive training in skills which will help them in their transition off of public assistance.

The Providence Housing Authority was created in 1939 as a result of the Housing Act of 1937. Today the Providence Housing Authority manages 2.600 units in six family developments, seven elderly/disabled developments, and 200 units of scattered site housing which are located throughout the city. In addition to our developments, the PHA also administers 2.500 units of Section 8 housing through the Department of Rental Housing. The PHA oversees Section 8 Certificates (44\%), Vouchers (26\%), Moderate Rehabilitation (14\%), and 11-B Developments (16\%).

The Providence Housing Authority is organized into six ${ }^{\prime}$ separate departments and the Office of the Executive Director. Below is a brief description of each department. For a more detailed description of each department please see the environmental scans in the internal and external environmental analysis sections of this report.

The Providence Housing Authority's consolidated budget for fiscal year 1995 totaled \$41 million. This figure includes funding in the form of rental income, outside grants, modernization and development funds, Section 8 funds, and the PHA's operating subsidy.

\footnotetext{
INow seven. The Department of Special Projects was created under Strategic Plan 2000 to oversee the PHA's Family Self-Sufficiency Program and the Family Investment Center.
} 


\section{Office of the Executive Director}

The functions of the Executive Director's office include: overall management, monitoring the Goals Management Plan and the Performance Monitoring System, training, personnel administration, safety programs, insurance and risk management, security, public relations, Family Self-Sufficiency, newsletters (resident and employee), coordination of intergovernmental relations, resident relations, and the home ownership program. Various other functions are also performed by this office.

In addition, the Management Information Services Office was transferred from the Finance and Accounting Department to the Executive Office in 1994. Also in 1994, the Office of Policy, Planning and Resource Development was created as a branch of the Executive Office to prepare policy options for the Executive Director, apply for and manage special projects, oversee the administrative functions of the security program, and to identify and assist other departments in applying for grant funds.

\section{Department of Housing Management}

The Department of Housing Management consists of 37 staff members with an average of eleven years of professional housing experience. The department is primarily responsible for processing applications, leasing units, conducting annual inspections, and collecting rents. The Resident Selection Office reviews police reports, conducts home visits, and verifies information provided by applicants to determine each applicant's 
eligibility and suitability for public housing. The management site staff is responsible for the daily operations of the PHA's six family development and seven elderly/disabled developments.

\section{Department of Finance and Accounting}

The Department of Finance and Accounting consists of six employees responsible for all of the financing. accounting, budgeting and payroll functions at the PHA. The department accounts for funds, invests surplus funds, conducts an annual inventory of fixed assets, and pays housing assistance payments to private property owners participating in the Section 8 Program. The department is also primarily responsible for procuring supplies and materials.

\section{Department of Facilities Management}

The Facilities Management Department is the largest of the PHA departments with 98 employees. Formerly known as the Maintenance Department, this department is responsible for the physical upkeep of PHA property. Sixty percent of all work orders performed by this department in FY 1995 fell under the planned preventative category. Overall, the department performed 52,820 work orders during FY 1995.

\section{Department of Modernization and Development}

Staffed by nine full-time employees, the Modernization and Development Department is responsible for the renovation and rehabilitation of existing units and the development of new ones. Since 1987 this department has administered budgets totaling $\$ 110$ million. 
Major projects recently completed and currently being conducted by this department include comprehensive modernization of Hartford Park, Manton Heights and Codding Court, Section 504 handicapped accessibility modifications in high-rise developments and the development of scattered site developments located across the city. Chad Brown. Admiral Terrace and Sunset Village have also undergone extensive renovations.

\section{Department of Community Services}

The Community Services Department is primarily dependent upon outside grant funding. Currently, only nine percent of the department's salaries are paid through the PHA's operating budget. The department is comprised of three units: the Family Services Unit, the Preparation for Community Living Unit, and the Elderly Disabled Unit. The family unit provides educational and recreational activities and programs designed to keep our youth off drugs and in school through constructive activities. For adults, the family unit provides educational programs designed to support families to become self sufficient.

The elderly disabled unit provides health services, including a health clinic located in Dexter Manor. Other services and programs include bilingual social workers, meal sites, visiting nurses and pharmacists, transportation services, education, senior employment programs, and social activities. Programs are provided through collaboration with various external agencies such as the Providence Intown Churches Association (PICA), Project HOPE, the Visiting Nurses Association, and the University of Rhode Island. 
The Preparation for Community Living Unit educates and prepares new tenants for life at ion a community setting. Through this program all incoming tenants are educated about the responsibilities of community living. This unit also helps to educate residents with poor house keeping habits about the consequences of risks of such behavior and how to better take care of their homes.

\section{Department of Rental Housing}

The Department of Rental Housing administers the PHA's Section 8 Rental Housing Program. As noted above, the department oversees 2.500 rental housing units. Federal regulations require that a housing quality inspection be conducted before lease execution and on an annual basis. Property owners are notified of any deficiencies and are given a specified time to make repairs. Each program participant must also be re-certified on an annual basis. During this process the Section 8 participant's eligibility status is reviewed.

\section{The Residents}

The Providence Housing Authority is home to 5,183 public housing residents. This represents $3.2 \%$ of the population of Providence. These tenants reside in the PHA's 6 family and 7 elderly/disabled developments, and in scattered site units. Hartford Park is the largest family development with a population of 1,115 (141 residents also live in the elderly/disabled Hartford Tower). Chad Brown and Admiral Terrace, which are contiguous, have a combined population of 1,103. Sunset Village, an elderly/disabled development and the smallest of the PHA's conventional developments, is located next to Chad Brown and Admiral Terrace. The three are often referred to as Chad/Ad/Sun. 
Because of federal regulations, non-elderly residents with disabilities reside in elderly developments. This arrangement has led to a great deal of conflict due to the different lifestyles of the elderly and younger disabled residents. In 1994 the PHA submitted an "Allocation Plan" to the Department of Housing and Urban Development. This plan allows the PHA to designate Dominica Manor and Carroll Tower as elderly only housing.

The chart below details the PHA resident population by development.

\begin{tabular}{|c|c|}
\hline \multicolumn{2}{|c|}{$\begin{array}{l}\text { PROVIDENCE HOUSING AUTHORITY } \\
\text { RESIDENT POPULATION BY DEVELOPMENT }\end{array}$} \\
\hline DEVELOPMENT & POPULATION \\
\hline Admiral Terrace & 492 \\
\hline Chad Brown & 611 \\
\hline Hartford Park (Family Units) & 1115 \\
\hline Manton Heights & 912 \\
\hline Codding Court & 132 \\
\hline Roger Williams & 12 \\
\hline Scattered Sites & 602 \\
\hline SUBTOTAL (FAMILY) & $\overline{3,976}$ \\
\hline Hartford Tower (Elderly Units) & $14 !$ \\
\hline Sunset Village & 23 \\
\hline Dexter Manor 1 & 212 \\
\hline Dexier Manor II & 110 \\
\hline Dominica Manor & 218 \\
\hline Carroll Tower & 198 \\
\hline Kilmartin Plaza & 112 \\
\hline Parenti Villa & 193 \\
\hline SUBTOTAL (ELDERLY) & 1,207 \\
\hline TOTAL & 5,183 \\
\hline
\end{tabular}

There is a significant difference in the racial composition of our elderly/disabled and family developments. While $94 \%$ of family development households are either Hispanic or African American, the majority (56.5\%) of the elderly/disabled households are White. Further, while $90 \%$ of the households in the family developments are headed by women, 
only $48 \%$ of elderly/disabled development households are so headed. The following chart details the demographics of our resident population.

\begin{tabular}{|c|c|c|c|}
\hline \multicolumn{4}{|c|}{$\begin{array}{l}\text { PROVIDENCE HOUSING AUTHORITY } \\
\text { RESIDENT DEMOGRAPHICS }\end{array}$} \\
\hline & TOTAL PHA & $\begin{array}{c}\text { FAMILY } \\
\text { DEVELOPMENTS }\end{array}$ & $\begin{array}{c}\text { ELDERLY } \\
\text { DISABLED } \\
\text { DEVELOPMENTS }\end{array}$ \\
\hline \multicolumn{4}{|c|}{$\widehat{\mathrm{RACE}}$} \\
\hline HISPANIC & $42.2 \%$ & $57.5 \%$ & $22.6 \%$ \\
\hline WHITE & $29.4 \%$ & $5.8 \%$ & $56.5 \%$ \\
\hline AFRICAN AMERICAN & $28.6 \%$ & 36.4 & 19.7 \\
\hline ASIAN & $0.5 \%$ & $0.2 \%$ & $0.7 \%$ \\
\hline NATIVE AMERICAN & $0.3 \%$ & $0.1 \%$ & $0.4 \%$ \\
\hline \multicolumn{4}{|c|}{ GENDER (HOUSEHOLD HEAD) } \\
\hline MALE & $30 \%$ & $10 \%$ & $52 \%$ \\
\hline FEMALE & $70 \%$ & $90 \%$ & $48 \%$ \\
\hline \multicolumn{4}{|c|}{ AVERAGE INCOME } \\
\hline By Family & $\$ 7.579$ & $\$ 8.813$ & $\$ 6.2 .06$ \\
\hline
\end{tabular}




\section{Strategic Planning: A Case Illustration}

Chapter One: The Environment in Which the Strategic Plan Was Written

Introduction

Chapter Summary

Political Environment: December 1994-December 1995.

Impact of Events Upon the Providence Housing Authority

Chapter One Endnotes 


\section{CHAPTER ONE: THE POLITICAL ENVIRONMENT}

In addition to examining an agency's internal strengths and weaknesses, mandates, and mission, the Strategic Planning process is designed to examine the organization's external opportunities and threats before they reach crisis proportions. During the period of time the Providence Housing Authority conducted its strategic planning process. political and social change presented both very real threats and opportunities. These served to motivate and inspire the Strategic Planning teams. The spring of 1995 , when the PHA began the process which produced its Strategic Plan 2000, was a time of anticipation, hope, and anxiety for those involved with social welfare programs.

In 1992 the White House fell into the hands of the Democrats after twelve years of Republican control. But the change in administrations came more as a result of public perceptions that the national economy was sour than as a repudiation of the Republican political agenda of creating smaller government and shrinking the system of entitlement programs for the poor. In fact, the Clinton administration was elected, in part. upon a promise that he, as President, would "end welfare as we know it." Then in 1994, as if to hold the President to that promise, dramatic changes occurred in the composition of both Houses of the United States Congress as both the House and Senate changed to Republican control for the first time in forty years. The result was an agenda to make drastic changes to social entitlement programs while at the same time balancing the 
budget within seven years. Fearing for its very survival, the Department of Housing and Urban Development (HUD) quickly designed a "blueprint" for its "reinvention." This plan came as much in response to expected changes from the administration's Office of Management and Budget (OMB) as to the Republican Congress. The most striking result of this plan for housing authorities would be an eventual end to operating subsidies. Operating subsidies were created as a result of the 1968 Brooke Amendment, which limited the amount of rent a housing authority could charge its tenants to $25 \%$ of their adjusted gross income. (This figure was raised to $30 \%$ in 1981.) Previously housing authorities charged rents based upon the cost of operating the authority and the size of the apartment being rented. After the implementation of the Brooke Amendment many housing authorities could no longer charge rents at a level high enough to maintain operations. To keep housing authorities solvent, HUD contracted with the Urban Institute to develop a system to subsidize housing authorities for the cost of operating their programs. The result was the Performance Funding System (PFS), a formula to determine how much funding housing authorities should receive as a federal subsidy in addition to the rents they collect. This federal subsidy for housing authorities is known as the operating subsidy.

With both the Republican and Democratic parties committed to simultaneously changing the system of entitlement programs and the balancing the budget, and the Department of 
Housing and Urban Development pro-actively proposing changes in the delivery of public housing, it was a period of great consequence for public housing in America.

The following section of this document explores the actual political landscape facing housing authorities just prior to and during the strategic planning process conducted by the Providence Housing Authority. This material has been included to provide a picture of the political environment within which the PHA's strategic plan was written. This section is organized chronologically to illustrate developments in housing policy as they unfolded, beginning in January 1995, several months prior to the commencement of strategic planning activities at the Providence Housing Authority.

\section{SUMMARY OF EVENTS}

The remainder of this chapter follows the political process as it concerns the field of public housing in calendar year 1995. This material is organized by month and is broken down into several sections. This summary briefly illustrates the major activity covered in this chapter. The monthly information is important because it shows the development of important housing legislation during the year that the Providence Housing Authority's Strategic Plan 2000 was being written. It has been included to illustrate the uncertainty under which the PHA and all housing authorities operated during this time. 


\section{The Reinvention of HUD}

Several weeks after the 1994 election, HUD Secretary Henry Cisneros met with Congressman Rick Lazio, chairman of the House Subcommittee on Housing and Community Opportunity and announced that his agency was prepared to make major changes in its operations. In March, after much speculation, HUD delivered its "Reinvention Blueprint" to Congress. The most striking component of this Reinvention Blueprint was the conversion of all operating subsidies to tenant based vouchers (voucherization) which would take place over the period of six years. Robert J. Reid, Executive Director of the National Housing Conference referred to the plan as, "a sheer act of desperation." This assessment may have been more correct than he, at first, realized. A rumor in Washington has it that Secretary Cisneros called his assistant secretaries together on a Friday afternoon when the Office of Management and Budget was considering plans to eliminate HUD in response to the 1994 elections. According to the story, Cisneros and his team quickly developed the Reinvention Blueprint by Sunday afternoon and slipped it under the door where the OMB budget team was meeting, an act which spared the agency. Paul A. Leonard, HUD Deputy Assistant Director for Policy Development said of the plan, "facing the prospect of abolition, firmly defending the status quo was not a position we were prepared to take. What we put forward was a comprehensive proposal for fundamentally changing the nature of federal low-income housing assistance." In the end, the department changed to a policy which moved away from the drastic tenant based voucher program and moved towards a policy of greater deregulation and local control. 


\section{Rescission of HUD Funding}

In an effort to balance the budget by the year 2002. Congress rescinded $\$ 16.3$ billion dollars of FY 1995 funds, \$6.5 billion of which came from HUD programs. The final bill (HR 1944) was passed after a similar measure was vetoed by the President. This was the largest rescission in the history of the nation. Congress added $\$ 790$ million in funds for education, clean water, and the National Service Program to the original bill in order to overcome Presidential opposition. The new bill also included additional cuts of close to $\$ 1$ billion, $\$ 100$ million of which came from assisted housing programs. In addition to the funding cuts, the bill also included $\$ 7.2$ billion in additional funding of which $\$ 290$ million was used for disaster assistance for the Oklahoma City bombing in which 35 HUD emplovees were killed.

\section{The Budget Process}

For much of the year Congress debated funding levels for FY 1996 including appropriations for HUD. While FY 1996 began on October $1^{\text {st }} 1995$, no funding bill had been signed into law by the end of calendar year 1995. Between the beginning of FY 1996 and the end of December 1995, two Continuing Resolutions had been passed to allow the government to continue to function, and budget deadlock between the Congress and the White House resulted in two HUD shut downs. Out of thirteen different appropriations bills, the White House and Congress disagreed on eight. One of those upon which there was disagreement was the VA/HUD and Independent Agencies Appropriations bill HR 2099. HUD is funded out of subcommittees in the House and Senate which are also responsible for funding the Veterans Administration and 
independent agencies such as the Environmental Protection Agency (EPA) and NASA. After half a year of Congressional action on this bill, which proposed a total of $\$ 80.6$ billion in spending ( $\$ 9.3$ billion less than in FY 1995), it was vetoed by President Clinton. While the bill only funded HUD at $\$ 19.3$ billion, significantly less than the FY 1995 funding level of $\$ 25.7$ billion and the FY 1996 level of $\$ 24.3$ billion requested by the Clinton Administration, the Presidential veto came not as a result of cuts in funding for housing programs, but rather because of the elimination of the Corporation for National Community Service which oversees the AmeriCorp program and a $22 \%$ reduction in funding for EPA.

\section{Congressional Housing Legislation}

The following legislation was proposed during the year that the Providence Housing Authority was writing Strategic Plan 2000. Greater detail concerning the content and evolution of these bills can be found in the following sections of this chapter.

Representative Rick Lazio, (R-NY) Chairman of the House Subcommittee on Housing and Community Opportunity proposed a bill that would replace the Housing Act of 1937 , overhaul HUD and concentrate most funding into block grants, and provide greater flexibility for local agencies to administer programs. It was approved by the House Banking and Financial Services Committee on November $9^{\text {th }}, 1995$.

Senator Connie Mack (R-FL) proposed legislation in the Senate (S.1260) which would also provide HUD funding in the form of block grants, one for housing authority 
operating budgets and one for capital improvements. It generally provided less flexibly for local agencies than the Lazio bill, but more than the status quo. This bill was approved by the Banking, Housing and Urban Affairs Committee on October $26^{\text {th }}, 1995$.

Senator Lauch Faircloth (R-NC). Representative Joel Hefley (R-CO), and Representative Sam Brownback (R-KS) proposed legislature (S 1145 and HR 2198) to eliminate HUD completely. In its place they called for vouchers to be given to all current public housing residents which could be used to stay in public housing or to move into the private rental market. The bill also dispersed all current HUD functions to other governmental, nonprofit and private agencies. 


\section{DECEMBER 1994}

Pointing to the conservative political climate of the post 1994 election period HUD Secretary Henry Cisneros announced plans for drastic changes for his department which would come in the form of HUD"s "Reinvention Blue Print". In a December 15 th speech he told reporters, "We were under a direct presidential order to change the department or face elimination." "ii

\section{JANUARY 1995}

\section{The Reinvention of HUD}

In January 1995, it was estimated that a proposed balanced budget amendment and a proposed middle class tax cut would result in cuts to funding for public housing of 20 $30 \%$. Also in this month HUD began to spell out the components of its reinvention blue print which was written in December 1994.

On January 13, 1995 key HUD officials including Secretary Henry Cisneros and Assistant Secretary for Public and Indian Housing Joseph Shuldiner met with public housing industry officials to discus HUD's "reinvention blueprint." The plan called for the consolidation of public housing programs into two block grants, the Public Housing Capital Fund and Public Housing Operating Subsidies Fund. A third block grant would be created for the Section 8 rental housing program. Eventually, after a two year interim period. HUD would end assistance to housing authorities through operating subsidies and would instead provide vouchers directly to public housing tenants. Under this plan 
housing authorities would have to compete in the overall market place as a provider of low income housing for tenants who would use vouchers to rent housing in either the private or public market. Housing officials were immediately critical of the voucher plan. Richard Nelson Jr., Executive Director of the National Association of Housing and Redevelopment Officials (NAHRO) remarked, "How does HUD expect more than one million basically sound housing units that were built and designed under strict. limiting HUD requirements, to compete in the market place? The playing field is not level. Further, why should public housing be competitive if it is intended to serve as temporary housing during a family's struggle to become self sufficient?"iv

On January $19^{\text {th }}$, Secretary Cisneros testified before the Senate Appropriations Subcommittee of VA, HUD and Independent Agencies. During his testimony Cisneros stated that the reinvention blueprint would "present a profound change in the logic of federal housing policy and will generate significant budget savings over the next five years." He further stated that it "reflects a dramatic shift towards policies that will impose market constraints on HUD's support for affordable housing." Savings would come from a greater emphasis on the demolition of obsolete housing and the switch from direct program funds in the form of operating subsidies to housing authorities to tenantbased (voucher) subsidies. Cisneros predicted that the voucher system would drive down the over-all levels of funding needed to support public housing. Cisneros also outlined changes in the manner in which public housing residents would be selected. By allowing more working families into public housing and focusing on job training and education 
programs, average incomes of tenants would increase, thus decreasing the level of federal subsidies needed.

Major changes under the HUD reinvention blueprint would come in two separate stages. In the first stage, 60 separate HUD programs would be consolidated into three performance-based block grants. Housing authorities which were known for high levels of performance would be given bonus points under the distribution formula and would be granted greater levels of flexibility in implementation. Cisneros testified that, "as much as possible, [HUD] wants to build real world market incentives into these funds." $\mathrm{He}$ further argued for the consolidation of HUD programs into these block grants by stating that, "HUD cannot continue to operate with this program baggage obscuring its mission and confusing its customers." Although the HUD Inspector General had identified 240 separate HUD programs, many of these were set-asides, technical assistance funds, and inactive programs, which would be eliminated or included in the three block grants. The second stage of the reinvention of HUD would be the move from funding housing authorities through the operating subsidy to the direct provision of vouchers to public housing residents.

In a late January satellite teleconference, Secretary Cisneros noted that the switch to tenant based housing vouchers for public housing would occur in FY 1998, although he noted that this date was subject to change. He further announced that the vouchers would be administered through a state housing agency rather than directly through local housing agencies. 


\section{FEBRUARY 1995}

\section{The Reinvention of HUD}

On February $6^{\text {th }}$, Secretary Cisneros began to outline HUD's proposal for its Fiscal Year 1996 Budget stating that it would begin, five years of "the most dramatic changes this department has seen since its creation." ${ }^{\text {vii }}$ This proposal called for a $\$ 100$ million increase over the 1995 funding level of $\$ 25.7$ billion. According to the Secretary, $88 \%$ of these funds were to go to pay for commitments previously made by HUD. Under this budget the secretary outlined plans for savings of $\$ 13$ billion in outlays and $\$ 51$ billion in budget authority over five years. A significant amount of savings ( $\$ 476$ million) would come from the proposed rescission by Congress of FY 1995 funding. Other saving would come from money appropriated, but never spent, for programs such as the Public Housing Choice in Management Program ( $\$ 100$ million) and unused lead abatement funds ( $\$ 80$ million).

Further savings in outlays would be generated by this plan by reducing fair market rents for the Section 8 program from the 45 th percentile to the 40 th percentile (reducing the rents paid to private landlords participating in this program). Additional proposed savings would come from changing tenant admissions policies to encourage families who are working or are able to work to move into public housing by opening public housing to residents with higher incomes who would need less of a housing subsidy. HUD also proposed changing the rent structure for FHA insured Section 8 project based multifamily housing. The Secretary's budget reduced annual budget needs further by freezing 
appropriations at FY 1996 levels with no increases for inflation, changing Section 8 contract renewals, and eventually switching to tenant based vouchers for the public housing program. ${ }^{\text {vii }}$

Under this budget. 60 programs would be consolidated into 8 separate funds which would later be consolidated into 3 block grants. The eight funds specified in this proposal are as follows:

1. Public Housing Capital Fund

2. Public Housing Operating Subsidies Fund

3. Housing Certificates

4. FHA Multi-family Housing Resolution Activities

5. Community Opportunity Fund

6. Affordable Housing Fund

7. Homeless Assistance Fund

8. The Housing Opportunities for People With AIDS Program (HOPWA)

In Congress, criticism of the HUD reinvention plan came from both sides of the aisle. Speaking before the National Assisted Housing Management Association (NAHMA) on February $21^{\text {st }}$, Congressman Joseph Kennedy (D-MA) stated:

"We cannot use the few, worst examples of public housing as an excuse to turn every unit of public housing, and every unit of assisted housing, into vouchers. It will mean less affordable housing and more homelessness in the long run. It will mean massive dislocation for the elderly. ... This reorganization simply fails the basic test. ... The vast majority of public housing in this country is well run and provides a valuable service. Many public housing projects do not look greatly different from the project based Section 8 housing, yet public housing is vilified."

On February $28^{\text {th }}$ while speaking before the National Council of State Housing Agencies, Senator Christopher Bond (R-MO) stated: 
"The President's FY 1996 budget offers little in the way of concrete solutions to fiscal, program, and organizational problems faced by the department. The administration seeks budget increases during the next five years, then gives lip services to block grants which are little more than extensions of current programs which will be micro-managed at the federal level through what HUD call performance-based goals. In this budget crisis it's clear this Congress wants to change HUD, and reforms must take place. It's equally clear that reform is extremely vulnerable to uninformed demagogues, something we must avoid." ${ }^{\text {x }}$

Also at that same conference, Congressman Rick Lazio (R-NY) stated, perhaps in preparation for the announcement of his own housing bill in March, that, "there are two camps in the Republican Party, those who want to dismantle HUD and retreat from housing. and the second. which I belong to, that wants to focus on programmatic changes. There will be a federal role in housing for the foreseeable future."'xi

On February $2^{\text {nd }}$, housing industry leaders testified before the Senate Appropriations subcommittee on VA, HUD, and Independent Agencies chaired by Senator Christopher (Kit) S. Bond. Gregory Byrne, President of the Council of Large Public Housing Authorities (CLPHA) argued that tenant based vouchers should be tested on a small scale before being implemented across the board. Pointing to questions concerning the stability of the public housing program if this plan should be implemented he said, "these are certainly answers I'd want before divesting myself of $\$ 90$ billion' worth of assets.' ${ }^{\text {'xii }}$ Richard Gentry, then Senior Vice President of NAHRO argued against cuts which would reduce the operating subsidies paid to housing authorities by noting that tenant income in

\footnotetext{
'The approximate value of the nation's public housing inventory.
} 
public housing has declined from $34 \%$ of median income in 1981 to just $16 \%$ in 1995 . He further noted that rents now cover just $42 \%$ of the costs of operation and utilities.

When asked by Senator Richard Shelby (R-AL) why housing authorities should receive funds directly and not through a state agency as was proposed by HUD for the tenant based voucher program, Richard Gentry said, "States don't have the same oversight capability as HUD, therefore funneling funds through the states would simply add a layer of bureaucracy."xii

\section{Rescission of HUD Funding}

On February $23^{\text {rd }}$, the House HUD/VA subcommittee yoted to rescind a total of $\$ 7.258$ billion in FY 1995 HUD budget authority. This rescission included cuts in the following areas: $^{\text {xir }}$

- $\$ 2.694$ billion in incremental Section 8 vouchers and certificates

- $\$ 1.157$ billion in public housing modernization funds for public housing

- $\$ 690.1$ million in public housing development

- $\$ 349.4$ million Community Development Block Grant funds

- $\$ 549.4$ million in funding for severely distressed public housing

- $\$ 404$ million in public housing operating subsidies

- $\$ 465.1$ million for the Low-Income Housing Preservation and Resident Home-ownership Act program. (LIPRHA)

Senator Christopher (Kit) Bond (R-MO), the chairman of the VA/HUD and Independent Agencies Appropriations Subcommittee noted that HUD's share of the rescission would be lighter under the Senate version. Speaking before the National Council of State Housing Agencies he said, "we have rescissions coming out of our committee that will 
not look like the ones coming out of the House. They will probably be for a lesser amount." $\times$ Bond noted that both the House and the Senate rescission proposals would be designed to reflect the original request for the FY 1995 budget. Pointing to $\$ 33.2$ billion in annual carryover balance he said, "these are funds that Congress has appropriated for specific needs and programs which HUD, in many cases, has failed to administer in a timely fashion. ${ }^{\times \times 1}$

In a February $24^{\text {th }}$ press conference Secretary Cisneros argued that the Congressional budget rescission would fall primarily on HUD and the low-income people served by the agency. "These are early, draconian, painful cuts that will hurt people in America who are the most vulnerable," and that the cuts, "will guarantee that living conditions in the worst of our public housing will continue to deteriorate and that families with the worst housing needs in the country will not receive assistance." $x v i i$ He also predicted that an anticipated $\$ 404$ million cut in operating subsidies would lead to a reduction in the maintenance of housing authorities and could result in 1,768 local housing agencies receiving only $62 \%$ of their public housing operating subsidy. Assistant Secretary Nicolas P. Retsinas pointed out that HUD may not be able to comply with some of the components of the anticipated rescission bill because of signed contracts made which obligate the agency's funds.

Richard Nelson Jr., Executive Director of the National Associating of Housing and Redevelopment Officials claimed, "It is clear that the burden to balance the budget and provide a tax break for the middle class is being placed on the backs of the poor."xviii 
Representative Henry Gonzales (D-TX) said, "these rescissions cut at the heart of the housing programs for the nations most vulnerable citizens."

\section{MARCH 1995}

\section{The Reinvention of HUD}

According to an early February version of the HUD reinvention blue print, funding under the housing certificate fund (the eventual voucherization of public housing) would go to Public Housing Authorities and not states. HUD's plan in this version is to phase in the housing certificates over a three to six year period. HUD announced that it would require only minimum program standards designed to allow housing authorities to develop strategies concerning ceiling rents, admissions and screening procedures, occupancy preferences, and the use of capital and management funds. Further, the one-for-one replacement rule (requiring that for every unit demolished or disposed of by a housing authority another be built or acquired), federal preferences and grievance procedures would be eliminated. ${ }^{\mathrm{xx}}$ Housing authorities would still have to adhere to national fair housing law and HUD national income targets.

On March $20^{\text {th }}$, HUD issued additional details on the reinvention blueprint. Funding for the Community Opportunity and Affordable Housing funds would be based upon an analysis of need which would be identified by state and local planners. For the Housing Certificate Fund, housing authorities would be required to develop strategic plans for the implementation of the housing certificates (voucherization). These strategic plans would have to be developed to be consistent with the state's consolidated housing plan. 
HUD planned to base the design of the Community Opportunity Fund on the current CDBG program and would develop a set of national goals. In addition to the regular formula based funding ( $70 \%$ of entitlement communities and $30 \%$ to states), an additional $\$ 250$ million would be available in a bonus pool for localities with a history of good performance. HUD also planned set asides for some specific programs and would continue to require that $70 \%$ of all funds be targeted to low and moderate income people. ${ }^{x x_{1}}$

The Affordable Housing Fund would be based upon the HOME program and funding would be distributed to localities $(60 \%)$ and States $(40 \%)$. Under the Housing Certificate Fund, funding would be distributed directly to housing authorities which would be required to develop a strategic plan for "voucherization" over a 3-6 year period. During this time housing authorities would be deregulated, "non-viable" projects would be demolished or sold, and project based assistance would be converted to tenant based assistance. ${ }^{\mathrm{x} x 11}$

The transition would be phased in using the following three stages: ${ }^{x \text { iii }}$

- Stage One: PHA's allowed to become more competitive through the use of ceiling rents and income adjustments for families with higher income. One for one replacement would be recalled, disposition requirements would be repealed, federal procurement standards would be eliminated, and lead based paint requirements would be revised.

- Stage Two: Funding would be distributed using the new Housing Certificate fund based upon the fair market value of the PHA's housing units. Funding would still be project based and market rents 
would include costs of services (without exceeding fair market rent levels).

- Stage Three: All funds would be converted to tenant-based assistance. Families would be able to use their certificate for any qualified unit regardless of rent level. PHA's would be allowed to adjust a families income level to try to encourage occupancy by working families. Former public housing residents who remained would be subject to community services requirements.

\section{Rescission of HUD Funding}

On March $2^{\text {nd }}$ the House Appropriations Committee approved a $\$ 7.231$ billion rescission of FY 1995 carryover funds as part of a larger $\$ 20$ billion spending cuts package. The burden of the cuts shouldered by HUD represented a substantial portion of both the $\$ 16.9$ billion of cuts coming out of the VA/HUD and Independent Agencies appropriations ( $77.6 \%)$ subcommittee as well as the overall $\$ 20$ billion package $(42.9 \%)$. A vote by the full house was scheduled for March $15^{\text {th }}$ and occurred on March $16^{\text {th }} .{ }^{\text {xiv }}$

Under the committee vote, the Low-Income Housing Preservation and Resident Homeownership Act program (LIHPRHA) was cut by $\$ 464.1$ billion which basically terminated the program. Section 8 incremental vouchers and certificates were also eliminated in a $\$ 2.785$ billion cut. A draft of the Committee report stated, "At a time when HUD has significant outstanding long-term spending growth liabilities, the committee is concerned about the department entering into additional Section 8 contracts." $x x$ A breakdown of some of the rescission items approved of by the Appropriations Committee on March $2^{\text {nd }}$ are as follows:

- $\$ 2.785$ billion in incremental Section 8 vouchers and certificates

- $\$ 1.157$ billion in public housing modernization funds for public housing 
- $\$ 690.1$ million in public housing development

- $\$ 523$ million in funding for severely distressed public housing

- $\$ 404$ million in public housing operating subsidies

- $\$ 32$ million in Drug Elimination grants

- \$464.1 million for the Low-Income Housing Preservation and Resident Home-ownership Act program. (LIPRHA)

Gorden Cavanaugh. General Counsel for the Council of Large Public Housing Authorities (which includes Providence) pointed out that since the bill calls for $\$ 404$ million in cuts for operating subsidies (and therefore operating budgets), "they will have a larger impact than it seems at first. You will begin to see PHA's that will have to shut their doors in many situations." ${ }^{\times \times v 1}$ Concerning the $\$ 1.2$ billion in cuts for public housing modernization, Richard Nelson Jr. (NAHRO) stated, "if units don't get modernized, they will deteriorate further and become uninhabitable." ${ }^{\text {xxvii }}$ He estimated that 75,000 units would be affected by the rescission. He also commented that, "the proposed cuts are absolutely ridiculous. It appears that some in Congress want to make the case that public housing doesn't work. Some of LHAs face real problems and these rescissions will increase their number. How are these agencies supposed to rehab. and modernize public housing and fight drug and crime problems at developments with out the funds that the federal government previously told them they will receive?'xxvii In his estimation the recession would result in public housing authorities receiving only $81 \%$ of their federal operating subsidy as determined under PFS.

HUD reported that under the rescission bill the St. Paul MN housing authority would lose $\$ 1.029$ million in operating subsidy, $\$ 4.161$ in Comprehensive Grant Program funds and 
$\$ 123,767$ in drug elimination funding. Janet Blesener told the NAHRO Monitor that the cuts in operating subsidies would be particularly difficult for her agency to absorb. "Operating budget cuts will come out of two places: salary staff positions and non-routine maintenance." ${ }^{{ }^{x i x}}$ Operating subsidies comprise $46 \%$ of the agency's operating budget. The estimated loss of $40 \%$ of the agency's Comprehensive Grant program funds would also affect the agency by leaving modernization projects unfinished. The director of the Philadelphia Housing Authority also commented on the proposed cuts, "if our operating subsidies are reduced, the only place we could cut is in maintenance and security, which make up $70 \%$ of our operating budget. We've already taken steps to tighten up our operations." $x \mathrm{xxx}$

On March $16^{\text {th }}$ the full House voted on and approved a $\$ 17.2$ billion Rescission Bill (HR 1158) which included the expected $\$ 7.2$ billion in rescission of FY 1995 funds for HUD programs. These rescinded funds were targeted under the bill for disaster assistance costs and deficit reduction. The bill passed by a vote of 227-200. As expected the Bill would eliminate the Low Income Housing Preservation and Resident Home Ownership Act (LIHPRHA) and eliminate incremental Section 8 Certificates and Vouchers ${ }^{\mathbf{x x i}}$

Speaking at the National Association of Housing and Redevelopment Officials' Legislative Conference on March $24^{\text {th }}$, Jonathan Gautier, a professional staff member for the House Appropriations Subcommittee told housing officials that committee members looked for programs that had large annual increases and which were funded at levels higher than the White House requested. These characteristics applied to both public 
housing operating subsidies and public housing modernization funds. HUD was further targeted because it had $\$ 200$ billion of unspent appropriations. ${ }^{\mathrm{x} \times 11}$

Also on March $16^{\text {th }}$, the Senate voted to cut $\$ 400$ million from Public Housing Development funds for the FY 1996 budget as a part of the Defense Department Supplemental Appropriations Bill. This funding was re-targeted to NASA to build a wind tunnel for commercial airline development. About this $\$ 400$ million rescission Senator Barbara A. Mikulski (D-MD) said, "Given the Administration"s proposal to reinvent HUD, which the VA/HUD subcommittee will be addressing in the Fiscal Year 1996 bill. it makes little sense to add to the existing public housing inventory." $x \times x i i$ Senator Christopher Bond (R-MO) said during the floor debate, "This is an effort to get us back on track for transforming out-of-control housing and urban development policies. We need to stop spending in areas where we cannot spend wisely, but we need to save manufacturing jobs." $\times x \times x i v$

On March $24^{\text {th }}$, the Senate Appropriations Committee approved a rescission bill for $\$ 13.3$ billion of which $\$ 4.637$ billion would come from funding approved for HUD for FY 1995 and prior years. The bill did not cut funding for operating subsidies, severely distressed public housing, drug elimination grants, or CDBG. Of the Senate bill, NAHRO Executive Director Richard Nelson said, " We are pleased that, just as Senator Kit [Christopher] Bond indicated to our membership at the legislative conference, the Senate has decided to restore the crucial operating subsidy and CDBG funds cut by the House. It is also heartening that the modernization and development cuts are lower in the Senate 
bill, but we still think Housing and Community Development programs are asked to shoulder a disproportionate share of Congress' budget cutting efforts." ${ }^{\times x \times v}$

\section{Congressional Housing Legislation}

Speaking before the National Association of Counties on March $6^{\text {in }}$. Congressman Rick Lazio. Chairman of the House Banking Subcommittee on Housing and Community Opportunity, announced that the House Housing Subcommittee was working on public housing legislation. "The Housing Act of 1937 is outdated and filled with duplicative programs, many of which have no relation to housing; our re-write will provide for broad federal guidelines that are flexible enough to allow state and local entities, in conjunction with residents, to design programs that reflect their particular needs and priorities.... The federal government should have an over-arching but limited role in housing policy." $\times x \times v 1$ Lazio went on to outline the principles behind his vision of a re-invented Department of Housing and Urban Development. ${ }^{\text {xxxvi }}$

- Programs would be flexible to respond to local circumstances

- Delivery mechanisms would coordinate programs at a community level

- It would be results driven

- It would promote market based solutions and allow residents to choose where they live

- HUD assistance would encourage family and work, would be temporary, and would promote self-sufficiency

According to Lazio, the reinvention of HUD should be based upon the Community

Development Block Grant Program (CDBG) which he pointed to as a "successful, community driven program that bases its success on the capabilities of local initiatives." 
According to Lazio. "following this model. local government would take on more of a partnership role." ${ }^{\prime x \times m ~}$

At the NAHRO Legislative Conference on March $24^{\text {th }}$, Lazio stated, "I"m not here to defend HUD, but I'm not a dismanteler; our goal is to help redefine HUD's mission; what it needs to be first. then what its structure should be." ${ }^{\text {xxxix }}$

Also at the NAHRO Legislative Conference, Senator Christopher Bond began to outline his plan for housing. His plan would:

- Consolidate all public housing programs into one flexible block grant given directly to local housing authorities

- Allow for mixed incomes at all elderly developments and

- Eliminate the one-for-one replacement requirement

Bond further stated that he did not think that voucherization would be a workable program and that HUD's Fair Housing Division and Fannie Mae and Freddie Mac should be moved to the Justice Department and the Department of the Treasury respectively.

\section{APRIL 1995}

\section{Rescission of HUD Funding}

The Senate continued to work on their rescission package which totaled approximately $\$ 4.8$ billion in FY 1995 and prior year funds. On April $5^{\text {th }}$ an agreement was made between then Senate Majority Leader Robert Dole (R-KN) and Minority Leader Thomas A Daschle (D-SD) to restore a total of $\$ 336$ million in FY 1995 funding for housing and development funding in the following amounts for the following programs: 
- $\$ 220$ million for public housing modernization

- $\$ 80$ million for Indian housing

- $\$ 36$ million for community development financial institutions

The restoration of these funds was paid for by increasing the rescission of Section 8 contract renewal funds from $\$ 500$ million to $\$ 1$ billion. ${ }^{\mathrm{xl}}$

In mid April the Housing Development Reporter reported that the House-Senate conference committee working on the rescission bill still had to work out disagreements over cuts proposed by the House for the following programs:

- Operating subsidies

- Demolition and reconstruction of severely distressed public housing (HOPE 6)

- Drug elimination programs

- Youth Build

- Community Development Block Grants (CDBG)

The Senate committee report recommended funds be rescinded at significantly lower levels than the House and tended to focus more on limiting future obligations. The committee report stated, "given the constraints on discretionary funding, even maintaining existing contracts may not be possible, and, therefore, adding more to the inventory makes little sense."xli The committee also recommended that modernization funds be made eligible for other purposes such as demolition, replacement housing, temporary relocation assistance, and drug elimination activities. It was also recommended that the one-for-one replacement rule be repealed. 
In a separate development. the House-Senate conference committee dropped the proposed $\$ 400$ million from the Defense Department Supplemental Appropriations bill (H.R. 889) which was going to be used to build a wind tunnel to assist in the development of commercial airliners.

\section{Other Matters}

On April $19^{\text {th }}, 35$ HUD employees were murdered in the explosion which destroyed the Murrah federal building in Oklahoma City. Funding for the Federal Emergency Management Agency would be allocated for this disaster from some of the money saved in the 1995 Rescission bill.

\section{MAY 1995}

\section{The Reinvention of HUD}

On May $1^{\text {st }}$, HUD sent to Congress a proposal for the consolidation of development programs into two performance-based grants, the voucherization of public housing through a tenant certificate fund, and the revision of the low-income housing preservation process.

Under this proposal a Housing Certificate Fund would be funded at $\$ 7.66$ billion for FY 1996 and would be a single performance-based fund for Section 8 Certificates and Vouchers and public housing operating and capitol subsidies (after a period of transition). At first, operating and capitol improvement funds would be allocated using a project 
based subsidy during a transition period, after which funding would shift to tenant based certificates. Also proposed were several measures to deregulate housing authority operations such as allowing housing authorities to set ceiling rents, encourage occupancy by working families, set minimum rents, and design occupancy preferences. The proposal also recommended that demolition and disposition requirements be made less cumbersome and gave troubled housing authorities a year to improve or face being taken over by HUD. Current tenants would still be protected by their current lease provisions..$^{\prime \prime \prime}$

A Community Opportunity fund would be based on the CDBG program, and would be funded at $\$ 4.6$ billion for FY 1996. The 70\%-30\% split between entitlement communities and state funding would be maintained and a $\$ 250$ million bonus pool would be available for high performers with proposals for activities designed to spur job creation in low income areas. The Affordable Housing Fund would be funded at $\$ 3.3$ billion in FY 1996 and would be based upon the HOME program.

Following a May 19 th hearing before Congress. Secretary Henry Cisneros announced that he did not think the HUD reinvention plan for the voucherization of public housing would survive opposition from key members of the Senate. Christopher Bond (R-MO) was quoted as saying, "I can tell you right now, it's not going to fly." In his opening statement he stated, "Frankly, I'm still wondering when we will get to the bottom of this programmatic, administrative, and budgetary sinkhole. Despite your best efforts, I'm still not sure what the administration is recommending." ${ }^{\text {"lii }}$ Criticism for the plan came from 
both sides of the aisle. Senator Barbara A. Mikulski (D-MD) stated, "I believe it will be too expensive and unpredictable in terms of its affect on the housing stock." $\times 114$

\section{Rescission of HUD Funding}

With the Conference Committee still working on differences between the House and Senate versions of the 1995 Rescission bill (H.R. 1157), HUD obligated FY 1996 operating subsidies to housing authorities with fiscal years beginning on July 1 st. HUD claimed that this meant that any cuts made in the rescission bill for operating subsidies would have to fall on the 784 housing authorities whose fiscal year begins in October. HUD estimated that the House's proposed $\$ 404$ million rescission of operating subsidies would result in these housing authorities receiving only $8 \%$ of their eligible subsidy under PFS. Mary Ann Russ, Director of Assisted Housing in HUD's Office of Public and Indian Housing stated that, "this late in the fiscal year there is no equitable way to spread the operating subsidy dollars anyway. The people in the House know this would affect housing authorities whose fiscal years begin in October. Hopefully, this will encourage Congress not to rescind the operating subsidies. I don't think they want to put October $1^{\text {st }}$ agencies out of business. ${ }^{x / v}$

On May $16^{\text {th }}$, the House and Senate Conference Committee completed work on the FY 1995 budget rescission. The total cut for HUD funding under this bill was $\$ 6.3$ billion, a figure in between the House ( $\$ 7.2$ billion) and Senate $(\$ 4.9$ billion). Under this bill operating subsidies, the replacement of distressed housing, and drug elimination programs all received full funding. The conference committee also dropped a proposal to 
cut $\mathrm{CDBG}$ funding by $\$ 349$ million. The following funding cuts were included in the bill: ${ }^{x \mid \mathrm{w} 1}$

- Incremental Section 8 vouchers/certificates ( $\$ 1.95$ billion)

- Section 8 voucher/certificate renewals ( $\$ 1.177$ billion)

- Public Housing modernization (\$815 million)

- New public housing construction (\$620 million).

- Section 8 loan management set-aside (\$148 million)

- Lead based paint abatement ( $\$ 85$ million)

- Special projects ( $\$ 22$ million)

On May, $24^{\text {th }}$ the Senate passed the rescission legislation (HR 1158). It was expected at this time that the President would veto this bill because of cuts in assisted housing funds and housing for people with AIDS.

\section{The Congressional Budget Process}

In a hearing of the House Appropriations Subcommittee on VA/HUD and Independent Agencies, Chairman Jerry Lewis (R-CA) noted that he had not yet received any instruction from the Republican House leadership concerning the FY 1996 budget for housing.

Congress began work on the budget resolution for FY 1996. At this point it was estimated that the cost for renewing expiring Section 8 units would be $\$ 75.8$ billion over the next seven years. The House passed its budget resolution on May $18^{\text {th }}(\mathrm{H}$. Con Res. 67 ) and the Senate passed its resolution (S. Con. Re. 13) on May 25 . While these budget resolutions set spending and revenue targets, they are not law and thus are not subject to a Presidential veto. Under the House plan total outlays would rise from \$1.586 trillion in 
FY 1996 to $\$ 1.815$ trillion in FY 2002. The House plan also called for $\$ 350$ billion in tax cuts including a 50\% reduction in the capital gains tax, a measure which was passed in March. The Senate tentatively agreed to tax cuts depending upon the feasibility of maintaining plans for a projected balanced budget by 2002 . $^{\text {lvii }}$

The House Budget Committee plans to administer housing and community development funds in the form of block grants to states with a final reduction of aggregate funding of $20 \%$ by FY 2002. The House also proposed ending Section 8 Incremental vouchers and certificates and renewing only $50 \%$ of vouchers and certificates turned in by tenants who no longer need assistance. The Senate Budget Committee proposed a block grant for public housing and a block grant for assisted housing programs. The Senate estimated a savings of $\$ 5.7$ billion over then next five years through administrative cost savings and the termination of programs. The committee also recommended cutting CDBG funds by $50 \%$ with funding targeted to areas of greatest need. It was projected that this would save $\$ 7.6$ billion from FY 1996-FY 2000. ${ }^{\text {vviii }}$ Concerning plans to reduce funding for some programs in order to balance the budget Congressman Lazio (R-NY) stated, "we're going to be doing less, but hopefully we'll be doing it better." "xix

\section{Congressional Housing Legislation}

Congressman Lazio spoke about his housing bill on May, $9^{\text {th }}$ at the National Community Development Association (NCDA) Annual Conference. He proposed a consolidation of the HOME and CDBG programs which would be funded using the 70/30 current CDBG program's split between entitlement community and state funding. He also announced 
plans for extensive deregulation. "we're going to allow you to react based upon your own local needs, but we'll have to measure your output."

\section{JUNE 1995}

\section{The Rescission of HUD Funding}

As expected. President Clinton vetoed the Rescission bill HR 1158 citing cuts in housing assistance programs and housing for AIDS patients. Republicans in Congress did not have the votes to override the veto and agreed to work with the White House to reach a compromise. Congressional staffers noted that if a compromise could not be reached, the rescission cuts proposed for the FY 95 budget would have to come from the FY 96 budget since Congress " balanced budget plan factored in the rescission.

\section{The Congressional Budget Process}

On June $23^{\text {rd }}$, the House/Senate conference committee agreed on a seven year budget resolution which would result in a balanced budget by the year 2002. The plan would include the renewal of all existing Section 8 vouchers and certificates, the creation of housing block grants to be administered at the state and local level, and would reduce total outlays by $\$ 892.6$ billion over seven years based upon spending "authorized under current law" The cuts include a $28 \%$ cut in funding for the CDBG program and estimates the cost of Section 8 renewals at $\$ 34$ billion over the seven year period. The plan would also include $\$ 245$ billion in tax cuts designed to spur the economy if the Congressional Budget Office (CBO) certifies that the budget would still be balanced in seven years." 


\section{The White House Budget Process}

On June $13^{\text {th }}$, the White House announced its plan to balance the budget in ten years (opposed to the seven year time span proposed by Congress). While no details were provided concerning cuts in housing programs, the proposal calls for $\$ 92$ billion in cuts in discretionary spending programs, $\$ 27$ billion in defense programs and $\$ 65$ billion in nondefense programs. The proposal also included a form of middle class tax cut.

\section{Congressional Housing Legislation}

On June $29^{\text {th }}$ a Congressional HUD task force co-chaired by House Representatives Sue Myrick (R-NC) and Sam Brownback (R-KS) and Senators Lauch Faircloth (R-NC) and Spencer Abraham (R-MI) discussed their proposed bill (HR 2198/ S 1145) to basically dissolve the Department of Housing and Urban Development. Included in their plan were the following: ${ }^{\text {lii }}$

- The elimination of FHA multifamily insurance

- The dispersal of HUD's non-core activities to other agencies and the private sector

- The conversion of all public and assisted housing funding to block grants

- the elimination of the HUD Secretary as a Cabinet position

- The voucherization of HUD (as was included in HUD's own reinvention plan) only the vouchers would be overseen by HUD staff transferred to the Department of Health and Human Services. 


\section{JULY 1995}

\section{The Rescission of HUD Funding}

The White House and Congress came up with a compromise bill for the rescission of FY 1995 funding (HR 1944) which replaces the previous rescission bill vetoed by the President. The total rescission in the compromise bill was $\$ 16.4$ billion. Congress agreed to add $\$ 200$ million in funding including $\$ 15$ million for housing for people with AIDS. Congress passed this bill on June 29th, but the Senate was not able to vote on the bill. Senators Paul Wellstone (D-MN) and Carol Mosely-Brawn (D-Ill) refused to end debate protesting cuts to low-income energy assistance and consumer counseling for the elderly. Then Senate majority leader Bob Dole (R-KN) removed the measure from the floor and refused to bring it up for consideration unless the Senate would agree to a vote on the bill without amendments and with limited discussion. Minority leader Tom Daschle attempted to get these Senators to drop their objectives.'"1 Eventually this bill passed the Senate in the following weeks.

\section{The Congressional Budget Process}

On July $10^{\text {th }}$ the House HUD/VA Appropriations Subcommittee approved a FY 1996 appropriations bill. This bill included $\$ 19.1$ billion in budget authority for HUD, $\$ 6.3$ 
billion lower than the FY 95 funding level and $\$ 5.24$ billion lower than the White House budget request. The plan included no funding for the following programs: w

- Incremental Section 8 vouchers and certificates (previously funded at $\$ 2.7$ billion)

- Public housing development (previously funded at $\$ 600$ million)

- HOPE 6 program for severely distressed public housing (previously funded at $\$ 500$ million)

- Drug elimination programs (previously funded at $\$ 290$ million)

- Funding for multifamily housing disposition (previously funded at $\$ 555$ million)

The plan also included cuts in the following programs:

- Public housing modernization ( $\$ 2.5$ billion in FY 1996 down from $\$ 3.7$ billion in FY 1995)

- Operating subsidies ( $\$ 2.5$ billion in FY 1996 down from $\$ 2.9$ billion in FY 1995)

- Indian housing development (\$100 million FY 1996 down from $\$ 282$ million n FY 1995)

- Homeless assistance (\$576 million down from $\$ 1.12$ billion in FY 1995)

The plan included increases in funding for:

- Section 8 contract renewals (from $\$ 3.3$ billion in FY 1995 to $\$ 4.9$ billion in FY 1996

- Also CDBG and HOME funding was frozen at the current level. This went against the budget resolution which would have cut CDBG funding by $28 \%$.

The plan included the following regulatory relief measures:

- Suspension of the Brooke Amendment for one year.

- The implementation of a $\$ 50$ minimum rent plus utility costs to be paid by the tenant

- A one year repeal of the one-for-one replacement law and federal admission preferences

- The implementation of a $\$ 50$ minimum rent on Section 8 tenants and an increase in the ceiling rent from $30 \%$ of tenant income to $32 \%$ 
Subcommittee Chairman Jerry' Lewis (R-CA) stated, "the subcommittee is funding those programs that work while beginning the process of reducing or eliminating programs that are repetitive or ineffective. ${ }^{\text {iv }}$ Commenting on the proposed budget during a July 12 th press conference HUD Secretary Henry Cisneros said, "This will bring an increase in rents for people who don't have a dime to spare. Public housing authorities will be forced to raise their rents to make up for deficits in operating funds. And what I've found in my travels around the country is that these people don't have a lot of money. The subcommittee says they're saving money and putting America on a glide path to a balanced budget. This is not a glide path. This is a crash course that puts people in dire straits. "ivi

This proposal was approved by the full House Appropriations Committee on July, $18^{\text {th }}$ with minor changes, and on July 31 ${ }^{\text {st }}$, the House passed its FY 1996 budget for HUD (HR 2099 ) by a vote of 228-193. The bill provided for funding at an overall level of $\$ 19.5$ billion, $\$ 5.1$ billion less than FY 1995. The bill did not include the repeal of the Brooke Amendment or the implementation of minimum rents for public housing. The bill did eliminate federal admissions preferences, the one-for-one replacement rule, and established a minimum rent of $\$ 50$ or $32 \%$ of the tenant's income (which ever is higher) for the Section 8 rental assistance program. The following list of programs illustrates changes in funding levels under this bill: ${ }^{\text {wn }}$

- $\quad$ CDBG and HOME: Fully funded at FY 1995 levels 
- Operating subsidies cut from $\$ 2.9$ billion in FY 1995 to $\$ 2.5$ billion in FY 1996. NAHRO notes that if operating subsidies were to be fully funded under PFS it would be funded at $\$ 3.1$ billion. $\$ 2.5$ billion would only fund the program overall at $78 \%$ of the full level as determined under PFS.

- Modernization for public housing cut from $\$ 3.7$ billion in FY 1995 (minus a $\$ 815$ million rescission) to $\$ 2.5$ million in FY 1996.

- McKinney homeless assistance program funds were cut by $\$ 444$ million.

- Section 8 incremental units were not funded under this bill, neither were public housing development, drug elimination programs, or HOPE 6 for severely distressed public housing.

- Housing Opportunities for People with AIDS (HOPWA), Section 202 and Section 811 programs were consolidated into a "special needs housing fund" funded at $\$ 1.44$ billion ( $\$ 450$ million less than the combined total funding for these programs in FY 1995.

\section{AUGUST 1995}

\section{Rescission of HUD Funding}

HUD issued an August notice to Public and Indian Housing Authorities concerning the need to recapture $\$ 815$ million in modernization funds due to the Congressional rescission. \$600.4 million of Comprehensive Grant Program (CGP) funds had to be recaptured. The remaining modernization funding rescinded was handled through the CIAP program, set asides, and reserve funds.

\section{The Congressional Budget Process}

The Senate subcommittee on VA/HUD and Independent Agencies announced its plans to mark up its fiscal year 1996 appropriations bill on September $11^{\text {th }}$. 


\section{The Reinvention of HUD}

Both the National Association of Housing and Redevelopment Officials (NAHRO) and the General Accounting Office (GAO) issued reports claiming HUD's voucherization plan would be more costly than estimated by the department, that modernization of units was a key factor to the plan (and its cost), and that variations in costs for operating under tenant based vouchers Vs public housing costs varied greatly depending on the particular housing market and the developments in question. NAHRO announced that it surveyed housing authorities and found that $38 \%$ of units would not be able to compete in the market place.

\section{SEPTEMBER 1995}

\section{The Congressional Budget Process}

On September $13^{\text {th }}$ the Senate Appropriations Committee approved the FY 1996 appropriations bill (HR 2099). Under this version of the bill, HUD would receive $\$ 20.4$ billion in total budget authority. The committee voted to delay funding for New Low Income Housing Preservation and Project-Based Section 8 Mark to Market programs for one year because the Congressional Budget Office (CBO) indicated that funding for the bill was $\$ 580$ million over its allocation. Both the CDBG and HOME programs received funding at the same level as in FY 1995. Other funding levels for programs include:

- $\$ 2.8$ billion for operating subsidies

- $\$ 250$ million for public housing modernization

- $\$ 240$ million for incremental Section 8 units

- \$171 million for HOPWA 
- $\$ 75$ million for lead paint reduction

The bill would also broaden the allowable uses of modernization funds, end the one for one replacement rule, end federal admissions preferences, allow for greater discretion in the setting of rents (allowing a minimum rent of $\$ 25$ and market based ceiling rents). For the Section 8 program the bill adjusted fair market rents to the 40 th percentile, set the Administrative fee at $7 \%$, and ended the take one take all rule. The bill would also move fair housing enforcement duties to the Justice Department along with $\$ 30$ million in program funds. Commenting on this provision Secretary Cisneros said, "The Justice Department does not have the staff resources, day-to-day interaction, or administrative structure to handle cases routinely resolved by HUD without litigation. Housing discrimination is still a painful reality in America today. Sadly, many more families would experience it if this rider is not removed from the bill."

\section{The White House Budget Process}

On September $30^{\text {th }}$ President Clinton signed into law a continuing resolution to allow government agencies to function after the FY 1996 begins on October $1^{\text {st }}$. This was necessary because an agreement between the White House and Congress on an overall appropriations bill was not likely in the near future. The continuing resolution funds programs at $5 \%$ less than the average of the House and Senate proposals, and no program was allowed to be funded under 10\% of its FY 1995 level.

\section{Congressional Housing Legislation}


While speaking at the Public Housing Authority Directors Association Legislative Conference on September $14^{\text {th }}$, House Housing Subcommittee Chairman Rick A. Lazio continued to outline his proposed housing legislation. His plan would repeal the Housing Act of 1937 and reform assisted and public housing. He referenced the HUD Task Force bill to eliminate the department in announcing his plan to replace HUD with a new Department of Communities saying, "I do not believe the solution lies in taking parts of HUD, defective parts, and spreading them throughout the government, perhaps to an already bloated Department of Health and Human Services." ${ }^{.9 x}$ Under the Lazio bill housing authorities would have to go through both an accreditation process and a review process where they would be rated as extremely well managed, well managed, troubled, or dysfunctional. Housing authorities which scored poorly would have specific time frame to improve or face extinction. "Frankly", Lazio stated, "this bill shows a lot of intolerance for PHAs that have been corrupt and incompetent and are non-performers." The bill lists 100 troubled PHAs along with plans to dissolve the ten worst.

Accredited housing authorities would be required to prepare five year strategic plans for funding which would be administered in five year block grants to allow greater flexibility. Housing authorities that are troubled may be funded for shorted periods of time. The bill allows housing authorities to serve residents earning up to $80 \%$ of the median area income and allows for mixed income developments.

During a September $29^{\text {th }}$ hearing held by the House housing subcommittee on HR 2406, Lazio stated "the majority of public housing authorities in this country do a good job of 
providing affordable housing to deserving families. We should empower effective, well run housing authorities to do a better job. However for those that are chronically troubled, we must admit the failure and end the monopoly of a failed management structure. ${ }^{"|x|}$

During a Senate Banking Committee hearing concerning the proposed Senate housing bill (S. 1260) HUD secretary Henry Cisneros stated, "in its current form the bill swings the pendulum too far towards unfettered control by local bureaucracies and away from prudent national standards and appropriate federal oversight."'xii

Senator Lauch Faircloth (R-NC), co-sponsor of the bill said to Cisneros "I don't think we agree on much. but we do agree that the future of HUD lies with vouchering out of public housing." "Hxii Cisneros, however, had been backing away for months from plans to voucherize public housing and said only, "I'm deferring to the wisdom of the Senate on this." ${ }^{\prime \mid x_{i}}$ This was seen as the secretary distancing himself from the plan because at that point the Senate as a whole clearly opposed this proposal. Committee Chairman Alfonse M. D'Amato (R-NY) voiced these sentiments when he stated "as far as the PHAs are concerned, you just can't cut them loose overnight; you'll have chaos."'xx

\section{October 1995}

Congressional Housing Legislation 
During an October $13^{\text {th }}$ hearing of the House Housing Subcommittee. Secretary Cisneros expressed his concern that the accreditation board created under the Lazio housing bill (HR 2406) would duplicate services provided by HUD under its oversight capacity. "Which roles are uniquely the federal governments and which roles can be assigned or delegated to an independent entity need to be explained with great care. Will HUD retain independent audit and enforcement powers to protect public housing residents and taxpayers when it sees the need? Will HUD retain the ultimate right to approve performance standards?"Ixvi HUD Inspector General Susan Gaffney echoed these concerns "we risk confusion in making the board into just another bureaucratic layer and having HUD continuing to do business as usual.".|lvvii

While Cisneros supported the bill's implementation of the consolidation of HUD programs into block grants (a proposal which was included in the early stages of the HUD reinvention blueprint) he said of the decreases in funding levels included in the Lazio plan that, "the impact of these proposed funding reductions would be stark and immediate."1xviii

On October 26th, the Senate Banking Committee approved the Senate housing bill (S 1260). An amendment was included which was proposed by Subcommittee Chairman Connie Mack (R-FL) to allow separate funding for the revitalization of distressed public housing, self sufficiency programs and service coordinators, and drug elimination grants. 


\section{NOVEMBER 1995}

\section{The Congressional Budget Process}

On November $16^{\text {th }}$ the House/ Senate Conference Committee agreed to a FY 1996 HUD/VA appropriations bill (HR 2099). The Conference Committee approved the Senate's higher level of funding for operating subsidies ( $\$ 2.8$ billion rather than $\$ 2.5$ billion), preserved the PHDEP program and the program for severely distressed public housing (funded at $\$ 280$ million, significantly lower than the $\$ 500$ million funding level for FY 1995) and set the figure for Section 8 renewals at the lower figure originally proposed by the Senate $(\$ 4.35$ billion rather than the $\$ 4.94$ billion figure proposed by the House). The Conference Committee also chose to fund the modernization of public housing at the lower House figure of $\$ 2.5$ billion. ${ }^{\mid \mathrm{x} x}$ Also under the Conference Committee agreement, the Section 202, 811 and Housing Opportunities for People With AIDS (HOPWA) programs were all funded separately rather than as a single "special needs" program. Both the HOME and CDBG programs were funded at their FY 1995 levels and Section 8 program administrative fees were set at $7.65 \%$ for the first 600 units and $7 \%$ for each additional unit.

Even with the agreement reached in the Conference Committee, however, it remained unlikely that the overall bill would become law in its current state. A presidential veto was expected due to Congressional cuts in programs for the Environmental Protection Agency (EPA) and the AmeriCorps public service initiative. It was feared by some housing industry professionals that the restoration of funds for these programs would have to come from housing and community development programs. NAHRO Executive 
Director Richard Nelson Jr. commented on the situation by saying, "this year has been a long struggle to maintain reasonable funding for core housing and community development programs. While we share the President's dismay about reductions in AmeriCorps and some environmental programs, we know the White House also values successful, progressive programs like CDBG and HOME. I hope the President will consider all the ramifications before he makes his veto decision. ${ }^{\text {"lkx }}$ In an unusual move, the House voted 216-208 to send the bill back to the Conference Committee on November $29^{\text {th }}$ in order to increase funding for Veterans' health care benefits by $\$ 213$ million.

Due to the failure of the White House and Congress to reach a compromise on a continuing appropriations resolution or an overall FY 1996 budget, HUD was forced to shut down on November $14^{\text {th }}$, the day after the expiration of the previous continuing resolution. In a November $13^{\text {th }}$ statement, HUD Secretary Henry Cisneros stated, 'President Clinton is right to stand firm in the face of Congress' attempt to make major policy changes and force draconian cuts in ongoing programs by attaching them to temporary government financing measures. There is no question the American people will pay the price for a federal showdown brought on by Congressional leaders who insist on playing politics with the budget."1xxi HUD sent home 11,000 employees and kept 125 essential staff member at the Washington HUD office and local field offices. One effect of the shut down was that HUD could not process FHA mortgage insurance applications. HUD typically processes 2,500 per day. HUD was also unable to pay its bills or review cases of housing discrimination. 


\section{Congressional Housing Legislation}

On November $2^{\text {mil }}$, the House Banking Committee began to mark up the U.S. Housing Act of 1995 (HR 2406) which would replace the Housing Act of 1937. Committee Chairman James A. Leach (R-IA) announced that he planned to attach it to HR 2099, the VA/HUD appropriations bill. The subcommittee completed the mark up on November $9^{\text {th }}$. The bill would reduce the administrative fees paid to housing authorities for each of the Section 8 vouchers and certificates they over see to $6.5 \%$ for the first 600 units and $6 \%$ for all remaining units. The bill would also merge all public housing programs into a block grant, merge the Section 8 voucher and certificate programs, and eliminate the Brooke Amendment, lease and grievance rules, the Section 8 take one take all rule, and the onefor-one replacement rule. The committee also included in the bill amendments to require that $25 \%$ of households served by housing authorities earn less than $30 \%$ of the median area income, that rent increases be phased in over three years, that housing authorities provide vouchers to tenants living in buildings deemed too expensive to maintain, and to disallow tenants from being admitted to public housing on the basis of claiming alcohol or drug problems as a disability. ${ }^{\mid x \times i 1}$

In the November $15^{\text {th }}$ issue of the NAHRO Monitor, the professional association's newsletter, that organization estimated that under the Lazio bill's revised Section 8 administrative fee $91 \%(2,300)$ local agencies which administer Section 8 vouchers and certificates would lose more than $15 \%$ of their administrative fee income and that 700 agencies would see decreases of over $20 \%$. These figures were updated in the November 
$30^{\text {th }}$ issue which estimated that under the reductions in Section 8 administrative fees proposed under the Conference Committee agreement for HR 2099, housing authorities would lose a total of $\$ 76$ million. Under the Lazio bill it was estimated that housing authorities would lose a total of $\$ 174$ million. NAHRO estimates that if housing authorities were to receive their Section 8 administrative fees at the current funding levels, they would receive $\$ 764$ million in administrative fees in FY 1996. Administrators for the Seattle Housing Authority, which oversees 2,600 Section 8 certificates and 1,200 vouchers, estimate that they would lose $\$ 500,000$ in administrative fees under proposed housing legislation which would result in staff cuts of $20 \%$. The Los Angeles Housing Authority estimated losses of $\$ 4.5-5$ million in administrative fees for the 28.000 vouchers and certificates which they administer. Officials estimate that this would result in the loss of 75 staff members. ${ }^{\text {Ixxiii }}$

In action on the Senate bill, which would merge public housing programs into two formula based block grants, an amendment submitted by Senator Lauch Faircloth (R NC) was passed which would allow for no new construction of public housing unless it was designed to replace demolished units. Defeated were Faircloth amendment proposals to eliminate HUD by Oct. 1st 1998 and require the voucherization of public housing units unless public housing authorities could prove that maintaining public housing developments was cheaper than voucherization. Faircloth stated, "when HUD was created in 1965 it was a failure and billions of dollars later it still is." ${ }^{\text {"xxir }}$ Unlike the House bill, the Senate bill (S 1260) maintained the Brooke Amendment rent limit at 30\% of the family's adjusted income for families earning less than $50 \%$ of the median area 
income. The Senate bill would also require that $40 \%$ of units be used for households earning below $30 \%$ of the median area income and that at least $70 \%$ of units be for families earning less that $60 \%$ of median area income.

Also in November, the House and Senate approved a seven year budget reconciliation bill (HR 2491).

\section{DECEMBER 1995}

\section{The Reinvention of HUD}

In a December $6^{\text {th }}$ interview with writers for the Housing and Development Reporter, HUD Secretary Cisneros outlined his Blueprint II plan for HUD which he planned to submit with the 1996 budget. The plan included: $:^{1 \times x v}$

- The consolidation of McKinney Act homeless assistance programs into a more coherent program with greater discretionary powers for implementing communities.

- Greater integration of the HOME program into an overall department home ownership strategy.

- Continuing innovation in public housing, focusing on changing the physical landscape, revising the social services support system to encourage self-sufficiency and changing regulations to encourage better operations without the need for HUD rescue efforts.

During the interview Cisneros noted that many of the proposals he had for HUD were contained in Congress' 1996 appropriations bill HR 2099 including the elimination of the take one take all rule for Section 8 and allowing housing authorities to set ceiling rents in order to attract working families. The secretary also noted that he would no longer push for the full voucherization of public housing due to a lack of Congressional support. 


\section{The Congressional Budget Process}

On December $6^{\text {th }}$ the House approved the FY 1996 HUD appropriations bill (HR 2099) which was amended to fund Section 8 administrative fees at the FY 1995 level. Also on December $6^{\text {in }}$, the President vetoed HR 2491, Congress' seven year budget reconciliation bill.

Final versions of the VA/HUD appropriations bill passed in the House (December $7^{\text {th }}$ ) and the Senate (December $14^{\text {th }}$ ). In addition to freezing Section 8 administrative fees at FY 1995 levels, the bill also included an additional $\$ 213$ million for veteran health care programs requested by the House. On December $18^{\text {th }}$ the President vetoed the bill citing the elimination of the Americorps program and cuts in environmental programs as his biggest concerns. The president also expressed concern for the lack of funding for economic development initiatives and incremental Section 8 vouchers and the transfer of fair housing duties to the Justice Department. Senator Christopher Bond (R-MO), chairman of the VA/HUD appropriations subcommittee was quoted as saying, "we have been unsuccessful in gaining the attention of the White House to negotiate a reasonable compromise on their demands for more spending, far more than what any balanced budget plan can accommodate. That is the source of my very deep frustration over this bill. ${ }^{\cdot / \times \times 11}$

On December $18^{\text {th }}$, HUD was forced to close again after a continuing resolution to fund the agency ran out on December $15^{\text {th }}$. 10,800 employees were sent home and 1,900 
remained after Congressional complaints after the last shutdown that the staffing level was inadequate. In a letter to Secretary Cisneros after the November shut down Congressman Lazio stated that the staffing level, "was not sufficient to perform essential and legally mandated functions under HUD's responsibility."

In a statement summing up the thoughts of many on Capitol Hill, Senator Barbara A. Mikulski (D MD), ranking democrat on the Senate VA/HUD Appropriations Subcommittee stated, "this has been the toughest year I have ever faced as a member of the Appropriations Committee. This year was so tough simply because of the modest allocation we received, and that was due to issues related to the budget. The amount the subcommittee was allowed to devote to so many important priorities is indeed skimpy."'|x:vu!

\section{How All of this Impacted the Providence Housing Authority:}

During the year the strategic plan was written it was estimated that housing authorities would face substantial losses of funding due to the rescission bill and Congressional budget cuts. At the time it was estimated that Congress would cut housing authority operating subsidies by $21.8 \%$. It was estimated that this loss would equal approximately $\$ 1,185,640$ (the PHA was being funded at $96 \%$ of eligible subsidy under PFS or $\$ 5,438,718$ ). At the time it was believed that such a deep cut in the operating subsidy 
would result in cut backs in maintenance and management functions including loss of staff.

In the first fiscal year following the creation of the PHA's strategic plan, the PHA only received funding at $89 \%$ of the available subsidy under PFS. This resulted in a loss of approximately $\$ 800,000$. Fortunately this cut in funding did not result in a loss of either services or personnel because the PHA was able to use reserve funds to offset this loss.

The Providence Housing Authority also lost substantial funds due to the rescission of modernization money. The PHA lost approximately one million dollars in Comprehensive Grant Program funding in the rescission which resulted in the delay of the modernization of the West End's Codding Court development, adding an additional year to the expected completion date. The funding also delayed the construction of handicapped accessible units at the Dominica Manor and Kilmartin Plaza elderly/disabled developments for an unspecified time.

Also in the first fiscal year following the creation of the strategic plan, the Providence Housing Authority lost a substantial amount of funding due to changes in the Section 8 Administrative fee structure. The administrative fee is paid to housing authorities to pay for the costs of running the Section 8 rental housing program. It is widely assumed that these fees paid to HA's are greater than the actual cost of administering the program and that housing authorities use these funds to cover other operating costs. (This is not unreasonable when one considers that housing authorities due not receive the full amount 
of funding for operating subsidies under PFS.). The fee structure was reduced by Congress from an administrative fee of $8.2 \%$ of the cost of the voucher or certificate subsidy to $7.5 \%$ for the first 600 units overssen by the housing authority, and from $7.65 \%$ to $7 \%$ for all units above that figure. In practical terms this is a reduction of $\$ 51.92$ for each of the first 600 units and $\$ 48.45$ for each of the remaining units. It is estimated that the PHA will receive $\$ 99,797$ less when the reduction in administrative fees for the voucher. certificate and project based programs are considered.

It was also estimated that the Public Housing Drug Elimination Program would be discontinued. These cuts were not implemented and the program was funded at the full FY 1995 level. These cuts would have been devastating to the Providence Housing Authority`s drug education. teen pregnancy awareness, cultural enrichment, and social activities programs run by the PHA in its family developments. The PHA had received $\$ 1.738$ million in PHDEP funds in the three years prior to the time the cuts were proposed and funds the entire Community Services Department (except the Department Director) from grant funding. The loss of PHDEP funding would have resulted in a drastic cutback or elimination of the above mentioned programs and the elimination of the department.

As expected, the political events in 1995 had a significant affect on public housing authorities nationally and the Providence Housing Authority. The losses in funding mentioned above total almost $\$ 2$ million, and these funding reductions came without any of the proposed housing legislation becoming law. The pace at which changes in the 
external environment affect the operations of the Providence Housing Authority appears to be increasing every year. The social, political, and economic forces which helped to motivate the PHA's strategic planning teams in 1995 have not dissipated. A strategic plan is more than just a product, it is also a process; and the process of Strategic Plan 2000 is far from over. 


\section{ENDNOTES}

\section{CHAPTER ONE}

' Congressional Quarterly Weekly Reports. September 7, 1996. Page 2517.

"Congressional Quarterly Weekly Reports. September 7, 1996. Page 2517.

iiiHousing and Development Reporter: Current Developments. Warren Gorham Lamont. January 2. 1995. Vol. 22. No. 34. Page I.

1 NAHRO Monitor lanuary 31. 1995. Vol. XVII. No. 2. Page !.

- NAHRU Monitor January 31. 1995. Vol. XVII. No. 2. Page 2.

$\checkmark$ NAHRO Monitor January 31, 1995. Vol. XVII, No. 2. Page 4.

"Housing and Development Reporter: Current Developments. Warren Gorham Lamont. February 13. 1995. Vol. 22. No. 37. Page 610.

vii NAHRO Monitor February 15, 1995. Vol. XV1l, No. 3. Page 2

${ }^{1 \times}$ NAHRO Monitor February 15, 1995. Vol. XVII, No. 3. Page 2

${ }^{x}$ Housing and Development Reporter: Current Developments. Warren Gorham Lamont. March 13, 1995. Vol. 22, No. 44. Page 677.

${ }^{*}$ Housing and Development Reporter: Current Developments. Warren Gorham Lamont. March 13, 1995. Vol. 22, No. 44. Page 678.

"NAHRO Monitor February 15. 1995. Vol. XVII. No. 3. Page 5

"'NAHRO Monitor February 15, 1995. Vol. XVII, No. 3. Page 5

"Housing and Development Reporter: Current Developments. Warren Gorham Lamont. February 27, 1995. Vol. 22. No. 42. Page 642

* Housing and Development Reporter: Current Developments. Warren Gorham Lamont. February 27, 1995. Vol. 22. No. 42. Page 642.

${ }^{\times v_{1}}$ Housing and Development Reporter: Current Developments. Warren Gorham Lamont. March 13, 1995. Vol. 22, No. 44. Page 702

x*" Housing and Development Reporter: Current Developments. Warren Gorham Lamont. March 13, 1995. Vol. 22, No. 44. Page 702.

*wis Housing and Development Reporter: Current Developments. Warren Gorham Lamont. March 13, 1995. Vol. 22. No. 44. Page 702.

kix Housing and Development Reporter: Current Developments. Warren Gorham Lamont. March 13, 1995. Vol. 22. No. 44. Page 703

${ }^{\times x}$ Housing and Development Reporter: Current Developments. Warren Gorham Lamont. March 13. 1995. Vol. 22. No. 44. Page 676

${ }^{k \times 1}$ Housing and Development Reporter: Current Developments. Warren Gorham Lamont. March 27, 1995. Vol. 22. No. 46. Page 732.

kxiitHousing and Development Reporter: Current Developments. Warren Gorham Lamont. March 27, 1995. Vol. 22. No. 46. Page 733.

xxiiiHousing and Development Reporter: Current Developments. Warren Gorham Lamont. March 27, 1995. Vol. 22, No. 46. Page 733.

xxiv NAHRO Monitor March 15. 1995. Vol. XVII. No. 5. Page 1

${ }^{x \times}$ Housing and Development Reporter: Current Developments. Warren Gorham Lamont. March 13. 1995. Vol. 22. No. 44. Page 674.

"w) Housing and Development Reporter: Current Developments. Warren Gorham Lamont. March 13, 1995. Vol. 22. No. 44. Page 703

rwv" Housing and Development Reporter: Current Developments. Warren Gorham Lamont, March 13, 1995. Vol. 22, No. 44. Page 702.

xws" NAHRO Monitor March 15, 1995. Vol. X'VIl. No. 5. Page 1.

${ }^{x \times 1 x}$ NAHRO Monitor March 15, 1995. Vol. XVII, No. 5. Page 2. 
rxx NAHRO Monitor March 15, 1995. Vol. XVII, No. 5. Page 2

${ }^{\times \times 1}$ Housing and Development Reporter: Current Developments. Warren Gorham Lamont. March 13, 1995. Vol. 22. No. 46. Page 707.

×x×"NAHRO Monitor March 31, 1995, Vol, XVIl, No. 6. Page 4

*xx"1"Housing and Development Reporter: Current Developments. Warren Gorham Lamont. March 13, 1995. Vol. 22. No. 46. Page 707

${ }^{\times \times \times \mid v}$ Housing and Development Reporter: Current Developments. Warren Gorham Lamont. March 13, 1995. Vol. 22. No. 46. Page 707

${ }^{x \times r}$ NAHRO Monitor March 3I, 1995. Vol. XVII, No. 6. Page 4

"xrvi Housing and Development Reporter: Current Developments. Warren Gorham Lamont. March 13, 1995. Vol. 22. No. 44. Page 687

xxw: Housing and Development Reporter: Current Developments. Warren Gorham Lamont. March 13, 1995. Vol. 22. No. 44. Page 687

rxrsut Housing and Development Reponer: Current Developments, Warren Gorham Lamont. March 13. 1995. Vol.

22. No. 44. Page 688

${ }^{x \times x i x}$ NAHRO Monitor March 31, 1995. Vol. XVII, No. 6. Page 3.

${ }^{\times 1}$ Housing and Development Reporter: Current Developments. Warren Gorham Lamont. March 13, 1995. Vol. 22. No. 48. Page 738

xil Housing and Development Reporter: Current Developments. Warren Gorham Lamont. March 13, 1995. Vol. 22. No. 48. Page 767

xin Housing and Development Reporter: Current Developments. Warren Gorham Lamont. March 13, 1995. Vol. 22. No. 52. Page 830

xtwh Housing and Development Reporter: Current Developments. Warren Gorham Lamont. June 5, 1995. Vol. 23. No 4. Page 37

xir Housing and Development Reporter: Current Developments. Warren Gorham Lamont. June 5, 1995. Vol. 23. No 4. Page 37.

xiv NAHRO Monitor May 15, 1995. Vol. XVII, No. 9. Page 2.

*iv'Housing and Development Reponer: Current Developments. Warren Gorham Lamont. May 22. 1995. Vol. 23. No. 2. Page 3.

*iv"Housing and Development Reporter: Current Developments. Warren Gorham Lamont. May 22, 1995. Vol. 23, No. 2. Page 30.

"W'Housing and Development Reporter: Current Developments. Warren Gorham Lamont. May. 22, 1995. Vol. 23. No. 2. Page 31.

xhix Housing and Development Reporter: Current Developments. Warren Gorham Lamont. May 22. 1995. Vol. 23. No. 2. Page 4.

'Housing and Development Reporter: Current Developments. Warren Gorharn Lamont. May 22, 1995. Vol. 23. No. 2. Page 3.

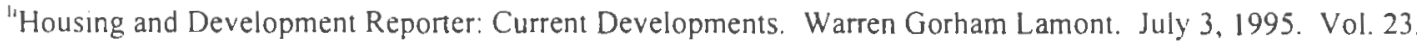
No. 8. Page 127.

lii Housing and Development Reporter: Current Developments. Warren Gorham Lamont. July 17, 1995. Vol. 23, No. 10. Page 131 .

I'mousing and Development Reporter: Current Developments. Warren Gorham Lamont. July 17, 1995. Vol. 23. No. 10. Page 132

"Housing and Development Reporter: Current Developments. Warren Gorham Lamont. July 17. 1995. Vol. 23. No. 10. Page 130

"Housing and Development Reporter: Current Developments. Warren Gorham Lamont. July 17, 1995. Vol. 23. No. 10. Page 130

iv'Housing and Development Reporter: Current Developments. Warren Gorham Lamont. July 17. 1995. Vol. 23. No. 10. Page 159

"NAlNAHO Monitor May 15, 1995. Vol. XVII, No. 15. Page 2.

Ivi' Housing and Development Reporter: Current Developments. Warren Gorham Lamont. September 25, 1995. Vol. 23. No. 20. Page 291.

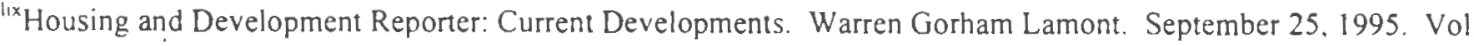
23, No. 20. Page 292. 
${ }^{*}$ Housing and Development Reponer: Current Developments. Warren Gorham Lamont. September 25. 1995. Vol 23. No. 20. Page 294

${ }^{1 \times 1}$ Housing and Development Reponer: Current Developments. Warren Gorham Lamont Octoher 9. 1995. Vol. 23. No. 22. Page 324

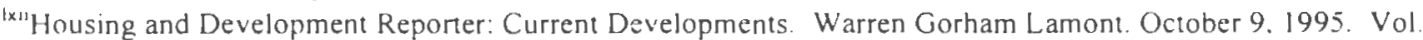
23. No. 22. Page 323.

ix"'Housing and Development Reporter: Current Developments. Warren Gorham Lamont. October 9. 1995, Vol. 23, No. 22. Page 323.

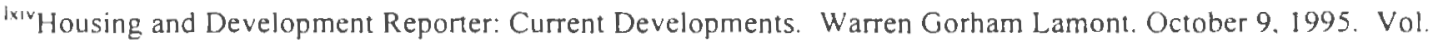
23. No. 22. Page 323

"Housing and Development Reponer: Current Developments. Warren Gorham Lamont. October 9. 1995. Vol. 23. No. 22. Page 323

"Wh fousing and Development Reponer: Current Developments. Warren Gorham Lamont. (Jctoher 23. 1995. V'ol 23. No. 24. Page 357

ixw Housing and Development Reporter: Current Developments. Warren Gorham Lamont. Uctoher 23. 1995. Vol 23. No. 24. Page 357.

Ixv'"Housing and Development Reporter: Current Developments. Warren Gorham Lamont. October 9. 1995. Vol. 23. No. 22. Page 357.

Ixix NAHRO Monitor November 30. 1995. Vol. XVII, No. 22. Page 4.

ixx NAHRO Monitor November 30, 1995. Vol. XVII, No. 22. Page 4.

${ }^{l \times x}$ Housing and Development Reporter: Current Developments. Warren Gorham Lamont. November 20, 1995. Vol. 23. No. 28. Page 42I.

Ixx" NAHRO Monitor November 15, 1995. Vol. XVII, No. 21. Page 2.

Wx"l Housing and Development Reporter: Current Developments. Warren Gorham Lamont. December 4. 1995. Vol. 23. No. 30. Page 453

laxin Housing and Development Reporter: Current Developments. Warren Gorham Lamont. November 6, 1995. Vol. 23. No. 26. Page 414.

ixw Housing and Development Reporter: Current Developments. Warren Gorham Lamont. December 18. 1995. Vol. 23. No. 32. Page 481 .

1xxv1 Housing and Development Reporter: Current Developments. Warren Gorham Lamont. Januany 1, 1996. Vol. 23. No. 34. Page 513.

Ixxvil Housing and Development Reporter: Current Developments. Warren Gorham Lamont. January 1, 1996. Vol. 23. No. 34. Page 543.

Ixxvm Housing and Development Reporter: Current Developments. Warren Gorham Lamont. January 1, 1996. Vol 23. No. 34. Page 543. 


\section{CHAPTER TWO: THE STRATEGIC PLANNING PROCESS}

The formal strategic planning process has been used on a wide scale by the private sector for the past thirty or so years, although one strategic planning model. the Harvard Policy Model which focuses on SWOT (strengths, weaknesses, opportunities and threats) analysis, has been a part of the curriculum at the Harvard Business School since the 1920`s. Strategic planning really grew in the private sector when the world market began to change in the 1960s. By the end of the 1960 's, three fourths of all large industrial companies in the United States had conducted formal strategic planning. By the mid-1980s, over half of all publicly traded companies employed a strategic planning process. ${ }^{i}$ The one public sector organization which has been using strategic planning since its early days as a formal planning model has been the Department of Defense. In the past decade and a half, as more governmental and non-profit agencies have found their futures to be less certain, the environments in which they operate less stable and their stakeholders more demanding, they have begun to use formal strategic planning.

Strategic planning is a pro-active process by which an organization attempts to control its destiny rather than allowing future events to do so. By appraising future opportunities and its own existing and future strengths and weaknesses, an organization can help ensure its success and avoid identifiable problems. Central to the strategic planning process is the idea that an agency can help to shape its future and the nature of its environment through its current actions and 


\section{Strategic Planning: A Case Illustration}

Chapter Two: The Strategic Planning Process

What is Strategic Planning?

Benefits of Strategic planning

The Strategic Planning Model

Step One: Agreement to Plan

Step Two: Clarifying Mandates

Step Three: Mission Statement

Step Three A: Values Identification

Step Four: External Environmental Scanning

Step Five: Internal Environmental Scanning

Step Six: Strategic Issues Identification

Step Seven: Strategy Development

Step Eight: Vision of Success

Chapter Two Endnotes 
decisions. Russell Ackoff, professor at the Wharton Business school noted, strategic "planning is anticipatory decision making. It is the process of deciding before action is required."'

But in order to control and shape its future, an agency must first define what that future should look like. Through the development of a mission statement, a set of mandates, goals and objectives and a clear vision of success, an agency identifies what its purpose is and what success would mean. By identifying what the agency exists to achieve and developing a clear picture of success, an agency can better develop steps to achieve this future. Strategic planning therefore focuses as much on what is accomplished and for what reason as it focuses on methods of achievement.

Strategic planning requires the organization's intimate and enthusiastic involvement, often using formal and informal teams, in providing information, making decisions, and successfully implementing them. Because it involves gathering information concerning the agency's internal and external situation. it is important to involve agency members from all major sections, departments, and functional areas.

Strategic planning provides a framework for decision making in the organization by establishing organizational mandates, mission and goals and a vision of success. Organizational members can use these tools to decide if programs or decisions are consistent with the overall design of the organization. "To be successful, a strategic planning process should provide the criterion for making day-to-day organizational decisions and should provide a template against which all such decisions can be evaluated."'ii 
While there are many different models for strategic planning, including several new ones designed specifically for the not for profit world, they all have certain characteristics in common. In their book. Applied Strategic Planning: A Comprehensive Guide. Leonard Goodstein, Timothy Nolan and William Pfeiffer list six factors of strategic planning: ${ }^{\text {iv }}$

- Strategic planning is a coherent, unifying. and integrative pattern of decisions. This means that strategy development is conscious, explicit, and proactive.

- Strategy is a means of establishing an organization's purpose in terms of its long term objectives, action plans, and allocation of resources.

- Strategy is a definition of an organizations competitive domain: What business the organization really is in.

- Strategy is a response to internal strengths and weaknesses and to external opportunities and threats in order to develop competitive advantage.

- Strategy becomes a logical system for differentiating executive and managerial tasks and roles at corporate, business and functional levels, so that structure follows function.

- Strategy is a way of defining the economic and non economic contribution the organization will make to its stakeholders, its raison d'etre. 


\section{Benefits of Strategic Planning}

There are numerous benefits to strategic planning. To fully appreciate the benefits of strategic planning, it is useful to recognize its nature: it is product and process. The process involves a systematic examination of the organization and its environment by those who have a stake in its future success. The product is a written document specifying the actions required to achieve future goals based on the information unearthed during the planning process. Together, these components of strategic planning yield numerous benefits to any organization.

In the introduction to Strategic Planning: Threats and Opportunities for Planners, John Bryson and Robert Einsweiler list several benefits to strategic planning::

- Helps the agency to think strategically and develop effective strategies.

- Establishes priorities.

- Helps the agency to make decisions based on an understanding of their future consequences.

- Develops a coherent and defensible basis for decision making.

- Enables the organization to exercise maximum discretion in the areas over which it has organizational control.

- Allows for a process by which the organization can make decisions across levels and functions.

- Solves major organizational problems.

- Improves organizational performance.

- Deals effectively with rapidly changing circumstances.

- builds teamwork and expertise.

In Applied Strategic Planning: A Comprehensive Guide, Leonard Goodstein, Timothy Nolan and William Pfeiffer list the following benefits of strategic planning: ${ }^{\text {vi }}$ 
- The process allows people in the agency to make decisions and discuss alternatives using a common language and a shared set of values.

- The process allows agencies to unleash energy in a manner that is focused behind a shared vision.

- The planning process increases the agency's capacity to implement ideas.

- The process helps the agency to better understand the environment in which it exists.

- The process forces agencies to look ahead, not just at the immediate future.

Other important benefits of strategic planning are the development of a means through which to allocate resources, the building of consensus. and the development of benchmarks which show both agency members and outsiders where the agency stands and how far it has progressed. 


\section{Strategic Planning Model}

There are numerous strategic planning models available. In writing the Providence Housing Authority's strategic plan the Bryson model was used. The Bryson model was developed by John M. Bryson, associate professor of planning and public affairs at the Hubert H. Humphrey Institute of Public Affairs, and associate director of the Strategic Management Research Center at the university of Minnesota. After reviewing several models, this one was deemed to be the most appropriate for the organization.

\section{Professor Bryson's model consists of ten steps:}

1. Initial Agreement Plan for Planning

2. Mandates

3. Mission/Values By Stakeholders

4. External Environment

5. Internal Environment

6. Strategic Issues

7. Strategies

8. Organizational "Vision of Success"

9. Actions

10. Results

Each of the steps is explained in greater detail elsewhere in this manual. See the next page for a diagram and process flow chart of the Bryson model. 


\section{Strategic Planning Process}

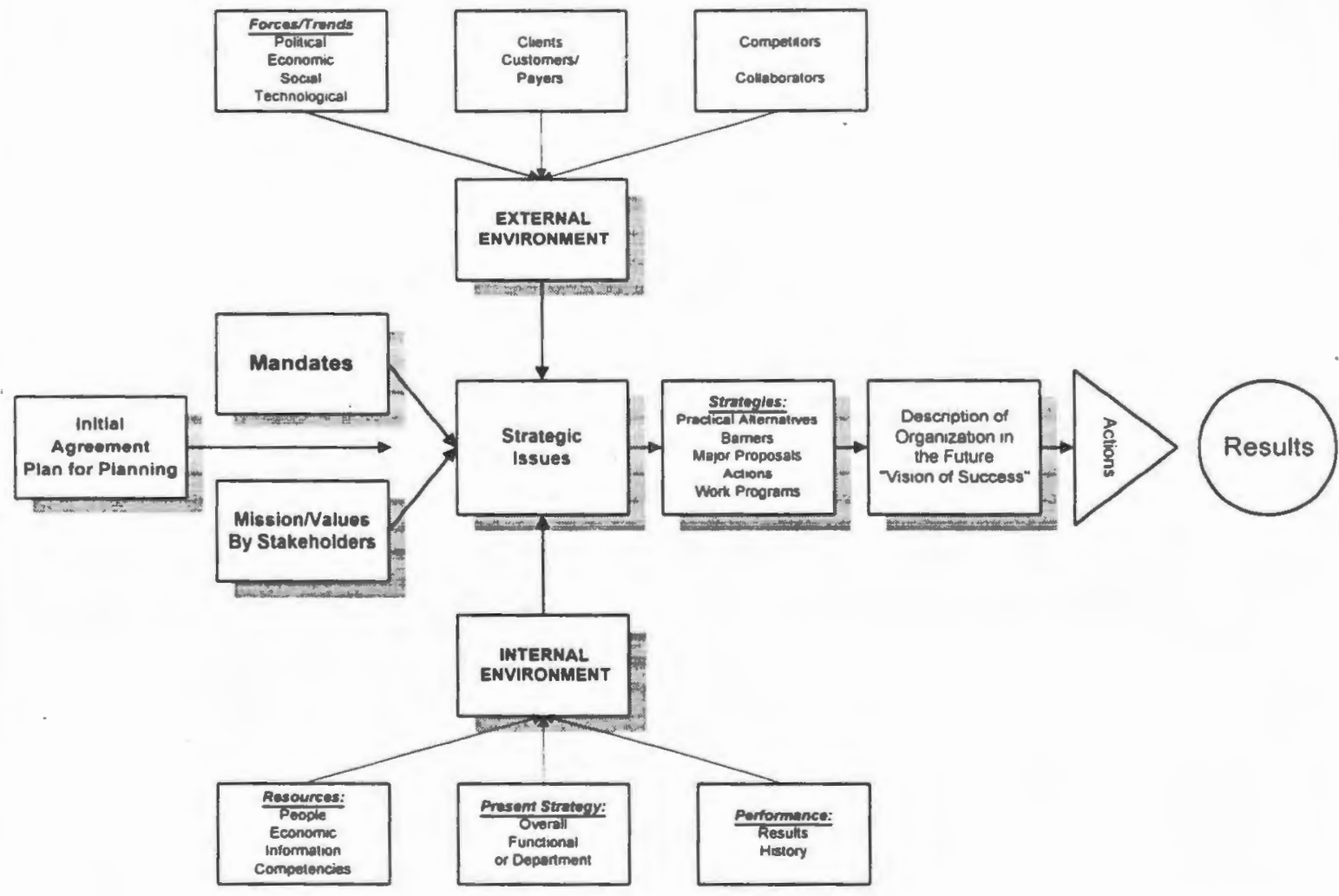

Source: Bryson, John M. 1988. Strategic Planning for Public and Nonprofit Organizations. Jossey-Bass. San Francisco 


\section{Step One}

Agreement to Plan

The first step of the strategic planning process occurs when management and front line personnel discuss the process and agree to proceed. In this step, the agency members are introduced to the nature, purpose and process of strategic planning. Next, a strategic planning team or teams is created to guide and oversee the process.

If this step is not initiated by senior management personnel, such as the company's CEO or an agency's Executive Director, it is crucial that they give their informed approval to the project. The strategic planning process will involve a significant investment of time on the part of high level and front line personnel through out the agency. Having the chief executive support the planning process ensures that personnel resources through out the agency can focus the needed attention to this project.

Once the Providence Housing Authority developed strategic planning teams, these teams attended training on strategic planning and on the Bryson model as a whole. Throughout the process the members of the strategic planning teams met as a whole to discuss progress, and to learn in more detail what was required of them under each step of the process. Strategic planning teams consisted of departments directors and several staff members from each department, the executive director, the deputy director, and staff responsible for overseeing specific functional areas performed by the PHA such as the promotion of self-sufficiency (now a separate 
department created under the strategic planning process), home ownership, security; insurance and risk management, and personnel issues. 


\section{Step Two}

\section{Clarifying Mandates}

Mandates are defined as the external expectations placed upon an organization. The purpose of this step is to clarify these external expectations. When identifying its mandates, an organization should consider both its formal and informal mandates. Formal mandates are often stipulated within legislation. charters. ordinances, articles, and contracts. Informal mandates are also often placed upon an organization. These mandates are based upon generally understood expectations. While not as official as formal mandates, they are often equally binding.

Many organizations are not aware of what their mandates are and feel more tightly constrained than is necessary. Further, organizations often mistakenly operate under the assumption that if something is not expressly defined within their mandates, that they cannot do it. 


\section{Step Three}

Mission Statement

The clarification of an organization's mission is of great importance to the concept of strategic planning. Before an agency can successfully plan strategies for its long-term success, it must first define what that success will encompass. The mission statement defines the agency`s purpose or fundamental reason for existence ${ }^{\text {"I" }}$. The mission statement will direct the agency's policy and performance, and serve as the yardstick by which the organization is to be measured. The mission statement will further serve to broaden the agency's focus beyond its mandates and narrow the agency's vision of its proper place within the community. An example of an industry which failed to properly define its mission concerns the railroads. Once the center of transportation for people and goods, the railroad companies continually defined themselves as being in the railroad business. Had they defined themselves as being in the transportation and shipping business, they may have taken advantage of newer forms of technology such as the automobile and later the airplane. This did not happen and other industries were able to take advantage of both these new technologies, as well as the lack of vision found in the rail road industry.

The failure of the railroad industry was to define its mission by its current outputs rather than by clients needs. That this is crucial in the for profit sector is obvious, but more and more the not for-profit sector faces pressures from competing stakeholders who demand the agencies resources and time (or in many cases the elimination of the agency all together). While the identification of the client is clear in the for-profit sector, governmental and non-profit agencies 
must clearly identify who their clients are. For that reason, information gathered through the stakeholder analysis process is very imprortant to the formulation of the agency's mission.

According to Bryson, an agency developing a mission statement must answer three questions. First, the agency must define its organizational mandates. It is difficult to picture an agency as being a success when it has failed to accomplish the basic expectations placed upon it. Second, the agency must determine what it hopes to accomplish. Beyond what it must do, an organization often has more flexibility to affect change than is realized by its members. Third. the agency must determine which goals are both realistic and appropriate for the agency to set for itself. The mission statement incorporates the dreams and ideas of the internal and external stakeholders and provides a more unified and directed vision for the role of the agency. While mandates are often unnecessarily limited in scope, no agency can possibly solve all of the problems surrounding it. and it is inappropriate for the organization to even make the attempt.

In addition to the three steps listed above, Bryson notes that agencies should answer the following six questions when developing a mission statement.

1. Who are we?

2. What are the basic social or political needs we exist to fill?

3. What do we do to recognize or anticipate and respond to these needs or problems?

4. How should we respond to our key stakeholders?

5. What is our philosophy and what are our core values?

6. What makes us distinctive or unique?

Finally, strategic planning is an iterative process. Information gathered in later steps such as stakeholder analysis and environmental scans will be helpful in revising the agencies mission 
statement. It is common for an agency to go back and revise the mission statement at various stages of the planning process.

\section{Step Three (A)}

\section{Value Identification}

\footnotetext{
"We've learned. . that the soft stuff and the hard stuff are becoming increasingly intertwined. A company's values - what it stands for, what its people believe in are crucial to its competitive success. Indeed, values drive the business."

-Robert Haas, Chairman and CEO, Levi Straus
}

\section{Values}

While values identification is not a separate step under the Bryson model, it is an important component of the strategic planning process. A person"s "values" answer the question "What's important to me?" Our values are the deep-seated pervasive standards that influence almost every aspect of our lives: our moral judgments, our responses to others, our commitments to personal and organizational goals. 
If everyone had the same values with the same priorities, it would be easy to work in groups. Most teams, however, have adversity of values and beliefs. To help teams work better and make decisions that lead to commitment and action. it is necessary to see the range of values that influence the decision-making process and find ways to prioritize and clarify the values used.

Shared mission, values, and vision brings people together. They unite and provide the link between diverse people and activities. A shared essence is the expression of what people have in common, of what they, in community, are committed to. People who share values or vision are more likely to take responsibility; they are more likely to challenge the bounds of convention. In organizations where this essence is developed, people do not assume they are powerless. They believe they have the power to contribute directly.

Central to an organization's fulfillment of its obligations is the clarity of its values. Before developing a mission, vision and strategy, an organization must come to agreement about what it stands for, both in its customer service and community relations, and within itself, in its dealing with employees. A group must also determine how they will work together, how they will treat each other and what bonds them together.

Values are the essence of an organization's philosophy for achieving success. They are the bedrock of corporate culture. Values provide employees with a sense of common direction and guidelines for day-to-day behavior. If an agency's mission or vision of success is at odds with its corporate culture or corporate values, there will serious built in problems which will hinder the agency's performance. This can occur, especially in the current atmosphere for governmental 
agencies where changed is being forced at a rapid pace from external pressures. The housing industry is facing this dilemma now with the debate about the reinvention of HUD. Clearly many in the industry want housing authorities to allow tenants with higher incomes so that the housing authorities will have higher rents and more operational income. Proponents of higher incomes also argue that bringing in working residents will bring into public housing an examination of the culture of work, and will help show current residents that there is reward for hard work. But many in the industry have strong values against allowing people with higher incomes. Many feel that, especially with shrinking federal dollars, housing authorities should focus on serving the poorest of the poor. It is quite realistic to imagine a housing authority where the organizational values favor serving the poorest of the poor being forced for financial reasons into developing a mission statement in which working families would be served. This could seriously undermine the level of energy, enthusiasm and the quality of work performed by agency members. This is clearly important when one considers the fact that one of the major benefits of strategic planning is that it helps the agency to focus the attention and energy of its members around a shared vision of success. That shared vision of success is defined by the values of those agency members.

There are many different exercises available for organizations that are undertaking the process of defining their values. For the PHA's 1995 Strategic Plan a value card exercise was conducted. This exercise asked teams (departmental strategic planning teams were created early in the strategic planning process) to rank a set of values by the degree to which they believed it was an organizational value. The five different degrees were always, often, sometimes, seldom and never. Teams were given a set of cards with different values such as "honesty" and "creativity" 
and were asked to place five cards under each of the five categories. The results were then compared from department to department, and for the PHA as a whole. The instrument used by the PHA further broke values down into the following categories: social responsibility. mastery, self development, relationship, continuity, and lifestyle. This exercise is helpful in developing both a mission statement, and the organizational vision of success. 


\section{Step Four}

\section{External Environmental Analysis}

Under the Bryson model, steps four and five, the external and internal environmental scans are conducted simultaneously. In many planning models they are conducted continuously throughout the process and even after the formal plan has been conducted. This is currently the case with the Providence Housing Authority's Strategic Plan 2000. Now a year into implementation, the PHA is currently in the process of updating both its internal and external environmental scans.

These two steps are at the heart of the process because they gather information not just concerning environments, but about people, beliefs, attitudes, and values. These steps examine the environment from very different levels and the focus at this step illustrates the type of strategic planning model being used. Some models focus exclusively on SWOT, strengths. weaknesses, opportunities and threats, analysis, while other focus upon stakeholder analysis. The Bryson model and the strategic planning process conducted by the Providence Housing Authority attempts to do both. While examining both the internal environment and the agency's strengths and weaknesses and the external environment and the opportunities and strengths for the agency, the PHA also conducted both an internal and an external stakeholder analysis.

\section{External Environmental Scans}


The external environmental analysis is the fourth step in the strategic planning model offered in the John Bryson book, Strategic Planning for Public and Non-Profit Organizations. viii One major component of the environmental analysis is the external environmental scan. The external scan focuses on those factors external to the organization which can influence funding and participation. The Bryson Model identifies three areas for which information must be obtained: Forces/Trends (People, Economic, Social, Technological), Clients/Customers, and Competitors/Collaborators. It is important to note that while past long-range planning process have identified the external environment and extrapolated a scenario for the future based upon the continuation of this environment, the strategic planning process is based upon the assumption of a constantly changing environment. This results in two key differences from traditional long range planning. First: because under the strategic planning process plans are not created to exist within a static environmental framework, the plan is created to control and change this environment rather than to simply exist within it. Second. because the environment is constantly changing, environmental scanning (both internal and external), must be done continuously.

Goodstein suggests breaking this analysis into four separate areas, three of which are external and one which is internal. The first of these areas is the macro environment, and it concerns broadly defined factors such as social factors. demographics changes in technology, and the political situation. The next level of analysis according to Goodstein is the industrial environment. This examines factors concerning the structure of the particular industry in question. The next level of analysis is the competitive environment. This would include profiles of competitors, market separation, market patterns, and industry research and development. The 
final stage of analysis. this one internal, would be an examination of the organization. This would include the structure of the particular organization, the organization's history and its strengths and weaknesses. ${ }^{i x}$

\section{External Stakeliolder Analysis}

Another important part of the external environmental analysis is the external stakeholder analysis. This step identifies issues from the perspective of those who view the agency's operations from the outside. External stakeholders include agencies and people who affect or are affected by the agency's operations. Many of them work directly with the agency's clients and staff and can offer important perspectives on day-to-day operations and long-range planning.

A survey should be sent to stakeholders, either by the agency or a neutral third party. These surveys ask stakeholders to give their views on the proper role of the agency within the community. Questions would revolved around the agency's mandates, missions, and SWOT (Strengths, Weaknesses, Opportunities and Threats). Follow-up of stakeholders is a vital component of this process. A record of follow-up calls and letters should be kept, as well as a record of the order and dates of return. Finally, in order to maximize returns, questionnaires should be kept as brief and non-technical as possible while still allowing for the collection of important information. If the survey appears too intimidating, stakeholders will most likely fail to respond. 


\section{Step Five}

Internal Environmental Analysis

\section{Internal Environmental Scans}

The Internal environmental analysis is the fifth step in the eight step strategic planning model offered in John Bryson's book Strategic Planning for Public and Non-Profit Organizations. ${ }^{\times}$An internal environmental scan, also known as situation analysis, is a major component of this process. This step entails an assessment of an organization's present position in its current environment. This involves the identification of present and potential problems and opportunities in the organization.

\section{Internal Stakeholder Analysis}

Another major aspect of the internal environmental analysis is the internal stakeholder analysis. This step identifies issues from the insider's perspective. Data is collected in the form of surveys which are given to internal stakeholders (administration, management, boards of commissioners, staff and other employees if desired). If the agency has a large number of employees or functions, it may be necessary to divide into strategic planning teams based upon departments or functional areas. Teams may consist of entire departments, or a representative and knowledgeable sample. Internal stakeholders analysis surveys should focus on the agency's mandates; missions; and SWOT (Strengths, Weaknesses, Opportunities and Threats). 


\section{$\underline{\text { Step Six }}$}

\section{Strategic Issue Identification}

Strategic issues identification is the sixth step in the Bryson strategic planning. "The purpose of the strategic issues identification step is to identify the fundamental policy choices facing the organization concerning its mandates, mission, and product or service level mix: clients. consumers, or users; cost; financing; organization; or management." ${ }^{\text {xi }}$ Further, "strategic issues define the organization's choices about how it will fit in to the environment in which it exists." This step was developed when strategic planning was still primarily geared towards the corporate world. Companies engaged in strategic planning needed a step between strength. weakness, opportunity and threat (SWOT) identification and the development of strategies. This step is based primarily on previous steps in the strategic planning process. In this step the members of the strategic planning team identify strategic issues by examining the SWOT analysis, the agency's mission, mandates, and external and internal environmental scans. Often times this becomes an iterative process where the planning team must return to a past step and develop it further. It is common for planners involved in the issues identification step to go back and redefine the agency's mission statement.

"An issue is assumed to be strategic if planners perceive it will involve decisions and activities related to changes in the basic long-term goals and objectives of an organization, and the adoption of courses of action and the allocation of resources necessary for carrying out those changed goals."xiii Issues are usually designed to re-enforce strengths, correct weaknesses, capitalize on possible opportunities and avoid threats. ${ }^{\text {xiv }}$ 
The issues chosen during this step will help to guide the organization into the future. An organization that fails to properly address strategic issues will be unprepared to respond to external threats and will likely miss out on important opportunities to grow and prosper.

Externally, the strategic issues step looks from the outside in, concentrating on the organization's mandates and external environmental scan. Internally, the agency must develop issues based upon the mission, internal environmental scan and organizational values. ${ }^{x v}$ A clear understanding of the both the internal and external aspects and situation of the agency is crucial to understanding the relevance of a strategic issue.

A strategic issue is different from a routine operational issue. Strategic issues are defined by specific criteria, and are designed to be the major focus of attention for the agency's decision makers. First. a strategic issue is described succinctly, usually in a single paragraph. It is framed as a question that the agency can do something about. If the agency is unable to do anything about a problem, it is not a strategic issue. Further, a strategic issue should have several possible answers. Second, when writing a strategic issue, strategic planners should list the factors that make it a fundamental policy question. Factors come from the agency's mandates, mission, values, or SWOT. Third, consequences for not addressing the issue should be stated. If there are no consequences for failing to address the issue, then it is not a strategic issue. If the agency will be destroyed or miss a highly significant opportunity by failing to address the issue, then it is a very strategic issue. ${ }^{\mathrm{xi}}$ When defining the significance of strategic issues, it is helpful to order them by priority, category or by time frame. 
While it may be tempting to skip strategic issues identification and go straight to strategy development. this step is crucial to the over-all strategic planning process. Bryson lists five benefits that come from focusing on issues identification.

1. Attention is focused upon what is truly important. Often times agencies fall into the 80-20 trap. The "key decision makers usually spend 80 percent of their time on the least important 20 percent of their jobs." "xvii

2. By focusing on issues rather than answers, the agency can gain a true understanding of what the real problems are, and how they affect the agency.

3. Identifying issues creates "the kind of useful tension necessary to prompt organizational change."*viii Organizations only change when they feel they have to. Identifying issues and their consequences often provides important motivation and incentives.

4. Issue identification gives important clues about how to solve problems. "By stating exactly what it is about the mission, mandates and internal and external factors that makes an issue strategic, one also gains some insight into possible ways that the issue might be resolved. ${ }^{\text {xix }}$ By framing issues in these terms, the strategic planning team will be better prepared to take advantage of strengths and opportunities and overcome weaknesses and threats.

5. This step makes the entire strategic planning process seem more real to the participants. By focusing on the correspondence between organizational thought, behavior and consequences, the process becomes less academic and more real. 


\section{Step Seven}

\section{Strategies}

The seventh step of John Bryson's strategic planning model is the formulation of strategies.

"Strategies are defined as a pattern of purposes, policies. programs, actions, decisions, or resource allocations that define what an organization is, what it does, and why it does it." ${ }^{\mathrm{xx}}$ This step of the strategic planning process forms a bridge between an organization's mission and the outside environment. In his book Team Based Strategic planning C. Davis Fogg defines this step as, "the means, the ways, the hows, the devilishly detailed methods by which organizations accomplish their objectives. ${ }^{, \times x}$

Having completed the external and internal environmental scans, the internal and external stakeholder analysis, and a review of our mandates and mission, the last step, strategic issues identification. defined the PHA's current situation relative to the outside environment. In this step, strategies are developed to address strategic issues and to achieve desired goals and a vision of success.

Strategic issues can be developed for differing levels within an agency. For example, four basic levels offered by Bryson are: xxii $^{x}$

1. Grand strategy for the organization as a whole.

2. Strategic public planning unit (SPPU) or strategic nonprofit planning unit (SNPPU) strategies. Note, however that if the organization as a whole and the SPPU or SNPPU are synonymous, the first two categories will be the same; if not, the SPPUs or SNPPUs may be divisions, departments, or units of larger organization. 
3. Program or service strategies.

4. Functional (such as financial, staffing, facilities, and procurement) strategies.

One fundamental aspect of strategic planning is creativity. There is no point in attempting the process if strategies are mundane and designed to maintain a "business as usual" attitude. Creativity in developing alternatives and visions is a crucial part of strategy formulation. Remember that strategic planning often leads to drastic change. While it is true that change is inevitable (especially considering the current external environment for public housing) it is vital for organizational survival that such change be planned for and directed. An organization that fails to develop effective strategies to translate its mission statement into the context of its environment is doomed to fail.

Bryson identifies five questions that must be asked of the strategic issues we identified in the past step. ${ }^{x \times 11}$

1. What are the practical alternatives, dreams or visions we might pursue to address this strategic issue, achieve this goal, or realize this scenario?

2. What are the barriers to the realization of these alternatives, dreams or visions?

3. What major proposals might we pursue to achieve these alternatives, dreams, or visions directly, or to overcome the barriers to their realization?

4. What major actions with existing staff must be taken within the next year to implement the major proposals?

5. What specific steps must be taken within the next six months to implement the major proposals and who is responsible?

These questions were designed to facilitate the development of successful strategies. The second question is asked early on in order to create an effective and well thought out plan to overcome barriers. "Listing barriers here ensures that barriers are dealt with directly rather than haphazardly."xxiv 
The fourth step focuses on existing staff and resources. It is designed to get members of the organization thinking about strategic changes from a personal point of view. Strategy formulation is designed to start where the organization currently finds itself. Any additional resources or staff allocation will have to be planned for based upon the agency's current situation. This question is designed to be asked again every year or two.

The fifth question asks for specific steps to be identified and assigned. This question is designed to be re-asked every sixth months. The third question will have to be re-examined every two to three years, and the first two should be examined again every three to five years.

The Providence Housing Authority developed strategies by departmental teams and functional areas. After developing the mission, mandates, and a set of strategic issues developed through extensive external and internal environmental scanning, these teams developed strategies to address these strategic issues. This process did include many operational issues as well as strategic issues. Teams developed strategies using the goals management planning model. First teams developed a set of goals. Goals were defined as broad, non-specific aspirations. For each of these, a set of objectives was developed. Objectives followed the SMART method, meaning that they were Specific, Measurable, Action oriented, Realistic, and Time-bound. The final step of this process included developing tasks, a set of steps with assigned responsibilities which would result in the completion of each objective. In total, the Providence Housing Authority strategic planning teams developed 103 goals, 250 objectives and over 1,000 tasks. Each of 
these is monitored on a quarterly basis. Monitoring and evaluation focuses on the objective level of attainment. 


\section{Step Eight}

\section{Future Vision of Success}

"Where there is no vision, the people perish."

\section{Proverbs}

"Research has shown that people who have an understanding or reason for what they are doing, do much better in times of stress. This sense of coherence of mission helps people focus and endure challenges that stand in the way of their realizing their vision. With a clear mission, people know what is important to them and can focus on this activity. They can be strategic and pick priorities, rather than be reactive." ${ }^{p \times x}$

"Shared mission, values and vision brings people together. They unite and provide the link between people and activities. A shared essence is the expression of what people have in common, of what they, in community, are committed to. People who share values or vision are more likely to take responsibility; they are more likely to challenge the bounds of convention." ${ }^{\text {"xvi }}$

Developing a future vision of success is the eighth step in the Bryson model. "The purpose of [this] step is to develop a clear and succinct description of what the organization or community shall look like as it successfully implements its strategies and achieves its full potential." step includes envisioning the fulfillment of the organization's mission statement, but goes further. This actual vision of success should be short (no more than ten pages), inspiring. and encouraging. Organizational members should know that they will be supported in their efforts to 
bring about the realization of this vision. Goodstein et. al. state that a vision of success, "provides members of the organization with a view of the future that can be shared, a clear sense of direction, a mobilization of energy, and a sense of being engaged in something important.

This step is not necessary to improve organizational effectiveness, but it can be very useful.

Bryson lists the following eleven benefits for the development of a vision of success:

1. Organizational Members are given specific, reasonable and supportive guidance about what is expected of them and why.

2. It provides people with a needed conception of success and desirable behavior.

3. If there is agreement on the vision, and if clear guidance and decision rules can be derived from it, the organization will gain an added increment of power.

4. The vision of success helps give support to organization members who are pursuing the vision.

5. The vision of success helps people go beyond predicting the future into making it.

6. The vision of success creates tension between the current state of affairs and the desired vision.

7. Vision can inspire a calling among organizational members.

8. A well articulated vision of success will at least implicitly help people recognize the barriers to realization of the vision and thereby assist in overcoming them.

9. A vision of success helps organizational members lead and manage themselves.

10. A vision of success can help to reduce organizational conflict.

11. To the extent that the vision of success is widely shared, it takes on a moral quality that can infuse the organization with virtue.

"A vision is a picture of a preferred state, a description of what it would look like to be some years from now. It is a dynamic picture of the future. It is more than a dream or a set of hopes; it is a commitment." ${ }^{\prime x x v i i i}$

Under the Bryson model there are three steps in this process. 
Step One: Bryson lists seven things that should be included in an organization's vision of success: $: x \times 1 \times$

1. The organization's mission.

2. The organization's basic philosophy and core values.

3. The organization's goals.

4. The Organization's basic strategies.

5. The organization's performance criteria.

6. Important decision rules.

7. Ethical standards expected of all employees.

Step Two: Circulate the vision of success to organizational members and key stakeholders after "appropriate consultations, reviews and sign-offs."

Step Three: Use the vision of success when debating or discussing major and minor organizational decisions and actions. This allows the vision of success to affect organizational behavior and performance.

In addition to the Bryson model, Cynthia D. Scott, Dennis T. Jaffe, Glen R. Tobe offer useful guidance for developing a vision of success in their book, Organizational Vision, Values and Mission. According to their method, a vision of success answers the following questions: ${ }^{x \times x}$

1. If we could be whatever we wanted in five years, what would we be?

2. How would we know we were there?

3. What would be a "stretch" for ourselves?

4. What kind of organization do we want to be?

5. What do we really want to do or create?

6. What would be worth committing to over the next ten years?

7. How do we differentiate ourselves from our competition?

8. What are the right things for us to do? 
In addition, Scott, Jaffe and Tobe list the following items as components to a powerful vision Statement: $:^{x \times 11}$

1. Presents where we want to go.

2. Is easy to read and understand.

3. Captures the desired spirit of the organization.

4. Dynamically incomplete so people can fill in the pieces.

5. Compact, can be used to guide decision making.

6. Gets people's attention.

7. Describes a preferred and meaningful future state.

8. Can be felt/experienced/gives people goose bumps when they hear it.

9. Gives people a better understanding of how their individual purpose could be realized in the group or company.

10. Provides a motivating force, even in hard times.

11. Is perceived as achievable.

12. Is challenging. compelling, stretching beyond what is comfortable. 


\section{END NOTES}

\section{CHAPTER TWO}

'Jerome L. Kaufman and Harvey M. Jacobs. A Public Planning perspective on Strategic Planning. From: Sirategic plannıng Threats and Oppontunities. Eds. Bryson, John and Robert C. Einsweiler: Chicago: Planners Press. (P) 56)

"Goodstein, Leonard D. et al. Applied Strategic Planning: A Comprehensive Guide. New York: McGraw Hill inc (P 3$)$

"'Goodstein. Leonard D. et al. Applied Strategic Planning: A Comprehensive Guide. New York: McGraw Hill Inc. (P. 1)

"Goodstein, Leonard D et al. Applied Strategic Planning: A Comprehensive Guide. New York: McGraw Hill lnc. (P. 3)

${ }^{\vee}$ Bryson, John and Rober C. Einsweiler: Strategic planning: Threats and Opportunities. Chicago: Planners Press. (P. 3)

"Goodstein. Leonard D. et al. Applied Strategic Planning: A Comprehensive Guide. New York: McGraw Hill Inc. (P. 6) viiBryson. John M. Strategic Planning for Public and Nonprofit Organizations. San Francisco: jossey-Bass

"'i"'Bry son. John M. Siralegic Planning for Public and Nonprofn Organizanions. San Francisco: Jossey-Bass

" (iondstein. Leonard D. et al. Applied Strategic Planning: A Comprehensive Guide. New York: McGraw Hill Inc. (P. 1241)

'Bryson. John M. Siralegic Planning for Public and Nonprofit Organizations. San Francisco: Jossey-Bass

"Bryson. (P. 161)

"Bryson. (P. 245)

xiiiRing. Peter Smith. 1988. Strategic Issues: What Are They and From Where Do They Come? From Strategic Planning: Threats and Opportunities. Ed. John M. Bryson and Robert C. Einsweiler. American Planning Association. Chicago. (P. 71 ) xivfogg, C. Davis. 1994. Team Based Strategic Planning: A Complete Guide to Structuring, Facilitating and Implementing the Process. American Management Association. New York. (P.152)

$x$ Bryson. (P. 49)

xviBryson. (P. 57)

xviiBryson. (P. 140)

xviiiBryson. (P. 14I)

vixpryson. (P. 141$)$

xiBryson. (P 13.)

xxi_ Team Based Strategic Planning. (P. 12)

xxiiBryson. (P |64)

xxiiiBryson. (P 169)

xxivBryson. (P 169)

xxvCynthia D. Scott, Dennis T. Jaffe, Glen R. Tobe. 1993. Organizational Vision, Values and Mission. Crisp Publications, Inc. Menlo Park. (P 61.)

xxviScott. jaffe, and Tobe. (P. 20)

xxviiBryson, (P 184)

${ }^{x \times 4+}$ Scott, Jaffe, and Tobe. (P. 81)

"xix Bryson, (P 186)

"Bryson. (P 168)

'“'Scolt. Jaffe. and Tobe. (P. 88)

"'Scott. Jaffe. and Tobe. (P. 90) 


\section{Strategic Planning: A Case Illustration}

Chapter Three: Strategic Plan 2000

Introduction

Step One: Agreement to Plan

Step Two: Clarifying Mandates

Step Three: Mission Statement

Step Three A: Values Identification

Step Four: External Environmental Scanning

Step Five: Internal Environmental Scanning

Step Six: Strategic Issues Identification

Step Seven: Strategy Development

Step Eight: Vision of Success 


\section{CHAPTER THREE: STRATEGIC PLAN 2000}

The material included in this chapter is taken directly from Strategic Plan 2000. The author of this paper served as the primary author and the project manager for the Providence Housing Authority's Strategic Plan 2000. Several sections of Strategic Plan 2000 were not, however, written by the author of this paper. These sections are as follows:

The mandates for the mandate section were compiled by the Executive Director of the Providence Housing Authority, Stephen J. O'Rourke.

The environmental scans were written by individual strategic planning teams and were edited primarily by Stephen J. O'Rourke. Because these scans were so lengthy and were not written by the author of this paper, they have been included as an appendix. It should be noted that the author has conducted training for the strategic planning teams and other staff members on how to conduct the environmental scanning process.

The Providence Housing Authority's Vision of Success was written by Marcia Sullivan, then Executive Assistant to the Executive Director. Currently Ms. Sullivan serves as the director of the Department of Special Services, a department which was created under Strategic Plan 2000. 


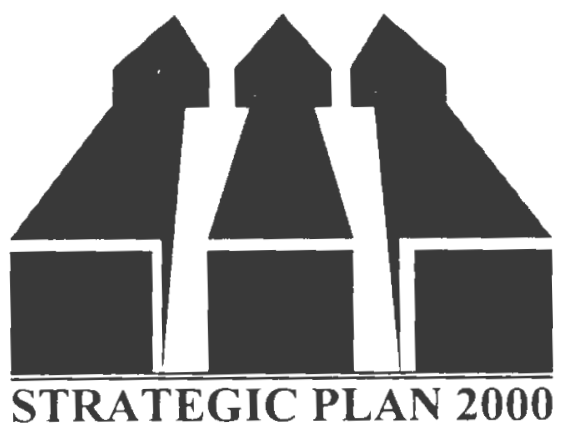

\section{Introduction}

The Providence Housing Authority is at an important turning point in its 56 year history. As a public housing agency, the PHA exists within the framework of a rapidly changing social environment. The public discourse concerning social policy in America has advanced to the point where drastic changes are not only inevitable, but have already begun. These changes will undoubtedly affect the ability of the PHA to serve our residents and the Providence community as a whole. Faced with budget rescissions by the Congress and "reinvention" by its primary funding source, the Department of Housing and Urban Development, the PHA's mission will become increasingly difficult. The Congress is already making plans to reduce HUD's FY 1996 budget and it is anticipated that public housing will bear an inordinate share of the program cuts. The PHA has already seen reductions in the funding of several programs including our elderly security program and the Comprehensive Grant program. Additional cuts are also expected.

At the time this strategic plan was written, budget proposals on Capitol Hill included a $21.8 \%$ reduction in public housing operating subsidies, a $47.9 \%$ reduction in capital improvement funds, a nation wide reduction of Section 8 funds of $\$ 2.7$ million with no new certificates and vouchers, and a $\$ 411$ million reduction nation wide in Special Needs Housing. Other areas of concern for the PHA are the proposed elimination of Public Housing Development funds, and the zeroing out of the Youth Sports Program and the Senior Services Coordinators Grant.

Considering the size of the budget deficit, Congress is faced with a formidable challenge in attempting to balance the budget by the year 2002, a mere 7 years. Only a small portion of the budget is discretionary, that is, not an entitlement program that can easily be altered. That leaves HUD programs in jeopardy, since they are part of the discretionary budget subject to reductions. With the public housing program receiving mostly negative publicity because of a relatively small number of poorly run and deteriorated housing authorities, the chances of Congress' support in relation to other programs is dim.

\section{History}

The public housing program has never been a popular program. From its inception in 1937, it has gained little popular support. In the 1930's organized lobbying efforts, principally from the National 
Realtors Association, came close to blocking the passage of the Housing Act of 1937. The debate centered around claims that government intervention in the private housing market would socialize housing and compete with the private sector housing market. President Franklin Roosevelt did not include public housing as part of his New Deal legislative package and had to be convinced of the need for housing legislation. Even then, his support for the program came largely due to its job creation potential which he hoped would help offset high unemployment during the Depression

Contemporary opposition to public housing is a result of many factors, but focuses around two major points: the Federal fiscal situation and the failure (real or perceived) of the public housing program to fulfill its original mission to serve as transitional housing.

Congress created public housing to alleviate blighted conditions in slum areas of cities and to provide temporary housing for low-income families. In its earliest years public housing served this role well. Many low-income families, especially after World War II, lived in public housing developments for short periods of time in order to get their economic lives in order and to move into the economic mainstream. It was unusual for families to live in public housing beyond a few years.

Today public housing is considered by some to be the housing of last resort. Many residents, due to their lack of education and job skills, remain for longer periods of time. Some families are multigenerational residents of public housing. Housing authorities, particularly the large urban authorities, are seen as being mismanaged, severely deteriorated and crime ridden. This is the image of public housing projected to the public every day by the news media. While we in the profession are aware that this depiction of public housing is not an accurate portrayal of our program, our efforts to educate the general public have not been successful. Of the approximately 3,200 public housing authorities in the United States, only 100 are considered distressed, that is, not well managed or suffering from the effects of irregular funding. Even this housing authority had its dark period when funding was not adequate to sustain our most basic operations. Today the Providence Housing Authority continues to be under funded for our most basic funding source - the allowable expense level (AEL). Housing authorities of similar size and populations receive a considerably higher AEL.

\section{The Reinvention of HUD}

Another factor affecting the survival of the PHA is the status of future funding from HUD. The Department of Housing and Urban Development is itself in jeopardy of extinction. Many members of the new Congress have expressed interest in abolishing the department and transferring a limited number of functions to other Federal departments or State and local governments. In reaction to the potential elimination of HUD, Secretary Cisneros, with the Administration's encouragement, created a hastily prepared plan to "reinvent" the department. Although highly fluid (it has evolved several times since its original unveiling), the basic thrust of the plan calls for a transition with the final result being that HUD would no longer distribute any direct funds to local housing authorities (LHAs)

The first phase of this three phase program maintains the status quo, with housing authorities continuing to receive funds as they presently receive them. In the second phase, which would also be the second year of the transition, all housing authority and Section 8 programs would be consolidated into three block grants. One would cover the operating subsidies and other related costs. The second would provide for capital improvements by consolidating all modernization and development programs. The third would combine all Section 8 programs and functions. The final phase of HUD's reinvention plan calls for the "voucherization" of the public housing program. LHAs would no longer receive funds from HUD, rather, all current residents of public housing 
would receive housing vouchers to choose where they want to live, including privately-owned units. Housing authorities, in effect, would have to compete with the private market for residents. Theoretically, residents would exercise market decisions and move, or remain, depending on conditions, to better dwelling units. Housing authorities that could not compete with the private sector would presumably go out of business. It remains unknown at this time who or what agency would assume responsibility for the existing assets.

The department would initiate these changes along with the "deregulation" of the industry which would allow for more local decision-making and flexibility. Already the department has terminated several HUD handbooks and processes. Initially the transition period was going to be three years. Now, however, HUD has determined that this time period is unrealistic and it will take substantially longer to complete the transition.

\section{Change: Danger and Opportunity}

At this time, the future of public housing is not clear; there is great speculation about where we'll be in the year 2000. One thing is known: there will be change. What form this change will embody is unclear at this time, but changes will take place either through the budget or from HUD's reaction to the Congress.

The PHA is in an enviable position in that we can prepare for the changes that are coming. We have adopted the following quote from $\mathrm{R}$. Kanter for our strategic planning process:

\section{"Change is disturbing when it is done to us, Exhilarating when it is done by us"}

The Chinese character that represents crisis is a combination of two other characters. The first represents danger, and the second opportunity. This is a perfect illustration of the concepts behind strategic planning. While change initially appears frightening, it can also be beneficial. Charles F. Kettering once said, "the world hates change, yet it is the only thing that has brought progress." Strategic planning looks at the relationships between an agency's strengths, weaknesses, opportunities and threats. While current changes appear threatening, they also represent the opening of new opportunities. The forces behind change in Washington are driven as much by a philosophy of deregulation as by a philosophy of budget cutting. Housing Authorities have felt constrained by federal preferences, Davis Bacon requirements, the one-forone replacement rule, rent-to-income ratios, occupancy regulations, and burdensome procurement policies. If regulatory relief becomes real, we may very well be able to "do more with less." The only way to bring about these new opportunities while minimizing the changes that threaten our operations is to plan for change and to participate in guiding it.

In order to meet the challenge of continuing to provide the highest level of services possible within the context of this changing environment, the PHA has developed this strategic plan. This plan was written with the help and input of hundreds of residents, social service providers and PHA management and staff. The planning process was designed to include and incorporate a diverse range of perspectives. This process will help us better understand how current and expected changes will affect the agency so that we might approach problems proactivly rather than reactively

In short, while no plan can address every foreseen and unforeseen issue facing an agency, the strategic plan is designed to guide the PHA through what promises to be an era of great consequence for public housing in America. 


\section{Step One: \\ Agreement to Plan}

The first step of the strategic planning process is the agreement to plan. This occurs when management and front line personnel discuss the process and agree to proceed. In this step, the agency's members are introduced to the nature, purpose and process of strategic planning. Next, a strategic planning team is created to guide and oversee the process. The first duty of the strategic planning team is the development of a working timeline. At one point in the process our time line had to be lengthened due to longer than.expected response times for our external stakeholder analysis surveys and revisions of the environmental scans.

The Providence Housing Authority had previously conducted strategic planning workshops, so the concepts were not new. On 11 May 1995 the departmental directors and key personnel were reintroduced to the process through an information session. During this session the basic tenets of strategic planning were reviewed and the Bryson model was explained step by step. Department directors were then instructed to form small strategic planning teams. These teams were responsible for writing internal and external environmental scans, participating in an internal stakeholder analysis, several planning retreats and planning sessions. The retreats and sessions covered various steps of the strategic planning process such as issue identification, strategy formulation and goals management planning.

The Public Housing Unit of the Providence Police Department was included due to the importance of security related issues. Initial resident survey and external stakeholder analysis returns indicated that security related issues were one of the most critical concerns for public housing. The Providence Housing Authority's 1995 Social Service Needs Assessment further supported the urgent nature of issues regarding drugs, crime and safety. It was therefore decided that members of the PHU would form a separate strategic planning team to address these issues. The members selected for the strategic planning teams are listed in the following chart.

\begin{tabular}{|l|l|l|}
\hline \multicolumn{1}{|c|}{$\begin{array}{c}\text { PROVIDENCE HOUSING AUTHORITY } \\
\text { STRATEGIC PLANNING TEAMS } \\
1995\end{array}$} \\
\hline \multicolumn{1}{|c|}{ TEAM MEMBER } & \multicolumn{1}{|c|}{ POSITION } & \multicolumn{1}{|c|}{ DEPARTMENT } \\
\hline & \multicolumn{1}{|c|}{} & \\
\hline Stephen J. O'Rourke & Executive Director & Executive \\
\hline Domenic V. Schiano & Deputy Director & Executive \\
\hline Marcia Sullivan & Exec. Asst. to Executive Director & Executive \\
\hline Christopher Delvaille & Policy Analyst & Executive \\
\hline Stacy Tobin & Intern & Executive \\
\hline & \multicolumn{1}{|c|}{} & \\
\hline Jay Hall & Director & Housing Management \\
\hline Donna DeMeo & Manager/Elderly Disabled Housing & Housing Management \\
\hline Terri Green & Administrative Assistant & Housing Management \\
\hline Jean Bryant & Manager/ Resident Selection & Housing Management \\
\hline
\end{tabular}

(Continued Next Page) 


\section{PROVIDENCE HOUSING AUTHORITY STRATEGIC PLANNING TEAMS \\ 1995 \\ -CONTINUED-}

\begin{tabular}{|c|c|c|}
\hline TEAM MEMBER & POSITION & DEPARTMENT \\
\hline Joseph Braga & Director & Finance \& Accounting \\
\hline Robert Previte & Accounting Manager & Finance \& Accounting \\
\hline Lou Tomasso & Accountant & Finance \& Accounting \\
\hline Ralph Deissler & Director & Facilities Management \\
\hline Bill Cuomo & Operations Planner & Facilities Management \\
\hline Abhijit Brahmachari & Assistant Operations Planner & Facilities Management \\
\hline Denise Healy & Administrative Assistant & Facilities Management \\
\hline Ron Torbik & Director & Modernization/Development \\
\hline Judy Kenower & Planning Assistant & Modernization/Development \\
\hline Richard Goodison & Modernization Specialist & Modernization/Development \\
\hline Paul Stockman & Development Coordinator & Modernization/Development \\
\hline Anne Cunningham & Director & Community Services \\
\hline Cheryl Durand & Supportive Services Coordinator & Community Services \\
\hline Sorrel Gerety & Education Coordinator & Community Services \\
\hline Angelo Pirri & Director & Rental Housing \\
\hline Yvonne Longo & Senior Program Representative & Rental Housing \\
\hline Richard Silvestro & Program Representative & Rental Housing \\
\hline Paul Brousseau (Sgt.) & Public Housing Unit & Providence Police \\
\hline Paul O'Rourke & Public Housing Unit & Providence Police \\
\hline John Costa & Public Housing Unit & Providence Police \\
\hline Glen Cassidy & Public Housing Unit & Providence Police \\
\hline
\end{tabular}




\title{
Step Two:
}

Clarifying Mandates

\begin{abstract}
Mandates are defined as the external expectations placed upon an organization. The purpose of this step is to clarify these external expectations. When identifying its mandates, an organization should consider both its formal and informal mandates. Formal mandates are often stipulated within legislation, charters, ordinances, articles, and contracts. Informal mandates are also often placed upon an organization. These mandates are based upon generally understood norms and expectations. While not as official as formal mandates, they are often equally binding

Many organizations are not aware of what their mandates are and feel more tightly constrained than is necessary. Further, organizations often mistakenly operate under the assumption that if something is not expressly defined within their mandates, they cannot do it. This is not necessarily true. It is often beneficial for an agency to develop a mission statement that goes well beyond what it is mandated to do. Organizational members might decide that what their agency ought to do exceeds what it is mandated to do.
\end{abstract}

In this step, the strategic planners list, interpret and clarify the boundaries of relevant mandates. In Strategic Planning for Public and Non-Profit Organizations, Bryson explains that clarifying exactly what an agency's mandates are increases the likelihood that they will be met. Also, listing what mandates the agency faces enhances the possibility of developing a mission that is not simply a reiteration of the agency's mandates. Once the organization's members are clear about what they must do, they are free to define the proper role for the agency within their community.

\section{ORGANIZATIONAL MANDATES}

The Providence Housing Authority operates under the dictates of many mandates, both formal and informal. Below is a listing of these mandates followed by a more in depth description and commentary

\section{Formal Mandates:}

The Providence Housing Authority is governed by several legal (formal mandates) documents, including

- R. I. General Laws (Volume 7, Section 45:25 "City Housing Authorities")

- City of Providence Home Rule Charter (Article XI, Section 1107)

- Certificate of Incorporation (Providence Housing Authority)

- By-Laws of the Providence Housing Authority

- Annual Contributions Contract (ACC) with HUD

- Code of Federal Regulations

- Public Housing Management Assessment Program (PHMAP)

- Numerous HUD Handbooks, Notices and Memoranda 


\section{Informal Mandates:}

The PHA is also governed by several informal (non-legal) mandates established by the management of the housing authority, including

- 3-Year Goals Management Plan

- Quarterly Performance Indicators

- Monthly Performance Goals

FORMAL MANDATES

\section{Rhode Island General Laws (45:25)}

Section $45: 25$ of the R. I. General Laws, a/k/a the housing authorities law, establishes the procedure for creating a local housing authority. Originally passed in 1939 in response to the US Housing Act of 1937, this section sets forth the requirements a city must meet and maintain to create a local housing authority.

The housing authorities law also cites the corporate powers of the authority, membership of the board, apportionment and terms of commissioners, removal of commissioners, tenant selection, power of the board, compensation, and compliance with federal regulations. It also establishes procedures for cooperation between authorities, exemption from zoning requirements, payments in lieu of taxes, supplemental powers, and tax exempt status.

Section 45-25-15. Powers of authority enumerated, lists the numerous powers exercised by the authority in undertaking its responsibilities. Some of the enumerated powers of the housing authority include:

... investigating living and housing conditions in the city; determine where unsafe and unsanitary housing exists; studying and making recommendations on housing; planning, constructing, improvement and repair of existing housing projects; management of housing projects; to change the city map, to plan, replan, zone, or rezone any part of the city or municipality; to lease or rent any of the dwelling or other accommodations or any of the land, buildings, structures or facilities embraced in any housing project and to establish and revise the rents charged.

This section also states the powers of the housing authority to sell bonds, transfer property, and to borrow money for the purposes of providing housing to low-income residents of the city.

\section{Comments on R. I. General Laws}

Many of the powers enumerated by this section are enhanced or diminished by federal law, particularly with regard to the establishment of rents. The requirement to maintain a reserve for the payment of outstanding bonds is also obsolete in that the federal govemment provides the funding to retire outstanding bonds.

Of particular importance to the contemporary housing authority is the ability to sell bonds for the purpose of providing housing for low- and moderate-income families and the exemption from local zoning requirements. These features of the law provide the housing authority with a substantial amount of latitude 
to develop new housing stock. Recent changes in federal regulations and the federal tax code also provide some impetus to provide more affordable housing in the city.

However, the expansion of housing in the city of Providence may be limited due to several reasons: (1) the city already possess a disproportionate share of assisted housing in the State of Rhode Is/and (2) any additional public housing would have a negative impact on the city's tax base due to our tax exempt status, and (3) the uncertainty of future federal policy on housing. All these mitigating factors will have to be examined closely before the authority sails in uncharted water. At the same time, rewards go to risk-takers; if our anticipated netum is greater than our initial investment, perhaps this is the path to the future.

\section{City of Providence Home Rule Charter}

The City of Providence Home Rule Charter, Article XI Boards and Commissions. Section 1107 Providence Housing Authority states

"... There shall be a Providence Housing Authority consisting of eleven commissioners, nine of whom shall be appointed by the mayor, and two of whom shall be elected by the city council from among its members. All commissioners shall be residents and domiciliaries of the city."

Section 1107 furthers goes on to enumerate the terms of office for the commissioners, method of filling vacancies, selection of chairman, what constitutes a quorum, compensation of commissioners, and the removal from office of sitting commissioners.

Of particular importance to the housing authority is subsection (c) ...

"The Providence Housing Authority shall have all the powers, duties and responsibilities in connection with the provisions of adequate housing for the people of the city, and for all other purposes, as set forth in applicable laws of the state and of the federal government, and this Charter, now or hereafter in effect for housing authorities generally or the Providence Housing Authority in particular."

\section{Comments on the Providence Home Rule Charter}

The Providence Home Rule Charter was updated and adopted on 18 September 1980. The changes from the original charter are not substantial. While the Charter Commission did not grant exclusive powers to the housing authority, it perhaps envisioned a less complex environment. Since adoption of the original charter, several city departments and agencies have been created whose primary responsibilities include housing. Of particular importance is the city's Department of Planning and Development, the Providence Plan, and the Providence Plan Housing Corporation. The city has also been responsible for the creation of numerous city-wide and neighborhood-based nonprofit housing corporations.

The charter provides very broad and exclusive powers to the housing authority ("...shall have all the powers, duties... in the connection with the provisions of adequate housing...") which can be interpreted in many ways. Certainly it was not the intention of the members of the Providence Home Rule Charter Commission to grant exclusive rights to the housing authority to provide housing for the people of the city. The Charter Commission took place when the city had a Department of Planning and Development, as well as a Mayor's Office of Community Development. which was consolidated with the Planning and Development Department in 1984 


\section{PHA Certificate of Incorporation}

A City Council resolution authorizing the submittal of the PHA's Application for Certificate of Incorporation, dated 11 July 1939, includes a section which states:

That the City Council of the City of Providence, Rhode Island, after having given due consideration to the physical condition and the age of certain buildings in the City, the degree of overcrowding, the light and air available to the inhabitants of such dwelling accommodations, the size and arrangements of the rooms, the sanitary facilities, and the extent to which conditions exist in such dwellings which endanger life or property by fire or other causes, hereby determines, finds and declares in pursuance of the provisions of the Housing Authorities Law of the State of Rhode island:
A. Unsanitary or unsafe inhabited dwelling accommodations exist in this city; and,
B. There is a lack of safe and sanitary dwelling accommodations in this City available for all inhabitants thereof.
C. There is a need for a housing authority in this City.

The primary aim of establishing a housing authority in the city of Providence was to alleviate poor housing conditions in the city. The PHA was granted authority to undertake surveys of housing conditions and to make recommendations to the city fathers on how to ameliorate unsafe and unsanitary conditions.

\section{Comments on the PHA's Certificate of Incorporation}

The PHA was established in response to the provisions of the federal Housing Act of 1937. The responsibilities of the housing authority were written to meet the requirements of the Act, that is, they would conduct housing surveys, identify blighted areas, eliminate housing conditions that were detrimental to the health and safety of residents and apply for funding to construct new public housing developments.

The PHA has successfully met this formal mandate from its inception in 1939. Since that time, 14 public housing developments were created throughout the city. The PHA is the largest housing provider to lowincome residents in the city and state with 2,554 units. An additional 106 units are either under construction or being planned for construction next year. The PHA also administers a rental housing program with approximately 2,300 units. The mandate of the original Certificate of Incorporation has been met.

\section{PHA Board of Commissioners (By-Laws of the Commission)}

The bylaws of the PHA Board of Commissioners consists of seven articles which explain the structure of the board, the officers/officials of the board and their duties, when and where meetings will take place, finances, and an amendment process. Nothing in the bylaws affects the day-to-day operations of the housing authority.

\section{Comments on PHA Board of Commissioners By-Laws}

The bylaws of the Board of Commissioners do not pertain to the PHA's operations nor does it mandate any programs. The bylaws deal exclusively with board operations.

\section{Annual Contributions Contract (Department of Housing and Urban Development)}

The Annual Contributions Contract (ACC) is an agreement between the housing authority and the Department of Housing and Urban Development which guarantees permanent financing of public housing and certain Section 8 projects. It also agrees to provide the difference between project 
revenues and debt service on bonded indebtedness through an annual contribution on subsidy paid to the housing authority. As its obligation in the contract, the authority guarantees that it will maintain the low-rent character of the project.

The ACC consists of two parts. Part I determines the legally authorized amount of funds a housing authority will receive from HUD. Part II, currently, is a lengthy document which consists of five articles on operating a housing authority.

Article I has twenty-six sections dealing with the development of public housing. It includes sections on Efficiency and Economy in Development and Administration and Performance and Payment Bonds.

Article $/ I$ and has twelve sections dealing with such topics as Leases, Low Rent Character of Projects, and Repair, Maintenance and Replacement.

Article III covers the Provisions Common to Development and Operation and has thitteen sections including: Compliance With the Cooperation Agreement, Insurance Coverage, Books of Accounts and Records, and Financial and Operating Statements.

Article IV deals with the Fiscal Provisions Governing Development and Operation. This section has twenty-three sections and covers such topics as: General Depository Agreement and General Fund, Development Cost, Temporary Notes, Operating Budgets, Debt Service Fund, etc

Article $V$ consists of eighteen sections and is titled Defaults, Breaches, Remedies, and General Provisions. Topics covered in this section include Conveyance of Title, Continuance of Annual Contributions, Interest of Members and other topics.

\section{Comments on the Annual Contributions Contract}

The ACC is the Bible for operating a public housing authonity. However, the ACC is very outdated and has been scheduled for replacement in the very near future. Many of the provisions of the old ACC are no longer applicable. The Department of Housing and Untan Development plans to replace the existing sixtyfive page document with an updated version that is only a few pages. Literature on HUD's reinvention claims that an ACC will not exist once housing authorities reach the last "voucherization" stage. Housing authorities will then be required to comply with "broad general principles" that are consistent with federal statutory law. The new version of the ACC is due shortly.

\section{Code of Federal Regulations (CFR)}

The Code of Federal Regulations consists of both statutory and regulatory requirements mandated by the Congress and the Department of Housing and Urban Development. The CFR consists of numerous sections dealing with the operation of public housing and Section 8 programs, as well as various other programs managed by the PHA.

\section{Comments on Code of Federal Regulations}

The CFR contains all the existing rules and regulations goveming housing authonities. Both the public housing and Section 8 regulations are contained in the CFR. It is unclear at this time what effect deregulation will have on the CFR. If LHAs are truly "deregulated", then the CFR should not govem our every action. The CFR will probably contain the broad general guiding principles mentioned above.

\section{Public Housing Management Assessment Program (PHMAP)}

The PHMAP implements section 502(a) of the National Affordable Housing Act of 1990 (NAHA) and evaluates the performance of public housing agencies in major areas of management operations. PHMAP consists of twelve indicators and various subparts of the primary indicators. These indicators are weighted to represent HUD's priorities. Housing authorities are rated on a scoring system of 100 . A score of 60 is "standard;" a score of 90 or greater is "high performer." 
The Providence Housing Authority consistently scores in the high $70 \mathrm{~s} / \mathrm{low} 80 \mathrm{~s}$ due to our low operating reserve level and routine operating expenses. We score very high (mostly As) on key areas such as inspections, resident initiatives, contract administration, and other key areas we believe are important to the operation of the PHA. Improvements in our low performance areas, such as operating reserves, would ultimately affect our high performance indicators resulting in little net improvement. It has been the conscious policy of the PHA to ignore our reserve level if it would jeopardize our other indicators.

\section{Comments on PHMAP}

Even before HUD's reinvention discussions, the department decided to revise all but one of the PHMAP indicators. This will be very beneficial to the Providence Housing Authority, since greater weights will be given to those indicators of activities we perform well. The operating reserve indicator, our weakest score, is being eliminated completely. There is no official word on how PHMAP will be affected by reinvention and deregulation. Theoretically, if the ACC no longer exists, PHMAP will be moot.

\section{HUD Handbooks, Notices and Memoranda}

The Department of Housing and Urban Development issues numerous handbooks, notices and memoranda on the operation of programs it funds. Though too numerous to mention in this space, there is a handbook, notice or memoranda for every program or operation HUD is involved with creating and financing.

\section{Comments on HUD Handbooks, Notices and Memoranda}

HUD recently issued a memorandum terminating most of their handbooks. This was considered a first step in their much touted deregulation process. While rescinded. HUD suggests housing authorities continue to use them as "guides."

\section{INFORMAL MANDATES}

\section{Three-Year Goals Management Plan}

The PHA developed a three-year goals management plan in 1993. The plan contains the goals and objectives of the PHA's six departments, security program, and the executive/administrative office. The plan consists of 98 goals, 166 objectives and 908 tasks. The plan is informally monitored monthly, formally semi-annually.

\section{Quarterly Performance Indicators}

The housing authority has institutionalized a quarterly report of performance indicators the PHA departments are supposed to attain. There are 189 performance indicators covering every area of operation at the PHA. Reports are submitted the fifteenth of January, April, July, and October.

\section{Monthly Performance Goals}

Each department has certain performance goals which must be attained on a monthly basis While many are repeats of the Quarterly Performance Indicators, they are vitally important to the successful operation of the PHA. Indicators, such as rent collected, occupancy rates, unit turnover, and work order completion need to be met on a continual basis.

Comments on Goals Management Plan, Performance Indicators and Monthly Performance Goals The PHA will continue to use these management tools to track our performance and to readily identify its strengths and weaknesses. The Goals Management Plan will be updated on an as needed basis, but at least every three years. An update will be part of this strategic planning process 


\section{Organizational Mandates Summary}

The Providence Housing Authority was created and continues to operate under numerous mandates from the federal, state and local levels of government. Each mandate, regardless from which source, directs the Providence Housing Authority to create, maintain, administer and operate affordable housing in the city. Other mandates are really secondary to the primary mandate which was a direct response to the federal Housing Act of 1937. Neither the state general laws nor the city charter has significantly changed our mandate since we were created in 1939. The only change at the state level was in the number of commissioners serving on the board.

The federal government has manufactured the most significant changes as Congress and the Department of Housing and Urban Development have altered their level of effort and emphasizing different constituencies. Public housing, originally conceived for the short-term housing of the "working poor," now houses long-term, very-low income families with a plethora of social problems. Congress and HUD have responded to this change with a series of programs to assist these families-usually too little to have a significant impact.

Housing for the elderly has been transformed from tranquil retirement homes to tense living spaces due to federal mandates requiring the mixing of young disabled with the elderly. Only recently has HUD-at Congress' direction-established a procedure for housing authorities to declare some buildings as elderly only.

The PHA must brace itself for the next series of mandates from HUD and/or the Congress. HUD has declared another "reinvention" that will have a major impact on our operations. The most recent reinvention calls for a block grant for public housing and eventually giving vouchers to all residents. Residents would decide whether they would remain in public housing or seek housing elsewhere. No subsidy would be provided to public housing authorities once this "voucherization" goes into effect. 


\section{Step Three Developing the Mission Statement} If you don't know where you're going, any plan will do
-Peter Drucker

Three outstanding attitudes- obliviousness to the growing dissatisfaction of constituents, primacy of selfaggrandizement, and the illusion of invulnerable status- are persistent aspects of folly -Barbara Tuchman, March of Folly

The clarification of an organization's mission is of great importance to the concept of strategic planning. Before an agency can successfully plan strategies for its long term success, it must first define what that success will encompass. The mission statement defines the agency's purpose or fundamental reason for existence'. The mission statement will direct the agency's policy and performance, and serve as the yardstick by which the organization is to be measured. It will further serve to broaden the agency's focus beyond its mandates and narrow the agency's vision of its proper place within the community.

In providing the organization with a social justification for its existence, the mission statement begins with the identification of a social or political need. This need or needs explain why the agency does what it does (the vision of success illustrates what the agency should look like as it fulfills its mission). This clear identification of important needs provides the agency with a sense of cohesion and can boost the morale of those involved. Bryson notes that, "agreement on an organizational mission that embraces socially desirable and justified purposes should produce enthusiasm, even among organizational members." ${ }^{2}$ While the mission statement is formulated with input from external stakeholders, it is directed internally. It lets organizational members see "how what they do is tied to a greater purpose." Bryson notes that most discussion inside organizations focuses around small trivial issues. The mission statement helps organizational members to focus their attention on what is truly important.

One important point about developing a mission statement is that a business or agency's mission is defined by the client's needs and not the product the agency has to offer. This aspect of the planning process is well illustrated by the successes and failures in the business sector. The decline of the railroad industry in the early part of this century could well have been avoided if railroads had defined themselves by their clients needs, rather than by their product. Had they understood that they were in the transportation industry (and not simply the railroad business) they could have taken advantage of technological advances such as truck and airplanes. Instead, these opportunities became threats.

On the other hand, the diversification of Pitney Bowes has allowed that company to remain the industry leader in its field. Originally a producer of postage meters, Pitney Bowes expanded into the mail automation business.

They now produce machines that take letters from computer disks and "put them on organizational letterheads, collate them with other material, fold the material, insert the collated and properly folded materials in an envelope on which it also has printed the recipients' full name and address, seal the envelope, apply the proper postage, and sort the envelopes by postal code." ${ }^{\text {B }}$ By expanding the definition of what business they were in. Pitney Bowes has remained a strong and growing corporation. 
New areas for growth potential can be based upon the agencies internal strengths. Indeed part of the strategic planning process is the development of strategies that help organizations take advantage of external opportunities and minimize external threats by maximizing internal strengths. One question that must be answered in developing a mission statement is, "what makes our organization unique?" Answering this question can provide important clues to help the agency define what business it wants to be in. Strengths that are unique to an organization are called distinctive competencies. An example of how this concept worked in the private sector occurred when AT\&T enlarged its mission to include the creation of a credit card company. While this was a new area for AT\&T, the company had an extensive billing infrastructure already in place. This distinctive competency allowed AT\&T to expand and take advantage of a new opportunity by maximizing the potential of a strength that was already in place. $^{5}$

\section{Stakeholder Analysis}

While the mission statement often broadens the agency's purpose beyond the agency's mandated obligations, no agency can serve everyone, and not all people have the same needs. Every agency exists in an "arena in which individuals and groups contest for control of its attention, resources, and output." In order to determine the agency's proper role within the community, choices have to be made. While examining distinctive competencies is one way to help narrow the agency's focus, a stakeholder analysis is another important tool. A stakeholder is described by Bryson as "any person, group, or organization that can place a claim on an organization's attention, resources, or output, or is affected by that output." He further goes on to state that, "the key to success in public and non-profit organizations is the satisfaction of key stakeholders".?

An agency that does not include its stakeholders in planning for the future can have the best plans and the best intentions, and fail completely. When United Airlines attempted to broaden its mission from being in the airline business to being in the travel business it missed an important opportunity to grow and prosper because key stakeholders were not included, and their support was not sought. The company's attempt to purchase the Weston Hotel chain and Hertz Rental Company thus met with failure, and the CEO was replaced. ${ }^{8}$

Stakeholders are often grouped by various categories. Often organizations will list stakeholders by such factors as their level of support for, or opposition to the agency, the degree to which they can affect the agency's operations, or differing services needs. For public and non-profit agencies, the two primary groups of stakeholders are stakeholders that control funding and stakeholders that receive services and participate in programs implemented by the agency. Collaborators and competitors are also important groups that need to be acknowledged. It is important to understand that stakeholders will judge an organization based upon their own criteria. Thus, when formulating a mission statement it is important to know what the agency's stakeholders expect in terms of services and performance. If the organization's mission is in conflict with the expectations of important stakeholders, success is unlikely.

The Providence Housing Authority conducted both an internal and external stakeholder analysis. These were distributed to the members of the Strategic planning teams before they met to discuss changes in the PHA's mission statement. Input from outside agencies and internal staff and management helped to define the proper business of the PHA. A summary of the external stakeholder survey results is located in the External Environmental Analysis section of this report, and a summary of the internal stakeholder survey results is located in the section covering the Internal Environmental Analysis. 


\section{Values}

Because the mission statement often has a moral component, (this is especially true for public and non-profits agencies) values play an important role in this step of the strategic plan. If the mission statement is to be useful in guiding the organization, it "must be congruent with the desired organizational values." ${ }^{\prime 9}$ Bryson quotes Robert Haas, the chairman and CEO of Levi Straus as saying, "we've learned...that the soft stuff and the hard stuff are becoming increasingly intertwined. A company's values - what it stands for, what its people believe in - are crucial to its competitive success. Indeed, values drive the business."

This attitude was displayed in 1982 during the Tylenol cyanide scare. Seven people in the Chicago area died of cyanide poisoning when they ingested Tylenol capsules that had been tampered with. While the tampering occurred outside of the company and was limited at that time to the Chicago area, Johnson \& Johnson, the company that produces Tylenol removed all capsules across the United States. The cost of this operation was $\$ 100$ million. Further, the company began an educational campaign involving 2,500 employees to alert providers of possible dangers. ${ }^{10}$ That Johnson \& Johnson operated in an ethical fashion is clear. What is interesting to note is that their actions flowed directly from the company's credo developed in 1940 which states, "We believe our first responsibility is to the doctors, nurses, and patients, to mothers and all others who use our products and services." ${ }^{11}$ By following the dictates of their organizational values, Johnson \& Johnson suffered short term financial losses, but they were able to demonstrate clearly that they were a company that understood the importance of honor and integrity. Organizational members could feel a sense of pride and important stakeholders remained loyal.

Within time, Tylenol was able to regain its market share and the doctors, nurses, patients, mothers and other consumers continued to use this product with confidence. This is a clear example of how organizational values have a tangible effect on long term success. As Robert Haas noted, "the soft stuff and the hard stuff are becoming increasingly intertwined." This is important for the survival of public agencies. With the public trust in government in general, and public housing authorities in particular, at an all time low, it is vital that the Providence Housing Authority stand for clear moral and ethical standards. After conducting exercises to determine organizational values, a clear statement of ethical responsibility was included in the PHA's mission statement. The next section of this report describes this process in greater detail.

\section{Helps To Mediate Conflict}

One added benefit to the development of a mission statement is that it provides a framework through which to mediate conflict. By channeling activity towards a larger social goal, the mission statement provides organizational members with a way to measure organizational ends and guide conflict. By understanding the nature of the problems the agency exists to serve, competing solutions can be assessed using objective criteria. Further, a truly inspiring mission statement designed to incorporate organizational values can guide discussion away from self serving interests by providing moral weight to the overall goals of the agency.

\section{Summary}

The mission statement should be short and inspiring. It is designed to inspire the organization's members and provide a social justification for its existence. By clarifying the purpose of the organization it allows for more effective leadership and a consistent focus. The mission statement incorporates input from both internal and external stakeholders and seeks to define a role for the 
agency that is consistent with the organization's values and that goes beyond the role imposed by external mandates.

\section{Developing A Mission Statement}

In developing a mission statement, an agency must first answer three basic questions. First, the agency must define its organizational mandates. It is difficult to picture an agency as being a success when it has failed to accomplish the basic expectations placed upon it. Second, the agency must determine what it hopes to accomplish. Beyond what it must do, an organization often has more flexibility to affect change than is realized by its members. Third, the agency must determine which goals are both realistic and appropriate for the agency to set for itself. The mission statement incorporates the dreams and ideas of the internal and external stakeholders and provides a more unified and directed vision for the role of the agency. While mandates are often unnecessarily limited in scope, no agency can possibly solve all of the problems surrounding it, and it is inappropriate for the organization to even make the attempt.

\section{A Mission Statement goes beyond an agency's mandates but limits the agency's focus within the community}

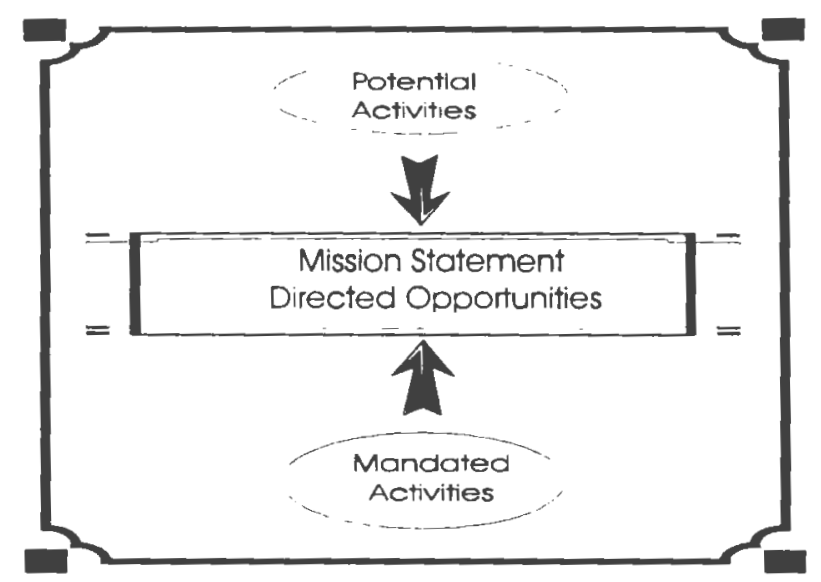

In addition to the three steps listed above, agencies should answer the following six questions when developing a mission statement.

1. Who are we?

2. What are the basic social or political needs we exist to fill?

3. What do we do to recognize or anticipate and respond to these needs or problems?

4. How should we respond to our key stakeholders?

5. What is our philosophy and what are our core values?

6. What makes us distinctive or unique? 
Finally, strategic planning is an iterative process. Information gathered in later steps such as stakeholder analysis and environmental scans will be helpful in revising the agency's mission statement. It is common for an agency to go back and revise the mission statement at various stages of the planning process.

\section{The Providence Housing Authority's Mission Statement}

A mission statement is a declaration of organizational purpose. The PHA has had a written mission statement since 1987. It was changed once in 1991 to reflect the social and economic needs of residents and staff. As information was collected for the strategic plan it was distributed to the different departmental strategic planning teams. Each of these teams examined resident survey results, the internal and external stakeholder analysis results, the environmental scans from all of the departments, and a five year performance indicator summary. Planning teams also participated in various brain storming retreats and sessions in which strategic issues, organizational values, and future strategies were discussed. After reviewing all of this information, planning teams were given copies of the mission statement as it had been updated in 1991. Each team had a specified amount of time to suggest.changes. These suggestions were then compiled, handed out and discussed in a meeting of the teams to revise the mission statement. Each team was given the opportunity to explain their suggestions and a vigorous debate followed.

The result was a revised mission statement that covers nine different points. While the primary mission of the PHA remained unchanged during the 1991 update it was changed slightly from:

"Provide decent, safe and sanitary housing and the highest level of service to responsible, low-income families and individuals."

To

"Provide affordable, decent, safe, and sanitary housing through the maintenance of our existing units and the development of new units."

A separate section also stated that it is the PHA's mission to:

"Create an environment which enables residents to live responsibly and with dignity."

There are nine parts to our mission statement. In addition to the above, which is considered our primary mission (cited in mandates from the federal, state and local governments), the other sections are directed toward other needs of our residents and staff. For example, with HUD and the Congress emphasizing resident economic independence through self-sufficiency, we added several sections in 1991 dealing with resident development which were also included in the 1995 update for the strategic plan.

"To support residents in their efforts to achieve self-sufficiency."

PHA staff members are also considered in the existing mission statement:

"To enable PHA staff to improve their performance through appropriate vision, training and career development."

The mission statement also incorporates the organizational values chosen by the PHA (please see next section) by stating that it is the mission of the Providence Housing Authority 
"To honor public commitments in a fiscally and ethically responsible manner."

and

"To create and maintain public confidence in the Authority's operations and staff."

\section{Providence Housing Authority}

\section{Mission Statement}

It is the mission of the Providence Housing Authority to:

- Provide affordable, decent, safe, and sanitary housing through the maintenance of our existing units and the development of new units

- To create an environment which enables residents to live responsibly and with dignity

- To support residents in their effort to achieve self-sufficiency

- To honor public commitments in a fiscally and ethically responsible manner

- To create and maintain public confidence in the Authority's operations and staff

- To ensure that the facilities owned and managed by the PHA are marketable in the community and are appealing to residents

- To enable the PHA staff to improve their performance through appropriate vision, training, and career development

- To establish performance goals that meet or exceed industry standards and that optimize the use of available resources to achieve our performance objectives

- To assist the city, state, and national governments in identifying and addressing housing needs 


\section{Step Three A: \\ Identifying Organizational Values}

\section{$\underline{\text { Values }}$}

While values identification is not a separate step under the Bryson model, it is an important component of the strategic planning process. A person's "values" answer the question "What's important to me?" Our values are the deep-seated pervasive standards that influence almost every aspect of our lives: our moral judgments, our responses to others, our commitments to personal and organizational goals. We all have belief systems we live by. Our beliefs and value systems are deeply connected. We are motivated and make decisions based on these belief systems and values. Often these values are unconscious.

If we all had the same values with the same priorities, it would be easy to work in groups. Most teams, however, have diversity of values and beliefs. To help us work better as a team and make decisions that lead to commitment and action, it is necessary to see the range of values that influence the decision-making process and find ways to prioritize and clarify the values used.

Values defined: "A principle standard or quality considered inherently worthwhile or desirable." The root for value is valor, which means strength. Values are a source strength, because they give people the power to take action. Values are often emotional and often difficult to change.

\section{Values are the Foundation for Vision}

Values are the essence of an organization's philosophy for achieving success. They are the bedrock of corporate culture. Values provide employees with a sense of common direction and guidelines for day-to-day behavior.

Shared mission, values, and vision brings people together. They unite and provide the link between diverse people and activities. A shared essence is the expression of what people have in common, of what they, in community, are committed to. People who share values or vision are more likely to take responsibility; they are more likely to challenge the bounds of convention. In organizations where this essence is developed, people do not assume they are powerless. They believe they have the power to contribute directly.

\section{Values at Work}

Central to an organization getting the job done today is the clarity of its values. Before mission, vision and strategy, an organization must come to agreement about what it stands for, both in its customer service and community relations, and within itself, in its dealing with employees. A group must also determine how they will work together, how they will treat each other and what bonds them together.

One of the most important keys to greater effectiveness is a close link between personal and organizational values. A survey by the American Management Association of 1,460 managers and chief executive officers suggests that an understanding of this relationship will provide new leverage for organizational vitality. This relationship, when mismanaged, can provide the breeding ground for conflict and cynicism. The survey provided solid evidence that shared values between the individual and the company are a major source of both personal and organizational effectiveness. 
The same report showed that when managers' values were congruent with the values of their companies, their personal lives were in better shape, their approach to their job more optimistic and their stress lower. Employees' sense of what is important strongly influences their commitment and motivation.

\section{Values Provide Guidance}

Values are one of our most special achievements as human beings. A person acts not just in service to personal needs, but also out of a broader sense of what is important and meaningful. In fact, values are the deepest and most powerful motivators of personal action. Values represent an organizing principle for our lives, as well as an organization.

\section{Highest Ranked Values}

Research conducted on American values found that until recently, values have remained quite stable over time. Of the six values ranked highest in 1968 (honesty, ambition, responsibility, forgiveness, broadmindedness, and courage) the same were ranked highest in 1981. In this 13year period it was also found that American society was undergoing changes in certain values, shifting away from a collective norm to a more individualized orientation. (NOTE: These were the rankings for personal values, rather than organizational values)

\section{Identifying Values}

There are many different exercises available for organizations that are undertaking the process of defining their values. For the PHA's 1995 Strategic Plan a value card exercise was conducted. This exercise asked teams (departmental strategic planning teams were created early in the strategic planning process) to rank a set of values by the degree to which they believed it was an organizational value. The five different degrees were always, often, sometimes, seldom and never. Teams were given a set of cards with different values such as "honesty" and "creativity" and were asked to place five cards under each of the five categories. The results were then compared from department to department, and for the PHA as a whole. The instrument used by the PHA further broke values down into the following categories: social responsibility, mastery, self development, relationship, continuity, and lifestyle. This exercise is helpful in developing both a mission statement, and the organizational vision of success.

On Friday, September 8,1995 , the seven planning teams which comprise the PHA's Strategic Planning Team met to conduct a Value Card Exercise. The exercise consists of reviewing and prioritizing a list of values in order of their importance to the team and the organization as a whole.

The PHA's Strategic Planning Team consists of at least three members from each of the PHA's six departments plus the Office of Executive Director.

For the purposes of this exercise, only those values which were ranked "ALWAYS" and "OFTEN" valued are considered. Not surprisingly, the values ranked by the seven teams were closely related.

\section{PHA Organizational Values Ranking:}

The seven teams participating in the value card exercise were asked to rank in order the five values they always and often value. The following values were chosen. The number in the parenthesis indicates the number of times the value was chosen by the teams. 


\begin{tabular}{|ll|}
\hline ALWAYS VALUED: & \\
1. Honesty & $(6)$ \\
2. Communication & $(5)$ \\
3. Integrity & $(4)$ \\
4. Competence & $(4)$ \\
5. Teamwork & $(3)$ \\
\hline
\end{tabular}

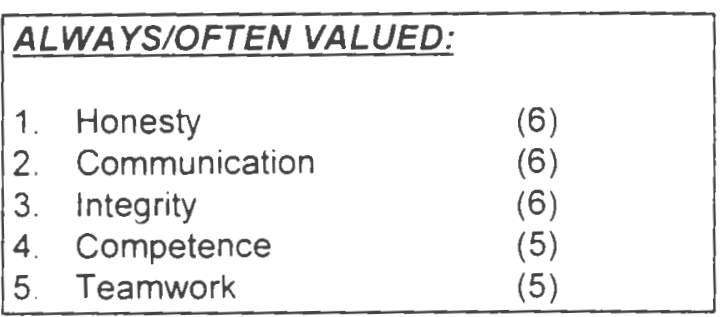

There is consistency in the value system at the Providence Housing Authority. Each of the teams identified the five values as important for the PHA to consider when conducting our work.

\section{Team Rankings}

The team ranking of values was remarkably similar. The following table lists each team and the number of times they cited a value in the top five identified by all the teams.

TEAM

Executive

Finance \& Accounting

Housing Management

Modernization \& Development

Community Services

Rental Housing

Facilities Management

\section{NUMBER OF TOP RANKED VALUES CHOSEN}

$\begin{array}{ll}4 \text { of } 5 & (80 \%) \\ 4 \text { of } 5 & (80 \%) \\ 3 \text { of } 5 & (60 \%) \\ 3 \text { of } 5 & (60 \%) \\ 3 \text { of } 5 & (60 \%) \\ 3 \text { of } 5 & (60 \%) \\ 2 \text { of } 5 & (40 \%)\end{array}$

4 of $5 \quad(80 \%)$

4 of $5(80 \%)$

3 of $5 \quad(60 \%)$

3 of $5 \quad(60 \%)$

3 of $5(60 \%)$

2 of $5(40 \%)$

The Facilities Management Department identified with the group $40 \%$ of time. This may be attributed to the team selecting many "personal" values relating to the individual rather than team values.

The values chosen may be identified further through the value category they belong to. There are six value clusters: (1) Social Responsibility, (2) Mastery, (3) Self Development, (4) Relationship, (5) Continuity, and (6) Lifestyle.

The five top ranked values chosen by the PHA Planning Team fall into three value categories. Honesty and Integrity fall into the "Social Responsibility" category. The values in this group are often considered good in themselves. There is no way to argue or prove, for example, that tolerance is more important than tradition or family. Each person simply holds one value more strongly than another.

Communication and Teamwork fall into the "Relationship" category. These values represent people whose primary motivation is developing personal relationships, helping and working with other people, feeling part of a group or team and sharing experience. People who have values in this cluster seek validation from other people and define their achievements in terms of what they have done for and with others. They seek contact, communication and community at work. They value their standing with others.

Competence comes under the "Mastery" category. Values in this category represent the achiever or individualistic pursuits, where success is defined in terms of mastery, status, power 
and position. This value cluster focuses on achievement in the external world. People motivated by these values want to have visible achievements, and they want these recognized by others. They want to be in a position of authority and to be seen as "winners" in competitive situations.

\section{Other Values and Rankings}

\begin{tabular}{|cc|}
\hline ALWAYS: & \\
Respectful & $(2)$ \\
Achievement & $(2)$ \\
Fairness & $(2)$ \\
Tolerance & $(2)$ \\
Creativity & $(1)$ \\
Perseverance & $(1)$ \\
& \\
& \\
& \\
& \\
\end{tabular}

\begin{tabular}{|cc|}
\hline ALWAYS / OFTEN: & \\
Rationatity & $(4)$ \\
Diplomacy & $(4)$ \\
Achievement & $(4)$ \\
Knowledge & $(4)$ \\
Fairness & $(4)$ \\
Tolerance & $(3)$ \\
Creativity & $(3)$ \\
Perseverance & $(2)$ \\
Neatness & $(2)$ \\
Respectful & $(2)$ \\
& \\
\hline
\end{tabular}

(Values cited once: Stability, Loyalty, Courageous, Health, Family, Advancement, Self-Accomplishment, Consensus, Personal Growth, Inner Harmony.) 


\section{PROVIDENCE HOUSING AUTHORITY TEAM VALUES}

\begin{tabular}{|c|l|l|l|l|}
\hline $\begin{array}{c}\text { ALWAYS } \\
\text { VALUED }\end{array}$ & EXECUTIVE & $\begin{array}{l}\text { FINANCE \& } \\
\text { ACCOUNTING }\end{array}$ & $\begin{array}{l}\text { HOUSING } \\
\text { MANAGEMENT }\end{array}$ & $\begin{array}{l}\text { FACILITIES } \\
\text { MANAGEMENT }\end{array}$ \\
\hline 1 & Honesty & Teamwork & Integrity & Honesty \\
\hline 2 & Integrity & Communication & Honesty & Respectful \\
\hline 3 & Teamwork & Competence & Fairness & Family \\
\hline 4 & Competence & Honesty & Respectful & Integrity \\
\hline 5 & Achievement & Achievement & Communication & Personal Growth \\
\hline $\begin{array}{c}\text { OFTEN } \\
\text { VALUED }\end{array}$ & & & & \\
\hline 1 & & & & \\
\hline 2 & Rationality & Stability & Knowledge & Knowledge \\
\hline 3 & Fairness & Neatness & Diplomacy & Courageous \\
\hline 4 & Communication & Perseverance & Rationality & Self-Acceptance \\
\hline 5 & Diplomacy & Rationality & Consensus & Creativity \\
\hline & Advancement & Fairness & Competence & Health \\
\hline
\end{tabular}

\begin{tabular}{|c|l|l|l|}
\hline $\begin{array}{l}\text { ALWAYS } \\
\text { VALUED }\end{array}$ & $\begin{array}{l}\text { MODERNIZATION \& } \\
\text { DEVELOPMENT }\end{array}$ & $\begin{array}{l}\text { COMMUNITY } \\
\text { SERVICES }\end{array}$ & RENTAL HOUSING \\
\hline 1 & Knowledge & Tolerance & Communication \\
\hline 2 & Communication & Communication & Teamwork \\
\hline 3 & Fairness & Integrity & Perseverance \\
\hline 4 & Honesty & Creativity & Honesty \\
\hline 5 & Compelence & Competence & Tolerance \\
\hline OFTEN & & & \\
\hline VALUED & & & \\
\hline 1 & & Diplomacy & Inner Harmony \\
\hline 2 & Integrity & Achievement & Integrity \\
\hline 3 & Rationality & Knowledge & Diplomacy \\
\hline 4 & Teamwork & Teamwork & Neatness \\
\hline 5 & Creativity & Loyalty & Achievement \\
\hline & Tolerance & & \\
\hline
\end{tabular}




\section{Additional Employee Organizational Values Information}

An additional values exercise was conducted during a retreat for PHA employees who were not members of their departmental strategic planning teams. Three to four employees were selected from each department along with the new family self-sufficiency coordinator and the president and vice president of the Codding Court Residents Association. Each department participated in the values card exercise and, as illustrated in the tables below, their answers were remarkably similar to those of the strategic planning teams.

\section{Top Five Organizational Values of the Identified by PHA Members}

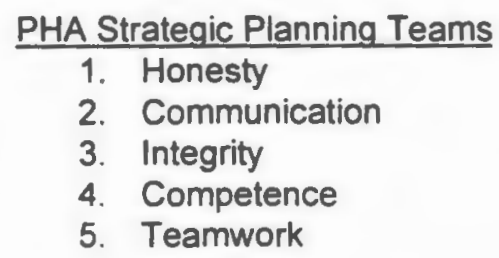

\begin{tabular}{c} 
PHA Staff (Non-Planning Team) \\
\hline Honesty/lntegrity \\
Teamwork \\
Communication \\
Knowledge \\
Achievement
\end{tabular}

\section{Top Five Organizational Values of the Identified by PHA Members (Non-Strategic Planning Team Members by Department)}

\begin{tabular}{|c|c|c|c|}
\hline $\begin{array}{c}\text { PHA } \\
\text { Non-Planning Team }\end{array}$ & Community Services & $\begin{array}{c}\text { Rental } \\
\text { Housing }\end{array}$ & Facilities Management \\
\hline Honesty/lntegrity (5) & Teamwork & Teamwork & Honesty \\
\hline Teamwork (5) & Loyalty & Knowledge & Communication \\
\hline Communication (5) & Communication & Honesty & Competence \\
\hline Knowledge (3) & Knowledge & Diplomacy & Teamwork \\
\hline Achievement (3) & Creativity & Achievement & Achievement \\
\hline $\begin{array}{c}\text { PHA } \\
\text { Non-Planning Team } \\
\end{array}$ & $\begin{array}{c}\text { Modernization and } \\
\text { Development } \\
\end{array}$ & $\begin{array}{l}\text { Finance and } \\
\text { Accounting } \\
\end{array}$ & Housing Management \\
\hline Honesty/Integrity (5) & Integrity & Teamwork & Teamwork \\
\hline Teamwork (5) & Honesty & Communication & Communication \\
\hline Communication (5) & Tolerance & Knowledge & Achievement \\
\hline Knowledge (3) & Competence & Respectful & Honesty \\
\hline Achievement (3) & Security & Competence & Community \\
\hline
\end{tabular}




\section{Step Four}

\section{External Environmental Analysis}

The fourth step in the Bryson strategic planning model is the external environmental analysis. All organizations exist within the context of a larger social, political and economic environment. An organization must be aware of external forces and trends in order to plan for the future. An agency that fails to assess its external environment will be vulnerable to outside threats and will miss important opportunities to grow and prosper. An important aspect of the strategic planning process is its emphasis on assessing a changing environment. In this process it is recognized that current trends may change, and that the agency must be prepared to meet the demands of many possible versions of the future. This focus separates strategic planning from traditional long term planning which assumes a stable future.

There are two main types of analysis that fall under the external environmental analysis step. The first is the external environmental scan which focuses on those external factors which can influence funding and participation for the organization. The Bryson Model identifies three areas for which information must be obtained: Forces/Trends (Political, Economic. Social, and Technological, also known as PESTs), Clients/Customers, and Competitors/Collaborators. Each of the Providence Housing Authority's departmental planning teams completed an analysis based upon each of these three areas. External environmental scans were also conducted for the following areas: politics and the political process; job training, employment and self-sufficiency; homeownership/develop ment opportunities; and security (represented by the Public Housing Unit).

The other important part of the external environmental analysis is the external stakeholder analysis. This step identifies issues from the perspective of those who view the agency's operations from the outside. Bryson defines stakeholders as, "any person, group, or organization that can place a claim on an organization's attention, resources, or output, or is affected by that output." He further goes on to

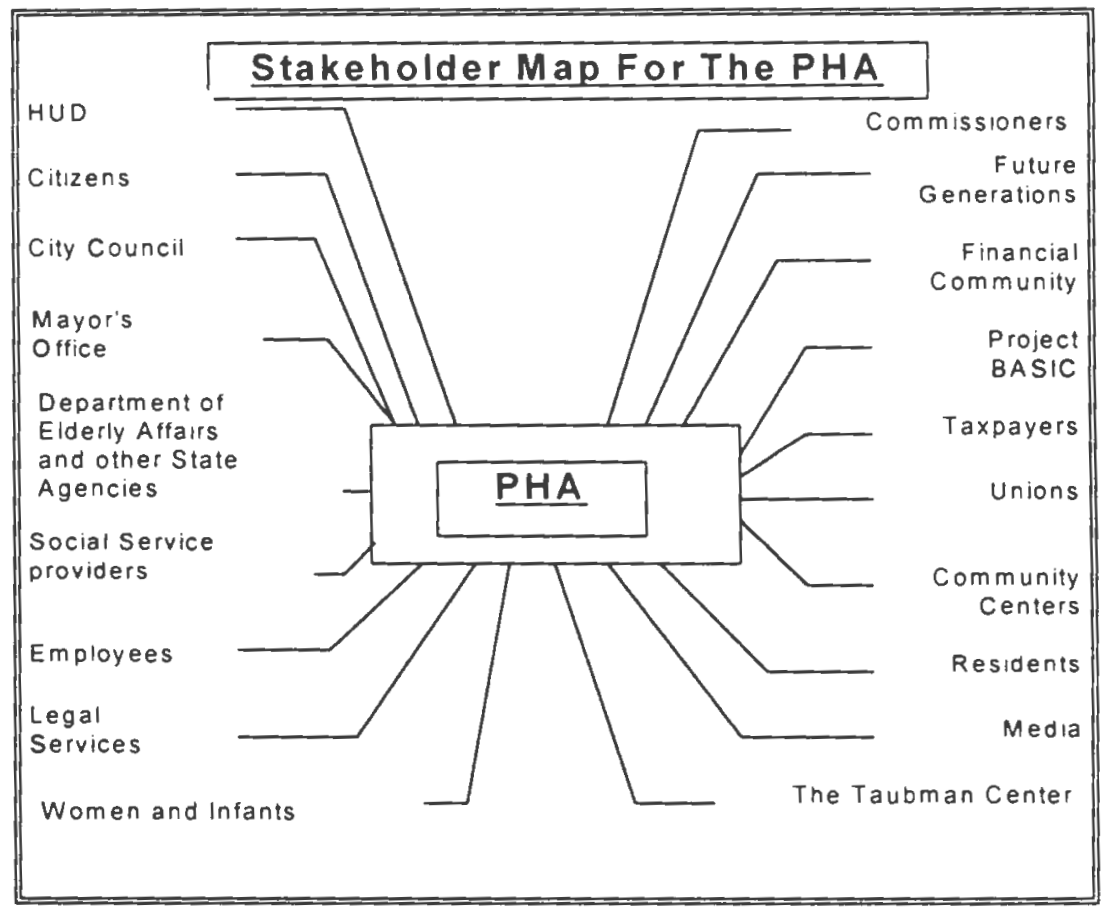
state that, "the key to success in public and non-profit organizations is the satisfaction of key stakeholders". 12 This step is particularly important for public agencies because the justification for their existence is based upon the satisfaction of stakeholders. The mission of most public agencies is to provide services or programs to various stakeholder groups. 
But public agencies also receive their mandates and funding from stakeholders. Therefore, a public agency that fails to satisfy its stakeholders is not only missing the point of its existence, but is in danger of becoming obsolete. Because stakeholders vary in agenda, focus, organization and strength, it is important for an agency to be aware of the types of stakeholders that place demands (often competing with other stakeholders for money, services, attention and resources) upon the agency.

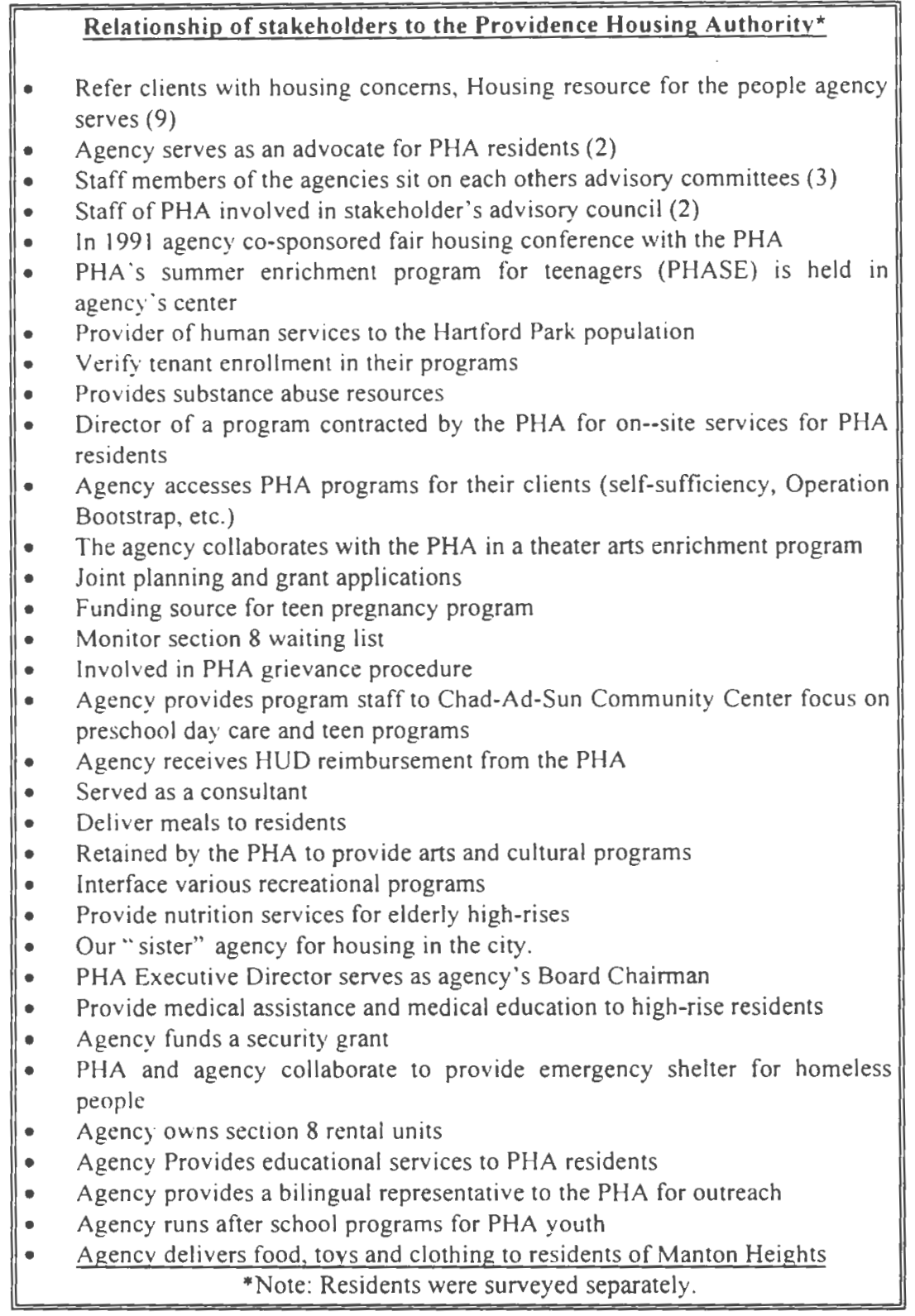

In Strategic Planning for Public and Nonprofit Organizations, Professor Bryson uses the example of the Division of Fisheries and Wildlife of the Department of Natural Resources of a Midwestern state to illustrate the importance of properly identifying key stakeholders. While more than a quarter of the state's population identified themselves as anglers and hunters, this division was under constant attack from its stakeholders. As the Division of Fisheries and Wildlife found itself under increasing attack, it embarked upon the strategic planning process. What was discovered was that the division saw the fish and wildlife as their stakeholders and not the state's citizens (who, unlike the animals, vote and pay taxes). An agency that operates against the interests of its stakeholders, causing them to feel as though the agency is not interested in their concerns, cannot succeed. ${ }^{13}$

The Providence Housing Authority's primary stakeholders are our residents. Surveys were sent to our conventional housing, scattered site and Section 8 residents, as well as to several of our largest Section 8 landlords. These surveys were designed to help us understand what aspects of our performance are strengths and what aspects need more attention. 
In addition to our residents, detailed surveys were created and distributed to 70 other external stakeholders. A preliminary list of key stakeholders was generated by several members of the strategic planning committee. This list was then distributed among staff members who deal directly with our stakeholders. Additional stakeholders were then added to the list and the surveys were mailed out.

In dealing with stakeholders it is important to realize that stakeholders will measure the organization based upon their own criteria, not the agency's. Therefore, it is important to understand a picture of success based on the outsider's point of view. Stakeholders of the PHA were asked to identify what they expect from our agency concerning programs and services. Stakeholders were also asked to give their interpretations of the PHA's mandate and mission, and were given the opportunity to let us know what they feel are the internal strengths and weaknesses and the external opportunities and threats of our agency. These questions were not only designed to help us plan to meet our goals and objectives for the future, but to better understand what is expected of us by our stakeholders. Strategic planning is an iterative process, and it is useful to use the analysis of stakeholder surveys to help formulate the agency's mission statement.

The following section contains summaries of the results of the departmental environmental scans. the resident surveys, and the external stakeholder analysis. Copies of actual the surveys can be found as appendices at the end of this report

\section{EXTERNAL ENVIRONMENTAL ANALYSIS:} RESULTS OF THE 1995 RESIDENT SURVEY

\section{Introduction}

Strategic planing was originally designed as a tool to help corporations plan effective strategies to grow and prosper. While it has evolved into a tool for governmental and non-profit organizations, the fundamentals of the process have remained. Under the corporate model, the primary external stakeholder a company dealt with was its client base. The Providence Housing Authority exists to provide housing and services for our residents. In order to provide the highest possible level of services it is important to generate input from them. To achieve this, surveys were created and sent to our residents. Separate surveys were created for residents of conventional public housing, scattered site, and Section 8 housing. Surveys were also sent to a select number of Section 8 landlords. A copy of each of these surveys has been included in the appendix section of this report.

The following section details the results of the resident survey for conventional housing tenants conducted as part of the 1995 Strategic Plan. Information provided through the resident survey helps to provide strategic planners with a view of the PHA's operations as seen by the people we serve.

Included in this section is an explanation of the methodology used in the survey, and an analysis of the results for the five sections (Community Services, Facilities Management, Management, Security, and Tenants' Associations).

\section{Methodology}

This survey was distributed to all family and elderly/disabled developments and was completed by almost 400 residents of conventional public housing. The survey was divided into five sections based upon Providence Housing Authority departments. Each section was comprised of a series of questions asking residents to rank their level of satisfaction with various services provided by 
the departments. The results of the survey have been counted by numbers of responses (Poor, Fair, Good, Very Good, Excellent) for each question. These qualitative statistics were each assigned a numerical value from one (1) to five (5) with one representing a poor performance rating and five an excellent rating.

In the following analysis, the median of the numerical statistics was calculated. The median score (a numerical value) was then translated into an overall qualitative score (Poor, Fair, Good, Very Good, Excellent.) While it is somewhat unconventional to use a median statistic for this type of sample, the analysis works because the qualitative rankings are based upon a consistent continuum of values. The median measures the number at which half of respondents ranked the departments performance of the service higher and half ranked the performance worse. At times the numerical median value contained the fraction .5. When this occurred the fraction was rounded upwards to a numerical value that could be translated into a qualitative score.

The mean statistic (the sum of the answers for the question divided by the number of the questionnaires) was not used in order to avoid outlier effects and because almost none of the mean scores for the individual questions translated easily into qualitative scores. The mode statistic (the answer most frequently given) was not used due to the possibility that the performance of the department might be improperly assessed based upon a single nonrepresentative group of residents. For example, in using the mode statistic for a question where the total number of responses was 13 , and 5 people answered poor, but 4 people answered good and 4 answered very good, the majority of the people gave answers indicating that they were satisfied with the service, but the mode statistic would be translated into a score of poor, because that was the answer most frequently given.

A pilot survey was conducted at Roger Williams prior to the Authority wide survey. This survey was mailed to the entire population and its accuracy was assessed by a comparison between the returned surveys and the actual development population. While the Authority wide survey was distributed to a specified percentage of residents in each development, a similar examination for representativeness was conducted easily for each development with the demographic information provided concerning the actual and surveyed populations. Since the pilot survey at Roger Williams, additional questionnaires have been received and the figures for that development have been re-calculated.

It should be noted that there are slight variations between the surveys given to family development residents and the surveys distributed in the elderly/disabled developments. These variations were necessary due to differences in service programming. Copies of the surveys have been included at the end of this report. Tables providing a quick reference for survey result by departments can be found directly following the narrative of this section.

\section{Community Services Section}

The results for the Community Services section were very positive. The figures for the total of Providence Housing Authority residents indicate that residents were very satisfied with the level of services provided by this department. Of the fifteen questions asked in this section (this number includes questions asked in both the family and elderly/disabled developments) all received a median score that translated into a qualitative score of "Good" (9) or "Very Good" (6). It should be noted that one factor which might have effected this section was the existence of tenants' associations. It is possible that the existence of strong and responsive tenants' association might have skewed results in instances where tenants could not differentiate between services rendered by the tenants' association and those provided by the PHA

\section{Family Developments:}

The total responses for family developments indicated high levels of satisfaction for programs designed for youth and teens, but a significant level of dis-satisfaction for programs aimed at 
adults. In this section programs geared towards the over-all family development population or youth and teens all received qualitative scores of "Good" (5) and "Very Good" (4). However. programs aimed at adults (Job Training, Education for Adults, and Recreation for Adults) received qualitative scores of only "Fair." The question concerning overall services for adults did, however, receive a score of "Good."

An examination of the results from the individual family developments helps to pinpoint areas of concern. Admiral Terrace was the most positive of all family developments receiving only scores of "Good." Codding Court was also very positive. Eleven of the twelve questions received scores of "Good" (6) or Very Good" (5.) The one ranking of fair was for the question regarding job training services. Manton Heights also received eleven scores of either "Good" (4) or "Very Good" (7) with the question concerning recreation services for adults receiving the only score of "Fair." Chad Brown received four scores of "Fair", all for questions concerning services for adults. All other responses were positive including a very rare score of "excellent" for substance abuse prevention. The Hartford Park family survey also yielded results showing high leveis of satisfaction for youth and teen programs and low levels of satisfaction (four marks of "Fair") for programs targeting adults. However, the over-all score for adult services was "Good," and one of the "fair" rankings was for AIDS/STD education. By far, the development displaying the highest levels of dis-satisfaction was Roger Williams which gave low scores for all but one category (interestingly enough this was a score of "Good" for the question concerning over-all level of services for adults). All other services at Roger Williams received scores of "Fair" (4) or "Poor" (7).

\section{Elderiy/ Disabled Developments}

The total response from the elderly/disabled developments was very positive. Of the ten questions asked in this section, all received scores of either "Good" (7) or "Very Good" (3). By far the most positive response came from Dominica Manor. At Dominica, residents rated five services as "Excellent", four as "Very Good" and one as "Good." None of the ten services included in the survey received a negative score. Parenti Villa also received positive scores on all ten sections, six scores of "Very Good" and four of "Good." Carroll Tower residents scored all but one category as "Good" (4) or "Very Good" (5). The one category receiving a score of "Fair" concerned community room activities. Residents at Hartford Towers were satisfied with all services except recreation for adults and handicapped accessibility, each of which scored as "Fair."

In Dexter Manor, residents scored all but two categories as "Good." Job training and AIDS/STD education both received marks of "Fair." These services also received "Fair" marks from Kilmartin Plaza (along with Substance Abuse Prevention and Education for Adults.) All other services at Kilmartin received scores of "Good."

The lowest level of satisfaction for elderly/disabled tenants was displayed in the results of Sunset Village. Of the ten sections in the survey, six received qualitative scores of "Poor" and one of "Fair". Handicapped accessibility and access to medical care received scores of "Very Good," and the question concerning over-all levels of service received a score of "Good."

\section{Programs and Services}

The elderly/disabled developments ranked all but two categories positively. The two areas of concern, categories in which three or more developments scored the program or service negatively, were job training and AIDS/STD education.

The results from the family developments were also positive. Programs for youth scored especially high. The three areas of concern were all programs targeting adults. These categories were job training, education for adults, and recreation for adults. 


\section{Facilities Management}

The Authority wide results for this section were positive. Of the thirteen questions (including questions asked in both the family and elderly/disabled development surveys), eleven received an Authority wide qualitative score of "Good." However, two other categories, quality of painting and pest and rodent control received scores of "Fair."

Family Developments:

The results for the total family developments were less positive than the Authority-wide results While eight of the thirteen categories received a score of "Good," five: quality of painting. pest and rodent control, snow removal, graffiti prevention and removal, and laundry services received ratings of "Fair."

Of the family developments. Admiral Terrace residents were the most satisfied. Out of the thirteen categories on the survey, they rated twelve as "Good" with only pest and rodent control receiving a score of "Fair." Codding Court received "Good" scores on six categories with the remaining seven receiving a score of "Fair." Chad Brown received "Good" scores in seven categories, but also received ratings of "Fair" on four categories and "Poor on two others. Manton Heights and the Hartford Park Family units rated four categories as "Fair" and the remaining as "Good." Finally, Roger Williams residents rated eight categories as "Good", three as "Fair" and two as "Poor."

\section{Elderly/Disabled Developments:}

The total score for the elderly/disabled developments was quite good. Only one category, pest and rodent control, received a score of "Fair." The remaining eleven received qualitative scores of "Good." Carroll Tower and Parenti Villa both received "Good" scores on eight categories and scores of "Very Good" for the remaining four. Hartford Tower received three "Very Good" scores, Kilmartin Plaza received two "Very Good" scores and Dominica received one. The remaining categories in those three developments all received scores of "Good."

Dexter Manor received a score of "Good" on eight categories and "Very Good" on two more. Quality of painting and pest and rodent control, however, both received scores of "Fair." The Sunset Village results indicated the lowest level of satisfaction among the Elderly/Disabled developments. While utilities scored "Very Good" and snow removal and graffiti removal and prevention were ranked "Good," eight of the remaining nine categories were rated "Fair" with the ninth receiving a score of "Poor."

\section{Programs and Services}

In the elderly/disabled developments all categories scored well. With the exception of Sunset Village, which is clearly a trouble spot that needs attention, the only negative marks for the Facilities Management section were from Dexter Manor where the quality of painting and pest and rodent control were perceived as problems.

In the family developments overall service; maintenance and upkeep of grounds, buildings and hallways; utilities; response to work orders; and trash removal all scored well. Trouble spots included categories in which three or more developments scored the programs or service negatively. These included: quality of painting, pest and rodent control, graffiti removal and prevention, snow removal, laundry services, and play areas.

\section{Summary of the Management Section}

The results for the management section of the 1995 resident survey were positive when viewed Authority wide. All eight questions received a qualitative score of "Good" when figures were compiled for all residents. 
Family Developments:

While the overall scores for the Management Department were positive, the scores in the family developments were less encouraging. Total family development scores ranked five categories, including overall service as "Fair." The three categories receiving overall scores of "Good" in the family developments were fairness in rent collections, explanations of PHA rules, and annual inspections.

Codding Court was the bright exception in the family developments. This development gave all eight categories a score of "Good." The Hartford Park (family) development also displayed a relatively high level of satisfaction. Six of the eight sections received a score of "Good", with quickness of response and explanations of PHA rules both receiving scores of "Fair." Roger Williams residents listed overall service, follow-up of resident concerns, and concern for resident's well being as "Fair" with the remaining five categories receiving scores of "Good."

Chad Brown, Admiral Terrace, and Manton Heights were the developments of concern in this section. All three ranked overall service, quickness of response, follow up of resident concerns, and level of communication as "Fair." Further, two of the three scored concern for resident's well being as "Fair." On a more positive note, two of the three developments scored fairness in rent collections, explanations of rules, and annual inspections as "Good."

Elderly/Disabled Developments:

The response from the elderly/disabled developments was more positive than that of the family developments. Consistent with the scores for the total PHA figures, the Management Department received a score of "Good" for all eight categories. Holding to this pattern, Dexter Manor, Kilmartin Plaza, and Dominica Manor each rated all eight sections as "Good."

Carroll Tower and Parenti Villa gave even higher scores. The residents at both Carroll and Parenti scored six categories as "Good" and two as "Very Good." Both scored annual inspections as very good, and Carroll residents scored fairness in rent collections as "Very Good" while at Parenti overall service scored a "Very Good" rating.

Residents at Hartford Tower rated seven of the eight categories as "Good" with concern for residents well being scoring the only "Fair" in that development. Sunset Village was the only elderly/disabled development with troubling survey results for this section. While half of the categories did receive a rating of "Good," overall service, explanations of rules, and concern for residents' well being received scores of "Fair" and annual inspections received a rating of "Poor."

\section{Programs and Services}

All categories received high scores in the elderly/disabled developments. Sunset Village scored four sections negatively, but other than that development, the only other negative ranking was a score of "Fair" for concern for resident's well being at Hartford Tower. The results from the Family developments, however, point to several trouble spots. Fairness in rent collection and explanations of PHA rules scored well, but five categories scored poorly, receiving negative ratings from three or more developments. These categories were overall service, quickness of response, follow-up of resident concerns, concern for residents' well being, and levels of communication.

\section{Summary of the Security Section}

The Authority-wide results for the Security section were disappointing. While the question concerning police response time to calls elicited an over-all score of "Good," both the question referring to over-all security and the question referring to the level of concern showed by police received scores of "Fair." In this section, however, the over-all score is insufficient to describe the survey results. The results varied greatly between the family and elderly/disabled developments. 
Further, statistical analysis of the family developments, which scored low (no family development rated a single question positively) shows that respondents who have lived in PHA housing for shorter periods of time rated security more favorably than residents who have lived at the PHA for longer periods of time. With the exception of some high negative scores from residents who have lived in PHA housing for a period of one to three years, the pattern is consistent

One possible explanation for this trend has to do with perception. This survey measures residents opinions about services and programs, but does not measure things such as the actual police response time to calls. In recent years security at the PHA has been a focus of concern. In order to better protect residents the PHA has increased manpower, patrols, and the number of police reserves operating in the high-rises. A computerized data entry and information system has also helped to boost security. It is possible that these increased security measures, while noticed by newer residents, have yet to be felt by residents whose perceptions were formed before these improvements were implemented.

While this trend also exists in the elderly/disabled developments, the over-all ratings for these developments were much more encouraging. The three questions already mentioned, over-all security, police response time to calls, and the level of concern shown by police were all rated as "Good." An additional question concerning the effectiveness of PHA security guards was also rated as "Good."

\section{Areas of Concern:}

Regardless of the trend concerning length of time in PHA housing, the negative ratings for the family developments is clearly an area of concern. This is true for all categories in all family developments. In the case of the elderly/disabled developments, Sunset Village (contiguous with Chad Brown and Admiral Terrace) and Dominica Manor are also areas of concern. The results for Dominica Manor were particularly surprising given the level of increased efforts at that development. It should be noted that the disappointing results at Dominica Manor were not consistent with the results of the 1995 Comprehensive Social Service Needs Assessment completed in October 1995.

\section{Tenants' Associations}

The Tenants' Associations operating in the Providence Housing Authority's developments exist to serve as advocates and service providers for our residents. Over-all, the results of the survey were mixed. All three questions were scored as "Fair" for the over-all family developments. The over-all elderly/disabled development scores were "Good" for all three questions. While Hartford Tower and Kilmartin Plaza scored "Poor" for all three questions, these developments do not currently have tenants' associations. Parenti Villa is also without an official tenants' association, although a score of "Good" for over-all effectiveness was given. Of particular concern in the family developments were Chad Brown, Manton Heights, Roger Williams (all scored "Fair" for all three questions), and Hartford Park which scored two "Fairs" and a "Poor".

Chad Brown, Admiral Terrace, and Sunset Village not only share the same location (the three developments are contiguous), they also share the same tenants' association. That does not, however, mean that residents in these developments feel the same way about the performance of their tenants' association. Chad Brown rated all three categories of this section as "Fair" while Admiral Terrace ranked each question as "Good" and Sunset Village scored as "Very Good" for all three sections. Sunset Village is an elderly/disabled development consisting of 24 units.

With the process for the creation of official tenants' associations underway at the high-rises, Hartford Tower, Kilmartin Plaza and Parenti Villa should all see improvements in resident satisfaction. At the family developments, Chad Brown, Manton Heights, Hartford Park and Roger Williams are clearly the next areas for improvements. HUD has recently promulgated rules requiring the certification of tenants' associations at each development. The regulations require 
impartial, third party supervised, regularly held elections. Any tenants' association not complying with HUD's requirements will not be eligible for resident service funds. As the re-certification process nears completion, new elections will give residents the opportunity to affect change at their developments.

EXTERNAL ENVIRONMENTAL ANALYSIS:

CONVENTIONAL DEVELOPMENT SURVEY RESULTS:

The tables on the following pages have been included in order to provide a quick reference. They illustrate the results of the survey of conventional development residents. These charts are organized by department. There are separate charts for the results of the elderly/disabled and the family developments, and each chart contains a listing of all questions asked in the surveys. 
PROVIDENCE HOUSING AUTHORITY STRATEGIC PLAN 2000

RESIDENT SURVEY RESULTS

FAMILY DEVELOPMENTS

FACILITIES MANAGEMENT SECTION

\begin{tabular}{|c|c|c|c|c|c|c|c|c|}
\hline Service & Total PHA & $\begin{array}{l}\text { Total } \\
\text { Family } \\
\end{array}$ & $\begin{array}{c}\text { Codding } \\
\text { Court }\end{array}$ & Chad Brown & $\begin{array}{l}\text { Admiral } \\
\text { Terrace } \\
\end{array}$ & $\begin{array}{l}\text { Manton } \\
\text { Heights }\end{array}$ & $\begin{array}{l}\text { Hartford } \\
\text { Park }\end{array}$ & $\begin{array}{l}\text { Roger } \\
\text { Williams }\end{array}$ \\
\hline Overall Service & Good & Good & Good & Good & Good & Good & Good & Good \\
\hline $\begin{array}{l}\text { Maintenance and } \\
\text { Upkeep: Building }\end{array}$ & Good & Good & Good & Fair & Good & Good & Good & Good \\
\hline $\begin{array}{l}\text { Maintenance and } \\
\text { Upkeep: Grounds }\end{array}$ & Good & Good & Good & Fair & Good & Good & Good & Good \\
\hline $\begin{array}{l}\text { Maintenance of } \\
\text { Hallways }\end{array}$ & Good & Good & Good & Good & Good & Fair & Fair & Good \\
\hline Utilities & Good & Good & Good & Good & Good & Good & Good & Good \\
\hline $\begin{array}{l}\text { Response to Work } \\
\text { Orders }\end{array}$ & Good & Good & Good & Good & Good & Good & Good & Good \\
\hline Quality of Painting & Fair & Fair & Fair & Poor & Good & Fair & Good & Fair \\
\hline $\begin{array}{l}\text { Pest and Rodent } \\
\text { Control }\end{array}$ & Fair & Fair & Fair & Poor & Fair & Good & Fair & Poor \\
\hline Snow Removal & Good & Fair & Fair & Fair & Good & Fair & Good & Fair \\
\hline $\begin{array}{l}\text { Graffiti Removal/ } \\
\text { Prevention }\end{array}$ & Good & Fair & Fair & Good & Good & Good & Fair & Fair \\
\hline Trash Removal & Good & Good & Fair & Good & Good & Good & Very Good & Good \\
\hline Laundry & Good & Fair & Fair & Good & Good & Fair & Fair & Good \\
\hline Play Areas & Good & Good & Fair & Fair & Good & Good & Good & Poor \\
\hline
\end{tabular}


13. Immigration, immigration reform (2)

14. Ethnocentrism, lack of socio-economic mixture (2)

15. Drug enforcement, substance abuse (2)

16. Medicare waivers and move towards assisted living (1)

17. Rise in unemployment (1)

18. Major social institutions such as public schools need to change (1)

19. Alcohol lobby (1)

20. Number of applications and current demand for public housing (1)

21. Lowering the standard to fill elderly housing demand (1)

22. Broad range of income for the working poor (1)

23. Davis Bacon wages (1)

24. Lack of adequate staff (1)

25. Getting rid of GPA (1)

26. Rise in number of low-income families (1)

27. Tax payers attitudes about the PHA and programs for the poor (1)

28. Court's view that public housing is the housing of last resort (1)

The number in parenthesis indicates the number of PHA strategic planning teams which gave each response. Eight teams participated in the Internal Stakeholder Analysis.

\section{SECTION FOUR: STRATEGIC ISSUES}

A strategic issue is defined as a fundamental policy choice affecting an organization's mandates mission, values, service level, cost, financing, organization and management. ${ }^{16}$ Ultimately, strategic issues will be determined through a thorough analysis of both the internal stakeholder analysis (including the internal and external environmental scans) and the external stakeholder analysis and the resident survey.

The planning teams identified funding cuts, the rise in crime, the rise in low-income families, changing demographics (leading to increasing numbers of elderly) and the deterioration of the family as strategic issues. Strategies suggested included the increased exploration for possible funding sources, greater collaboration with other agencies and the education and involvement of political decision makers in public housing issues.

The practical alternatives listed by multiple departments were fiscal discipline, which was listed by three departments, and greater collaboration with other agencies which was listed by two departments. Consistent with the SWOT section answers, economic reality and political and regulatory constraints were listed as barriers which would prevent the PHA from addressing important issues. Increased searches for funding and better education of legislators were offered as proposals that might overcome these barriers. Also suggested was the creation of a five year strategic plan.

\section{Strategic Issues as Perceived by the Departmental Planning Teams}

1. Increased security leading to fewer gangs and less lawlessness (5)

2. Funding cuts (5)

3. Changing populations leading to increasing populations of elderly (2)

4. Deterioration of the family, obtaining more housing for people (2)

5. Rise in the number of low income families (2)

6. Aging properties (1)

7. Deteriorating neighborhoods (1)

8. Middle class leaving the city (1)

9. Frailty leading to congregate housing and assisted living (1)

10. Physical improvements to high-rises to increase marketability (1) 
PROVIDENCE HOUSING AUTHORITY STRATEGIC PLAN 2000

RESIDENT SURVEY RESULTS

ELDERLYIDISABLED DEVELOPMENTS

FACILITIES MANAGEMENT SECTION

\begin{tabular}{|c|c|c|c|c|c|c|c|c|c|}
\hline Service & Total PHA & $\begin{array}{c}\text { Total } \\
\text { Elderly/ } \\
\text { Disabled }\end{array}$ & $\begin{array}{l}\text { Dexter } \\
\text { Manor }\end{array}$ & $\begin{array}{l}\text { Hartford } \\
\text { Tower }\end{array}$ & $\begin{array}{l}\text { Carroll } \\
\text { Tower }\end{array}$ & $\begin{array}{l}\text { Kilmartin } \\
\text { Plaza }\end{array}$ & $\begin{array}{l}\text { Parenti } \\
\text { Villa }\end{array}$ & $\begin{array}{l}\text { Sunset } \\
\text { Village }\end{array}$ & $\begin{array}{l}\text { Dominica } \\
\text { Manor }\end{array}$ \\
\hline Overall Service & Good & Good & Good & Good & Good & Good & Good & Fair & Good \\
\hline $\begin{array}{l}\text { Maintenance and } \\
\text { Upkeep: Building }\end{array}$ & Good & Good & Good & $\begin{array}{l}\text { Very } \\
\text { Good }\end{array}$ & $\begin{array}{l}\text { Very } \\
\text { Good }\end{array}$ & $\begin{array}{l}\text { Very } \\
\text { Good }\end{array}$ & Very Good & Fair & Good \\
\hline $\begin{array}{l}\text { Maintenance and } \\
\text { Upkeep: Grounds }\end{array}$ & Good & Good & Good & $\begin{array}{l}\text { Very } \\
\text { Good }\end{array}$ & $\begin{array}{l}\text { Very } \\
\text { Good }\end{array}$ & Good & Good & Fair & Good \\
\hline $\begin{array}{l}\text { Maintenance of } \\
\text { Hallways }\end{array}$ & Good & Good & $\begin{array}{l}\text { Very } \\
\text { Good }\end{array}$ & $\begin{array}{l}\text { Very } \\
\text { Good }\end{array}$ & Good & Good & Good & Fair & Good \\
\hline Utilities & Good & Good & Good & Good & $\begin{array}{l}\text { Very } \\
\text { Good }\end{array}$ & Good & Very Good & Very Good & Good \\
\hline $\begin{array}{l}\text { Response to Work } \\
\text { Orders }\end{array}$ & Good & Good & Good & Good & $\begin{array}{l}\text { Very } \\
\text { Good }\end{array}$ & Good & Good & Fair & Good \\
\hline Quality of Painting & Fair & Good & Fair & Good & Good & Good & Good & Poor & Good \\
\hline $\begin{array}{l}\text { Pest and Rodent } \\
\text { Control }\end{array}$ & Fair & Fair & Fair & Good & Good & Good & Good & Fair & Good \\
\hline Snow Removal & Good & Good & Good & Good & Good & Good & Very Good & Good & Good \\
\hline $\begin{array}{l}\text { Graffiti Removall } \\
\text { Prevention }\end{array}$ & Good & Good & Good & Good & Good & $\begin{array}{l}\text { Very } \\
\text { Good }\end{array}$ & Very Good & Good & Good \\
\hline Trash Removal & Good & Good & Good & Good & Good & Good & Good & Fair & Good \\
\hline Laundry & Good & Good & $\begin{array}{l}\text { Very } \\
\text { Good }\end{array}$ & Good & Good & Good & Good & Poor & $\begin{array}{l}\text { Very } \\
\text { Good }\end{array}$ \\
\hline
\end{tabular}


PROVIDENCE HOUSING AUTHORITY STRATEGIC PLAN 2000 ,

RESIDENT SURVEY RESULTS

FAMILY DEVELOPMENTS

COMMUNITY SERVICES SECTION

\begin{tabular}{|c|c|c|c|c|c|c|c|c|}
\hline Service & Total PHA & $\begin{array}{l}\text { Total } \\
\text { Family }\end{array}$ & $\begin{array}{l}\text { Codding } \\
\text { Court }\end{array}$ & $\begin{array}{l}\text { Chad } \\
\text { Brown }\end{array}$ & $\begin{array}{l}\text { Admiral } \\
\text { Terrace }\end{array}$ & $\begin{array}{l}\text { Manton } \\
\text { Heights }\end{array}$ & $\begin{array}{l}\text { Hartford } \\
\text { Park. }\end{array}$ & $\begin{array}{l}\text { Roger } \\
\text { Willams }\end{array}$ \\
\hline Overall Service & Very Good & Good & Good & Good & Good & Very Good & Very Good & Fair \\
\hline Overall Service: Adults & Good & Good & Very Good & Fair & Good & Good & Good & Good \\
\hline Overall Service: Youth & Very Good & Very Good & Very Good & Good & Good & Very Good & Very Good & Poor \\
\hline Job Training & Good & Fair & Fair & Fair & Good & Good & Fair & Poor \\
\hline Education: Adults & Good & Fair & Good & Fair & Good & Good & Fair & Fair \\
\hline AlDSISTD Education & Good & Good & Good & Good & Good & Good & Fair & Poor \\
\hline Substance Abuse Prevention & Good & Good & Very Good & Excellent & Good & Very Good & Very Good & Poor \\
\hline Recreation: Adults & Good & Fair & Good & Fair & Good & Fair & Fair & Poor \\
\hline Recreation: Youth & Very Good & Very Good & Very Good & Good & Good & Very Good & Very Good & Fair \\
\hline Youth Sports & Very Good & Very Good & Very Good & Good & Good & Very Good & Very Good & Fair \\
\hline Teen Pregnancy Prevention & Good & Good & Good & Good & Good & Very Good & Very Good & Poor \\
\hline Education: Youth & Very Good & Very Good & Good & Very Good & Good & Very Good & Very Good & Poor \\
\hline
\end{tabular}


PROVIDENCE HOUSING AUTHORITY STRATEGIC PLAN 2000

RESIDENT SURVEY RESULTS

ELDERLYIDISABLED DEVELOPMENTS COMMUNITY SERVICES SECTION

\begin{tabular}{|c|c|c|c|c|c|c|c|c|c|}
\hline Service & Total PHA & $\begin{array}{c}\text { Total } \\
\text { Elderly } \\
\text { Disabled }\end{array}$ & $\begin{array}{l}\text { Dexter } \\
\text { Manor }\end{array}$ & $\begin{array}{l}\text { Hartford } \\
\text { Tower }\end{array}$ & $\begin{array}{l}\text { Carroll } \\
\text { Tower }\end{array}$ & $\begin{array}{c}\text { Kilmartin } \\
\text { Plaza }\end{array}$ & $\begin{array}{l}\text { Parenti } \\
\text { Villa }\end{array}$ & $\begin{array}{l}\text { Sunset } \\
\text { Village }\end{array}$ & $\begin{array}{l}\text { Dominica } \\
\text { Manor }\end{array}$ \\
\hline Overall Service & $\begin{array}{l}\text { Very } \\
\text { Good }\end{array}$ & $\begin{array}{l}\text { Very } \\
\text { Good }\end{array}$ & Good & $\begin{array}{l}\text { Very } \\
\text { Good }\end{array}$ & $\begin{array}{l}\text { Very } \\
\text { Good }\end{array}$ & Good & $\begin{array}{l}\text { Very } \\
\text { Good }\end{array}$ & Good & Very Good \\
\hline Overall Service: Adults & Good & $\begin{array}{l}\text { Very } \\
\text { Good }\end{array}$ & Good & $\begin{array}{l}\text { Very } \\
\text { Good }\end{array}$ & $\begin{array}{l}\text { Very } \\
\text { Good }\end{array}$ & Good & Good & Fair & Excellent \\
\hline $\begin{array}{l}\text { Community Room } \\
\text { Activities }\end{array}$ & Good & Good & Good & Good & Fair & Good & Good & Poor & Excellent \\
\hline Job Training & Good & Good & Fair & Good & Good & Fair & $\begin{array}{l}\text { Very } \\
\text { Good }\end{array}$ & Poor & Excellent \\
\hline Education: Adults & Good & Good & Good & Good & Good & Fair & $\begin{array}{l}\text { Very } \\
\text { Good }\end{array}$ & Poor & Very Good \\
\hline AIDSISTD Education & Good & Good & Fair & Good & Good & Fair & $\begin{array}{l}\text { Very } \\
\text { Good }\end{array}$ & Poor & Good \\
\hline $\begin{array}{l}\text { Substance Abuse } \\
\text { Prevention }\end{array}$ & Good & Good & Good & Good & $\begin{array}{l}\text { Very } \\
\text { Good }\end{array}$ & Fair & $\begin{array}{l}\text { Very } \\
\text { Good }\end{array}$ & Poor & Very Good \\
\hline $\begin{array}{l}\text { Handicapped } \\
\text { Accessibility }\end{array}$ & Good & Good & Good & Fair & $\begin{array}{l}\text { Very } \\
\text { Good }\end{array}$ & Good & Good & Very Good & Very Good \\
\hline Access to Medical Care & $\begin{array}{l}\text { Very } \\
\text { Good }\end{array}$ & $\begin{array}{l}\text { Very } \\
\text { Good }\end{array}$ & Good & Good & $\begin{array}{l}\text { Very } \\
\text { Good }\end{array}$ & Good & $\begin{array}{l}\text { Very } \\
\text { Good }\end{array}$ & Very Good & Excellent \\
\hline
\end{tabular}


PROVIDENCE HOUSING AUTHORITY STRATEGIC PLAN 2000

RESIDENT SURVEY RESULTS

FAMILY DEVELOPMENTS

MANAGEMENT SECTION

\begin{tabular}{|c|c|c|c|c|c|c|c|c|}
\hline Service & Total PHA & $\begin{array}{l}\text { Total } \\
\text { Family }\end{array}$ & $\begin{array}{l}\text { Codding } \\
\text { Court }\end{array}$ & $\begin{array}{l}\text { Chad } \\
\text { Brown }\end{array}$ & $\begin{array}{l}\text { Admiral } \\
\text { Terrace }\end{array}$ & $\begin{array}{l}\text { Manton } \\
\text { Heights }\end{array}$ & $\begin{array}{l}\text { Hartford } \\
\text { Park }\end{array}$ & $\begin{array}{l}\text { Roger } \\
\text { Williams }\end{array}$ \\
\hline Overall Service & Good & Fair & Good & Fair & Fair & Fair & Good & Fair \\
\hline Quickness of Response & Good & Fair & Good & Fair & Fair & Fair & Fair & Good \\
\hline $\begin{array}{l}\text { Follow Up of Resident } \\
\text { Concems }\end{array}$ & Good & Fair & Good & Fair & Fair & Fair & Good & Fair \\
\hline $\begin{array}{l}\text { Fairness in Rent } \\
\text { Collections }\end{array}$ & Good & Good & Good & Fair & Good & Good & Good & Good \\
\hline Explanations of Rules & Good & Good & Good & Good & Good & Fair & Fair & Good \\
\hline Annual Inspections & Good & Good & Good & Good & Fair & Good & Good & Good \\
\hline $\begin{array}{l}\text { Concem for Well Being of } \\
\text { Residents }\end{array}$ & Good & Fair & Good & Fair & Good & Fair & Good & Fair \\
\hline Level of Communication & Good & Fair & Good & Fair & Fair & Fair & Good & Good \\
\hline
\end{tabular}


PROVIDENCE HOUSING AUTHORITY STRATEGIC PLAN 2000

RESIDENT SURVEY RESULTS

ELDERLYIDISABLED DEVELOPMENTS

MANAGEMENT SECTION

\begin{tabular}{|c|c|c|c|c|c|c|c|c|c|}
\hline Service & Total PHA & $\begin{array}{c}\text { Total } \\
\text { Elderlyl } \\
\text { Disabled }\end{array}$ & $\begin{array}{l}\text { Dexter } \\
\text { Manor }\end{array}$ & $\begin{array}{l}\text { Hartford } \\
\text { Tower }\end{array}$ & $\begin{array}{l}\text { Carroll } \\
\text { Tower }\end{array}$ & $\begin{array}{l}\text { Kilmartin } \\
\text { Plaza }\end{array}$ & $\begin{array}{l}\text { Parenti } \\
\text { Villa }\end{array}$ & $\begin{array}{l}\text { Sunset } \\
\text { Village }\end{array}$ & $\begin{array}{l}\text { Dominica } \\
\text { Manor }\end{array}$ \\
\hline Overall Service & Good & Good & Good & Good & Good & Good & $\begin{array}{l}\text { Very } \\
\text { Good }\end{array}$ & Fair & Good \\
\hline Quickness of Response & Good & Good & Good & Good & Good & Good & Good & Good & Good \\
\hline $\begin{array}{l}\text { Foliow Up of Resident } \\
\text { Concerns }\end{array}$ & Good & Good & Good & Good & Good & Good & Good & Good & Good \\
\hline $\begin{array}{l}\text { Fairness in Rent } \\
\text { Collections }\end{array}$ & Good & Good & Good & Good & $\begin{array}{l}\text { Very } \\
\text { Good }\end{array}$ & Good & Good & Good & Good \\
\hline Explanations of Rules & Good & Good & Good & Good & Good & Good & Good & Fair & Good \\
\hline Annual Inspections & Good & Good & Good & Good & $\begin{array}{l}\text { Very } \\
\text { Good }\end{array}$ & Good & $\begin{array}{l}\text { Very } \\
\text { Good }\end{array}$ & Poor & Good \\
\hline $\begin{array}{l}\text { Concern for Well Being of } \\
\text { Residents }\end{array}$ & Good & Good & Good & Fair & Good & Good & Good & Fair & Good \\
\hline Level of Communication & Good & Good & Good & Good & Good & Good & Good & Good & Good \\
\hline
\end{tabular}


PROVIDENCE HOUSING AUTHORITY STRATEGIC PLAN 2000

RESIDENT SURVEY RESULTS

FAMILY DEVELOPMENTS

SECURITY SECTION

\begin{tabular}{|c|c|c|c|c|c|c|c|c|}
\hline Service & Total PHA & $\begin{array}{l}\text { Total } \\
\text { Family } \\
\end{array}$ & $\begin{array}{l}\text { Codding } \\
\text { Court }\end{array}$ & $\begin{array}{l}\text { Chad } \\
\text { Brown } \\
\end{array}$ & $\begin{array}{l}\text { Admiral } \\
\text { Terrace } \\
\end{array}$ & $\begin{array}{l}\text { Manton } \\
\text { Heights } \\
\end{array}$ & $\begin{array}{l}\text { Hartford } \\
\text { Park } \\
\end{array}$ & $\begin{array}{c}\text { Roger } \\
\text { Williams } \\
\end{array}$ \\
\hline Overall Security & Fair & Fair & Fair & Fair & Fair & Fair & Fair & Poor \\
\hline $\begin{array}{l}\text { Police Response Time to } \\
\text { Calls }\end{array}$ & Good & Fair & Fair & Fair & Fair & Fair & Fair & Poor \\
\hline $\begin{array}{l}\text { Level of Concern Shown by } \\
\text { Police }\end{array}$ & Fair & Fair & Fair & Poor & Poor & Fair & Fair & Poor \\
\hline
\end{tabular}

RESIDENT SURVEY RESULTS

ELDERLYIDISABLED DEVELOPMENTS

SECURITY SECTION

\begin{tabular}{|c|c|c|c|c|c|c|c|c|c|}
\hline Service & Total PHA & $\begin{array}{c}\text { Total } \\
\text { Elderlyl } \\
\text { Disabled }\end{array}$ & $\begin{array}{l}\text { Dexter } \\
\text { Manor }\end{array}$ & $\begin{array}{l}\text { Hartford } \\
\text { Tower }\end{array}$ & $\begin{array}{l}\text { Carroll } \\
\text { Tower }\end{array}$ & $\begin{array}{l}\text { Kilmartin } \\
\text { Plaza }\end{array}$ & $\begin{array}{l}\text { Parenti } \\
\text { Villa }\end{array}$ & $\begin{array}{l}\text { Sunset } \\
\text { Village }\end{array}$ & $\begin{array}{l}\text { Dominica } \\
\text { Manor }\end{array}$ \\
\hline Overall Security & Fair & Good & Good & Good & $\overline{\text { Good }}$ & Good & Good & Poor & Fair \\
\hline $\begin{array}{l}\text { Police Response Time to } \\
\text { Calls }\end{array}$ & Good & Good & Good & Good & Good & Good & Good & Poor & Fair \\
\hline $\begin{array}{l}\text { Level of Concern Shown by } \\
\text { Police }\end{array}$ & Fair & Good & Good & Good & Good & Good & Good & Poor & Fair \\
\hline $\begin{array}{l}\text { Effectiveness of PHA } \\
\text { Security Guards }\end{array}$ & Good & Good & Good & Good & Good & Good & Good & Poor & Fair \\
\hline
\end{tabular}


PROVIDENCE HOUSING AUTHORITY STRATEGIC PLAN 2000

RESIDENT SURVEY RESULTS

FAMILY DEVELOPMENTS

TENANTS' ASSOCIATIONS

\begin{tabular}{|l|c|c|c|c|c|c|c|c|}
\hline \multicolumn{1}{|c|}{ Service } & Total PHA & $\begin{array}{c}\text { Total } \\
\text { Family }\end{array}$ & $\begin{array}{c}\text { Codding } \\
\text { Court }\end{array}$ & $\begin{array}{c}\text { Chad } \\
\text { Brown }\end{array}$ & $\begin{array}{c}\text { Admiral } \\
\text { Terrace }\end{array}$ & $\begin{array}{c}\text { Manton } \\
\text { Heights }\end{array}$ & $\begin{array}{c}\text { Hartford } \\
\text { Park }\end{array}$ & $\begin{array}{c}\text { Roger } \\
\text { Williams }\end{array}$ \\
\hline Overall Effectiveness & Good & Fair & Good & Fair & Good & Fair & Fair & Fair \\
\hline $\begin{array}{l}\text { Representation of Tenant } \\
\text { Concerns }\end{array}$ & Good & Fair & Fair & Fair & Good & Fair & Fair & Fair \\
\hline Level of Communication & Good & Fair & Good & Fair & Good & Fair & Poor & Fair \\
\hline
\end{tabular}

RESIDENT SURVEY RESULTS

ELDERLYIDISABLED DEVELOPMENTS

TENANTS' ASSOCIATIONS

\begin{tabular}{|l|c|c|c|c|c|c|c|c|c|}
\hline \multicolumn{1}{|c|}{ Service } & Total PHA & $\begin{array}{c}\text { Total } \\
\text { Elderly/ } \\
\text { Disabled }\end{array}$ & $\begin{array}{c}\text { Dexter } \\
\text { Manor }\end{array}$ & $\begin{array}{c}\text { Hartford } \\
\text { Tower }\end{array}$ & $\begin{array}{c}\text { Carroll } \\
\text { Tower }\end{array}$ & $\begin{array}{c}\text { Kilmartin } \\
\text { Plaza }\end{array}$ & $\begin{array}{c}\text { Parenti } \\
\text { Villa }\end{array}$ & $\begin{array}{c}\text { Sunset } \\
\text { Village }\end{array}$ & $\begin{array}{c}\text { Dominica } \\
\text { Manor }\end{array}$ \\
\hline Overall Effectiveness & Good & Good & $\begin{array}{c}\text { Very } \\
\text { Good }\end{array}$ & Poor & Good & Poor & Good & $\begin{array}{l}\text { Very } \\
\text { Good }\end{array}$ & Fair \\
\hline $\begin{array}{l}\text { Representation of Tenant } \\
\text { Concerns }\end{array}$ & Good & Good & $\begin{array}{c}\text { Very } \\
\text { Good }\end{array}$ & Poor & Good & Poor & Fair & $\begin{array}{c}\text { Very } \\
\text { Good }\end{array}$ & Fair \\
\hline \begin{tabular}{l} 
Level of Communication \\
\hline
\end{tabular} & Good & Good & $\begin{array}{c}\text { Very } \\
\text { Good }\end{array}$ & Poor & Good & Poor & Fair & $\begin{array}{c}\text { Very } \\
\text { Good }\end{array}$ & Fair \\
\hline
\end{tabular}


EXTERNAL ENVIRONMENTAL ANALYSIS

SCATTERED SITE SURVEY RESULTS

\section{Introduction and Methodology}

This survey was divided into two major sections. The first section was based upon three Providence Housing Authority departments (management, maintenance, and security). A series of questions asked residents to rank their level of satisfaction with various services provided by these departments. As was done in the conventional development surveys, the results were then calculated using the number of responses (Poor, Fair, Good, Very Good, Excellent) for each question. These qualitative statistics were each assigned a numerical value from one (1) to five (5) with one representing a poor performance rating and five an excellent rating

In the following analysis, the median of the numerical statistic was calculated. The median score (a numerical value) was then translated into an overall qualitative score (Poor, Fair, Good, Very Good, Excellent). While it is somewhat unconventional to use a median statistic for this type of sample, the analysis works because the qualitative rankings are based upon a consistent continuum of values. The median measures the number at which half of respondents ranked the departments performance of the service higher and half ranked the performance worse. At times the numerical median value contained the fraction .5. When this occurred the fraction was rounded upwards to a numerical value that could be translated into a qualitative score.

The mean statistic (the sum of the answers for the question divided by the number of the questionnaires) was not used in order to avoid outlier effects and because almost none of the mean scores for the individual questions translated into qualitative scores. The mode statistic (the answer most frequently given) was not used due to the possibility that the performance of the department might be improperly assessed based upon a single non-representative group of residents. For example, in using the mode statistic for a question where the total number of responses was 13, and 5 people answered poor, but 4 people answered good and 4 answered very good, the majority of the people gave answers indicating that they were satisfied with the service, but the mode statistic would be translated into a score of poor, because that was the answer most frequently given.

The second section consisted of open ended questions. These questions were designed to elicit responses concerning the degree to which residents feel they "fit in" with their neighborhoods. Questions asked residents about their participation in community events, their relationships with their neighbors and their need for services.

A demographic section was also included in the survey. A copy of this survey has been included as an appendix to this report. Of the 44 Scattered Site surveys sent out, 14 were returned. Percentages used in the analysis are based upon the percentage of those answering the individual questions, and not the total number of responses.

Over-all, most of the respondents seemed satisfied with the conditions in their scattered site homes. All three departments: management, maintenance and security, scored well. Residents generally seem to feel that scattered site units feel more like a home and provide them with more independence than conventional developments. Almost all of the respondents indicated that they feel weicome in their neighborhoods and that they do not plan to leave in the near future, and most seem to feel that the PHA provides an adequate level of services. 


\section{SECTION ONE: PHA DEPARTMENTS}

\section{Management}

The results of the management section were very positive. All of the eight services or programs that were included in the questions received a score of "good", "very good" or "excellent". Further, not a single question received a response of "poor." Residents rated both the explanations of PHA rules and the level of communications as "excellent." The one area of concern regarded the follow up of residents' concerns. While still receiving a rating of "good." this service was also rated as "fair" by three residents

\section{Maintenance}

The maintenance section was also very encouraging. All seven services and programs included in the questionnaire received positive ratings, including a rating of "excellent" for utilities. Pest and rodent control and the quality of home painting also received high scores with five $(42 \%)$ responses rating each as "excellent." Further, five of the seven services and programs received scores of "very good." Lawn care was the only real area of concern. While receiving a score of "good," this service also received several negative ratings from residents. One (8\%) scored the lawn care as "poor" and three $(25 \%)$ rated it as "fair."

\section{Security}

The security section was also encouraging. While the results for the security section in the survey of conventional family developments were disappointing (the results of the elderly/disabled developments were excellent), both the police response time to calls and the level of concern shown by police received scores of "very good" here. Over-all security received a rating of "good", and for all three questions, three $(30 \%)$ respondents gave ratings of "excellent". One resident wrote a note next to the question about the level of concern shown by police stating that there are problems with drug dealers near her home.

\section{SECTION TWO: OPEN-ENDED QUESTIONS}

The first three questions from this section asked scattered site residents how long they have lived in scattered site housing and PHA housing in general. If respondents had lived in both scattered site and conventional PHA housing, they were asked which they preferred and why. There seems to have been some confusion concerning these questions. Residents who answered that they lived in scattered site housing the exact same amount of time as they have lived in PHA housing over-all, (indicating that this was the only form of PHA housing they had lived in) still answered the questions concerning which form of housing they preferred. In fact, of the two respondents who gave answers indicating that they had lived in both forms of housing, neither responded to the questions asking which they preferred. In part, the confusion was due to poor wording of the first question which, instead of asking about PHA housing, should have been worded to include only conventional PHA housing.

The average length of time respondents lived in PHA housing is 2.8 years (approximately two years and seven months). Of the twelve respondents, two indicated that they have lived in conventional housing before moving to their scattered site unit. While neither of these residents answered the question about which type of housing they preferred, several of the other respondents did do so. Three respondents noted that scattered site housing feels more like a home or is more comfortable. Another two answered that they prefer scattered site housing because they feel that they are living with more independence. One respondent wrote that scattered site housing is more peaceful and less violent, and one answered that she does not care which type of housing she lives in as long as she gets along with her neighbors and the management.

Almost all ( 9 of 11 or $81 \%$ ) of the respondents feel that their scattered site house fits in with their neighborhood. One respondent noted that she feels a sense of ownership for her house. Another 
respondent said that she loves her neighborhood, but that she feels her neighbors don't think she belongs there. One respondent did not answer this question. The respondent who did not answer this question later stated that she is happy with her scattered site unit and is not planning on moving.

Of the ten respondents who answered the question regarding community services, three said that there are no services which they require that are unavailable to them in their neighborhood. Another three gave responses specifying a need for better security. Additional responses included the need for more community services, a street sign and a light for Cortez street, and jobs for working age children. Two respondents did not answer this question, and one simply answered "good". One of the respondents who did not answer this question stated in response to a later question that she thinks the PHA should assign police officers specifically to the scattered site units.

Of the eleven respondents who answered the question concerning activities for their children, five indicated that their children participate in a social service or recreation program in their neighborhood. One of those respondents noted that her children participate in the Boys' and Girls' Clubs. Six said that their children do not participate in neighborhood activities, and one respondent did not answer this question. Interestingly, the person who did not respond to this question said she thinks the PHA should find jobs for working age children.

Almost all of the respondents (10 of 12 or $83 \%$ ) indicated that they feel welcome in their neighborhood. Of the remaining two, one answered "somewhat, when I see my neighbors I say hello," and the other reported that she only feels welcome by other scattered site residents and "not the other people".

When asked if they are planing to move in the near future, ten out of the twelve respondents answered no. One resident said that she might move because her house is not in a very good section of Providence, and one indicated that she is planning on moving because of problems with neighborhood children.

The final question of the survey asked scattered site residents if there were things that the PHA should be doing to assist them. Five of the respondents answered no and two mentioned security related issues. Another resident wants a fence put around her yard and better screens along with home visits. One resident wanted a sign and a light for Cortez street, one doesn't know, and the final response was simply, "jobs."

\section{EXTERNAL ENVIRONMENTAL ANALYSIS: SECTION 8 SURVEY RESULTS}

In June 1995, the Providence Housing Authority sent surveys to 44 Section 8 Tenants. In response, we received $25(57 \%)$ completed tenant surveys. The surveys asked program participants to answer questions concerning their experiences with the Section 8 program and gave them an opportunity to rate the PHA's performance in several areas of service. The following report summarizes the results of the Section 8 survey.

The 25 Section 8 tenants who responded to the survey included residents who have participated in the program from a range of 1 to 13 years. Tweive, or $48 \%$ of these tenants have moved since entering the program. The two answers most commonly given for moves were that either their landlords were unprofessional or that they needed a larger apartment. 
Most $(80 \%)$ of the respondents received the information package given to new Section 8 residents by the PHA, and almost all of those tenants found it to be helpful. One respondent noted that it is difficult to remember the information because once a person is accepted into the program his/her primary focus is on finding a good apartment in a good neighborhood

Four questions in the survey asked tenants to rate the PHA's performance in the following areas: finding Section 8 apartments, annual inspections and recertifications, intervening with problems with the tenant's apartment, and the tenant's overall opinion of the PHA staff. Respondents were asked to rank these categories on a scale of "poor," "fair," "good," "very good," and "excellent." The rankings were very positive. For the question concerning finding apartments, $88 \%$ of the tenants answered "good", "very good", or "excellent." Similarly, $92 \%$ of respondents rated annual inspections and recertifications positively, and $84 \%$ were satisfied with the manner in which the PHA intervenes with problems in tenants' apartments. The most positive ranking was for the tenants' overall opinion of the PHA staff. The positive rating was $92 \%$, and $48 \%$ ranked the PHA staff as "excellent."

In response to the question asking tenants if there are additional ways in which the PHA could serve them, most $(68 \%)$ answered simply "no." Several did answer that more information would be useful. These respondents noted that after a few years tenants forget what was in the original information package and suggested a newsletter containing information regarding benefits, rules, regulations and housing laws. Another tenant requested help in becoming a homeowner

The final question on the survey asked residents if the ability to select a Section 8 apartment outside of the City of Providence affects where they chose to live. Most $(72 \%)$ answered "no." Other tenants answered that portability allowed them to move closer to better schools, and more convenient areas. Some noted that they were fine where they were or that stereotypes of Section 8 recipients and high rents force them to live in particular areas of the city.

\section{EXTERNAL ENVIRONMENTAL ANALYSIS:} SECTION 8 LANDLORD SURVEY

An additional questionnaire was mailed out to a limited number of large Section 8 Landlords. Of the ten sent out, four were completed and returned. While this is not a scientific study, it was designed to help identify any major problems with the PHA's administration of the program, or of the program itself. The four landlords together rented out more than 65 Section 8 units and had participated in the program from a range of 6 to 20 years. Three of the four had received the information package, and all of them found it helpful and did not have any further suggestions. One did not receive the package

In response to the question asking landlords to rate the PHA's performance in finding tenants, responses were "poor", "good", "excellent", and "it's not your job." Concerning annual inspections, the PHA was rated as "good" by two landlords, "very good" by the third, and "excellent" by the fourth. Respondents ranked the PHA's performance in intervening with problem tenants as "poor," "fair," "good," and "excellent." Concerning the respondents' overall opinion of the PHA, responses were "good," "very good," (listed by two landlords) and "excellent."

While there was little agreement among landlords on questions concerning tenant placement and intervening with problem tenants, it is encouraging that all four rated the PHA's handling of annual inspections and recertifications and the overall performance of the PHA favorably 
There was also a section for additional comments and suggestions. One landlord wrote "the program expects the apartment to be perfect before tenants move in but does not compensate for repairs." Another initially wrote "More help with problem tenants, such as inspections when requested because of damage to apartment. Not waiting until 'problem' has moved out. In the past 5 years, not once have we had an annual inspection. These should be routine." The PHA records reflected that the annual inspections for the units owned by this landlord have been conducted on a routine basis. The landlord was contacted and presented with this evidence. The landlord then requested, and completed a new survey. For the purposes of this analyses, only the more recently returned survey was used.

\section{EXTERNAL ENVIRONMENTAL ANALYSIS EXTERNAL STAKEHOLDER ANALYSIS RESULTS}

\section{Introduction}

The external stakeholder analysis identifies issues from the perspective of those who view our operations from the outside. External stakeholders include agencies and people who affect or are affected by the Providence Housing Authority's operations. Many of them work directly with our residents and staff and can offer important perspectives on the needs of our tenants.

In the spring of 1995, the Providence Housing Authority sent 70 surveys to various external stakeholders. Midway through this process the survey design was changed to increase our return rate. The original survey was sent to forty agencies, politicians and non-profit organizations. Because of an initial low rate of return, a new survey was created and sent to an additional 30 stakeholders. While the original survey was sixteen questions long, the revised version was shortened to ten. In follow up telephone contacts, stakeholders who received the original surveys were given the opportunity to receive a short version. After several rounds of follow up calls, an acceptable overall-return rate of $50 \%$ percent was achieved. (This includes both the original and the modified surveys.) While these results were encouraging, it is disappointing that we did not receive any completed surveys from city councilmen or state representatives. Not including the politicians, we achieved a return rate of $58 \%$.

The 35 returned surveys came from a wide range of agencies and organizations and varied drastically in levels of depth and detail. While the response rate was low for the original version of the survey, the quality of responses was often higher than the responses to the shorter version. It was not unusual to receive one word answers to questions designed to elicit in depth responses. Several organizations, some with a long history of collaboration with PHA operations felt that they did not know enough about us to answer the questions. It is possible that the overall context of an "external stakeholder analysis" was intimidating and should have been better explained. It might also be beneficial to send our stakeholders educational materials and newsletters explaining the PHA's operations and the programs and services we offer our residents. Regardless, the absence of responses from some organizations which, in the past have felt little reluctance to offer their opinions about the PHA, was disappointing.

It should be noted that results may have been more accurate had a neutral third party administered the survey. Because stakeholders were contacted by the PHA, and because of the nature of being a stakeholder, it is reasonable to assume that some responses may have been skewed towards the positive. Still, the responses we received appear to have been quite frank and honest and the suggestions and comments are an important component of the strategic planning process. These comments and suggestions offer us the chance to step back and view our own operations from the perspectives of different agencies with different agendas. 
The following report begins with a brief overview of the three sections that comprised the survey. The sections include mandates; missions; and SWOT (Strengths, Weaknesses, Opportunities and Threats). Stakeholders often gave more than a single response for each question, so the percentages are based upon the number of stakeholders answering each particular question and not the total number of respondents. It should also be noted that the number of respondents varies widely between questions that were included in both the long and short versions of the survey, and questions included only in the long version. Appendices to this report include copies of both the short and long versions of the survey, and a chart showing the composition of the stakeholders who responded to the survey was included in the introduction to the External Environmental Analysis section.

\section{SECTION ONE: MANDATES}

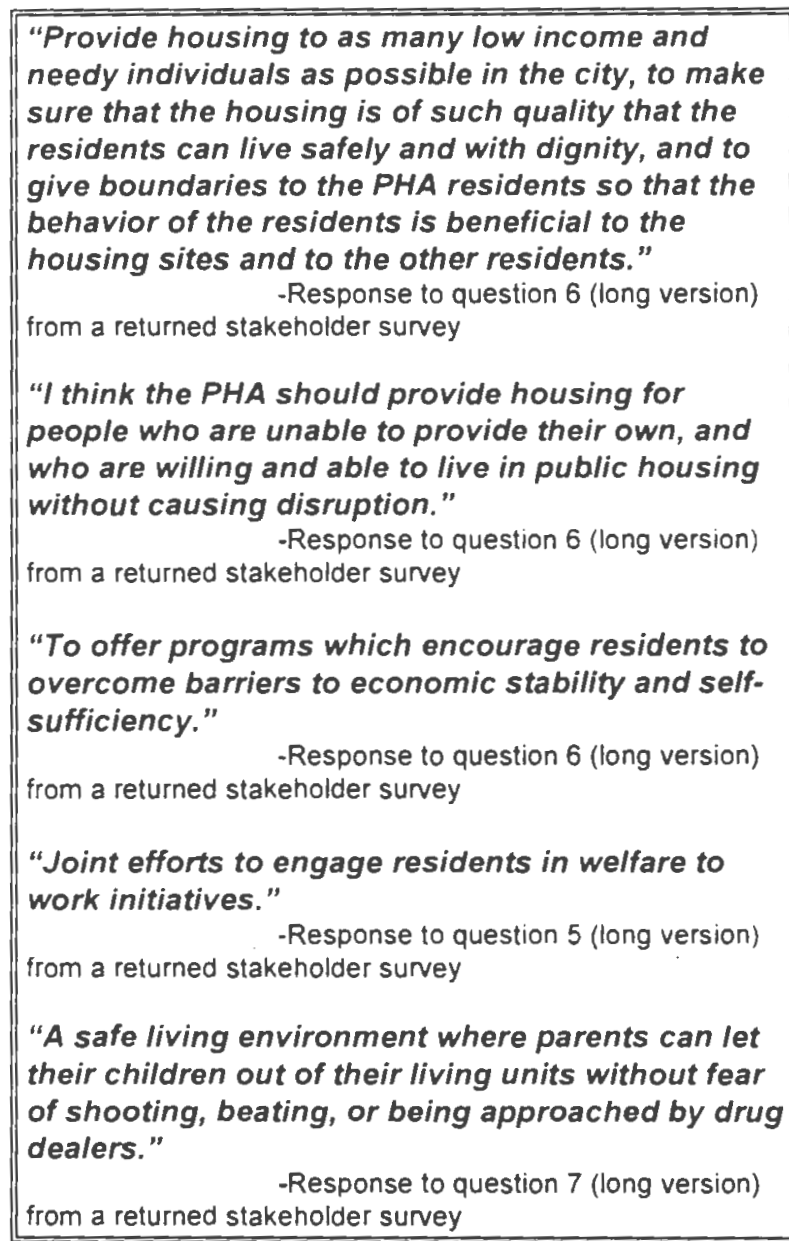

Mandates are defined as the external expectations placed upon an organization. In identifying its mandates an organization should consider both its formal and informal mandates. Formal mandates are often stipulated within legislation, charters, ordinances, articles, and contracts. A listing of the Providence Housing Authority's formal mandates can be found in the organizational mandates section of the strategic planning committee's final report. Informal mandates are also often placed upon an organization. These mandates are based upon generally understood expectations and while not as official as formal mandates they are often equally binding.

In terms of programs and services, respondents expect the PHA to provide decent, safe, sanitary and affordable housing. Further, it is expected that the PHA will promote welfare-to-work and selfsufficiency programs. Several stakeholders also noted that it is not only important that the PHA provide services itself, but that the PHA should contract out and seek service provision from other agencies. This response was also given in other sections of the survey.

When asked to give their understanding of the PHA's legal mandate, almost all stakeholders ( $85 \%$ of those who answered this question) listed the provision of decent, safe, sanitary housing. Other responses of note include encouraging tenant participation and community awareness, minimizing crime, and overcoming barriers to resident self-sufficiency. Further, when asked what services and programs they expected from the PHA, 62\% of survey respondents listed access to safe, sanitary and comfortable subsidized housing and $54 \%$ mentioned welfare to work programs. Other responses included contracting out for services, family planning and substance abuse prevention programs and sensitivity training for PHA staff. 


\section{The PHA's Mandates as Perceived by External Stakeholders}

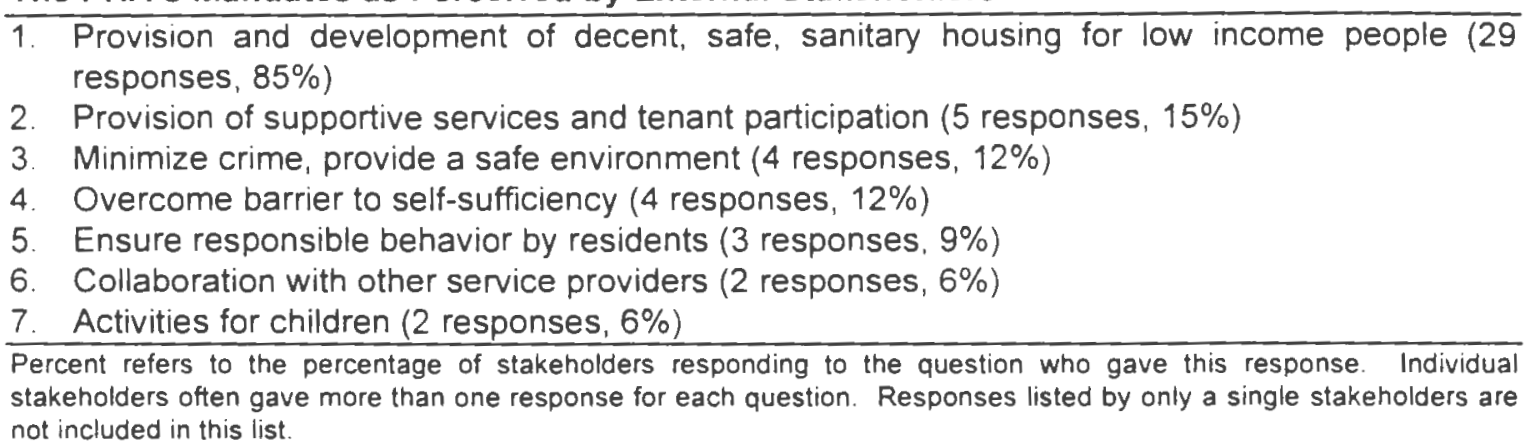

\section{SECTION TWO: MISSION}

The mission section is of great importance to the concept of strategic planning. Before an agency can successfully plan strategies for its long term success, it must first define what that success will entail. An agency's mission statement provides the social justification for the organization's existence and will direct the agency's policy and performance, and serve as the yardstick by which the organization is to be measured. In developing a mission statement, an agency must answer three questions. First, the agency must define its organizational mandates. It is difficult to picture an agency as being a success when it has failed to accomplish the basic expectations placed upon it. Second, the agency must determine what it hopes to accomplish. Beyond what it must do, an organization often has more flexibility to affect change than is realized by its members. Third, the agency must determine which goals are both realistic and appropriate for the agency to set for itself. The mission statement incorporates the dreams and ideas of the internal and external stakeholders and provides a more unified and directed vision for the role of the agency. While mandates are often unnecessarily limited in scope, no agency can possibly solve all of the problems surrounding it, and it is inappropriate for the organization to even make the attempt.

In this section of the external stakeholder analysis stakeholders answered questions concerning their views of the proper role of the PHA in the City of Providence, the needs the PHA exists to fill, their descriptions of the perfect agency, their assessment of our current level of performance and their ideas for a mission statement for the PHA. 
As is evident from the quotes from this section, beliefs about the proper role of the Providence Housing Authority vary among the people and agencies we work with. This is, of course, expected, and these responses illustrate the greater national debate concerning social welfare in America. The general response to the question concerning missions focused around the goals first stated during the Truman Presidency in the Housing Act of 1949. This Act stated as a national goal the provision of a "decent home and a stable living environment to every American family". But this mandate has grown. While many stress that public housing should be temporary, there is a common belief that more must be done beyond "bricks and mortar." Respondents felt strongly that the PHA should protect residents from crime and drug abuse, provide education programs, empower residents and promote self-sufficiency. As was illustrated in the past section, many of these services have gone beyond the mission stage, and are actually considered to be mandated policy.

When asked what they believe the most pressing issues are for the PHA, $62 \%$ of respondents gave responses relating to crime and substance abuse. Similarly, $54 \%$ listed a safe environment as an aspect that would be found if the PHA were to achieve perfection. When asked to define the proper role of the PHA within the Providence community, $55 \%$ of respondents said that as the largest landlord of subsidized housing (actually any type of housing) we should take a lead role in the development of housing policy. Also, $19 \%$ of responses listed the promotion of self-sufficiency as the proper role of the PHA.

\section{The PHA's Mission as Perceived by External Stakeholders}

1. Lead housing policy, be a model landlord, provide decent, safe, affordable housing for poor families (17 responses, 55\%)

2. Promote self-sufficiency ( 6 responses, $19 \%$ )

3. Be a facilitator with other social service agencies (2 responses, $6 \%$ )

4. Be an advocate for public services (2 responses, $6 \%$ )

5. Maintain facilities properly ( 2 responses, $6 \%$ )

Percent refers to the percentage of stakeholders responding to the question who gave this response. Individual stakeholders often gave more than one response for each question. Responses listed by only a single stakeholders are not included in this list

\section{SECTION THREE: SWOT}

SWOT stands for strengths, weaknesses, opportunities and threats. Strengths and weaknesses are internal factors in an organization's operations, and opportunities and threats represent outside forces. Questions in this section were designed to help assess internal strengths and weaknesses and pin-point outside threats and opportunities.

When asked to describe what makes the PHA a unique organization in the City of Providence, respondents answered that the PHA has a unique ability to address the daily needs of our residents who comprise a large percentage of the city's minority and low income citizens. Also mentioned was the ability to address crime, excellent leadership and professional management, and the ability to attract funding. When asked to rate the overall performance of the Providence Housing Authority on a scale "outstanding," "above average," "average," "below average," "unacceptable," and "unable to answer (don't know enough about your operations)," respondents rated the PHA very highly. The PHA was rated "above average" by $36 \%$ of respondents, "outstanding" by $27 \%$, "average" by $21 \%$, with the final $18 \%$ of respondents stating that they did not know enough about PHA operations to answer. 
When asked to identify areas in need of improvement, four answers were given by $18 \%$ of the stakeholders responding to this question. These were: further integration of services such as child care, crime prevention, and sensitivity training for PHA staff. While there was little agreement concerning weaknesses. there was general agreement about the PHA's strengths. When asked to list the PHA's strengths, stakeholders stressed the quality of the staff $(45 \%)$ and the quality of management, leadership and administration (36\%).

The external opportunity most often cited by stakeholders was to increase the levels of collaboration with other agencies and non-profits. This answer was given by $34 \%$ of those responding. Several, $(16 \%)$ of the stakeholders replied that they could not identify any opportunities. Other opportunities suggested included the acquisition of vacant lots $(6 \%)$, tapping into the enterprise community $(6 \%)$, and an even more aggressive search for federal and foundation funding sources $(6 \%)$.

When asked what external threats and

"The Providence Housing Authority has the soul of the city in its hands and knows the issues, needs, and diversity of the Population."

-Response to question 11 (long version) from a returned stakeholder survey

"Whenever I have contacted the PHA for assistance, their response has always been positive and direct. If there was any way of meeting the need, it was explored."

-Response to question 13 (long version) from a returned stakeholder survey

"At times I think it might be better for the PHA to sub-contract out its social and special services rather than trying to be all things to everyone."

-Response to question 9 (shor version) from a returned stakeholder survey

"Bad image, people don't look at the residents as people. They think about the PHA and think about drug dealers and car thieves but don't see the children and individuals as people. People see the developments as projects."

- Response to question 15 (long version) from a returned stakeholder survey

constraints would impact the PHA, stakeholders overwhelmingly listed federal budget cuts $(65 \%)$. Other responses included state and local funding $(26 \%)$, HUD reinvention $(26 \%)$, welfare reform $(27 \%)$, tendency to blame the poor $(13 \%)$, increased drug usage and crime rates $(10 \%)$, and the failing family structure $(6 \%)$.

\section{The PHA's Strengths as Perceived by External Stakeholders}

1. PHA staff (5 responses, $45 \%$ )

2. Leadership, management, and administration ( 4 responses, $36 \%$ )

Percent refers to the percentage of stakeholders responding to the question who gave this response. Individual stakeholders often gave more than one response for each question. Responses listed by only a single stakeholders are not included in this list.

\section{The PHA's Weaknesses as Perceived by External Stakeholders}

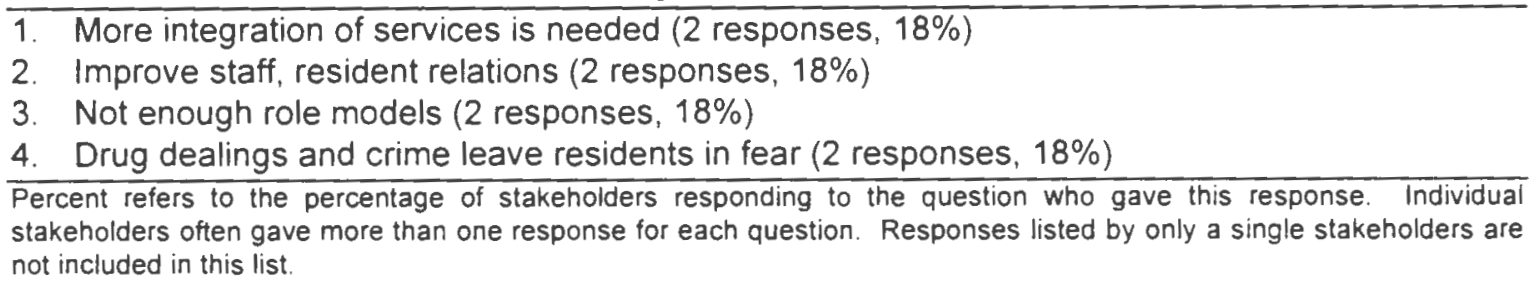

The PHA's External Opportunities as Perceived by External Stakeholders

1. Greater collaboration with other agencies (11 responses, $35 \%$ )

2. Could not answer (5 responses, 16\%)

3. Acquire vacant lots for new construction ( 2 responses, $6 \%$ ) 
4. Tapping into the Enterprise Community (2 responses, $6 \%$ )

5. More aggressive search for funding (2 responses, $6 \%$ )

Percent refers to the percentage of stakeholders responding to the question who gave this response. Individual stakeholders often gave more than one response for each question. Responses listed by only a single stakeholders are not included in this list.

The PHA's External Threats as Perceived by External Stakeholders

1. Federal budget cuts (20 responses, $65 \%)$

2. State and city governments and funding ( 8 responses, $26 \%$ )

3. Block grants, HUD reinvention ( 8 responses, $26 \%$ )

4. Welfare reform ( 7 responses, $23 \%$ )

5. Tendency to blame the poor ( 4 responses, $13 \%$ )

6. Increased drug problems (4 responses, $13 \%$ )

7. Increased crime problem (4 responses, 13\%)

8. Poor state economy ( 3 responses $10 \%$ )

9. Declining job market for unskilled workers (2 responses, $6 \%$ )

10. Immigration ( 2 responses, $6 \%$ )

11. Deteriorating housing conditions, housing stock ( 2 responses, $6 \%$ )

12. Failing family structure ( 2 responses, $6 \%$ )

13. Welfare system not geared towards self-sufficiency ( 2 responses, $6 \%$ )

Percent refers to the percentage of stakeholders responding to the question who gave this response. individual stakeholders often gave more than one response for each question. Responses listed by only a single stakeholders are not included in this list. 


\section{Step Five \\ Internal Environmental Analysis}

The internal environmental scan is the fifth step in the Bryson model of strategic planning. In this step the agency evaluates its strengths and weaknesses from the insider's perspective. Strengths and weaknesses are analyzed in order to understand how they might help or hinder the realization of the agency's mission.

An internal environmental scan, also known as a situational analysis, is a major component of the fifth step. The internal environmental scan is an assessment of the organization's present position in its current environment. Three main categories are examined: resources (inputs), present strategy (process), and performance (outputs). While most organizations have data regarding their inputs, fewer have detailed data concerning their outputs and the effects those outputs have on the agency's clients and stakeholders. It is vital that the agency develop ways to measure and present performance information. "If the organization cannot demonstrate its effectiveness against stakeholder's criteria, then regardless of any inherent worth of the organization. stakeholders are likely to withdraw their support. ${ }^{14}$

Planning teams from each of the six PHA departments participated in the internal environmental scanning process along with a representative from the self-sufficiency program, the Executive Director who covered the political process, and the Deputy Director who reported on personnel training, insurance and risk management.

As a part of the internal environmental scanning process, each department answered questions concerning: personnel, funding, information management, competencies, overall and departmental strategy, industry trends and market share analysis, stability and flexibility, efficiency and their current level of performance. In addition to the information presented in the internal environmental scans, a separate five year performance indicators report was compiled This study has been included as an appendix to this report

The other major component of the Providence Housing Authority's internal environmental analysis is the internal stakeholder analysis. This step identifies issues from the insider's perspective. Information is collected through the use of surveys which are given to internal stakeholders (administration, management, staff and other employees if desired). If the agency has a large number of functions or employees, it might be necessary to divide into strategic planning teams based upon departments or functional areas. Teams may consist of entire departments, or a representative and knowledgeable sample. Internal stakeholder surveys are designed to focus upon the agency's mandates, mission, and SWOT (Strengths, Weaknesses, Opportunities and Strengths).

For the PHA's internal stakeholder analysis, surveys were completed by departmental strategic planning teams. In addition to the six PHA departments, stakeholder surveys were completed by representatives from the Public Housing Unit, and the Homeownership and Self-Sufficiency programs. A more in depth description of the process precedes the summary of results later in this section. A copy of the survey is contained as an appendix to this report.

In the introduction to the external environmental analysis it was noted that an organization's success lies in the satisfaction of its stakeholders. This is true of internal stakeholders as well as external. Members of the administration, management, employees, and staff all affect and are affected by the agency and its performance. If an agency's mission and actions are inconsistent 
with the goals and values of its members, it is bound to fail. When an agency's members are included in the planning process, when they are given the opportunity to shape the direction of the agency, then they will feel more committed to the agency's overall success

\section{INTERNAL ENVIRONMENTAL ANALYSIS SUMMARY OF INTERNAL STAKEHOLDER ANALYSIS KEY QUESTIONS}

\section{Introduction}

Strategic planning is a future oriented process that will help the PHA provide the highest level of services possible within the context of a rapidly changing social environment. At the heart of this process is the identification of our mission and mandates as well as our internal strengths and weaknesses and the external opportunities and threats which will affect our organization and the people we serve. This is made possible through the input of both internal and external stakeholders, people who affect or are affected by the operations of the PHA. This input will allow us to develop policies and procedures to meet the public housing needs of the City of Providence in an efficient, effective and consistent manner.

The internal stakeholder analysis identifies issues from the insider's perspective. Data has been collected in the form of surveys which were given to each departmental strategic planning team. Departmental strategic planning teams consist of the director of the department and selected staff. In addition to the six official PHA departments, internal stakeholder analysis questionnaires were completed for security (by the Public Housing Unit) and family self-sufficiency/ job training.

\section{SECTION ONE: MANDATES}

Mandates are defined as the external expectations placed upon an organization. In identifying its mandates, an organization should consider both its formal and informal mandates. Formal mandates are often stipulated within legislation, charters, ordinances, articles, and contracts. A listing of the Providence Housing Authority's formal and informal mandates can be found in the organizational mandates section of this report. Informal mandates are also often placed upon an organization. These mandates are based upon generally understood expectations and, while not as official as formal mandates, they are often equally binding.

While mandates are used to formulate the organization's mission statement, a common mistake is for an organization to define its mission by its mandates. An organization should look beyond its mandates when, through its mission statement, it defines its proper place within the community.

In answering this section of the internal stakeholder questionnaire, the departmental strategic planning teams identified the provision of safe, sanitary and quality housing for low income people as the primary mandate. Other mandates of note included the provision of quality housing that would enhance Providence neighborhoods and the promotion of resident self-sufficiency.

Of the eight departments participating in the internal stakeholder analysis, six listed the provision of quality housing for low-income people as a primary program or service.

Other primary programs and services mentioned by multiple departments were the provision of quality housing stock to enhance Providence neighborhoods (3); Maintaining safe, decent and sanitary conditions (3); and the promotion of self-sufficiency (2). Other programs and services mentioned ranged from practicing fiscal responsibility to "aggressively seek[ing] out those in need of housing." 
There were many secondary services and programs listed by each of the eight departments. Of the fifteen programs and services mentioned, only two were mentioned by more than one department. These were to assist clients in the transition off of public assistance and to provide social services for residents. Both of these were mentioned by three departments. Among the remaining thirteen programs and services mentioned were the protection of taxpayer investments, advocacy for residents, and control over tenants' behavior

For the more direct question "what do you see as the PHA's mandates?" Six departments listed the provision of safe sanitary housing; four listed the adherence of laws and regulations (an issue which came up later in the analysis as an external constraint); and two listed the responsible spending of funds. Other answers included responding to the will of the people, the elimination of drug dealing, the maintenance of grounds and the professional treatment of residents.

\section{The PHA's Mandates as Perceived by the Departmental Planning Teams}

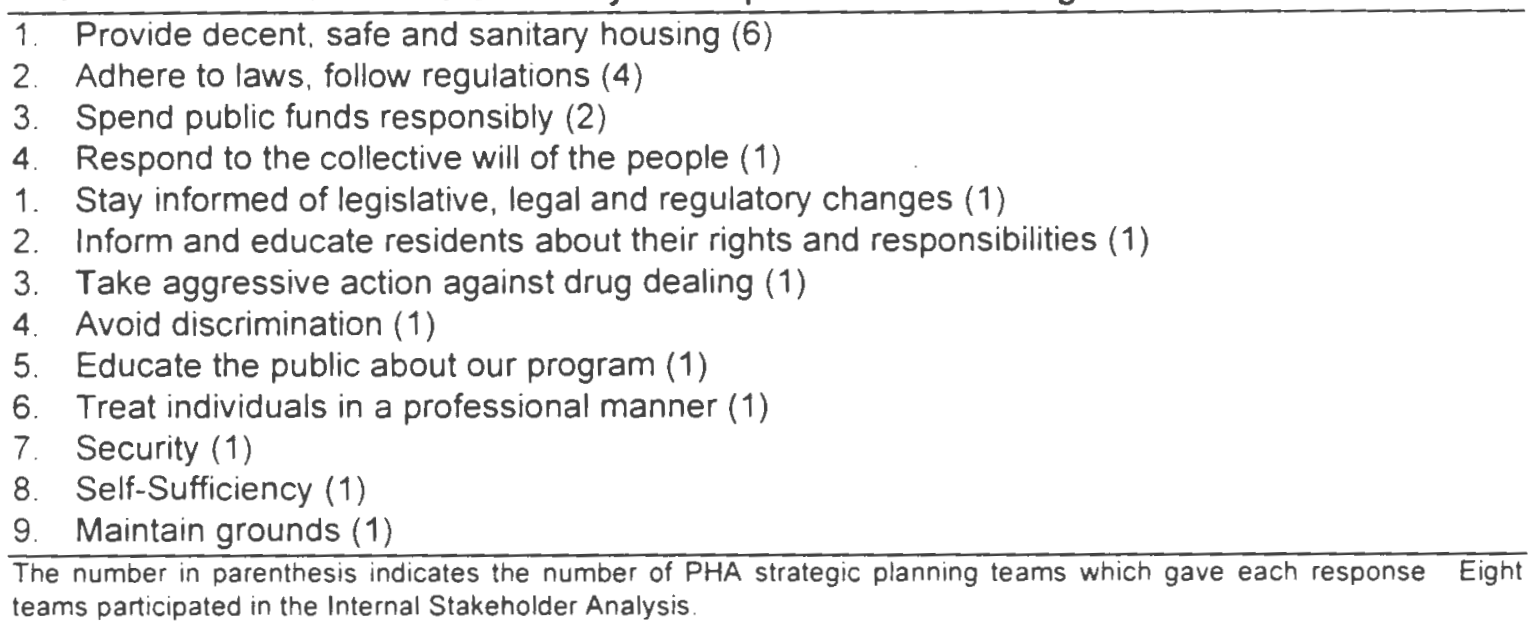

\section{SECTION TWO: MISSION}

An organization's mission provides the social justification for its existence. ${ }^{15}$ This mission statement is used to define the organization's purpose, direction and future. While based on the organization's mandates, the mission statement also incorporates the dreams and ideas of the internal and external stakeholders and provides a more unified and directed vision for the role of the agency. in this section of the internal stakeholder analysis. PHA department directors and their strategic planning teams answered questions concerning their views of: the proper role of the PHA in the City of Providence, the needs the PHA exists to fill, their descriptions of the perfect agency, their assessment of our current level of performance and their ideas for a mission statement for the PHA.

A quick overview of the responses to this section shows that departmental strategic planning teams identified the provision of safe, decent and sanitary housing as the primary mission of the Providence Housing Authority and the lack of affordabie housing as the primary need the PHA exists to fill. Other needs that stood out in the responses were the special needs of elderly and disabled residents, the creation of a crime free living environment and the promotion of resident self-sufficiency (this was seen as the most pressing need). The elimination of drug abuse and the appropriate handling of irresponsible and trouble-making tenants were identified as needs which we are failing to meet. 
The planning teams listed the maintenance of property, a strong central administration and the use of limited funds as areas in which the PHA does well. Areas that were identified as needing improvement were the enforcement of PHA rules and regulations, inter-departmental communication and unit turn around time.

A summary of the results shows that of the eight departments participating in the internal stakeholder analysis, five answered that the proper role of the PHA is to provide safe, decent and sanitary housing for low-income families. This was the only answer for this question that was duplicated by more than one department. Other answers included setting an example in the area of affordable housing, providing equal opportunity and fair housing, providing social services and youth activities and increasing the quality of life for the individuals we serve.

In answer to question seven concerning the needs the PHA exists to fill, seven departments answered the lack of safe affordable housing and two listed the special housing needs faced by the physically challenged and the elderly. Other responses included the lack of employment opportunities, the need for defensible space against crime, the failure of families and needs for community and social services.

Question eight, concerning needs we are not meeting contained many replies given by multiple departments. Four listed security for elderly residents and two listed the elimination of drug abuse and over-all security. Three departments also noted that the PHA allows too many irresponsible tenants to live in public housing and that residents are not held accountable for their actions. Three departments listed the need for a net increase in the number of affordable housing units and two departments said the PHA is not breaking the cycle of multi-generational public assistance dependence

When asked which needs are most pressing, three departments answered the need for a greater supply of housing, three answered the need to promote self-sufficiency and an end to the cycle of dependency and another two answered the need for over-all security. Many other replies such as improved care for elderly residents and easier evictions were given by single departments.

Three departments cited the maintenance of our property as an aspect of PHA operations that is done well. Another two departments listed efficient use of limited funds and the administration of resources. Central administration and management and community services activities and outreach were also listed by two departments. Five departments responded that levels of resident responsibility and the enforcement of rules and regulations need to be improved, and three noted the need for improved inter-departmental communication. Apartment turnaround time and painting and public relations efforts to increase the image of the PHA were both listed by two departments as unacceptable. Several other replies were given by only one department.

Four departments answered that responsible residents who abided by PHA rules and their leases were aspects that would be found in the perfect agency. Three departments noted the importance of compassion for residents. Two departments listed the capacity for meeting the special service needs of a diverse population of residents. The ability to offer different types of housing for different needs, fiscal soundness, dignity, and safety were also listed by two departments as aspects that would be found in the perfect agency.

When asked to write a mission statement for the Providence Housing Authority, seven departments included the provision of safe, high quality, decent housing for the poor; five departments included the provision of safe housing options; five included dedication to empowerment and the promotion of self-sufficiency; two departments listed resident participation in PHA operations and two listed collaboration with other agencies to meet the needs of residents.

\section{The PHA's Mission as Perceived by the Departmental Planning Teams}

Chapter Three: Strategic Plan 2000 
1. Provide clean, high quality, decent housing for the poor (7)

2. Provide safe housing options (5)

3. Dedication to self-sufficiency (5)

4. Encourage resident involvement, act on resident concerns (2)

5. Work with the City and other agencies to meet housing needs (2)

6. Act as the leading housing agency in the city (1)

7. Provide the greatest possible range of housing options (1)

8. Provide needed non-housing services to residents (1)

9. Enhance the quality of life in the City (1)

10. Act in a fiscally responsible manner (1)

11. Provide services based upon an award system (1)

The number in parenthesis indicates the number of PHA strategic planning teams which gave each response Eight teams participated in the Internal Stakeholder Analysıs

\section{SECTION THREE: SWOT}

SWOT stands for strengths, weaknesses, opportunities and threats. Strengths and weaknesses are internal factors in an organization's operations and opportunities and threats represent outside forces. Questions in this section were designed to help assess internal strengths and weaknesses and pin-point outside threats and opportunities.

The internal strengths identified by the planning teams included the PHA's visionary and goals oriented approach, its strong administrative leadership and its good reputation. Weaknesses were a lack of inter-departmental communication, insufficient funding and the lack of appropriate action concerning problem tenants

Greater collaboration with other agencies within the city, HUD reform and deregulation were seen as external opportunities. The external threats and constraints cited most frequently by the planning teams were the predicted HUD reinvention, federal cutbacks, papenwork and regulatory burdens, poor local and state economies, increasing levels of violence, and the political system which was seen as removed and uninformed in areas concerning public housing.

Question thirteen asked the departmental strategic planning teams to list ways in which the Providence Housing Authority is a unique organization in the city. Three answered that we are the largest landlord for lower-income families and three noted that we address shelter and social service needs for a diverse range of low-income families. In rating the over-all performance of the PHA, seven departments answered above average and the eighth said the PHA's over-all performance was outstanding.

Question fifteen asked departments to list five of the Providence Housing Authority's strengths noting which strength was the greatest. Seven departments listed PHA personnel as a strength (six of them listed personnel as the greatest strength). Five departments noted that we are visionaries and that we are goal oriented (one listed this as our greatest strength). Further, two departments noted that the PHA is well organized and has a strong administrative staff. One of these departments listed this as the greatest strength. Other frequently cited strengths were that we are well respected and have a good reputation (listed by four departments); that we have strong leadership; that we receive a lot of funding; and that we display team work (each listed by three departments). Further, two departments listed good relationships with residents and our security program as strengths

Six departments listed a lack of inter-departmental and inter-developmental communication as a weakness (two listed this as the greatest weakness). Three departments listed: insufficient funds, a lack of aggressive action against troubled tenants, resident screening, and an inability to stop 
crime as weaknesses (for each, one department rated the weakness as the greatest weakness facing the Providence Housing Authority). Two departments listed excessive regulation and reporting and union constraints as weaknesses with one department rating each as the greatest weakness. One department answered that low operating reserves were our greatest weakness. and two listed an unclear mission or focus as a weakness.

For question seventeen, regarding operational constraints, four departments listed funding and overworked staff, three departments listed dependence upon other departments, and two departments listed regulations, lack of inter-departmental training and security as weaknesses

Four departments listed greater collaboration with other agencies as an opportunity. Three departments listed HUD reform and deregulation, and two listed the financial commitment of the City and State and the utilization of bond authority as opportunities.

Questions nineteen through twenty-two were combined for evaluative purposes because similarities in the wording of the questions resulted in an inconsistent pattern of answers among the questions. The questions basically dealt with external constraints and factors that were likely to hinder our operations and limit the ability of the PHA to successfully implement a vision for success. Seven departments answered that HUD reinvention, the Contract with America and federal cutbacks would hinder PHA operations. Seven departments also listed excess paperwork and regulatory burdens as problems. Five departments listed welfare reform and four listed poor city and state economies as obstacles. Politics and a lack of focus and understanding of public housing by policy makers was seen as a problem by three departments. Also listed by three departments as hindrances were increases in gang activity and violence, resident screening. eviction procedures, the demise of family values and a general lack of respect for authority.

\section{The PHA's Strengths as Perceived by the Departmental Planning Teams}

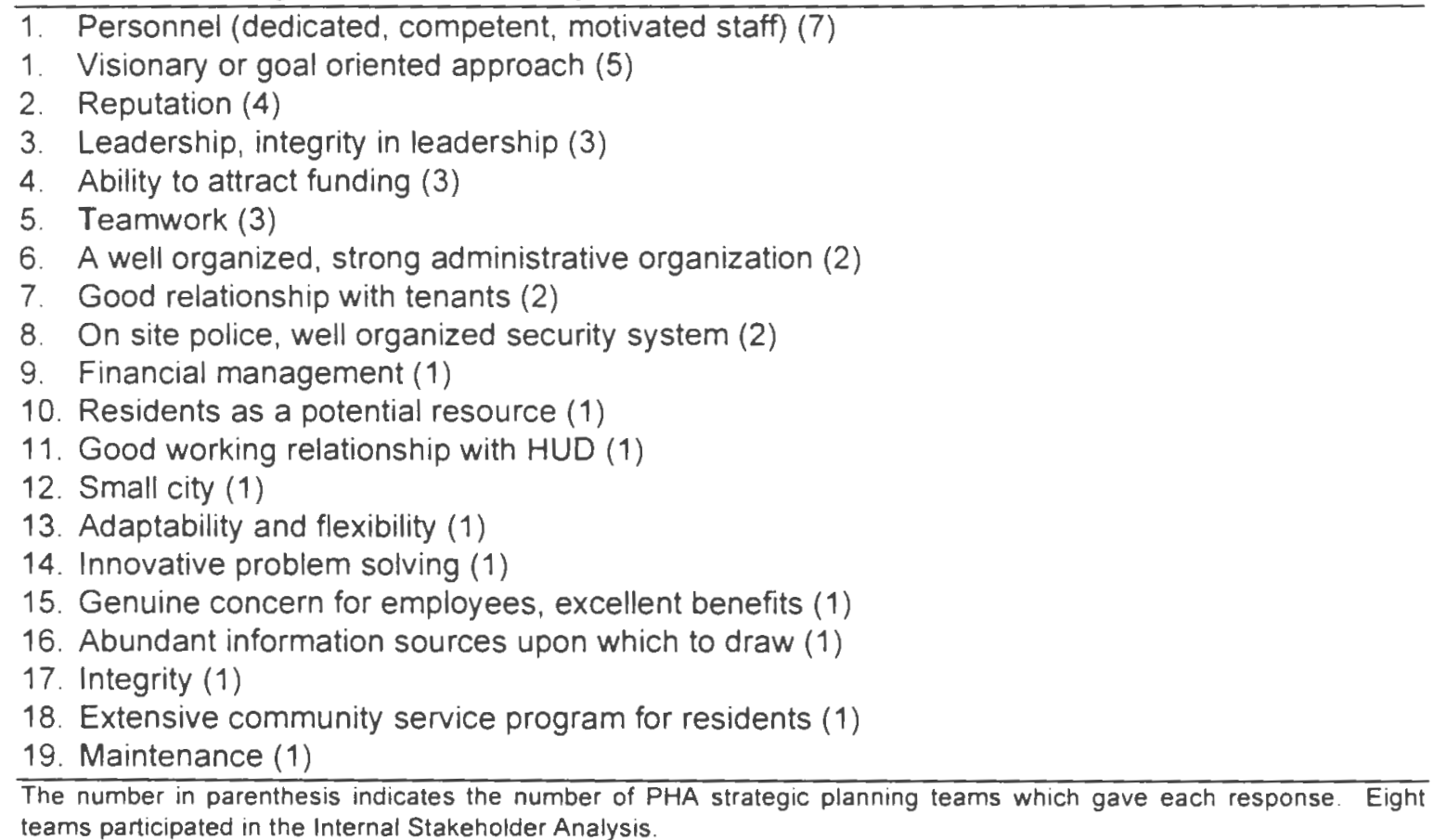


The PHA's Weaknesses as Perceived by the Departmental Planning Teams

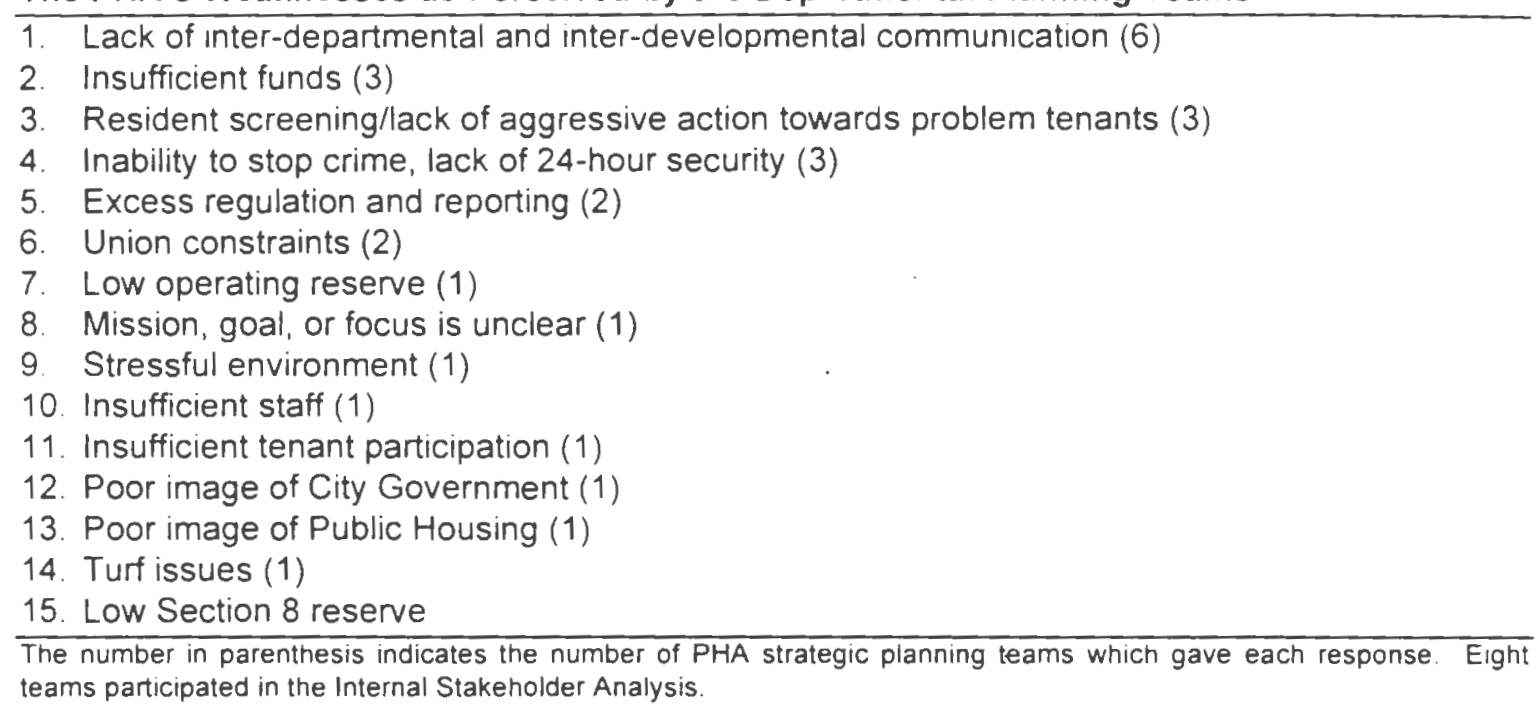

External Opportunities as Perceived by the Departmental Planning Teams

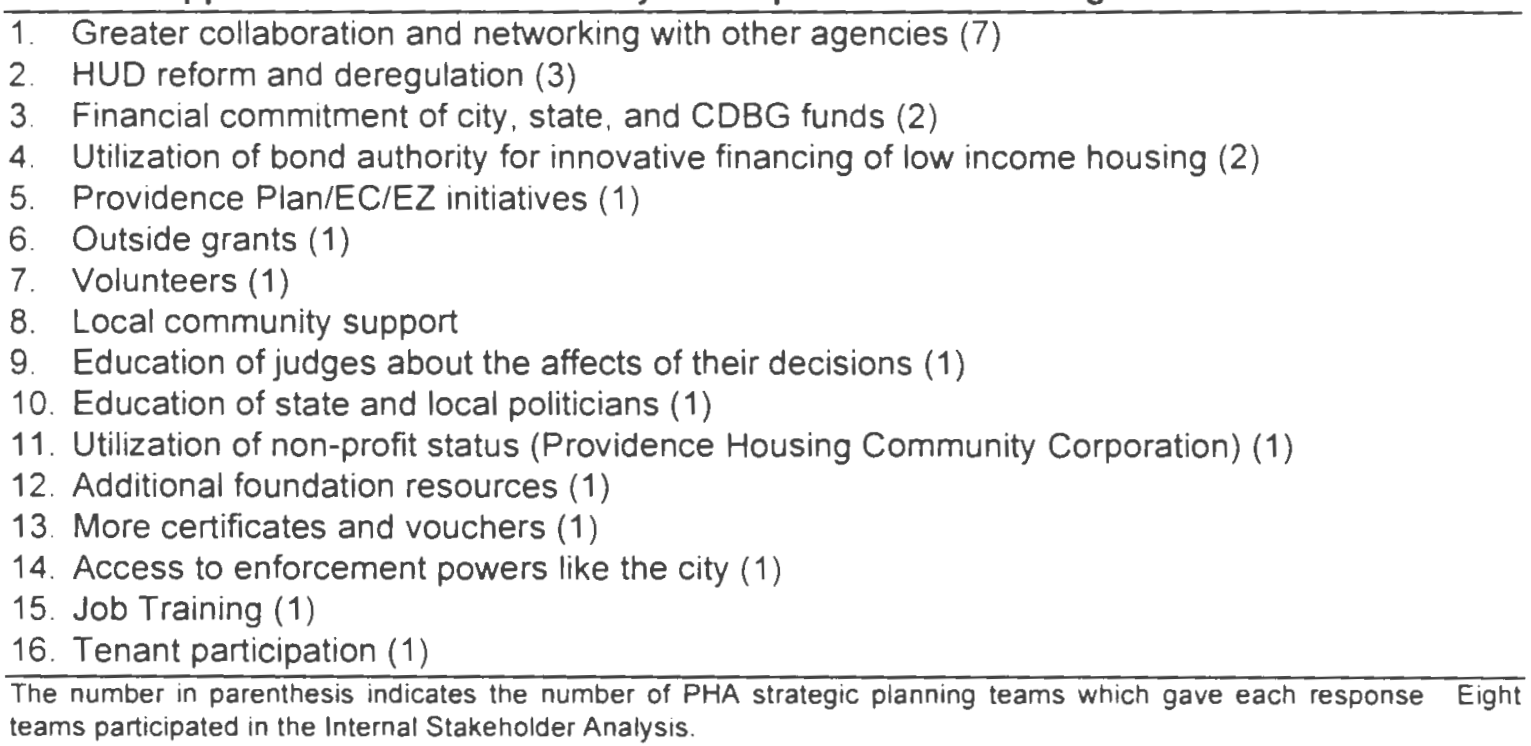

\section{External Threats as Perceived by the Departmental Planning Teams}

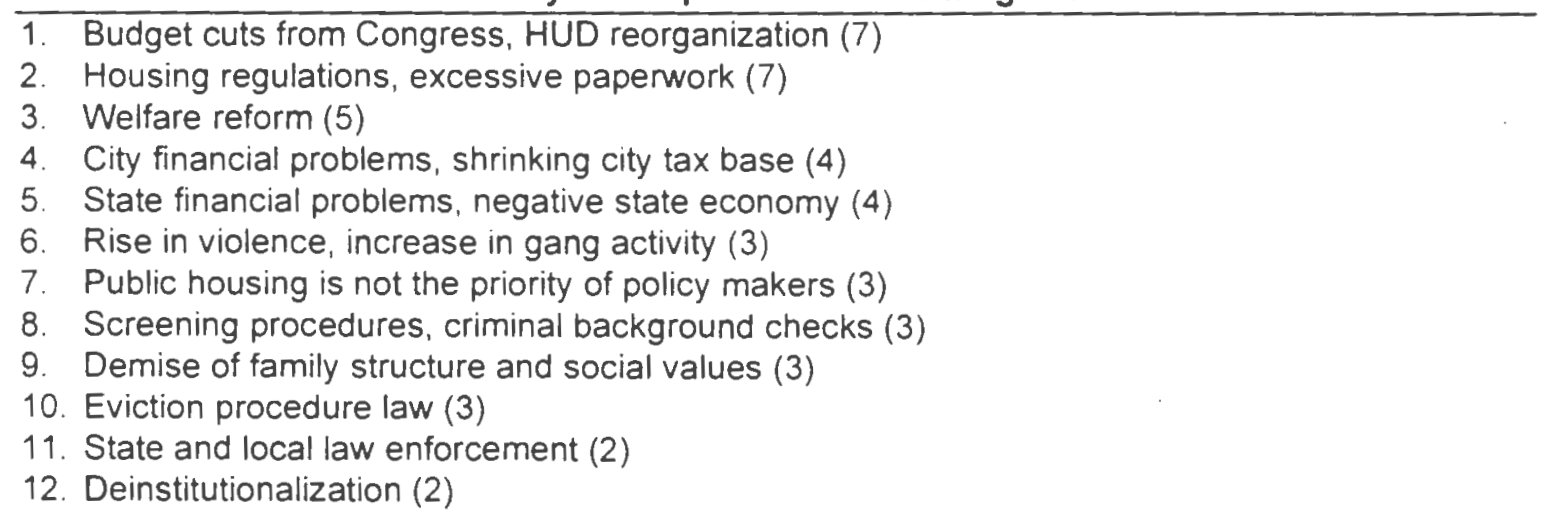


11. Interdepartmental communication (1)

12. Increased promotion of effective parenting and living skills (1)

13. Low reserve level leading to less financial stability (1)

14. Community and participant education and awareness (1)

15. Reduction in fraudulent program activity(1)

16. Competition with the private sector (1)

17. Management aggressiveness in addressing problem tenants (1)

18. Keeping the high-rises just for elderly (1)

The number in parenthesis indicates the number of PHA strategic planning teams which gave each response Eight teams participated in the Internal Stakeholder Analysis. 
scans. Teams also participated in training and value card exercises. After reviewing this wealth of information, the members of the strategic planning teams met for a day long retreat to identify issues and discuss other aspects of the strategic planning process.

\section{The September 19th Planning Retreat}

On 19 September 1995 the PHA strategic planning teams participated in a planning session at the Organizational Futures Urban Retreat Center. The session began with each individual answering the following questions:

1. What will strategic planning yield for the PHA?

2. What is your biggest strategic issue?

3. What is the greatest road block on the path towards implementation of the strategic plan?

4. What will the plan most demand you do differently?

During the remainder of the day the team members participated in a number of planning activities. Teams listed and discussed strategic issues and ordered them in terms of priority. Solutions and tasks were then discussed for several of the most pressing issues. Later in the afternoon new teams were created which crossed departmental lines to discuss issues such as areas of tension in public housing, important stakeholders and how to deal with them, and ways to improve collaboration at the PHA.

All of these exercises were photographically recorded by Organizational Futures and printed out in report form. Along with the information collected in previous stages of the strategic planning process, this information was central to the identification of strategic issues for the Providence Housing Authority.

\section{Benefits of the Strategic Issues Identification Step}

While it may be tempting to skip strategic issues identification and go straight to strategy development, this step offers many benefits to the over-all strategic planning process. Bryson lists five benefits that come from focusing on issues identification.

1. Attention is focused upon what is truly important. Often times agencies fall into the 80-20 trap. The "key decision makers usually spend 80 percent of their time on the least important 20 percent of their jobs." 23

2. By focusing on issues rather than answers, the agency can gain a true understanding of what the real problems are, and how they affect the agency.

3. Identifying issues creates "the kind of useful tension necessary to prompt organizational change." 24 Organizations only change when they feel they have to. Identifying issues and their consequences often provides important motivation and incentives.

4. Issue identification gives important clues about how to solve problems. "By stating exactly what it is about the mission, mandates and internal and external factors that makes an issue strategic, one also gains some insight into possible ways that the issue might be resolved.' 25 By framing issues in these terms, the strategic planning team will be better prepared to take advantage of strengths and opportunities and overcome weaknesses and threats

\footnotetext{
${ }^{1}$ Answers to questions two and four are listed later in this report
} 
5. This step makes the entire strategic planning process seem more real to the participants. By focusing on the correspondence between organizational thought, behavior and consequences, the process becomes less academic and more real.

\section{Outline of the Remainder of This Section}

The remainder of this section outlines the issues identification process as implemented by the Providence Housing Authority. Inciuded in this section are summaries of the September 19th planning session at Organizational Futures, the Internal and External Environmental Scans, the Internal and External Stakeholder Survey results and the Resident Survey results. These summaries are organized to illustrate the process through which the PHA identified strategic issues.

Following these summaries is the final list of Strategic Issues for the PHA. These issues are organized into six major themes. A discussion of each of the six themes explaining their strategic significance to the PHA concludes this section.

19 SEPTEMBER 1995

\section{ORGANIZATIONAL FUTURES PLANNING RETREAT}

INDIVIDUAL ANSWERS TO THE QUESTION: WHAT IS THE MOST IMPORTANT STRATEGIC ISSUE?

\section{Department of Modernization and Development}

- Funding

- Redirection of development office

- Choosing between competing projects

- Upkeep of housing stock with limited funds

\section{Department of Facilities Management}

- Training personnel

- Energy management and resident involvement

- Energy management and compllance with federal regulations

- Departments working together

\section{Department of Finance and Accounting}

- Making do with less funding (2)

\section{Security}

- Addressing the problems of crime in the PHA

- Separating short and long term crime related issues

- Crime/security (2)

\section{Office of the Executive Director}

- Maintain marketable housing stockj prioritization of issues

- Getting jobs for residents

- Foresight

- Strategic thinking

\section{Department of Community Services}

- Social services for elderly/disabled 
- Organlzing ali the parts

- Self-Sufficiency for residents

Department of Housing Management

- Staff training, getting people to buy into the process

- Teamwork between staff and residents

- Staff training

- Easier access to information on program changes

\section{Department of Rental Housing}

- Dealing with new regulations

- Keep the PHA operating

- Enforcement of regulations 


\section{SEPTEMBER 1995}

\section{ORGANIZATIONAL FUTURES PLANNING RETREAT}

INDIVIDUAL ANSWERS TO THE QUESTION: WHAT WILL THE PLAN MOST DEMAND YOU DO DIFFERENTLY?

\section{Proactive Planning/Thinking}

- More careful planning

- Contingency planning

- Expand researcti to explore new opportunities

- Expand grant writing capabilities and collaboration with other agencies

- Visualize housing in terms of the future

- Be creative, get more data

- More creativity

- Seek alternative funding

- Think more

\section{Reactive Planning/Thinking}

- Be flexible

- Design projects with bare bones scheme

- Adjust

- Funding will no longer be taken for granted

- Accomplish more with less

\section{Teamwork/Collaboration/Communication}

- Integrate skills with various teams

- Greater collaboration between PHA management, security, and residents

- Teamwork

- To work as a whole

- Work more closely

- Work together as a team

- Communicato

- Better communication and teamwork

\section{Other}

- More Jeeway

- Greater investment by residents

- Work on attainable goals

- Change attitudes about AFDC recipients

- More hands on training

- Change perception 


\section{ORGANIZATIONAL FUTURES PLANNING RETREAT}

STRATEGIC ISSUES AS DETERMINED BY THE PHA STRATEGIC PLANNING TEAMS

\section{Strategic Issues for the Providence Housing Authority}

- Raise housing quality standards

- Do at least the same, if not more, with less

- Less money to spend

- Convince landlords to take less money

- Get residents to own the problems

- Better communication yields more efficiency

- Ensure the PHA's survival

- Restructure to survive and provide better services

- Facilitate third party collaborations

- Maintain current structure or move to a true transitional housing model

- Drug culture

- Lack of family structure

- Troubled tenants and high unit turn-over

- Must have a secure environment to keep us marketable

- Increase resident income

- Elderly population want to leave for safety reasons

- The social mess

- Physical environment

- Lack of recognition that there are problems

- Too many petty rules

- Departmental Bias

- Turf issues

- Increase housing stock

- Lack of government

- Redefine roles between PHA and tenants

- Fear and resistance to change

- Media, public, perception

\section{The big thematic initiatives that cut across the whole agency}

- Launch a development corporation

- Develop non-government dollars

- Change public perception so funds don't dry up

- Move residents to economic Self-Sufficiency

- Contain trouble-making tenarits

- Increase unit turn around

- Communication across departments

- Security 


\section{THEMES FROM THE INTERNAL AND EXTERNAL ENVIRONMENTAL SCANS}

\section{BY PHA Departmental Strategic Planning Teams}

The following section outlines the issues and concerns mentioned by each departmental strategic planning team in their internal and external environmental scans. Because many of the concerns mentioned in the scans were not actual issues, the following section is organized into issues followed by the internal and external factors mentioned in the scans. While each issue may have many factors not mentioned in this section, only those issues and factors described in the environmental scans are listed below. Several teams listed issues without listing internal or external factors pertaining to them. The internal and external environmental scans completed by each department can be found in their entirety in the Internal Environmental Analysis and External Environmental Analysis sections of this report.

\section{POLITICS/ POLITICAL PROCESS}

\section{Issue: Funding}

\section{External Factors:}

- Competition with other agencies for discretionary funding

- Congress

- Federal Deficit

- HUD reinvention

- State: DEA elderly security grant, substance abuse coordinators, teen pregnancy prevention

- City Debt, little effect because we receive little funding

\section{PERSONNEL, TRAINING, INSURANCE AND RISK MANAGEMENT}

\section{Issue: High cost of salaries and benefits package}

\section{External Factors:}

- Health care costs

\section{Internal Factors:}

- Saving money through safety training and the reduction of insurance costs

- Save costs by improving employees training and safety resulting in less workers compensation payments and insurance costs

- Strengthen weaknesses through training

- Growing staff

- Team building 


\section{JOB TRAINING EMPLOYMENT AND SELF-SUFFICIENCY}

\section{Issue: Family Self-Sufficiency, the transition off welfare}

\section{External Factors:}

- Federal funding

- Tax payer/voter discontent

- Fragmentation of service providers

- Health insurance (residents often lose it they get jobs)

- Bias against welfare recipients

- Immigration

- Block grants are a possible opportunity

- Increasing AFDC enrollment

- Welfare reform movement

\section{Internal Factors:}

- We are in the position where we can provide more comprehensive case. management at a lower cost

- Family Investment Center

\section{HOMEOWNERSHIPI DEVELOPMENT OPPORTUNITIES}

Issue: Promote Homeownership Through Development Opportunities

And Possibly Develop for profit

\section{External Factors}

- HUD deregulation as an opportunity to take over other homeownership programs

- Collaboration with RIHMFC and the PPHC

- Work with the city to make abandoned property taxable again, possible CDBG funds?

- Banks and CRA requirements as an opportunity

- Welfare reform could force more people to work and increase the pool of home buyers

- If we continue to house only the poorest, we will need new income sources

- Technology allows us to make buildings at less cost and data allows us

to match homes with buyers and credit institutions

- Current low interest rates are an opportunity

- Competition from PPHC and other Community Development Corporations

\section{Internal Factors}

- PHA knows its clients well

- Need more market studies to identlfy the working poor 


\section{FINANCE AND ACCOUNTING}

\section{Issue: Funding, Specifically the Need to Increase Reserve Level}

\section{External Factors}

- HUD reinvention

- Politicians in Rhode Island can be used as allies

- GPA budget cuts increased our zero rent paying population

- Budget cuts

- Performance funding system has hindered our operations

- Regulatory relief

Internal Factors

- Competent staff with experience

- Good training

\section{Issue: Need to Phase Out IBM 36 System}

Internal Factors.

- Computer system is good, but we must update

Issue: Change the eviction procedure and the perception of the judicial system that we are the "housing of last resort"

External Factors

- Immigration

- Rise in single parent families

Issue: Build and sell low income housing

\section{HOUSING MANAGEMENT}

Issue: More training needed for report writing, training and planning (for the department)

Internal Factors

- Training as an opportunity

Issuc: Create recertification, rent collection teams (interdepartmental)

External Factors:

- GPA benefit cuts causo a strong rise in zero rent tenants

Internal Factors:

- High rate of rent collections 


\section{Issue: Trouble Making Tenants}

External Factors:

- Attitude that public housing is the housing of last resort (judges especially)

- Rise in illegitimacy

Internal Factors

- Security, surveillance cameras

- Mixing of elderly and young disabled populations

\section{Issue: Funding}

\section{External Factors:}

- Congress, and an estimated $22 \%$ reduction in operating subsidy

- Changes at HUD

- Possibility of using deregulation as an advantage

- Voucherization

\section{FACILITIES MANAGEMENT}

\section{lssue: Labor}

Internal Factors:

- Inability to discharge troublesome staffl union constraints

- Need for more training (current program will be redesigned in the fall), more communication

- Some unskilled laborers don't learn well

- High absenteeism

- Contract out some services such as grass cutting and painting at

scattered sites

- Identify inefficient workers

- Scattered site developments tax resources

- Strengths are strong leadership, skills and experience

- Privatize paint services

\section{Issue: Trouble making Tenants}

\section{Internal Factors}

- Repetitive jobs, such as vandalism, stifle creativity

Many work orders are avoidable

- Vandalism and drug related crime

- Disruptive tenants and their guests are a problem

- Need better screening; lease enforcement and crime and vandalism prevention

- Non-cooperation of tenants, not being home, vandalism, litter

- Need better relationship and communication with housing management 


\section{External Factors}

- Social decline: anti-social behavior

- Single parent households

- Drugs

- More support from judges, a change in the perception of the PHA as the housing of last resort

\section{Issue: Technology}

\section{Internal Factors}

- Computer system is a strength

- New software for the work order system will be forthcoming

- Centraily located energy management system a plus

- Energy saving technology saves money

\section{Issue: Self Sufficiency}

Internal Factors:

- Hire residents to promote self-sufficiency

\section{External Factors:}

- Welfare competes with entry level jobs

\section{Issue: Funding}

External Factors:

- Budget cuts

- Voucherization

\section{Issue Security:}

External Factors:

- Need more police

\section{MODERNIZATION AND DEVELOPMENT}

\section{Issue: Reductions in federal funding}

\section{External Factors:}

- HUD reinvention

- Block Grants and Voucherization; Inability to compete with non-public housing

- Regulatory relief/ getting rid of Davis Bacon/Hazardous Waste requirement and design development requirements 
Issue: Self-Sufficiency for residents

Internal Factors

- Greater partnerships with residents

- Greater involvement by upper management with lower management who are closer to the residents

External Factors

- Immigration

- Lack of two parent families

Issue: Improve the selection process at the scattered sites so we can get residents who will take care of the property

Internal Factors

- Spell out what is expected of residents in a contract

- Closer Involvement with faclilties management would help

- Greater partnerships with residents

- Greater involvement by upper management with lower management who are closer to the residents

- Better screening of tenants

External Factors

- Rise in Crime

Issue: Devise a better inventory control system

lssue: Technology

Issue: $\$ 20,000,000$ in current unmet needs will take 5-8 years to complete at present rates

Internal Factors

- Poor conditlon of heating systems

- Fire alarm upgrades needed at High-rises

Issue: Acquisition as an option for single family and duplex (instead of construction)

Internal Factors:

- Bond Authority

- PHA is a strong leader in research and planning 


\section{COMMUNITY SERVICES}

\section{Issue: Trouble Making Tenants:}

\section{Internal Factors}

- Service coordinators spend $80 \%$ of their time on $20 \%$ of the people (trouble making tenants).

- Make residents responsible - educate, stronger tenants' associatlons, training, job preparation

- Courts and the false idea that we are the housing of last resort

\section{External Factors}

- Increase in younger children

- Increase in teen parents

- Increase in Spanish speaking population

- Mentally and physically challenged

\section{Issue: Funding}

\section{Internal Factors}

- Dependent upon external sources of funding, (only $9 \%$ of salaries come from the PHA operating budget)

- Past success with grant writing

\section{External Factors}

- Block grants as an opportunity

PHA as housing leader for the city or state

- Have to become more clearly connected with state agencies that work with us and private foundations

- Increased information gathering is important for grant writing and networking with other agencies

- Collaborate with residents and other service agencies and funding services

- We will have to make the PHA more marketable if Voucherization occurs

\section{Issue: Tenant Self-Sufficiency}

\section{Internal Factors}

- Tenant participation

\section{External Factors}

- The education system is failing 
Issue: Percent of elderly will increase by $40 \%$ from $1990-2005$

External Factors

- Enlarge efficiencies to 1-2 bedroom apartments -

- Assisted living floors

- Work with other agencies to finance services and provide care for older residents

\section{Issue: Privatization}

Internal Factors

- Create a Providence Housing Cómmunity Corporation which would run public housing and develop new moderate income housing

Issue: Security

Issue: Explore a Team Oriented Approach

\section{RENTAL HOUSING}

\section{Issue: Funding/Anticipate changes at HUD}

External Factors

- Changes in the Section 8 program might decrease our administrative fees

- Section 8 Administration fees are a huge asset to the PHA, but we may see a decrease soon

- Voucherization, would this department handle it?

- Continuous changes in the Federal Register

\section{Issue: Resident Self-Sufficiency}

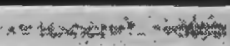

External Factors

- Welfare system competes with employment

- Illegitimate births, Immigration of low income people to Providence

\section{lssue: Communication}

Internal Factors:

- Weaknesses in communication between PHA renters and landlords

- Need better data and information management 


\section{PUBLIC HOUSING UNIT}

\section{Issue: Funding}

Internal Factors

- Increasing overtimê hours depleting fundś

\section{External Factors}

- Budget reductions risk reductions in patrol coverage

- Cuts in state funding for security guards at elderly developments

\section{Issue: Crime}

Internal Factors

- Need to maintain contact with PHA staff and residents

- Increasing arrest rates

- Community policing model

- Computer data system is very beneficial

\section{External Factors}

- Increasing acceptance of the drug culture 


\section{RESIDENT CONCERNS FROM THE RESIDENT SURVEYS}

The following is a list of concerns which appeared on the resident surveys. While specific developments had differing levels of concerns in different areas, this list includes only programs and services which received negative ratings from residents at three or more developments. A more in depth summary of the resident survey results can be found in the External Environment Analysis section of this report.

- Job training

- AIDSISTD oducation

- Recreation for adults

- Education for adults

- Painting

- Pest and rodent control

- Graffiti removal and prevention

- Snow removal

- Laundry services

- Play areas

- Levels of communication with residents and concern for

residents well-being

- Follow up of resident concerns/ quickness of response

- Security 


\section{INTERNAL STAKEHOLDERS SURVEY ISSUES}

Provide Decent, Safe, Sanitary Housing for Poor People

\section{Promote Self-Sufficiency}

- Breaking the cycle of multi-generational dependence

- Strengthen the family structure, social responsibillty

\section{Security}

- Drugs

- Violence

- Gangs

\section{Low Operating Reserve/ Financial Stability}

- Economỹ: National, state, local

- Make best use of funding, use money responsibly

\section{Social Services}

- Collaboration with outside agencies

- Increasing elderly population in the state

- Immigration

- HUD changes

- Welfare reform

- Special needs of elderly and physically challenged residents

Control Trouble Making Tenants' Behavior and Instill Accountability, Responsibility and Good House Keeping Habits

- Tenant selection and screening

- Court's view that we are the housing of last resort

\section{PHA Development Potential}

- Acquire vacant lots for development

- Use bond authority

\section{Deregulation}

- Regulatory burdens and paperwork

\section{Labor Costs}

- Apartment turn-around time

- Union constraints

- Maintain grounds and buildings

\section{Improve Image, Outreach}

- Planning, reporting, information

Inter-Departmental Communication 


\section{EXTERNAL STAKEHOLDERS SURVEY ISSUES}

\section{Self-Sufficiency}

- Welfare reform

- Perception of welfare recipients

- Failing family structure

\section{Crime and Security}

- Provide decent, safe, sanitary housing for low income people

- Substance abuse prevention

- Increasing drug rates

- Increasing crime rates

\section{Responsibility/ Behavior of Tenants}

- Increase tenant participation

\section{Development Potential}

- Acquire vacant lots for development

- Tap into the Enterprise Community

\section{Funding}

- Search for funding

- Budget cuts.

\section{Further Integration of Special Services}

- Activities for children

Maintain Property and Buildings

Greater Collaboration With Outside Agencies

\section{HUD Reinvention}


The final stage of the Strategic Issues Identification step is to organize and list the issues chosen as strategic issues for the Providence Housing Authority. Issues were deemed to be strategic if they were a consistent theme throughout the strategic planning process. An issue that was listed by a majority of the PHA's external and internal stakeholders and showed up on the resident surveys and environmental scans would most likely be chosen. Other issues were chosen because of their strategic significance to the PHA. While increasing the PHA's operating reserve or increasing efficiency through energy management might not have been consistent themes throughout the process, they were deemed to be vital to the survival of the PHA and the successful completion of our mission and mandated obligations.

The remainder of this section begins with a list of the Providence Housing Authority's strategic issues. These issues are grouped into six separate themes. Each of these themes is designed to be both broad and multi-departmental in scope. Responding to each of these themes will take a collaborative effort and a strategic mindset.

Following the list of strategic issues is a brief description of each one. Summaries of the strategic issues explain why the themes and issues are of strategic importance to the PHA. Each of these issues relates in some way to the PHA's mandates, mission statement and vision of success. The following section concerning strategies will outline the PHA's approach to respond to these themes and issues. 


\section{PROVIDENCE HOUSING AUTHORITY \\ STRATEGIC PLAN 2000}

\section{STRATEGIC ISSUE IDENTIFICATION}

\section{Theme One: Improve Living Conditions}

1. Security

2. Five Year Comprehensive Modernization Plan

3. Increase resident involvement and responsibility

\section{Theme Two: Self-Sufficiency}

1. Family Self-Sufficiency Program

2. Homeownership Program

3. Family Investment Center

- Case management

- Employment counseling

\section{Theme Three: General Management}

1. Increase Operating Reserve

2. Improve inter-departmental communication

3. Identify new funding sources

4. Reduce/control energy costs

5. Increase efficiency through restructuring and/or privatization

6. Public relations and outreach

7. Technology and computers

8. Team building

\section{Theme Four: Social Services}

1. Attract and provide for the growing elderly population

2. Collaboration with outside agencies

3. Strengthen parenting and family skills

4. Address growing violence in $18-25$ year old age group

\section{Theme Five: Development Efforts}

1. Roger Williams site

2. Office space

3. New maintenance garage

Theme Six: Reorganization/Re-engineering

1. Create New Special Projects Department

2. Reengineer Existing PHA Operations

3. Reinvent Existing Departments

4. Consider Privatization lssues 
Theme One

Improve Living Conditions

Many factors contribute to the quality of living conditions in public housing. For planning purposes, we have focused on three: modernization, security, and resident responsibility. Each of these factors impacts life in public housing in a distinct and meaningful way. Addressing these issues will involve multi-departmental planning and action. Strategies to address each of the themes developed in this section can be found in the following section on strategies.

Prevailing images of public housing are shaped by the media's attention to the nation's worst public housing developments. Images of troubled high-rise developments such as St Louis Pruitt-Igoe (demolished in the 1970s) and Chicago's Cabrini Green do not paint an accurate picture of public housing in America. A 1983 study by the United States Congressional Budget Office found that two thirds of the public housing units in the nation are administered by the 2,775 public housing authorities which operate fewer than 6,500 units. The majority $(54 \%)$ of the nation's PHAs operated fewer that 200 units. Further, $75 \%$ of family public housing developments were comprised of low rise buildings. Only $7 \%$ of the nation's public housing units were located in high-rise developments administered by PHAs operating more than 200 units. Finally, of the more than 3,000 public housing authorities in the United States, only 100 are considered distressed by the Department of Housing and Urban Development.

\section{Modernization}

While it is certainly true that public housing developments are often in need of physical improvements and modernization, it should be noted that some of these developments were originally built in the 1940s. Natural wear and tear (the PHA's first development was constructed in 1942) and improvements in materials and technology necessitate the need for continued modernization. Further, several high rise buildings in the Hartford Park development were demolished in the late 1980s to lower population density and increase open space, and all of our developments now include units designed to meet the special needs of handicapped residents.

In keeping with the PHA's Five-Year Comprehensive Plan for Modernization, Chad Brown, Admiral Terrace, Sunset Village, Manton Heights and Hartford Park (Phases I and II) have been completely modernized. Two buildings at Codding Court have also undergone complete modernization and the remaining work is scheduled over the next few years. Funding for the final phase of the Hartford Park renovations has also recently been approved.

\section{Security}

The information gathered for the Strategic Plan along with the results of a recent Social Services Needs Assessment point to security as the number one concern for residents. Gangs, violence and drugs are perceived as major problems both by those who live in our developments as well as by those who work with our residents. To deal with these problems members of the Providence Police Department's Public Housing Unit formed a strategic planning team and participated in planning events. This team took part in all aspects of the strategic planning process and, along with PHA staff, developed a goals management plan to address the issue of crime in public housing.

It is especially important to address the issue of crime strategically. While the social problems which contribute to high rates of crime often appear to be worsening, funding for the Elderly Security Program has been cut and overtime hours for the PHU (paid for by the PHA) are being spent at a rate that will exhaust allocated funds well before the end of the fiscal year. 


\section{Resident Responsibility}

Like crime and security, resident responsibility was a major theme throughout the strategic planning process. Both PHA staff and the external stakeholders who serve our residents constantly referred to the need to instill a sense of responsibility among residents and to deal effectively with trouble making tenants. This issue is important for several reasons. The Department of Community Services estimates that their service coordinators spend $80 \%$ of their time dealing with the $20 \%$ of residents who cause disruptions in programs and cause trouble in the developments. In an atmosphere of increasing social service needs and decreasing funding, resources must be redirected towards helping our tenants become self-sufficient.

Trouble making tenants also cost the PHA through damages and vandalism. Vandalism and litter work orders require the Facilities Management Department to use important staff time on preventable problems. Damages to apartments also hamper the operations of the PHA by adding substantially to the time it takes to turn over a vacant unit.

This problem taxes both the physical and personnel resources of the PHA and must be dealt with effectively. In addition to the financial costs involved, allowing trouble making tenants to remain unaccountable sends them the wrong message and undermines the morale of our responsible residents.

More outreach efforts will have to be made to educate judges about how their decisions effect public housing residents. Many judges operate under the belief that the PHA is the "housing of last resort" and thus make evictions very difficult. It is important to help these judges understand that by acting upon this belief they are often failing in their duties to help protect the interests of the majority of our tenants who are willing to abide by the law, their lease, and the rules and regulations which govern the PHA.

RELEVANT MANDATES
- Expectations of Stakeholders.
City of Providence Home Rule Charter (In broad terms).
Annual Contributions Contract (HUD).
Rhode Island General Laws 45:25.
PERTINENT SECTIONS OF THE PHA'S MISSION STATEMENT
- Provide affordable, decent, safe, and sanitary housing through the maintenance of our existing units and the
development of new units
To create an environment which enables residents to live responsibly and with dignity
To create and maintain public confidence in the Authority's operations and staff
TO ensure that the facilities owned and managed by the PHA are marketable in the community and are appealing to
residents
TIES TO OTHER ISSUES
Fear of crime damages the image of public housing.
Fear of crime makes public housing less marketable, particularly to the elderiy.

Note: For greater detail concerning the PHA's mandates and mission, please see the appropriate section of this report. 


\section{Theme Two}

\section{Family Self-Sufficiency}

Of the 1,230 families living in the PHA's family and scattered site developments, approximately 840 list their primary source of income as AFDC. This population will be affected by anticipated welfare reforms which are likely to include both time limits and work requirements. While work requirements may result in PHA residents increasing their income, time limits likely will result in an increase in residents with no income at all. (Recent cuts in the state General Public Assistance (GPA) program have resulted in a substantial increase in the percentage of PHA residents paying zero rent.) While the majority of AFDC recipients stay on welfare for less than two years at a time, $70 \%$ of those who leave welfare for a month return. Proposed welfare reforms include time limits which are cumulative, and thus would likely impact recipients with a tendency to leave and return to welfare.

Welfare dependency is a complex problem for the PHA. As was noted in the Housing Management Department's external environmental scan, the problem is not solved by changes in the economy. While it is tempting to think that increases in the availability of jobs will solve the problem, history has shown that this is not necessarily the case. In fact, the years of greatest growth in welfare dependency (from 1960-1975 national welfare rolls increased from 2.37 million cases to 7.62 million) were years when the national unemployment rate remained at about 4.9 to 5.5 percent. This rate of increase in welfare rolls was substantially greater than the rates from 1975 to 1986 , when unemployment rates remained well over $7 \%$ peaking at $9.7 \%$ in 1982 . While the availability of appropriate jobs is clearly a factor of welfare dependency, it is not the only factor. Other factors such as the rise in single parent families and teenage pregnancy better explain the problem.

In the State of Rhode Island, for example, $88.2 \%$ of families receiving AFDC are headed by a single parent, and fewer than $10 \%$ of all households in the state that do not receive AFDC benefits are single parent households. Further, $60 \%$ of recipients who began receiving AFDC benefits before their 22 nd birthday become chronically dependent, as opposed to $39 \%$ of those entering the program after their $22 \mathrm{nd}$ birthday. It is the social aspect of welfare dependency that makes public housing the logical vehicle through which to promote self-sufficiency. Because we are home to entire families, we can reach out to a new generation of children and help them make decisions that will allow them to have a future beyond public housing and government dependency. Through programs designed to be both educational and fun, the PHA is already attempting to teach children about the consequences of drug use, sexual promiscuity and dropping out of school.

To those of our residents who are currently dependent upon welfare, we can offer comprehensive resources and services to help them make the transition to self-sufficiency. In addition to adult education programs conducted through the Department of Community Services, the PHA runs a Family Self-Sufficiency Program, a Homeownership Program, and beginning next summer, a Family Investment Center. In addition to job training, the Family Investment Center Program will investigate job development opportunities for our residents.

Because we know our residents well and can offer comprehensive case management, we are in good position to impact this problem. Still, the complex nature of welfare dependency requires that the PHA take proactive steps to develop programs and services designed to transition families off of welfare. 


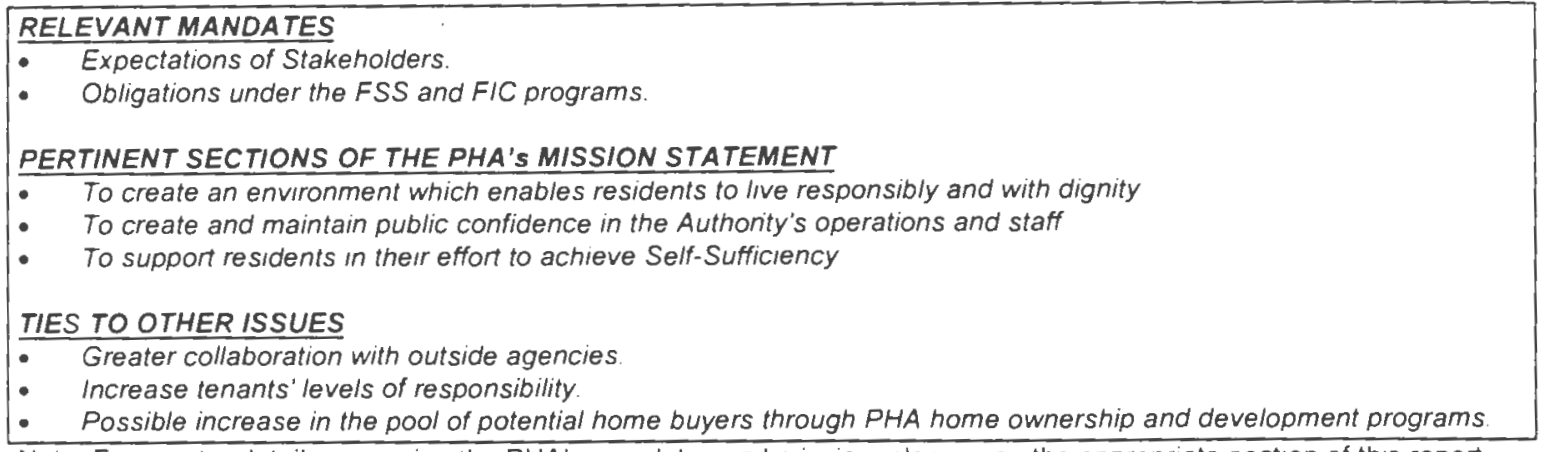

Note: For greater detail concerning the PHA's mandates and mission, please see the appropriate section of this report.

\section{Theme Three}

\section{General Management}

Technological improvements in computers have allowed PHA administrative and managerial offices to increase efficiency in report and grant writing, records retention and retrieval and information gathering. A new computer and data base has also greatly assisted the Public Housing Unit in managing information and tracking criminal activity. New networking capabilities have also increased inter-departmental communication, and the PHA already plans to phase out the IBM 36 system, thus allowing all PHA computers to run compatibly. Other suggested improvements include an interactive financial reporting system, a new work order system, and an improved inventory control system.

Technological advances have also increased efficiency and reduced costs in the area of energy management. The PHA's central energy control system has been a success; however, some heating systems are in poor condition and more planning and analysis is called for.

Greater levels of teamwork and inter-departmental communication will allow the PHA to function at maximum efficiency. Communication is important among PHA departments because the goals and actions of one department will likely have substantial repercussions for others. Teamwork and communication will allow the PHA as a whole to function in a clear and consistent manner. Reorganization and privatization of some services and functions is also an option which will be explored.

Greater collaboration with outside agencies and a search for new funding sources are important components of this theme. Public relations and outreach are needed to improve the image of public housing, attract funding and market our developments. Further, it is a goal of the PHA to increase our operating reserve. Operating reserves are currently measured under PHMAP and the indicator is expected to change from $40 \%$ to 90 days worth of operating funds in reserve. One external factor which influences this goal is the proposed reduction in administrative fees for the Section 8 program. The surplus from these fees has been used to avoid running an operating deficit. While the operating reserve has been the PHA's weakest PHMAP indicator, it has been our policy to ignore this indicator if improving it would jeopardize other scores.

While it is easy to approach general management issues from a purely operational perspective, it is often necessary to step back and look at our operations from a strategic vantage point. The purpose of this theme is to develop new approaches to dealing with every day business. 


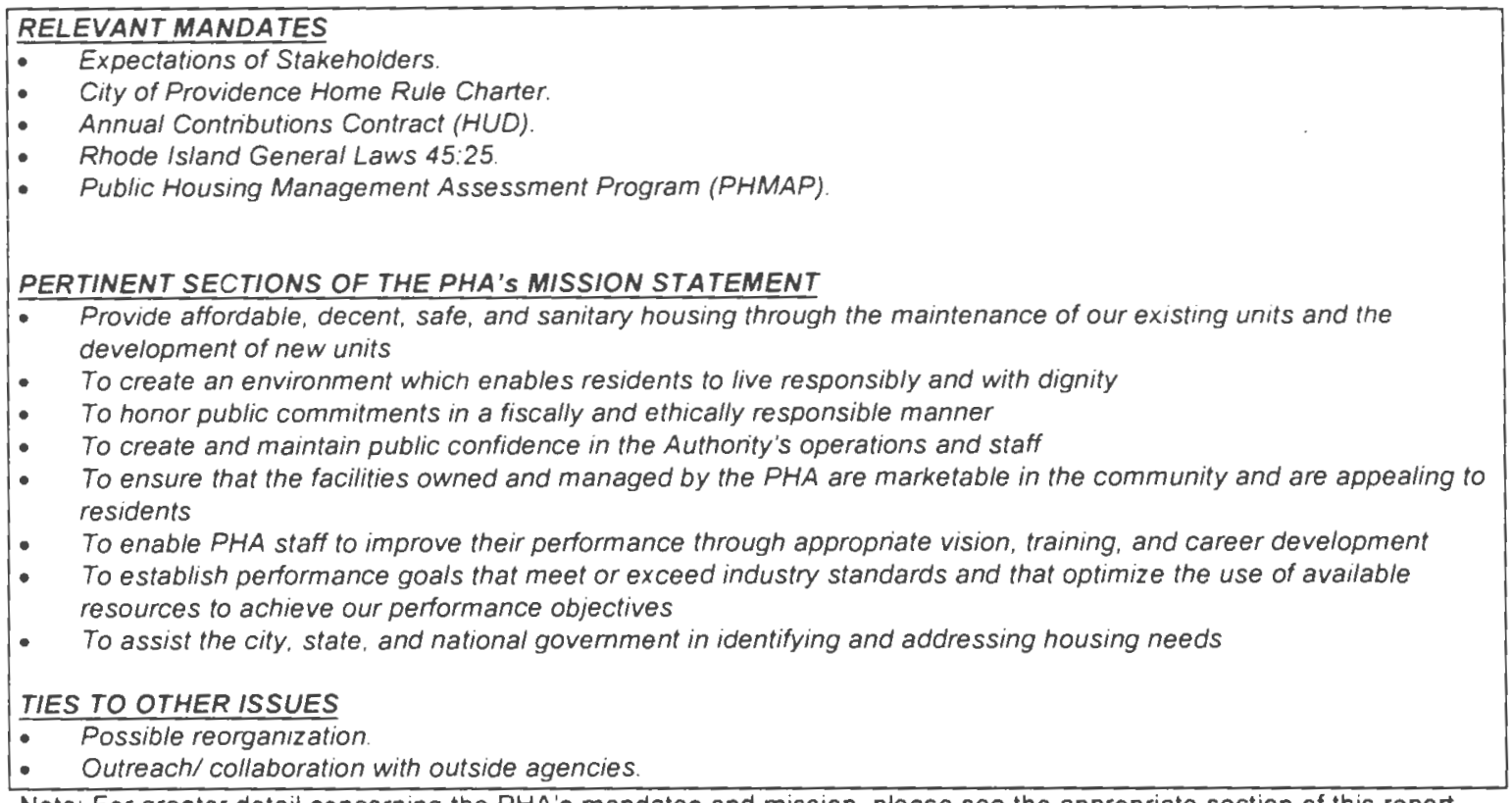

Note: For greater detail concerning the PHA's mandates and mission, please see the appropriate section of this report.

\section{Theme Four}

\section{Social Services}

Four strategic issues facing the Providence Housing Authority under the theme of social services are the increasing elderly population in the city and state, increasing levels of violence among 1825 year olds, the need to strengthen family and parenting skills, and the need for greater levels of collaboration with outside agencies. It is important to note that the theme "Social Services" does not apply specifically to the Department of Community Services. All of the major themes are designed to be broad in scope, and each one pertains to multiple departments.

\section{The Increasing Elderly Population}

The number of elderly living in the state is expected to increase by $40 \%$ between 1990 and 2005 . While this population will face specific housing needs, there is considerable competition for this market. Other housing providers are often able to offer a wide range of amenities tailored to the elderly population. Fear of crime along with federal regulations which, in the past, have required public housing authorities to house non-elderly disabled residents in elderly developments have contributed to low levels of interest in public housing among the elderly population. The mixing of the two populations has had a particularly negative impact on housing for elderly residents. In addition to basic differences in lifestyles between the elderly and non-elderly disabled, many of the non-elderly suffer from mental illness and drug and alcohol addictions. The problem is exacerbated by the reluctance of elderly to live in public housing, resulting in an increase in the non-elderly populations in elderly developments thus creating a downward spiral of demand. This has created an extremely tenuous living situation.

Recent changes in federal regulations, however, have allowed PHAs to designate specific developments as elderly only. The Providence Housing Authority recently became the second housing authority to have its allocation plan approved. Sr. Dominica Manor and Carroll Tower are now designated as elderly only housing. Young disabled residents currently living in these developments can take advantage of a special Section 8 allocation, but vacancies left by these residents must be filled within 60 days or the units are to be made available to other non-elderly 
applicants. There is, therefore, a need to increase our outreach efforts to reach the elderly population and to re-evaluate and re-organize the programs and services we offer this population. Failure to reach out to this population will result in the populations in these developments effectively remaining mixed. Currently, there is no waiting list of elderly applicants for these developments.

\section{Greater Collaboration With Outside Agencies}

The second major issue is the need to increase collaboration with outside agencies. The Providence Housing Authority deals with many and various social service providers. Continued collaboration will be necessary to maintain the highest level of services possible within an environment of decreasing funding. Already the PHA has seen significant cuts in our Comprehensive Grant, Elderly Security, and Teen Pregnancy programs and we expect cuts in our operating budget for the next fiscal year.

Because our residents are served by many social service agencies, there exists great potential to maintain collaborative efforts and establish new ones. The benefits of collaboration are particularly important for residents with special service needs. During our external stakeholder process, we discovered that many of the agencies who have worked with the PHA staff and residents for substantial periods of time know very little about what we do and what we hope to accomplish. Better communication is needed to ensure that the goals of the PHA and the agencies that serve our residents are consistent and designed to further the realization of our mission and vision of success.

\section{Strengthen Family and Parenting Skills}

The third issue under this theme is the need to strengthen and develop parenting and family skills. The majority of families in the PHA are headed by a single parent. In addition, many of these parents had their first child at a young age. Strong parenting skills are especially crucial for those residents attempting to achieve self-sufficiency while raising children.

\section{Violence Among Young Adults}

The final issue in this section pertains to violence among young adults. In both the strategic planning surveys and the 1995 Social Service Needs Assessment Survey, residents listed crime and security issues as their primary concern. The issue of violence is closely linked with the drug problems which plague public housing. The PHA currently administers a drug prevention program that seeks to provide positive alternatives to our residents. The PHA strategy also focuses on tenant selection and modernization as means to combat the problems created by drugs. Typically thought to be a security problem, the issue of violence in our developments must be confronted using a comprehensive multi-departmental approach.

RELEVANT MANDATES

- The PHA allocation plan.

- City of Providence Home Rule Charter (in broad terms).

PERTINENT SECTIONS OF THE PHA'S MISSION STATEMENT

- Provide affordable, decent, safe, and sanitary housing through the maintenance of our existing units and the development of new units

- To create an environment which enables residents to live responsibly and with dignity

- To support residents in their effort to achieve self-sufficiency

- To honor public commitments in a fiscally and ethically responsible manner

- To create and maintain public confidence in the Authority's operations and staff

- To ensure that the facilities owned and managed by the PHA are marketable in the community and are appealing to residents

- To assist the city, state, and national government in identifying and addressing housing needs

TIES TO OTHER ISSUES

- Greater collaboration with outside agencies. 
Outside funding sources

- Crime and security.

- The need to address crime.

- The need to reach out to and educate the community.

Note: For greater detail concerning the PHA's mandates and mission, please see the appropriate section of this report

\title{
Theme Five
}

\section{Development Efforts}

The current deficit reduction climate in Washington is also a climate of deregulation. This could benefit the Providence Housing Authority in two major areas. First, deregulation is likely to reduce costs for the PHA. Cumbersome record keeping requirements and regulatory burdens such as the Davis Bacon Act have resulted in inflated construction costs and excessive paperwork. The prevailing wage requirement under Davis Bacon alone adds an estimated $33 \%-40 \%$ to the labor costs of a construction project. Further, the Department of Modernization and Development staff spend an estimated 20 hours per week on Davis Bacon related paperwork. Should such requirements be repealed, it could result in a substantial savings to the PHA and would allow us to run our operations in a more efficient manner.

Deregulation could also affect the PHA by allowing us to broaden our mission into the area of development. Already the PHA plans to develop the area of the Roger Williams housing development site that was demolished in the late 1980's and early 1990's. There are currently 40 units of public housing left on this site leaving 23 acres of undeveloped land. An earlier proposal to build townhouses on 10.3 acres of the site fell through in January 1995, and the PHA resumed ownership. This summer the PHA conducted a survey of neighborhood homeowners in order to gain a better understanding of what neighborhood residents want for the site. The PHA also cleaned up the area as a sign of good faith.

In addition to the Roger Williams site there are approximately 8,000 vacant housing units located throughout the city. Should the PHA develop these lots and sell them through our homeownership program, these units would be returned to the tax rolls. This situation would benefit the PHA, low and moderate income families desiring to own their own home and the city.

Development projects may be funded through a number of different avenues. In addition to the PHA's bond authority, lending institutions are bound to philanthropic obligations under the Community Reinvestment Act. Current low interest rates are also in the PHA's favor, and it may be possible to tie development options in with the Providence Enterprise Community.

Other possible projects include the acquisition of garage and storage space for the Facilities Management Department and the relocation of the PHA's administrative offices from Dexter Manor II. Should the administrative offices be moved to a new location, two floors in Dexter Manor II would be opened up for additional housing units for the elderly and disabled.

\author{
RELEVANT MANDATES \\ - Rhode Island General Laws 45:25 \\ - PHA Certificate of incorporation. \\ - City of Providence Home Rule Charter (In broad terms). \\ - Annual Contributions Contract (HUD). \\ - \\ PERTINENT SECTIONS OF THE PHA'S MISSION STATEMENT \\ - Provide affordable, decent, safe, and sanitary housing through the maintenance of our existing units and the
} development of new units 
- To create an environment which enables residents to live responsibly and with dignity

- To assist the city, state, and national government in identifying and addressing housing needs

TIES TO OTHER ISSUES

- Increased collaboration with outside agencies.

- Possible ties to the PHA's FSS and FIC programs.

Note: For greater detail concerning the PHA's mandates and mission, please see the appropriate section of this report

\section{Theme Six}

\section{Reorganization/ Reengineering}

As a taxpayer-funded organization, the Providence Housing Authority has a moral and legal obligation to provide quality services at the lowest possible cost. In order to meet this standard along with the others listed in our mission statement, we are prepared to reexamine our organization to determine if there is a better way to provide services to our stakeholders. This section examines the themes of reorganization and reinvention along with several related secondary themes.

The Providence Housing Authority was established in 1939 around one primary goal: to temporarily house low-income people until they were in a financial position to live without government assistance. For many years, this model worked well. The average length of residency in public housing was two to five years and few families lived in the developments beyond a single generation. In the past two decades, public housing has gone through a dramatic change. Considered by many to be the housing of last resort, residents are increasingly staying for longer periods of time including many families currently in the midst of multi-generational stays in publicly assisted housing. Public policy has actually encouraged families to remain dependent on government assistance through a perverse system of disincentives that punishes the creation of formal two parent families, savings and employment, and fails to provide incentives to join the mainstream of American citizenship. Only recently, through the Family Self-Sufficiency and Family Investment Center programs and the PHA's own community center-based education programs, has the trend begun to reverse for families trapped in the cycle of dependency.

\section{New Department of Special Projects}

The information gathered during the strategic planning process clearly shows that we must assist our clients (residents) to break the bonds of helplessness by becoming economically independent. To address the needs of our residents, the PHA proposes several initiatives to be implemented by the year 2000. Of considerable importance will be the creation of a Department of Special Projects. This new department's principal responsibilities will include the coordination of both the Family Self-Sufficiency Program and Family Investment Center(s). Both of these programs promote economic independence through self-sufficiency. The Special Projects Department will also prepare special grant applications to promote education and employment for residents Presently, the duties of the FSS and FIC programs are being performed by a disparate group of individuals who need greater focus and impact. The creation of a new department sends a signal to our residents and our collaborators that we are committed to bringing about resident selfsufficiency. The primary goal behind the creation of this department is: to prepare our residents for the labor market and economic independence.

\section{Reengineering}

In a continuing effort to better serve our clients, the PHA will commence a reengineering effort starting in late 1996. This effort will examine our current methods of service delivery. Every aspect of performance and delivery will be reviewed and critically examined. Reengineering has been defined as: the rapid and radical redesign of strategic business processes-and the systems, policies, and organizational structures that support them-to optimize the work flow and productivity 
in an organization. The goals of the reengineering process are to increase profitability, customer satisfaction, revenues, quality, productivity, market share, accuracy, and speed while decreasing costs. As we enter into the Twenty-First Century, the PHA will continue to operate under the private sector paradigm.

\section{Reinvention}

The "reinvention" of the PHA is closely tied to the reengineering process. In fact, reinvention is usually the next step after the reengineering process has been completed The reinvention of government was popularized by the best selling book Reinventing Government: How the Entrepreneurial Spirit is Transforming the Public Sector written by David Osborne and Ted Gaebler. Their thesis is that mission-driven organizations that are results, goals and marketoriented and that provide alternative service delivery options are the most successful models for customer satisfaction. Combining reengineering and reinvention may result in an organizational structure entirely different from what we have today. However, such steps are necessary in an environment where housing authorities will be asked to provide more services with less funding. Under these conditions it is imperative that we reassess our entire organizational structure and redefine how we conduct our business. Governmental entities that fail to adopt current business practices are doomed to fail.

\section{Privatization}

In most cases the private sector delivers services cheaper and more efficiently than governmental entities. While certain functions remain the domain of government, many others are better performed by the private sector. A preliminary analysis of one type of service performed by $\mathrm{PHA}$ staff indicates that certain services can be privatized. At the same time, we recognize that some skilled positions, previously contracted for at high prices, are more cost effective if performed by PHA staff. The PHA will assess the options available to us based upon both quantitative qualitative and comparisons.

RELEVANT MANDATES
EXpectations of Stakeholders.
City of Providence Home Rule Charter.
Rhode Isiand General Laws 45:25.
PERTINENT SECTIONS OF THE PHA's MISSION STATEMENT
Provide affordable, decent, safe, and sanitary housing through the maintenance of our existing units and the
development of new units
To create an environment which enables residents to live responsibly and with dignity
To honor public commitments in a fiscally and ethically responsible manner
To create and maintain public confidence in the Authority's operations and staft
To ensure that the facilities owned and managed by the PHA are marketable in the community and are appealing to
residents
To enable PHA staff to improve their performance through appropriate vision, training, and career development
To establish performance goals that meet or exceed industry standards and that optimize the use of available
resources to achieve our performance objectives
To assist the city, state, and national government in identifying and addressing housing needs
TIES TO OTHER ISSUES
POSsible privatization of some functions or services.
Outreach/ collaboration with outside agencies.

Note: For greater detail concerning the PHA's mandates and mission, please see the appropriate section of this report. 


\section{Step Seven Strategy Formulation}

The seventh step of the Bryson model is the formulation of strategies. "Strategies are defined as a pattern of purposes, policies, programs, actions, decisions, or resource allocations that define what an organization is, what it does, and why it does it."126 This step of the strategic planning process forms a bridge between an organization's mission and the outside environment. Having completed the external and internal environmental scans, the internal and external stakeholder analysis, and a review of our mandates and mission, the past step, strategic issues identification, defined the PHA's current situation relative to the outside environment. In this step. strategies are developed to address strategic issues and to achieve desired goals and a vision of success

Strategic issues can be developed for differing levels within an agency. For example, four basic levels offered by Bryson are.27

1. Grand strategy for the organization as a whole

2. Strategic public planning unit (SPPU) or strategic nonprofit planning unit (SNPPU) strategies. Note, however that if the organization as a whole and the SPPU or SNPPU are synonymous, the first two categories will be the same; if not, the SPPUs or SNPPUs may be divisions, departments, or units of larger organization.

3. Program or service strategies.

4. Functional (such as financial, staffing, facilities, and procurement) strategies.

One fundamental aspect of strategic planning is creativity. There is no point in attempting the process if strategies are mundane and designed to maintain a business as usual attitude. Creativity in developing alternatives and visions is a crucial part of strategy formulation. Remember that strategic planning often leads to drastic change. While it is true that change is inevitable (especially considering the current external environment for public housing) it is vital for organizational survival that such change be planned for and directed. An organization that fails to develop effective strategies to translate its mission statement into the context of its environment is doomed to fail.

\section{PHA Strategic Planning Retreats}

The previous section concerning strategic issue identification discussed several PHA planning retreats. During these retreats planning teams also developed strategies to address strategic issues. During the September 19th planning retreat at Organizational Futures, planning teams identified strategic issues and developed appropriate strategies. Strategies were further developed during the October 4th-5th planning retreat at the Whispering Pines Retreat Center at the University of Rhode Island's Alton Jones Campus. During this two day retreat planning teams developed Goals Management Plans to address both strategic and operational issues.

Goals Management Plans list each departments' goals, objectives, tasks and activity indicators Goals are visions which are broad in scope. Objectives are measurable milestones that indicate movement towards the realization of a goal. Unlike goals, objectives are specific, measurable, 
attainable, realistic, and time bound. A goal might be "to address the problem of crime in public housing." An objective would be to institute four resident crime watches in the PHA's family developments by April 30th, 1996.

Tasks are even more specific than objectives. They are a list of all of the specific steps that must be done in order to complete each objective. They are time bound, measurable and are usually personnel specific Tasks are usually measured simply through an activity indicator which shows that the task has been successfully completed.

An additional planning retreat was conducted on November 8th to introduce both strategic and goals management planning to staff who were not involved with the departmental strategic planning teams. These staff members participated in exercises and developed both a SWOT (Strengths, Weaknesses, Opportunities and Threats) analysis of the PHA and a Goals Management Plan to address a particular weakness or threat. Much of the work completed by these staff members was incorporated into the strategic planning process.

All Plans were combined into a single document containing 103 goals and 250 objectives. The result is a monitorable, measurable collection of strategies which will enable us to successfully realize our vision of success while fulfilling our mandates and mission.

The goals and objectives developed for the PHA's Goals Management Plan have been included as an appendix to this report. 


\section{Providence Housing Authority}

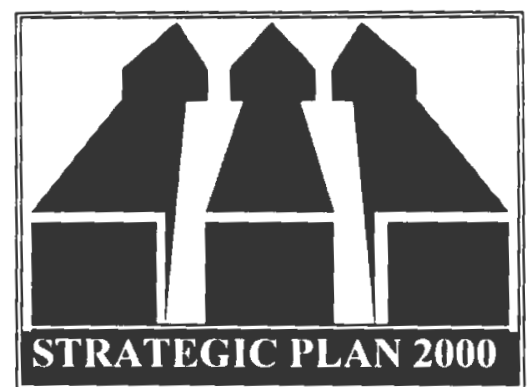

\section{Vision of Success}

$T^{\mathrm{h}}$ he Providence Housing Authority reaffirms, with the release of this strategic plan, its commitment to its mission. At its core, the strategic planning process is about identifying the unwavering principles, the core values, of an organization. When we began this process, the message from Washington went beyond even the most ominous-sounding budget cuts; the very existence of our agency and several thousand like it around the country was being called into question. In one sense, this plan is our response to the question: What purpose does a public housing agency serve? Herein we articulate our axiomatic ideals, our professional landscape... and boundaries, our vision of our future and a strategy for its manifestation. Our place in the world.

The Providence Housing Authority is rooted in its mission and will remain sustained by it. We will continue to provide quality housing in an environment uniquely beneficial to residents. We are enabled neither by particular programs nor by particular housing developments; we are the artery between housing resources and resident access to personal growth and economic independence. The best traditional housing management practices keep that connection alive...innovation can render it vibrant.

In our inventory of organizational values, honesty and communication emerged as our highest commonly held priorities. Certainly, we must acknowledge the importance of public confidence in us. Everyone who does business with the PHA -- every resident, every contractor, every vendor, every taxpayer with a question -- should walk away knowing they were dealt with squarely and given as much information as they wanted. Equally important is the need to reorganize in-house around a team-driven approach to advancing our mission. All of the strategic issues identified in this process call for interdepartmental responses. What better basis for a shift in public housing administration than the trust and mutual respect implicit in the values we hold strongest?

The public's confidence in us, and, indeed, our confidence in ourselves, will be derived from the degree to which we can measure our success. Information is power. We must continue to be driven by specific and quantifiable performance goals and objectives and to measure our attainment of them. The performance we manage is written by the cast: The Board of Commissioners, the staff and the residents. We have, thus far, operated in an environment where our internally generated goals are more or less consistent with federal mandates and, ideally, this will continue to be the case. However, the public housing industry has called, for many years, for 
deregulation of PHAs. We can support this important effort by continuing to exemplify a truly "independent" authority over our own operations.

This plan helps us identify the best route to improved fulfillment of our mission, and identification of strategic issues allows us to cover more territory by "working smarter." Some of the most powerful themes (issues identified repeatedly by residents, external stakeholders and staff across all departmental lines) require us to move into partnerships and to shore up efforts in areas that we need to begin to see as germane to our mission. Crime and the need for improved building security is now our problem. Multigenerational public assistance dependence is now our problem. Fortunately, we have sound ideas for addressing these issues. As we begin to see them as part of what we do, and not as external evils over which we have no control, we begin to see the possibility of a radically different, of a healthier, public housing program in Providence.

Anyone with any knowledge of the PHA who has had occasion to look over the archival records experiences at least one moment of understanding how much things have changed, and it usually makes them grin. Why are we bemused by the past? Probably because people seemed so endearingly unaware of what was coming. Historically, we have a unique perspective, especially on the value of progress. Better access to information, better construction technology, refined management practices and other attributes of our age allow us to shape our own future, rather than be swept along by it, as many of those people in the old black and white photographs of Dexter Manor and Chad Brown undoubtedly were. There are aspects, though, of a simpler public housing program which this planning process tells us we are not anxious to discard. We are bringing housing, a basic human need, into a new -- and, we hope, a better -- century. This plan begins to describe how to go about it. 
Endnotes

Strategic Plan 2000

1Bryson, John M. 1988. Page 49

${ }^{2}$ Bryson, John M. 1988. Page 96

${ }^{3}$ Goodstein, Leonard D. et al, Page 169

${ }^{4}$ Goodstein, Leonard D. et al, Page 172

${ }^{5}$ Goodstein, Leonard D. et al, Page 183

6Bryson, John M. 1988. Page 101

7Bryson, John M. 1988. Page 99

${ }^{8}$ Goodstein, Leonard D. et al, Page 172

${ }^{9}$ Goodstein, Leonard D. et al, Page 169

${ }^{10}$ Bryson, John M. 1988. Page 108

${ }^{11}$ Bryson, John M. 1988. Page 108

Step Four: External Analysis

12Bryson, John M. 1988. Page 99

13Bryson, John M. 1988. Page 100

Step Five: Internal Analysis

14Bryson, John M. 1988. Page 55

15Bryson, John M. 1988. Page 52

16 Bryson, John M. 1988. Page 139

Step Six: Issue Identification

${ }^{17}$ Bryson, John M. 1988. Page 161

${ }^{18}$ Bryson, John M. 1988. Page 245

19Ring, Peter Smith. 1988. Strategic Issues: What Are They and From Where Do They Come? From Strategic Planning: Threats and Opportunities. Ed. John M. Bryson and Robert C. Einsweiler. American Planning Association. Chicago. (P. 71)

20Fogg, C. Davis. 1994. Team Based Strategic Planning: A Complete Guide to Structuring, Facilitating and Implementing the Process. American Management Association. New York. Page 152

21 Bryson, John M. 1988. Page 49

22Bryson, John M. 1988. Page 148

23Bryson, John M. 1988. Page 140

24 Bryson, John M. 1988. Page 141

25Bryson, John M. 1988. Page 141

Step Seven: Strategy Formulation

268ryson, John M. 1988. Page 13

27 Bryson, John M. 1988. Page 164 


\section{Strategic Planning: A Case Illustration}

Chapter Four: Progress: A Year Later

Introduction

Method

Results

Barriers

Resolved Objectives

Obsolete Objectives

Objectives Due As Of December 1996

Departmental Summaries 


\section{Chapter Four: Progress, A Year Later}

\section{Introduction}

The following chapter details the progress made by the Providence Housing Authority in meeting the goals and objectives which comprise the Strategies (Goals Management Plan) component of the PHA's Strategic Plan 2000. The Strategic Plan 2000 document was completed in February 1996, so this represents almost a year's worth of implementation.

\section{Method}

In writing this assessment, interviews were conducted with members of the PHA's Departments and functional areas to determine the status of each of the objectives listed in the Providence Housing Authority's Goals Management Plan. The status of each objective was determined to fall into one of three categories, the "On Target" category. the "Problem" category, and the "Obsolete/Resolved" category. "Obsolete/Resolved" category objectives are not counted in the calculations for percentages of objectives in the "on target" or "problem categories." Each category has been further broken down by the degree to which work had been completed. The categories and sub-categories are listed and explained in the table below. 


\begin{tabular}{|c|c|c|}
\hline \multirow{4}{*}{$\begin{array}{l}\text { On Target } \\
\text { Category }\end{array}$} & Not Yet Begun & Activities have not begun and are not scheduled to begin until a later date. \\
\hline & Completed & $\begin{array}{l}\text { Objective has been completed satisfactorily. An objective, which must be completed } \\
\text { each year, is included in this sub-category, however, objectives which must be } \\
\text { completed more frequently than once per year are included in the ongoing sub- } \\
\text { category. }\end{array}$ \\
\hline & On schedule/Ongoing & Progress is on schedule or is proceeding on an ongoing basis and is on schedule. \\
\hline & In Progress & Progress is under way, but behind schedule by a month or less. \\
\hline \multirow{3}{*}{$\begin{array}{l}\text { Problem } \\
\text { Category }\end{array}$} & Not Yet Begun & Activities have not begun and but were scheduled to have already begun. \\
\hline & $\begin{array}{l}\text { In Progress or } \\
\text { Ongoing }\end{array}$ & $\begin{array}{l}\text { Progress is under way, but belind schedide by two months or more or progress is being } \\
\text { performed, on an ongoing basis but is behind schedule. }\end{array}$ \\
\hline & Barrier & Progress is/u ill be delayed dive to barrier/s. \\
\hline \multirow{2}{*}{$\begin{array}{l}\text { Obsoletel } \\
\text { Resolved } \\
\text { Category }\end{array}$} & Obsolete & Objective is not longer relevant or is no longer being pursued by the PHA. \\
\hline & Resolved & $\begin{array}{l}\text { The objective will be completed under a different objective or objectives or in a manner } \\
\text { different than originally planned, or the issue upon which the objective was based has } \\
\text { been resolved (does not have to be resolved in the PHA's favor). }\end{array}$ \\
\hline
\end{tabular}

The following sections summarize the progress of the Providence Housing Authority and each department in meeting the goals and objectives of the PHA's Goals Management Plan 1996-1999. Objectives that have been completed are contained in the on target category regardless of whether or not they were completed on time.

\section{PHA Wide}

Currently 175 or $73 \%$ of the PHA's objectives fall under the "on target" category and 64 $(27 \%)$ are in the problem category.

\begin{tabular}{|l|c|c|l|c|c|}
\hline \multicolumn{7}{|c|}{ January 1997} & \multicolumn{2}{c|}{ PROBLEM CATEGORY } \\
\hline & $\#$ & $\begin{array}{c}\% \text { of } \\
\text { Ootal }\end{array}$ & & $\begin{array}{c}\% \text { of } \\
\text { Total }\end{array}$ \\
\hline On Schedule/ Ongoing & 76 & $32 \%$ & Barrier & 20 & $8 \%$ \\
\hline Completed & $74(13)$ & $31 \%$ & In Progress/ Ongoing & 31 & $13 \%$ \\
\hline Not Yet Begun & 5 & $2 \%$ & Not Yet Begun & 13 & $6 \%$ \\
\hline In Progress & 20 & $8 \%$ & & & \\
\hline Category Total & 175 & $73 \%$ & Category Total & 64 & $27 \%$ \\
\hline Obsolete or Resolved & 11 & (No Longer Counted for percentage calculations) & \\
\hline
\end{tabular}

See page one for sub-category definitions. 
The number of completed objectives is now 74 or $31 \%$. This figure includes thirteen objectives that have been completed for this current year, but will have to be completed again on an annual basis. Barriers hamper a significant number of objectives. Barriers to completion affect $8 \%$ of all objectives and $31 \%$ of objectives in the "problem" category. These barriers are explained later in this chapter. 


\section{PROGRESS ON MEETING OBJECTIVES BY DEPARTMENT}

\begin{tabular}{|c|c|c|c|c|c|c|c|c|}
\hline & \multicolumn{4}{|c|}{ ON TARGET CATEGORY } & \multicolumn{3}{|c|}{ PROBLEM CATEGORY } & OTHER \\
\hline Department & $\begin{array}{l}\text { Not Yet } \\
\text { Begun }\end{array}$ & Completed & $\begin{array}{l}\text { On Schedule } \\
\text { or Ongoing }\end{array}$ & In Progress & $\begin{array}{l}\text { Not Yet } \\
\text { Begun }\end{array}$ & $\begin{array}{l}\text { In Progress or } \\
\text { Ongoing }\end{array}$ & Barrier & $\begin{array}{l}\text { Obsolete or } \\
\text { Resolved. }\end{array}$ \\
\hline Administration & 5 & $18(3)$ & 8 & 5 & 4 & 3 & 3 & 0 \\
\hline $\begin{array}{l}\text { Human Resources Insurance \& } \\
\text { Risk Management }\end{array}$ & 0 & $22(1)$ & $\overline{6}$ & 1 & 2 & 2 & 0 & 0 \\
\hline $\begin{array}{l}\text { Management Information } \\
\text { Systems }\end{array}$ & 0 & 0 & 2 & 0 & 1 & 5 & 0 & 0 \\
\hline Special Projects & 0 & 5 & 7 & 3 & 0 & 1 & 2 & 0 \\
\hline Security & 0 & $7(3)$ & 6 & 1 & 0 & 1 & 0 & 6 \\
\hline Finance \& Accounting & 0 & 5 & 5 & 0 & 0 & 0 & 8 & 0 \\
\hline Housing Management & 0 & 4 & 8 & 1 & 0 & 2 & 0 & 2 \\
\hline Facilities Management & 0 & $1(1)$ & 1 & 5 & 0 & 5 & 2 & 0 \\
\hline Modernization \& Development & 0 & $3(1)$ & 5 & 0 & 0 & 4 & 2 & 1 \\
\hline Community Services & 0 & $4(3)$ & 18 & 3 & 3 & 6 & 0 & 2 \\
\hline Rental llousing & 5 & $10(1)$ & 1 & 3 & 2 & 3 & 0 & \\
\hline Total & 5 & 74 & 76 & 20 & 13 & 31 & 20 & 11 \\
\hline
\end{tabular}

Number in parentheses () for the complete category indicate objectives which will have to be completed again on an annual basis. 


\section{Barriers}

The following barriers affected the completion of objectives by PHA departments. The number in parentheses indicates the number of objectives affected by the particular barrier.

- Delays in the replacement of the IBM 36 system with an authoritywide PC based system. (10)

- City Council approval for the Family Investment Center site was not secured until late July 1996. This was approximately seven months after the initial presentation was made to the Public Properties Subcommittee. Although this issue has now been resolved, the length of time taken to secure this site has thrown many of the Department of Special Services' objectives off schedule. The opening has also been delayed by unanticipated requirements imposed by the fire marshal. Not all of the objectives affected by these initial barriers are still in the problem category and some have been completed. ( 6 initially, now 2 )

- Require additional personnel. This barrier refers to a specific job function in the Finance and Accounting Department. (2)

- Data from external sources will not be ready on time. (1 initially, now 0)

- Environmental/Zoning issues and problems with contractors and developers. (1)

- Department requires technical assistance to complete objective. (1)

- Objective is held up by a lawsuit filed against the PHA. (2)

- Require greater collaboration with the MIS Department. (1)

- Objective requires greater level of input from the Board of Commissioners. (1) 


\section{Resolved}

Three departments accounted for the nine objectives designated as being resolved. The Security section (six), the Department of Community Services (two), and the Department of Modernization and Development (one).

\section{Security:}

A plan for resident crime watches has been modified to address implementation obstacles. This objected is currently being addressed by the Public Housing Unit in a less formal manner. (5)

External opposition to the use of Police Reserves to patrol the PHA's family developments has resulted in this objective being placed in the "resolved" category (not in the PHA's favor). (1)

\section{Modernization and Development:}

The PHA planned to respond to what appeared to be a local HUD change in enforcement policy for Davis Bacon requirements. A report was going to be prepared for the local HUD office to illustrate the additional costs of these requirements to the PHA. It was discovered, however, that this strengthened enforcement policy was promoted by HUD on a national level in cooperation with the Department of Labor and that it was not likely that the PHA would be able to affect this policy. (1) 


\section{Community Services:}

Programs designed to reach out to the 18-25 year old population have been re-assessed. Due to the difficulty in securing funding for programs to address this population, these two objectives will be absorbed into objectives and programs targeting adults and at-risk youth. (2)

\section{Obsolete}

Due to changes in federal regulations concerning federal preferences and the fact that HUD is no longer considering full voucherization of the public housing program, two objectives in the Housing Management section of the Strategic and Goals Management Plan have been deemed obsolete. 


\section{Objectives Due as of December, 1996}

The following table illustrates the number and percent of objectives currently due which have been completed by the Providence Housing Authority and each department and functional area.

Included in this chart are the numbers and current completion percentages for all objectives with due dates in or before December 1996. Also included is a column which illustrates the degree to which objectives that are currently due on an ongoing basis are being completed. Objectives which are not yet due or which have been deemed obsolete or resolved have been set aside.

\begin{tabular}{|c|c|c|c|c|c|}
\hline \multirow[b]{2}{*}{ DEPARTMENT } & \multicolumn{3}{|c|}{ OBJWCTNES DIEASOF DECEMIBER 1996} & \multicolumn{2}{|c|}{ OTUER OBJECTIVES } \\
\hline & (ONPIETE & ONGOTVG & $\begin{array}{l}\text { CONIBINED } \\
\text { PERCENT }\end{array}$ & $\begin{array}{l}\text { NOT TET } \\
\text { DUE }\end{array}$ & $\begin{array}{l}\text { RESOLIVED/ } \\
\text { OBSOLETE }\end{array}$ \\
\hline Administration & $\begin{array}{c}18 \text { of } 28 \\
(64 \%)\end{array}$ & $\begin{array}{c}7 \text { of } 7 \\
(100 \%)\end{array}$ & $71 \%$ & 2 & 0 \\
\hline $\begin{array}{l}\text { Human Resources Insurance \& Risk } \\
\text { Management' }\end{array}$ & $\begin{array}{c}22 \text { of } 27 \\
(81 \%)\end{array}$ & $\begin{array}{c}60 f 6 \\
(100 \%)\end{array}$ & $85 \%$ & $\overline{0}$ & 0 \\
\hline Management Information Systems & $\begin{array}{l}0 \text { of } 6 \\
(0 \%)\end{array}$ & $\begin{array}{l}2 \text { of } 2 \\
(100 \%)\end{array}$ & $25 \%$ & $\overline{0}$ & 0 \\
\hline Special Projects ${ }^{2}$ & $\begin{array}{l}50 f 9 \\
(56 \%)\end{array}$ & $\begin{array}{l}1 \text { of } 1 \\
(100 \%)\end{array}$ & $60 \%$ & 8 & $\overline{0}$ \\
\hline Security & $\begin{array}{l}7 \text { of } 9 \\
(78 \%) \\
\end{array}$ & $\begin{array}{c}6 \text { of } 6 \\
(100 \%) \\
\end{array}$ & $87 \%$ & 0 & 6 \\
\hline Finance \& Accounting & $\begin{array}{l}4 \text { of } 12 \\
(33 \%)\end{array}$ & $\begin{array}{c}4 \text { of } 4 \\
(100 \%) \\
\end{array}$ & $50 \%$ & 11 & 0 \\
\hline Housing Management & $\begin{array}{c}4 \text { of } 4 \\
(100 \%)\end{array}$ & $\begin{array}{l}6 \text { of } 8 \\
(75 \%)\end{array}$ & $83 \%$ & 3 & 2 \\
\hline Facilities Management ${ }^{2}$ & $\begin{array}{l}1 \text { of } 10 \\
(10 \%)\end{array}$ & $\begin{array}{c}1 \text { of } 1 \\
(100 \%)\end{array}$ & $18 \%$ & 3 & $\overline{0}$ \\
\hline Modernization \& Development & $\begin{array}{l}3 \text { of } 10 \\
(30 \%)\end{array}$ & $\begin{array}{c}2 \text { of } 2 \\
(100 \%)\end{array}$ & $18 \%$ & 2 & 1 \\
\hline Community Services & $\begin{array}{l}4065 \\
(80 \%) \\
\end{array}$ & $\begin{array}{c}10 \text { of } 13 \\
(78 \%)\end{array}$ & $78 \%$ & 16 & 2 \\
\hline Rental Housing & $\begin{array}{l}5 \text { of } 14 \\
(36 \%)\end{array}$ & $\begin{array}{l}10 \text { of } 10 \\
(100 \%)\end{array}$ & $63 \%$ & 0 & $\overline{0}$ \\
\hline Total & $\begin{array}{c}73 \text { of } 134 \\
(54 \%)\end{array}$ & $\begin{array}{l}55 \text { of } 60 \\
(92 \%)\end{array}$ & $66 \%$ & 45 & $\pi$ \\
\hline
\end{tabular}

'The Administration and Rental Housing and sections were affected by three barriers each.

${ }^{2}$ Of the four incomplete objectives for the Department of Special Projects, two were hampered by external barriers and one had formerly been affected by a barrier.

'Of the eight incomplete objectives for the Finance and Accounting Department, all were hampered by external barriers.

${ }^{t}$ The Deparment of Facilities Management faced barriers on two of their objectives and their operations are still hampered by the loss of the Operations Planner last summer. The Department of Modernization and Development was also affected by two extemal barriers. 
It should be noted that this standard is more strict than the standard used to designate projects as either "on target" or in the "problem" category. Under that standard an objective which will be completed within a month of the due date is still listed as being "on target" if there is reasonable evidence that the objective will be completed within that time frame.

\section{Administration}

The Administration section of the Strategic and Goals Management Plan includes nineteen goals comprised of forty-six separate objectives. The goals and objectives under

\begin{tabular}{|c|c|c|c|}
\hline \multicolumn{2}{|c|}{$\begin{array}{l}\text { ON TARGET } \\
\text { CATEGORY }\end{array}$} & \multicolumn{2}{|c|}{$\begin{array}{l}\text { PROBLEM } \\
\text { CATEGORY }\end{array}$} \\
\hline Number & $\%$ of Total & Number & $\%$ of Total \\
\hline 36 & $78 \%$ & 10 & $22 \%$ \\
\hline \multicolumn{4}{|c|}{ OBSOLETE/ RESOLVED } \\
\hline \multicolumn{2}{|c|}{ Number } & \multicolumn{2}{|c|}{$\%$ of Total } \\
\hline \multicolumn{2}{|c|}{0} & \multicolumn{2}{|c|}{ No longer counted in $\%$} \\
\hline
\end{tabular}

this section of the report apply to the

Executive Director, the Office of Policy, Planning, and Resource Development, the Board of Commissioners, and the Homeownership program. Human Resources, Risk Management, Insurance, Security, and MIS functions are contained in separate sections of the goals management plan. This section is currently "on target" in meeting $78 \%$ of its objectives. To date eighteen objectives have been completed and three objectives are affected by barriers (two from the lawsuit over the former Mandela Woods development site and one due to the need for action by the Board of Commissioners. Many of the objectives which have fallen off schedule involve large projects which have taken longer than expected due to coordination and scheduling difficulties with multiple internal and external participants, other issues which have taken priority, or re-thinking of the overall goal which they were designed to 
address. These projects include the education and training of the Board of Commissioners, Privatization of some PHA functions, and Reengineering.

Overall, twenty-eight of the objectives in this section had completion dates in or before December 1996 and an additional seven objectives are based on ongoing activities which are scheduled to occur during this time. All seven of the ongoing objectives are being met, and eighteen of the twenty-eight objectives $(64 \%)$ due in this section have been completed. Many of the objectives not yet completed fall under major projects such as the ones listed above.

Including the current ongoing objectives, the administration section is up to date on $71 \%$ of the objectives that had due dates or ongoing work dates in or before the month of December 1996.

\section{Human Resources, Insurance \& Risk Management}

The Human Resources, Insurance \& Risk Management section of the Strategic and Goals Management Plan includes eight goals comprised of thirty-three separate objectives. Currently $88 \%$ of the objectives in this section are "on target" and the number of completed objectives stands at twenty-two. There has been a substantial amount of cooperation between the Executive Office of Policy, Planning, and Resource Development and the Deputy Director. No barriers are currently listed in this section. 


\begin{tabular}{|c|c|c|c|}
\hline \multicolumn{2}{|c|}{$\begin{array}{l}\text { ON TARGET } \\
\text { CATEGORY }\end{array}$} & \multicolumn{2}{|c|}{$\begin{array}{l}\text { PROBLEM } \\
\text { CATEGORY }\end{array}$} \\
\hline Number & $\%$ of Total & Number & $\%$ of Total \\
\hline 29 & $88 \%$ & 4 & $12 \%$ \\
\hline \multicolumn{4}{|c|}{ OBSOLETE/RESOLVED } \\
\hline \multicolumn{2}{|c|}{ Number } & \multicolumn{2}{|c|}{$\%$ of Total } \\
\hline \multicolumn{2}{|c|}{0} & \multicolumn{2}{|c|}{ No longer counted in \% } \\
\hline
\end{tabular}

In this section, twenty-seven objectives had completion dates in or before December 1996. Of these, twenty-two $(81 \%)$ had been completed. Further, six objectives were designed to be completed on an ongoing basis with activities scheduled to occur during this time. All six of these objectives were currently being conducted.

Including the current ongoing objectives, the Human Resources, Insurance \& Risk Management section is up to date on $85 \%$

\begin{tabular}{|c|c|c|}
\hline \multicolumn{3}{|c|}{ OBJECTIVES DUE AS OF } \\
DECEMBER, 1996 \\
\hline COMPLETE & ONGOING & COMBINED \% \\
\hline 22 of 27 & 6 of 6 & $85 \%$ \\
\hline \multicolumn{3}{|c|}{ OTHER } \\
\hline NOT YET DUE & RESOLV D OBSOLETE \\
\hline 0 & 0 \\
\hline
\end{tabular}

of the objectives which had due dates or ongoing work dates in or before the month of December 1996.

\section{Management Information Systems}

Routine tasks such as PC trouble shooting and the pending replacement of the IBM 36

\begin{tabular}{|c|c|c|c|}
\hline \multicolumn{2}{|c|}{$\begin{array}{l}\text { ON TARGET } \\
\text { CATEGORY }\end{array}$} & \multicolumn{2}{|c|}{$\begin{array}{l}\text { PROBLEM } \\
\text { CATEGORY }\end{array}$} \\
\hline Number & $\%$ of Total & Number & $\%$ of Total \\
\hline 2 & $25 \%$ & 6 & $75 \%$ \\
\hline \multicolumn{4}{|c|}{ OBSOLETE/RESOLVED } \\
\hline \multicolumn{2}{|c|}{ Number } & \multicolumn{2}{|c|}{$\%$ of Total } \\
\hline \multicolumn{2}{|c|}{0} & \multicolumn{2}{|c|}{ No longer counted in $\%$} \\
\hline
\end{tabular}

system with a PC based system have been the primary focus of the MIS office since the release of the

Providence Housing Authority's Strategic

Plan 2000. The MIS office has also recently installed a new network server and a new scanner as well as several new computers and printers. The Authority-wide computer 
system remains the primary reason for a

low completion rate for the MIS office in

terms of meeting goals and objectives. It

appears that the original estimates

\begin{tabular}{|c|c|c|}
\hline \multicolumn{3}{|c|}{ OBJECTIVES DUE AS OF } \\
DECEMBER, 1996 \\
\hline COMPLETE & ONGOING & COMBINED \% \\
\hline 0 of 6 & 2 of 2 & $25 \%$ \\
\hline \multicolumn{3}{|c|}{ OTHER } \\
\hline NOT YET DUE & RESOLV D/ OBSOLETE \\
\hline 1 & \multicolumn{2}{|c|}{0} \\
\hline
\end{tabular}

written into the Goals Management Plan were overly optimistic. Currently the PHA is in the process of reviewing responses to the RFP. Cost estimates were higher than expected.

Six of the objectives listed in this plan were originally scheduled to be completed in or before December 1996. Further the remaining two objectives were designed to be completed on an ongoing basis with activities scheduled to be completed during this time period. While none of the objectives which are due have been completed, the ongoing objectives are currently being conducted.

Including the current ongoing objectives, the MIS section is up to date on $25 \%$ of the objectives which had due dates or ongoing work dates in or before the month of December 1996.

\section{Special Projects}

Barriers have continually hampered this Department, but it looks as though these problems have finally been solved. The Public Properties Subcommittee of the City Council took seven months to approve the site for the Family Investment Center. While this barrier (affecting 6 objectives) was technically removed in late July, 1996 when the site was approved, the affects of the delay continue to linger. The delay and the resulting 
inability of the department to hire new staff (without an operational FIC there was no

\begin{tabular}{|c|c|c|c|}
\hline \multicolumn{2}{|c|}{$\begin{array}{l}\text { ON TARGET } \\
\text { CATEGORY }\end{array}$} & \multicolumn{2}{|c|}{$\begin{array}{l}\text { PROBLEM } \\
\text { CATEGORY }\end{array}$} \\
\hline Number & $\%$ of Total & Number & $\%$ of Total \\
\hline 15 & $83 \%$ & 3 & $17 \%$ \\
\hline \multicolumn{4}{|c|}{ OBSOLETE/RESOLVED } \\
\hline \multicolumn{2}{|c|}{ Number } & \multicolumn{2}{|c|}{$\%$ of Total } \\
\hline \multicolumn{2}{|c|}{0} & \multicolumn{2}{|c|}{ No longer counted in $\%$} \\
\hline
\end{tabular}

office space to accommodate additional personnel) have caused several objectives to be delayed. The department is beginning to overcome these obstacles.

however. Two new staff members have been hired recently and the opening of the Family Investment Center is now planned for April of this year. A new obstacle has affected the Department's ability to open the FIC sooner. A sophisticated fire escape is now being required by the Fire Marshal which will add substantially to the cost of the building and disrupt the designs prepared by the architect.

The Department is currently "on target" in meeting I5 or $83 \%$ of its 18 objectives. There are $3(17 \%)$ in the "problem" category, and none listed as obsolete or resolved.

The department has also requested that three new objectives be added to their Goals Management Plan, of which two would be added as new objectives under new goals. These objectives include the establishment of a comprehensive school to work program for public housing youth, securing funding to continue Center \begin{tabular}{|c|c|c|}
\hline \multicolumn{3}{|c|}{ OBJECTIVES DUE AS OF } \\
DECEMBER, 1996 \\
\hline COMPLETE & ONGOING & COMBINED \% \\
\hline 5 of 9 & \multicolumn{1}{|c|}{ I Of 1} & $60 \%$ \\
\hline \multicolumn{3}{|c|}{ OTHER } \\
\hline NOT YET DUE & RESOLV'D/OBSOLETE \\
\hline 8 & & 0 \\
\hline
\end{tabular} operations beyond 1999, and to ensure that PHA residents are involved in a fully integrated state-wide welfare to work system. 
The six objectives affected by the site approval barrier all had completion dates prior to December 1996. Because of this, only five of the nine objectives $(11 \%)$ with completion dates in or prior to December 1996 have been completed. The one objective that was due during this period on an ongoing basis is being completed. This resulted in a completion rate for objectives due before or in December of $60 \%$ when current ongoing objectives are also counted.

\section{Security}

Members of the Office of Policy, Planning and Resource Development and the Public Housing Unit wrote the Security section of the Strategic Plan 2000. Several of the objectives in this section call for collaboration between the PHA's administrative office

\begin{tabular}{|c|c|c|c|}
\hline \multicolumn{2}{|c|}{$\begin{array}{l}\text { ON TARGET } \\
\text { CATEGORY }\end{array}$} & \multicolumn{2}{|c|}{$\begin{array}{l}\text { PROBLEM } \\
\text { CATEGORY }\end{array}$} \\
\hline Number & $\%$ of Total & Number & $\%$ of Total \\
\hline 14 & $93 \%$ & 1 & $7 \%$ \\
\hline \multicolumn{4}{|c|}{ OBSOLETE/RESOLVED } \\
\hline \multicolumn{2}{|c|}{ Number } & \multicolumn{2}{|c|}{$\%$ of Total } \\
\hline \multicolumn{2}{|c|}{6} & \multicolumn{2}{|c|}{ No longer counted in $\%$} \\
\hline
\end{tabular}
staff and the PHU. As these objectives were not included in the Administration section of the plan, they have not always been addressed properly. One of these objectives is the in-house security analysis of the PHA's developments. Several objectives have been completed recently due to the hiring of the new Safety Liaison Officer. This position will handle administrative duties and reports directly to the PHA's Executive Director. A former PHU member who has seventeen years of experience patrolling Providence's public housing recently filled the position.

Previously this section of the Strategic and Goals Management Plan faced several barriers. Five separate objectives were designed around the implementation of tenant 
crime watches. Reluctance among tenants to be openly identified as being associated with the police resulted in these objectives being addressed in a less formal yet still effective manner. These five objectives have now been declared resolved. A sixth objective in this section concerning the use of the police reserves in the family developments was also declared resolved. This objective reached an impasse due to external opposition from the Police Department. the City Solicitor's Office and the unions. These six objectives are not included in percentage calculations. The addition of the Safety Liaison Officer has helped the PHU reach an "on target" percentage for objectives of $93 \%$.

Of the nine objectives which were due in or before December 1996, $7(78 \%)$ have been completed. Of the six objectives that were scheduled to be addressed on an ongoing basis during this time, all six are being completed in a satisfactory

\begin{tabular}{|c|c|c|}
\hline \multicolumn{3}{|c|}{ OBJECTIVES DUE AS OF } \\
DECEMBER, 1996 \\
\hline COMPLETE & ONGOING & COMBINED \% \\
\hline 7 of 9 & 6 of 6 & $87 \%$ \\
\hline \multicolumn{3}{|c|}{ OTHER } \\
\hline NOT YET DUE & RESOLV'D/ OBSOLETE \\
\hline 0 & \multicolumn{2}{|c|}{6} \\
\hline
\end{tabular}
manner. The PHU and the OPPRD do plan some modifications to the Security Goals Management Plan. In particular, the objective concerning police response time to calls is being considered for revision because there is currently no record collection method in place so this objective cannot be evaluated. Including the current ongoing objectives, the Security section is up to date on $87 \%$ of the objectives that had due dates or ongoing work dates in or before the month of December 1996. 


\section{Finance and Accounting}

The Department of Finance and Accounting lists eight goals and eighteen objectives in its Goals Management Plan. This department remains hampered by barriers that affect eight of its eighteen objectives $(44 \%)$. For six of these objectives the barrier is the delay in the

\begin{tabular}{|c|c|c|c|}
\hline \multicolumn{2}{|c|}{$\begin{array}{l}\text { ON TARGET } \\
\text { CATEGORY }\end{array}$} & \multicolumn{2}{|c|}{$\begin{array}{l}\text { PROBLEM } \\
\text { CATEGORY }\end{array}$} \\
\hline Number & $\%$ of Total & Number & $\%$ of Total \\
\hline 10 & $56 \%$ & 8 & $44 \%$ \\
\hline \multicolumn{4}{|c|}{ OBSOLETE/RESOLVED } \\
\hline \multicolumn{2}{|c|}{ Number } & \multicolumn{2}{|c|}{$\%$ of Total } \\
\hline \multicolumn{2}{|c|}{0} & \multicolumn{2}{|c|}{ No longer counted in $\%$} \\
\hline
\end{tabular}
implementation of the PHA's new authority-wide software and hardware system. No department's Goals Management plan is impacted more by this delay than is the Department of Finance and Accounting's. A barrier in hiring for a new position hampers the other two objectives. For two objectives to be met, the department would need a new purchasing agent. Budget cuts, however, have resulted in decreases in funding for the agency and its operating budget, making new hires for additional positions a difficult proposition at this time. Of the remaining eight objectives

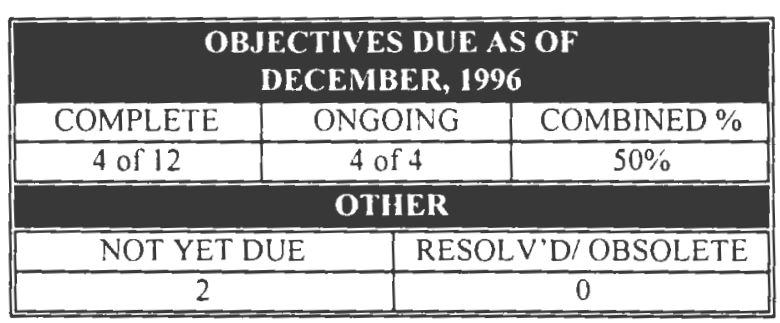
which all fall in the "on target" category, five have been completed, and five are being met in an ongoing fashion. Currently $10(56 \%)$ of the department's 18 objectives fall in the "on target" category and eight (44\%) are in the "problem" category.

Of the twelve objectives scheduled to be completed by December 1996, four $(33 \%)$ have been finished. Eight of the objectives were held back due to barriers. As mentioned above, two of these objectives had not been completed because of the need for a purchasing agent and six were hampered by delays in replacing the IBM 36 system. 
Additional four objectives for this department were designed to be completed on an ongoing basis. Of these, all four are being addressed satisfactorily.

Including the current ongoing objectives, the Finance and Accounting section is up to date on $50 \%$ of the objectives that had due dates or ongoing work dates in or before the month of December 1996.

\section{Housing Management}

The Department of Housing Management has proposed several significant changes in their Goals Management Plan. which have yet to be formally approved and integrated

\begin{tabular}{|c|c|c|c|}
\hline \multicolumn{2}{|c|}{$\begin{array}{l}\text { ON TARGET } \\
\text { CATEGORY }\end{array}$} & \multicolumn{2}{|c|}{$\begin{array}{l}\text { PROBLEM } \\
\text { CATEGORY }\end{array}$} \\
\hline Number & $\%$ of Total & Number & $\%$ of Total \\
\hline 13 & $87 \%$ & 2 & $13 \%$ \\
\hline \multicolumn{4}{|c|}{ OBSOLETE/RESOLVED } \\
\hline \multicolumn{2}{|c|}{ Number } & \multicolumn{2}{|c|}{$\%$ of Total } \\
\hline \multicolumn{2}{|c|}{2} & \multicolumn{2}{|c|}{ No longer counted in $\%$} \\
\hline
\end{tabular}
into the official PHA Goals Management Plan. The changes will incorporate the newly created inter-departmental Triage Teams and the departmental Marketing

Team into the department's Goals Management Plan. The proposed changes would also consolidate existing objectives.

The Department of Housing Management's Goals Management Plan is comprised of six goals and seventeen objectives. Two objectives (12\%) have been declared obsolete due to changes in federal regulations. These objectives were based upon the preferences system and the proposed tenant based voucher system. Obsolete or resolved objectives do not count towards the total percent figures. Therefore, percentages in this section are now calculated based upon 15 objectives rather than 17. 
Thirteen of the Department's objectives $(87 \%)$ currently fall within the "on target" category and two (13\%) fall within the "problem" category. Four objectives have been completed. The two objectives which fall in the "problem" category are

\begin{tabular}{|c|c|c|}
\hline \multicolumn{3}{|c|}{ OBJECTIVES DUE AS OF } \\
DECEMBER, 1996 \\
\hline COMPLETE & ONGOING & COMBINED \% \\
\hline 4 of 4 & 6 Of 8 & $83 \%$ \\
\hline \multicolumn{3}{|c|}{ OTHER } \\
\hline NOT YET DUE & RESOLV D/OBSOLETE \\
\hline 3 & \\
\hline
\end{tabular}
particularly problematic. These objectives concern the issues of unit turn-around time and occupancy rates.

Four of the department's seventeen objectives were scheduled to have been completed in or before December 1996. All four of these have been completed. Further, eight objectives are scheduled to be addressed on an ongoing basis during this time. Of these, $\operatorname{six}(75 \%)$ are being addressed satisfactorily. One of the objectives which still needs to be addressed concerns monthly occupancy rates.

Including the current ongoing objectives, the Housing Management section is up to date on $83 \%$ of the objectives that had due dates or ongoing work dates in or before the month of December 1996. 


\section{Facilities Management}

This department has been affected by the departure of the Operations Planner during the summer of 1995. This person was responsible for tasks listed in 13 of the Department's

\begin{tabular}{|c|c|c|c|}
\hline \multicolumn{2}{|c|}{$\begin{array}{l}\text { ON TARGET } \\
\text { CATEGORY }\end{array}$} & \multicolumn{2}{|c|}{$\begin{array}{l}\text { PROBLEM } \\
\text { CATEGORY }\end{array}$} \\
\hline Number & $\%$ of Total & Number & $\%$ of Total \\
\hline 7 & $50 \%$ & 7 & $50 \%$ \\
\hline \multicolumn{4}{|c|}{ OBSOLETE/RESOLVED } \\
\hline \multicolumn{2}{|c|}{ Number } & \multicolumn{2}{|c|}{$\%$ of Total } \\
\hline \multicolumn{2}{|c|}{0} & \multicolumn{2}{|c|}{ No longer counted in $\%$} \\
\hline
\end{tabular}

14 objectives. The Assistant Operations

Planner has spent a considerable amount of time filling in on these duties including learning the Heating, Ventilation, and Air-

conditioning (HVAC) system. This has resulted in significant delays in addressing stated goals and objectives.

The Department of Facilities Management has eight separate goals which are comprised of fourteen objectives. Of these fourteen, seven (50\%) are currently in the "on target" category and seven fall in the "problem" category. One objective has been completed, and this objective will have to be completed on an annual basis. Two objectives currently face the same barrier, the length of time it has taken to replace the IBM-36 system. The Department's efforts in addressing their Goals Management Plan remain

\begin{tabular}{|c|c|c|}
\hline \multicolumn{3}{|c|}{ OBJECTIVES DUE AS OF } \\
DECEMBER, 1996 \\
\hline COMPLETE & ONGOING & COMBINED \% \\
\hline 1 of 10 & 1 of 1 & $18 \%$ \\
\hline \multicolumn{3}{|c|}{ OTHER } \\
\hline NOT YET DUE & RESOLV'D/OBSOLETE \\
\hline 3 & & 0 \\
\hline
\end{tabular}
hampered by the lost the Operations Planner which has required the Department to focus time and attention to the Heating, Ventilation and Air Conditioning Controls (HVAC). This time would have been spent addressing many of the planning objectives currently in the "problem" category. 
Several objectives are listed in the "on target" category because reports and plans were produced. For several of these, approval from the Executive Director has not yet been given and modifications may be pending.

Of the Department's fourteen objectives, ten have due dates in or before December 1996. Only one $(9 \%)$ of these has been completed, and it will have to be addressed again on an annual basis. Further, a single objective was designed to be completed on an ongoing basis during this time. This objective is being addressed satisfactorily.

Including the current ongoing objectives, the Facilities Management section is up to date on $18 \%$ of the objectives that had due dates or ongoing work dates in or before the month of December 1996.

\section{Modernization \& Development}

The Department of Modernization and Development proposed minor changes for their

\begin{tabular}{|c|c|c|c|}
\hline \multicolumn{2}{|c|}{$\begin{array}{l}\text { ON TARGET } \\
\text { CATEGORY }\end{array}$} & \multicolumn{2}{|c|}{$\begin{array}{l}\text { PROBLEM } \\
\text { CATEGORY }\end{array}$} \\
\hline Number & $\%$ of Total & Number & $\%$ of Total \\
\hline 8 & $57 \%$ & 6 & $43 \%$ \\
\hline \multicolumn{4}{|c|}{ OBSOLETE/RESOLVED } \\
\hline \multicolumn{2}{|c|}{ Number } & \multicolumn{2}{|c|}{$\%$ of Total } \\
\hline \multicolumn{2}{|c|}{$T$} & \multicolumn{2}{|c|}{ No longer counted in $\%$} \\
\hline
\end{tabular}

Goals Management Plan. These changes were not, on the whole, substantive, but rather they reorganized existing goals and objectives. 
The Department of Modernization and development is responsible for fifteen objectives which comprise eight separate goals. One objective $(7 \%)$ has been deemed obsolete. This objective was based upon what appeared to be a local HUD change in enforcement policy for Davis Bacon requirements. It was hoped that a report could be compiled for the local HUD office to illustrate the additional costs of these requirements to the PHA. It was discovered, however, that HUD promoted this strengthened enforcement policy on a national level in cooperation with the Department of Labor, and that it was not likely that the PHA would be able to affect this policy. Because of this, percentages

\begin{tabular}{|c|c|c|}
\hline \multicolumn{3}{|c|}{ OBJECTIVES DUE AS OF } \\
DECEMBER, 1996 \\
COMPLETE & ONGOING & COMBINED \% \\
\hline Of 10 & 2 of 2 & $41 \%$ \\
\hline \multicolumn{3}{|c|}{ OTHER } \\
\hline NOT YET DUE & RESOLV D' OBSOLETE \\
\hline 2 & 1 \\
\hline
\end{tabular}
for this department are calculated using a denominator of fourteen objectives.

Eight objectives $(57 \%)$ fall in the "on target" category and six $(43 \%)$ fall in the "problem" category. An external barrier has hampered the objective that addresses the completion of construction for the remaining scattered site units. This barrier concerns problems with outside contractors and developers that have pushed the estimated completion time for this objective back from 31 December 1996 to December 1997.

Of the department's fifteen objectives, ten were scheduled to be completed in or before December 1996. Of these, three (30\%) have been completed. Further, two objectives are scheduled to be addressed on an ongoing period during this time. Both of these objectives are currently being met in a satisfactory manner. Including the current ongoing objectives. the Modernization \& Development section is up to date on $41 \%$ of 
the objectives which had due dates or ongoing work dates in or before the month of December 1996.

Both of the objectives listed as "not yet due" were objectives which are completed on an annual basis. Both of these were completed satisfactorily for the past year and are on schedule for completion for the current year.

\section{Community Services}

The Department of Community Services is responsible for fifteen goals and thirty-six objectives. Two $(6 \%)$ of the department's objectives have been categorized as being resolved. These two objectives were designed to focus on the 18-25 year-old age group.

\begin{tabular}{|c|c|c|c|}
\hline \multicolumn{2}{|c|}{$\begin{array}{l}\text { ON TARGET } \\
\text { CATEGORY }\end{array}$} & \multicolumn{2}{|c|}{$\begin{array}{l}\text { PROBLEM } \\
\text { CATEGORY }\end{array}$} \\
\hline Number & $\%$ of Total & Number & $\%$ of Total \\
\hline 25 & $74 \%$ & 9 & $26 \%$ \\
\hline \multicolumn{4}{|c|}{ OBSOLETE/RESOLVED } \\
\hline \multicolumn{2}{|c|}{ Number } & \multicolumn{2}{|c|}{$\%$ of Total } \\
\hline \multicolumn{2}{|c|}{2} & \multicolumn{2}{|c|}{ No longer counted in $\%$} \\
\hline
\end{tabular}
This age group was selected due to research that showed that violence is a severe problem among $18-25$ year-olds. In practice, providing specific programs for this group has proven problematic and the department will address this problem using a different approach. These residents will be served under the adult programs offered by the PHA. Further, programs are currently being implemented to target and help at-risk youth. These programs will address younger residents before they reach this age group, in an attempt to prevent violent behavior and help youth plan for this time in a productive and positive manner. Therefore, percentages for this department will be calculated using a denominator of thirty-four objectives. 
The Department has proposed a major reorganization of their Goals Management Plan.

These changes better categorize goals and objectives based upon the structure of the Department. By organizing goals based upon Administrative duties. Family programs. Elderly Disabled programs and Living Skills programs, it is expected that there will be higher levels of coordination, monitoring and accountability within the Department in addressing the plan.

Twenty-five (74\%) of the department's objectives fall in the "on target" category, and 9 (26\%) fall in the "problem" category.

Of the Department's thirty-six objectives, sixteen are still not yet due. Five objectives did have due dates in or before December 1996. Of these, four $(80 \%)$ have been completed. Further, thirteen objectives are scheduled to be completed on an ongoing basis during this time frame. Of these, ten $(78 \%)$ are being addressed satisfactorily.

\begin{tabular}{|c|c|c|}
\hline \multicolumn{3}{|c|}{ OBJECTIVES DUE AS OF } \\
DECEMBER, 1996 \\
\hline COMPLETE & ONGOING & COMBINED \% \\
\hline 4 of 5 & 10 of 13 & $78 \%$ \\
\hline \multicolumn{3}{|c|}{ OTHER } \\
\hline NOT YET DUE & RESOLV'D/OBSOLETE \\
\hline 16 & 2 \\
\hline
\end{tabular}

Including the current ongoing objectives, the Community Services section is up to date on $78 \%$ of the objectives that had due dates or ongoing work dates in or before the month of December 1996. 


\section{Rental Housing}

The Providence Housing Authority's Strategic and Goals Management Plan 1996-1999 lists fourteen goals comprised of twenty-four objectives which fall under the responsibility of the Department of Rental Housing. Of these objectives, sixteen $(67 \%)$

\begin{tabular}{|c|c|c|c|}
\hline \multicolumn{2}{|c|}{$\begin{array}{l}\text { ON TARGET } \\
\text { CATEGORY }\end{array}$} & \multicolumn{2}{|c|}{$\begin{array}{l}\text { PROBLEM } \\
\text { CATEGORY }\end{array}$} \\
\hline Number & $\%$ of Total & Number & $\%$ of Total \\
\hline 16 & $67 \%$ & 8 & $33 \%$ \\
\hline \multicolumn{4}{|c|}{ OBSOLETE/ RESOLVED } \\
\hline \multicolumn{2}{|c|}{ Number } & \multicolumn{2}{|c|}{$\%$ of Total } \\
\hline \multicolumn{2}{|c|}{0} & \multicolumn{2}{|c|}{ No longer counted in $\%$} \\
\hline
\end{tabular}
currently fall in the "on target" category. The remaining eight $(33 \%)$ fall in the "problem" category and no objectives have been deemed obsolete or resolved. Three objectives currently face barriers to completion. Two of these are dependent upon the completion of the replacement of the IBM 36 system or greater levels of collaboration with the MIS office, and the third requires technical assistance, presumably from the Office of Policy, Planning, and Resource Development.

All of the Department's objectives were scheduled to be completed or addressed on an ongoing basis before December 1996. Fourteen of these were designed to be

\begin{tabular}{|c|c|c|}
\hline \multicolumn{3}{|c|}{ OBJECTIVES DUE AS OF } \\
DECEMBER, 1996 \\
\hline COMPLETE & ONGOING & COMBINED \% \\
\hline 5 of 14 & 10 of 10 & $63 \%$ \\
\hline \multicolumn{3}{|c|}{ OTHER } \\
\hline NOT YET DUE & RESOLV D/ OBSOLETE \\
\hline 0 & \\
\hline
\end{tabular}
completed during this time and the other ten were designed to be addressed on an ongoing basis. Five $(36 \%)$ of the fourteen objectives scheduled to be completed have been completed and ten (100\%) of the ten ongoing objectives are being addressed satisfactorily. Including the current ongoing objectives, the Rental Housing section is up to date on $63 \%$ of the objectives that had due dates or ongoing work dates in or before the month of December 1996. 


\section{Strategic Planning: A Case Illustration}

Chapter Five: Conclusions

Accomplishments

Lessons Learned

Proposed Changes

Outlook for the Future 


\section{Chapter Five: Conclusions}

\section{Accomplishments}

The Providence Housing Authority's Strategic Plan 2000 document was extremely well received once it was made available to the public. The National Association of Housing and Redevelopment Officials (NAHRO) recognized the plan with a National Award of Merit and a Regional Award of Excellence. Further, the Department of Housing and Urban Development has directed both other public housing authorities as well as professional consultants to the Providence Housing Authority for assistance in developing strategic plans.

As was outlined in the previous chapter. the Providence Housing Authority is currently "on target" in meeting $73 \%$ of the objectives outlined in the strategies section of the plan. A total of 74 objectives (31\%) have been completed, and many are being addressed in an ongoing fashion. Further, many of the objectives that have not yet been completed are hindered by outside barriers beyond the control of the responsible department or the housing authority. A full 20 objectives are affected by these barriers (for more information please see the previous chapter).

\section{Lessons Learned}

Writing and implementing a strategic plan is a process that continues long after the ink of the original report has dried. The Providence Housing Authority not only monitors the 
progress of Strategic Plan 2000, but also updates and revises the environmental scans, conducts planning exercises to evaluate the progress of implementation and assess what changes need to be made. Along the way several lessons have been learned and ideas have been developed on how the process could have improved. The following is a list of suggestions, lessons, and ideas which come to mind as I look back over the past two years of both the formulation and implementation of the plan.

- It would have been helpful for objectives to be prioritized. The PHA has accomplished most of the immediate and important objectives, most of the "A" projects, however many of the "C" projects have yet to be completed. The difference in priority and importance of objectives does not show up in either the implementation plan or the monitoring plan. One result of this is that the $74 \%$ "on target" rate may seem deceptively low, as most of the high priority items have been addressed satisfactorily and other objectives have been put on the back bumer.

- The Providence Housing. Authority developed its strategies using a combination of operational and strategic planning techniques. The plan is strategic in that it is long term, examines fundamental business concepts such as the agency's mission, mandates and stakeholders, and because it involves authority-wide changes. It borrows from operational planning in that the plan includes short term and ongoing goals and objectives and because strategies 
were developed using departmental and functional area planning teams. Further, the tool used to develop the strategies was based upon the goals management model. Each department and functional area planning team developed their own separate goals management plan. Combined these individual plans comprise the PHA's 300 page Goals Management Plan 19961999. the strategy and implementation component of Strategic Plan 2000.

As a result, the plan risks developing strategies for separate departments that are inconsistent and even conflicting. For example, the Department of Housing Management has a goal of increasing the percentage of money collected that is owed by tenants. The Department of Facilities Management on the other hand wants to reduce costs and increase tenant responsibility for tenant inflicted damages. The result is that as the Department of Facilities Management pursues a more aggressive policy of charging tenants for damages, the Department of Housing Management has more tenant charges to collect and a greater percentage of tenant's accounts receivables.

Another result has been that objectives that require interdepartmental cooperation have been completed at a lower rate than those that are department specific. Because strategies are organized by individual departments and functional areas, it is possible for example, that a Housing Management Objective may have responsible parties in its own department and in the Department of Community Services but because that objective only 
appears in the Housing Management section, the Department of Community Services is not aware of its responsibilities under that objective.

- Finally, in cases where one department had the lead on an objective involving multiple departments, they often did not follow through in getting the necessary cooperation from the other departments. It appears that they did not feel that they had the authority to enforce the needed cooperation or did not want to exercise it. Therefore better coordination of goals and objectives is needed when a goal or objective involves multiple departments.

- Some strategic planning teams appear to have required greater assistance in completing the environmental scanning process. This is a considerably lengthy process and it may have been better to break the assignment into smaller sections and assign these sections individually. Some departments were more equipped than others to do this kind of planning and analysis. More training and technical assistance from the leaders of the strategic planning process may have been needed.

- Getting external stakeholders to respond to the surveys was significantly more time consuming than expected. At one point the survey itself was shortened substantially to increase the response rate. Follow up was a lengthy process. and gathering this information took nearly three times longer than expected. 
Many extermal stakeholders who regularly volunteer their opinion concerning the PHA's operations were not as eager to participate in the formal planning process.

- In an effort to make all of the objectives quantifiable, some required things beyond the PHA's control. An example of this occurred in the Housing Management section. The objective was to reduce applicants with criminal backgrounds by $25 \%$ within a specified period of time. While the PHA can control the number of applicants who will be screened, it cannot control how many of them have criminal backgrounds. To correct this particular issue the department is proposing the creation of a tougher screening policy as an alternative objective.

- It could have been helpful if Departments had included specified periods of time each week or each month to address their goals and objectives. This was noticeable during a recent planning retreat to assess the implementation of the strategic plan. When asked what gets in the way of implementing the plan the 32 participants gave the following answers.

- Time management

- People/ Clients

- Daily Crisis

- Daily Activities

- Paperwork

- External Rules and regulations

- Trying to do Too Much
15

8

2

2

1

1

1 
- It was discovered that time must be allowed to account for error in printing. When the Strategic Plans came back from the printers it was discovered that that one section of this double sided document had been copied single sided so it only included the odd numbered pages. Further, the goals management plans, the strategies section of the report came back with entire sections out of order. Eventually the printer corrected these problems and the PHA received a $30 \%$ discount for our troubles.

- For objectives that involve outside agencies, contingency plans should be developed if at all possible. If the agency in question must be involved, then an alternate time schedule should be developed in case the outside agency can't meet the deadlines specified in the strategic plan. Having to deal with outside agencies such as the City Council and outside developers set the Providence Housing Authority behind on several objectives.

\section{Changes}

After a planning retreat to evaluate the progress of the strategic planning process and implementation, several Departments recently requested changes to their Goals Management Plans, the strategy implementation sections of the strategic plan. 
The Departments which requested changes generally requested the consolidation of related goals and objectives, a reorganization of how they organized their goals and objectives so that responsibilities better fit the department's organizational structure, or a change in the way data was collected for monitoring purposes. These were bugs in the system which were discovered through a years worth of impartation.

\section{Qutlook for the Future}

Strategic planning is a continual process based upon constantly changing external and internal forces that affect the agency. The Providence Housing Authority continues to operate in a turbulent social and political environment. The future of public housing remains uncertain. Below are some of the factors that will affect public housing into the next century. These factors are largely the same as the ones discussed in chapter one of this document, in fact much of the pending legislation in Congress is really only a revision of the bills discussed in that chapter.

\section{Funding}

Funding will continue to be a serious concern for public housing agencies across the country. In an effort to balance the budget by the year 2002, the White House released a five-year budget plan on February $6^{\text {th }}$ of this year. The plan calls for reductions in funding for several key areas.'

- Operating Subsidies: Currently funded at $\$ 2.9$ billion for FY 1997 would be funded at the same level in FY 1998. After that they would 
drop down to $\$ 2.863$ billion in FY 1999 and then down to $\$ 2.8$ billion in the years 2000-2002.

- HOME and CDBG: The White House proposal calls for reductions in both of these programs. This is somewhat alarming due to the popularity of these programs and the fact they have been spared budget cuts in the passed.

- The HOPE VI program: Currently funded at $\$ 550$ million, funds would drop to $\$ 524$ million in FY 1998, \$485 million in FY 1999 and $\$ 400$ million from 2000-2002.

- The Pubic Housing Drug Elimination Program: Under the White House plan, PHDEP will be funded at the current level of $\$ 290$ million through the year 2002. When inflation is factored in this is often considered an actual decrease in funding by industry professionals.

- Modernization Funds. Modernization funds would remain at the FY 1997 level of $\$ 2.5$ billion in FY 1998 and would actually increase to 2.626 billion by FY 2002. While this is an increase in funds, the White House added several new set-asides for public housing supportive services, technical assistance, and tenant opportunity programs that would be funded out of this program.

These cuts will likely have a considerable affect on the operations of housing authorities across the nation. The Council of Large Public Housing Authorities (CLPHA) estimated 
recently that full funding of housing authority operating subsidies in FY 1998 would require $\$ 3.4$ billion, a number significantly higher than the White House or Congress plan to allocate."

The White House calculated the figures for this five-year budget plan using data from the Office of Management and Budget. While these data suggest the need for cuts in program dollars if the budget is to be balanced by the year 2002, they are optimistic compared to the figures prepared by the Congressional Budget Office. It is likely that actual funding levels will be set using figures somewhere in between those of these two agencies.

\section{Welfare Reform}

Welfare reform in the state of Rhode Island will impact the Providence Housing Authority both in the immediate future and over time. In the long run. residents who receive public assistance face work requirements and penalties for non compliance. Ultimately there is a lifetime time limit for cash assistance that may eventually result in a greater percentage of welfare recipients without income. However, proposed housing legislation in Congress forbids housing authorities from lowering rents for tenants who lose income due to noncompliance with welfare policies.

In the immediate future housing authorities in Rhode Island will be affected by the State's requirement that recipients of cash assistance receive $\$ 50$ less per month if they 
are also receiving housing assistance. There are approximately 900 families living in Providence public housing who receive AFDC. Since rent is set at $30 \%$ of their adjusted income, a reduction of $\$ 50$ in benefits will result in the PHA losing $\$ 16.70$ in rent per family per month. Multiplied by 900 families and twelve months this will result in a reduction in total rental income of $\$ 180,360$ per year. If the PHA's operating subsidy was funded at $100 \%$ the formula calculations would adjust for this loss. In reality, the PHA does not anticipate receiving 100\% of PFS funding anytime soon.

\section{Legislation}

Two housing bills have recently been introduced in Congress. Both bills, a Senate bill and a House bill are revised versions of previously drafted legislation which was discussed in the first chapter of this report. In the House, Representative Rick Lazio (RNY) Chairman of the House Banking Subcommittee on Housing Opportunity introduced HR 2: The Housing Opportunity and Responsibility Act of 1997. This bill is an updated version of HR2406, which died in conference committee last year. Included in the bill are the following components:"'

- Income targeting: At all times 35\% of all PHA units must be occupied by households with incomes below $30 \%$ of area median $(40 \%$ for Section 8).

- Residents receive a choice annually between a flat rent or $30 \%$ of their income. This is designed to act like a ceiling rent.

- Allows for screening by development in order to achieve a diverse income mix.

- Allows for Site based waiting lists for PHAs with more than 1250 units.

- Permanent repeal of the one-for-one replacement rule and federal preferences. 
- Permanent authorization for minimum rents $(\$ 25-\$ 50)$ and ceiling rents.

- Five year plan requirement.

- The creation of two block grants through which all public housing funding would be distributed: an operations fund and a capital improvements fund.

- A local government option which would provide funding in a single block grant to the city rather than the housing authority (Home Rule Option).

- Required elected residents on every PHA board.

- Resident community services requirement.

- Self-sufficiency contract requirements.

- Expanded powers for HUD to take over troubled PHAs.

- Expanded resident screening policies.

- A study of the accreditation boards idea introduced in HR 2406.

The component of HR 2 that has thus far generated the most controversy has been the Home Rule option. Under the proposed Home Rule Option, cities would not have to consult their housing authority. They would, however, have to apply to HUD and have a performance plan. The OMB originally proposed the block grant to localities, but it was withdrawn upon opposition from the White House and HUD. Housing authorities and professional agencies fear the loss of control over the funding for their programs. There are potentially serious consequences for public housing depending on how the Home Rule Option would be implemented and what performance standards and federal criteria would be established.

On the Senate side, Connie Mack (R-FL) introduced S. 462 on March $18^{\text {th }}$ of this year. This bill is basically a new draft of the previously introduced S.1260 which, like HR 2406, was discussed in the first chapter of this paper. S. 462 also establishes two block grants for public housing, an operating fund and a capital improvements fund. Section 8 
would be funded separately. Under this bill PHAs would be required to submit a comprehensive plan which would be consistent with the local Consolidated Plan. There are some differences between the former S. 1260 and S. 462. These are described below."

- The Brooke Amendment would be changed to require up to $30 \%$ of income for rent, rather than requiring the full $30 \%$.

- The required comprehensive plan would be streamlined and would require only that the housing authority address several broad categories.

- A new Public Housing Management Assessment Program (PHMAP) indicator would be added to cover security as well as tenant selection and screening.

- Forbids housing authorities from lowering rents based upon a loss of income by the tenant due to failure to comply with welfare reform requirements.

One important aspect of both of these bills is that they make permanent all of the regulatory relief (such as the repeal of the one-for-one replacement rule and federal preferences) which had been enacted previously under authorization bills. Because these reforms have been tied to authorization bills, they only last for the fiscal year for which they were introduced.

The political environment does not look promising for those in the public housing business. Political and budgetary pressures have already resulted in significant reductions in federal spending and public housing has taken a dramatically disproportionate share of these reductions. This is a trend that is expected to continue. Considering recent events such as proposed legislation to eliminate HUD altogether, those in the public housing field remain apprehensive about what the next few years will mean. 
It is fitting that there has been no closure or finality to these issues. It is this lack of certainty concerning the future and the environment in which public housing exists that served as the primary motivation for writing the Strategic Plan 2000 document. It will also serve as motivation to continue the strategic planning process, updating the existing information, and constantly rethinking how the agency fits into the environments in which it exists. 


\section{ENDNOTES}

\section{CHAPTER FIVE}

i NAHRO Monitor. February 28, 1997. Vol XVIX, No. 4. Pages 1-2.

ii Housing and Development Reponer: Current Developments. Warren Gorham Lamont.. February 24. 1997. Vol. 24. No. 42. Pages 61-670.

iii CLPHA Congressional Neus. February 3 rd. 1997

"I Iousing and Development Reporter: Current Developments. Warren Gorham Lamont. March 24. 1997. Vol. 24. No. 46. Pages 708-709 
Strategic Planning: A Case Illustration

References 


\section{References}

1. Armstrong, Robert L. NAHRO Monitor. 1995. "Following Up on Our Legislative Conference Efforts

" Joseph Haas (Ed.) 15 March, 1995. Vol. XVII, No. 5. Page 3.

2. Austin. Jan. (Ed.) 1996. Congressional Quarterly 1995 Almanac. Washington D.C. Congressional Quarterly.

3. Backoff, Robert W. and Paul C. Nutt. 1988. "A Process for Strategic Management with Specific Applications for the Nonprofit Organization." In Strategic Planning: Threats and Opportunities for Planners John Bryson and Robert Einsweiler (Eds.) Chicago. American Planning Association.

4. Barry, Bryan W. 1988. "Strategic Planning in a Nonprofit Organization: Model Cities Health Center." In Strategic Planning: Threats and Opportunities for Planners John Bryson and Robert Einsweiler (Eds.) Chicago. American Planning Association.

5. Bryson, John M. 1988. Strategic Planning for Public and Nonprofit Organization. San Francisco. Jossey-Bass.

6. Bryson, John and Rober C. Einsweiler. 1988. "The Future of Strategic Planning for Public Purposes." In Strategic Planning: Threats and Opportunities for Planners John Bryson and Robert Einsweiler (Eds.) Chicago. American Planning Association.

7. Bryson, John and Robert C. Einsweiler. 1988. "Introduction." In Strategic Planning: Threats and Opportunities for Planners John Bryson and Robert Einsweiler (Eds.) Chicago. American Planning Association.

8. Bryson, John and Harvey Jacobs. 1988. "Applying Private Sector Strategic Planning to the Public Sector" In Strategic Planning: Threats and Opportunities for Planners John Bryson and Robert Einsweiler (Eds.) Chicago. American Planning Association.

9. Collins, James C. and Jerry I Porras. 1994. Built to Last: Successful Habits of Visionary Companies. New York. Harper Business. 
10. Cooper, Stephen K.. 1995 "Senate Finance Committee Rejects Sunset of Housing Tax Credit" Housing and Development Reporter: Current Developments in Housing, Community Development, Finance and Taxation. 23 October 1995, Vol. 23, No. 24. Pages 353-383.

11. Council of Large Public Housing Authorities. Congressional News Brief. 3 February 1997. Reno and Cavanaugh, PLLC. Washington D.C.

12. Fogg, C. Davis. 1994. Team Based Strategic Planning: A Complete Guide to Structuring. Facilitating and Implementing the Process. New York. American Management Association.

13. Freedman, Allan. 1995. Congressional Quarterly Weekly Reports. "Senate Heading For A Showdown Over VA-HUD Spending Bill" 16 September 1995. Pages 2809-2811.

14. Freedman, Robert L. 1995 "House Panel Votes to Eliminate LIHPRHA Fund as Part of \$7.3 Billion HUD Rescission". Housing and Development Reporter: Current Developments in Housing. Community Development, Finance and Taxation. 27 February 1995, Vol. 22, No. 42. Pages 642-671

15. Freedman, Robert L. 1995 "HUD Releases Blueprint Plans, Lazio Seeks More FHA Detail. Certificate Fund Flexibility". Housing and Development Reporter: Current Developments in Housing, Community Development, Finance and Taxation. 27 March 1995, Vol. 22, No. 46. Pages $705-735$.

16. Freedman, Rober L. 1995 "Cisneros Sends Blueprint Legislation to Congress". Housing and Development Reporter: Current Developments in Housing. Community Development, Finance and Taxation. 8 May 1995, Vol. 22, No. 52. Pages 801-831.

17. Goodstein, Leonard D., J. William Pfeiffer, and Timothy M. Nolan. 1986. Applied Strategic Planning: A New Model for Organizational Growth and Vitality. In Strategic Planning: Selected Readings. San Diego. University, Inc.

18. Goodstein, Leonard D., J. William Pfeiffer, and Timothy M. Nolan. 1993. Applied Strategic Planning: A Comprehensive Guide. New York. McGraw Hill, Inc.

19. Gordon, Gerald L. 1993. Strategic Planning for Local Government. Washington DC. International City/ County Management Association. 
20. Hager, George. 1995. Congressional Quarterly Weekly Reports. "Stopgap Bill Allows GOP, Clinton Six More Weeks of Haggling" 30 September 1995. Pages 2972-2973.

21. Healy, Jon. 1995. Congressional Quarterly Weekly Reports. "Senate Passes VA-HUD Bill With Housing Program Fix" 7 September 1995. Pages 2526-2528.

22. Housing and Development Reporter: Current Developments in Housing, Community Development, Finance and Taxation. "Bond's HUD Reforms Include Block Grants" Charles C. Edson and Bruce S. Lane. (Eds.) 13 March 1995, Vol. 22, No. 44. Pages 677-678.

23. Housing and Development Reporter: Current Developments in Housing, Community Development, Finance and Taxation. "Housing Authorization Bill Possible in May, Says Lazio" Charles C. Edson and Bruce S. Lane. (Eds.) 13 March 1995. Vol. 22, No. 44. Pages 678-679.

24. Housing and Development Reporter: Current Developments in Housing. Community Development, Finance and Taxation. "\$7.2 Billion In HUD Rescissions: Senate Expected to Restore Some Funds" Charles C. Edson and Bruce S. Lane. (Eds.) 27 March 1995, Vol. 22, No. 46. Page 707.

25. Housing and Development Reporter: Current Developments in Housing, Community Development, Finance and Taxation. "Cisneros Defends Blueprint Flexibility, Quick 1995 Spending" Charles C. Edson and Bruce S. Lane. (Eds.) 10 April 1995, Vol. 22, No. 48. Pages 739-740.

26. Housing and Development Reporter: Current Developments in Housing, Community Development. Finance and Taxation. "Conferees Complete Work on Rescission Bill; Clinton Veto Likely" Charles C. Edson and Bruce S. Lane. (Eds.) 22 May 1995, Vol. 23, No, 3. Page 3.

27. Housing and Development Reporter: Current Developments in Housing, Community Development, Finance and Taxation. "Lazio Says House Bill to Include Private, Section 8 Mark to Market Proposal, HOME, CDBG Merger" Charles C. Edson and Bruce S. Lane. (Eds.) 22 May 1995, Vol. 23, No. 3. Pages $3-4$.

28. Housing and Development Reporter: Current Developments in Housing, Community Development, Finance and Taxation. "Critics Say House Budget Plan Will Cause Tenant Displacement" Charles C. Edson and Bruce S. Lane. (Eds.) 22 May 1995, Vol. 23, No. 3. Pages 4-5. 
29. Housing and Development Reporter: Current Developments in Housing, Community Development. Finance and Taxation. "Key Senators Oppose Conversion of Public Housing to Vouchers" Charles C. Edson and Bruce S. Lane. (Eds.) 5 June 1995, Vol. 23, No. 4. Pages 37-38.

30. Housing and Development Reporter: Current Developments in Housing, Community Development, Finance and Taxation. "Cisneros, Mayors Criticize Proposal to Eliminate HUD" Charles C. Edson and Bruce S. Lane. (Eds.) 17 June 1995, Vol. 23, No. 10. Pages 131-132.

31. Housing and Development Reporter: Current Developments in Housing, Community Development, Finance and Taxation. "Two Senators Block Second Rescission Bill" Charles C. Edson and Bruce S. Lane. (Eds.) 17 June 1995, Vol. 23, No. 10. Page 132.

32. Housing and Development Reporter: Current Developments in Housing, Community Development, Finance and Taxation. "Senate Appropriations Draft Has Funds for Public Housing Demolition, Changes in Housing Preservation" Charles C. Edson and Bruce S. Lane. (Eds.) 11 September. 1995, Vol. 23, No. 18. Pages 257-286.

33. Housing and Development Reporter: Current Developments in Housing, Community Development, Finance and Taxation. "Senate Panel Approves HUD Money Bill; Housing Preservation Changes. Mark to Market Funding Delayed" Charles C. Edson and Bruce S. Lane. (Eds.) 25 Sept. 1995, Vol. 23, No. 20. Pages 291-293.

34. Housing and Development Reporter: Current Developments in Housing, Community Development, Finance and Taxation. "Lazio Plans Legislation to Reform Assisted Housing, Replace HUD" Charles C. Edson and Bruce S. Lane. (Eds.) 25 Sept. 1995, Vol. 23, No. 20. Pages 294-296.

35. Housing and Development Reporter: Current Developments in Housing, Community Development, Finance and Taxation. "Cisneros Questions Role of Accreditation Board in Lazio Bill" Charles C. Edson and Bruce S. Lane. (Eds.) 23 October. 1995, Vol. 23, No. 24. Pages 357-358.

36. Housing and Development Reporter: Current Developments in Housing, Community Development, Finance and Taxation. "Cisneros Seeks Changes in PHA Reform Proposals; Housing Groups Testify" Charles C. Edson and Bruce S. Lane. (Eds.) 23 October. 1995, Vol. 23, No. 24. Pages 323-324. 
37. Housing and Development Reporter: Current Developments in Housing, Community Development. Finance and Taxation. "HUD Shuts Down After Clinton Vetoes Funding Bill" Charles C. Edson and Bruce S. Lane. (Eds.) 20 November. 1995, Vol. 23, No. 28. Pages 421-422.

38. Housing and Development Reporter: Current Developments in Housing, Community Development, Finance and Taxation. "Lower Fees Would Bring Layoffs, Service Cuts, PHA Officials Say" Charles C. Edson and Bruce S. Lane. (Eds.) 4 December. 1995, Vol. 23. No. 30. Pages 453-454

39. Housing and Development Reporter: Current Developments in Housing, Community Development. Finance and Taxation. "Mack Introduces Housing Reform Legislation in Senate" Charles C. Edson and Bruce S. Lane. (Eds.) 24 March 1997, Vol. 24, No. 26. Pages 708-709

40. Jacobs, Barry. 1995 "Cisneros Unveils Budget Signaling 'Dramatic Change' for HUD" Housing and Development Reporter: Current Developments in Housing, Community Development. Finance and Taxation. 13 February 1995, Vol. 22, No. 40. Pages 609-639.

41. Jacobs, Barry. 1995 "Blueprint 11 to Continue HUD Reinvention, Cisneros Says" Housing and Development Reporter: Current Developments in Housing, Community Development, Finance and Taxation. 18 December 1995, Vol. 23, No. 32. Pages 481-511.

42. Katz. Jeffery L. 1995. Congressional Quarterly Weekly Reports. "House Surprises Leadership. Rejects VA-HUD Agreement" 2 December 1995. Pages 3659-3661.

43. Katz, Jeffery L. 1995. Congressional Quarterly Weekly Reports. "Senate Anticipates Veto. Passes Program Cuts VA-HUDs $\$ 81$ Billion Spending Measure Now Heading to Conference" 30 September 1995. Pages 3003-3005.

44. Kaufman, Jerome L. and Harvey M. Jacobs. 1988. "A Planning Perspective on Strategic Planning" In Strategic Planning: Threats and Opportunities for Planners John Bryson and Robert Einsweiler (Eds.) Chicago. American Planning Association.

45. NAHRO Monitor. 1995 Cisneros Discusses HUD Blueprint With Public Housing Industry Leaders " Joseph Haas (Ed.) 31 January, 1995. Vol. XVII, No. 2. Pages 1-4.

46. NAHRO Monitor. 1995. "HUD's Proposed FY 1996 Budget Holds at 1995 Levels, Follows Blueprint" Joseph Haas (Ed.) 15 Feb., 1995. Vol. XVII, No. 3. Pages 1-5. 
47. NAHRO Monitor. 1995. "House Committee Approves Bill to Rescind \$7.3 Billion of HUD Funds" Joseph Haas (Ed.) 15 March, 1995. Vol. XVII, No. 5. Pages 1-5.

48. NAHRO Monitor. 1995. "Operating Subsidies for FY 95 Restored by Senate Appropriators "Joseph Haas (Ed.) 15 March, 1995. Vol. XVIl, No. 5. Pages 1-5.

49. NAHRO Monitor. 1995. "Senate Panels Discuss Reorganization of HUD During Joint Hearing " Joseph Haas (Ed.) 15 March, 1995. Vol. XVII, No. 5. Pages 6-7.

50. NAHRO Monitor. 1995. "H/CD Programs Are Likely Targets for FY 1996 Budget Cutting Efforts" Joseph Haas (Ed.) 15 May, 1995. Vol. XVI!, No. 9. Pages 1,2 and 4.

51. NAHRO Monitor. 1995. "HUD's Revised Monitoring Handbook Will Deregulate High-Performing LHA's" Joseph Haas (Ed.) 15 May, 1995. Vol. XVII, No. 9. Pages I and 4.

52. NAHRO Monitor. 1995. "H/CD Programs Are Likely Targets for FY 1996 Budget Cutting Efforts" Joseph Haas (Ed.) 15 May, 1995. Vol. XVII, No. 9. Pages 1 and 4.

53. NAHRO Monitor. 1995. "1995 Summer Conference: Delegates Urged to Keep Eyes on Prize: Deregulation" Joseph Haas (Ed.) 31 July, 1995. Vol. XVII, No. 14. Pages 1-2.

54. NAHRO Monitor. 1995. "House Appropriations Defer to Housing Subcommittee on Deregulation" Joseph Haas (Ed.) 31 July, 1995. Vol. XVIl, No. 14. Pages 1-6.

55. NAHRO Monitor. 1995. "House Approves FY 1996 HUD Appropriations Bill With Deregulation Provisions; Cuts in Key Programs" Joseph Haas (Ed.) 15 August, 1995. Vol. XVII, No. 15. Pages 15.

56. NAHRO Monitor. 1995. "Senate to Take Up HUD Appropriation, Authorization Bills Upon Retum" Joseph Haas (Ed.) 31 August, 1995. Vol. XVII, No. 16. Pages 1-5.

57. NAHRO Monitor. 1995. "Burden of Modernization Rescission Will Be Shared By All Recipient LHA's" Joseph Haas (Ed.) 31 August, 1995. Vol. XVII, No. 16. Pages 1-2. 
58. NAHRO Monitor. 1995. "NAHRO Comments on Senate's Draft H/CD Authorization Bill" Joseph Haas (Ed.) 15 Sept, 1995. Vol. XVII, No. 17. Pages 4-5.

59. NAHRO Monitor. 1995. "Congress Nears Conclusion of Appropriations, Reconciliation Process" Joseph Haas (Ed.) 15 Oct, 1995. Vol. XVII, No. 19. Pages 1-5.

60. NAHRO Monitor. 1995. "Both Houses Work on Re-Authorization Bills. Appropriations Conference Committee Delayed" Joseph Haas (Ed.) 15 Nov, 1995. Vol. XVII, No. 21. Pages I-4

61. NAHRO Monitor. 1995. "Conference Committee Approves Senate Funding Levels for Core H/CD Programs" Joseph Haas (Ed.) 30 Nov, 1995. Vol. XVII, No. 22. Pages I-5.

62. NAHRO Monitor. 1995. "Elections Leave Direction of H/CD Legislation Uncertain" Joseph Haas (Ed.) 30 Nov, 1995. Vol. XV1l. No. 22. Pages 1-2.

63. NAHRO Monitor. 1995. "HUD Notice Explains Method to Calculating Section 8 Administrative Fees" Joseph Haas (Ed.) 30 Nov, 1995. Vol. XVII, No. 22. Pages 1-2.

64. NAHRO Monitor. 1995. "HUD Appropriations Bill Retains FY 1995 Administration Fee Structure" Joseph Haas (Ed.) 15 Dec, 1995. Vol. XVII, No. 23. Pages I-2.

65. NAHRO Monitor. 1995. "White House Vetoes HUD Appropriations; Congress's Next Move Remains Unclear" Joseph Haas (Ed.) 31 Dec, 1995. Vol. XVII, No. 24. Page 1.

66. NAHRO Monitor. 1997 "Out Year Projections in Federal Budget Indicate Squeez on HUD Programs" Joseph Haas (Ed.) 28 February, 1997. Vol. XVIX, No. 4. Pages 1-2.

67. Poduska, Joseph P. 1995. "Cisneros Says Budget Cuts Will Save \$51 Billion Over Five Years." Housing and Development Reporter: Curtent Developments in Housing, Community Development, Finance and Taxation. Vol. 22. No. 38. Pages 577-607.

68. Poduska, Joseph P. 1995. "Senate Considers $\$ 4.8$ Billion Reduction In HUD Spending." Housing and Development Reporter: Current Developments in Housing, Community Development, Finance and Taxation. Vol. 22, No. 48. Pages 737-767. 
69. Poduska, Joseph P. 1995. "Rescission Bill Heads for Conference: Section 8 Reserves to be Used for Renewals." Housing and Development Reporter: Current Developments in Housing, Conmunity Development, Finance and Taxation. Vol. 22, No. 50. Pages 770-799.

70. Poduska, Joseph P. 1995. "Budget Plans Favor Section 8 Renewals, Block Grant Approach." Housing and Development Reporter: Current Developments in Housing, Community Development. Finance and Taxation. Vol. 23, No. 2. Pages 2-31.

71. Poduska. Joseph P. 1995. "Retsinas Warns Against Delaying Mark-To Market Plans." Housing and Development Reporter: Current Developments in Housing, Community Development. Finance and Taxation. Vol. 23, No. 6 .

72. Poduska, Joseph P. 1995. "Compromise Budget Resolution Assumes Renewal of Section 8 Contracts, Omits Mark-To-Market." Housing and Development Reporter: Current Developments in Housing, Community Development, Finance and Taxation. Vol. 23, No. 8. Pages 97-127

73. Poduska, Joseph P. 1995. "Fiscal 1996 Appropriations Bill Approved By House Subcommittee Cuts HUD Funding by 25\%." Housing and Development Reporter: Current Developments in Housing, Community Development, Finance and Taxation. Vol. 23, No. 10. Pages 130-159

74. Poduska, Joseph P. 1995. "Senate Passes HUD Money Bill, Would Permit Section 8 Renewals, Delay Fair Housing Transfer." Housing and Development Reporter: Current Developments in Housing, Community Development, Finance and Taxation. Vol. 23, No. 22. Pages 321-351.

75. Poduska, Joseph P. 1995. "Senate Committee Approves Public Housing Legislation; House Panel Begins Work on Compromise Bill." Housing and Development Reporter: Current Developments in Housing, Community Development, Finance and Taxation. Vol. 23, No. 26. Pages 385-415

76. Poduska. Joseph P. 1995. "HUD Shuts Down Again After Clinton Vetoes Funding Bill." Housing and Development Reporter: Current Developments in Housing, Community Development, Finance and Taxation. Vol. 23, No. 34. Pages 513-543.

77. Poduska, Joseph P. 1995. "HUD Proposes Consolidating Programs, Transforming FHA To Government- Owned Corporation" Housing and Development Reporter: Current Developments in Housing, Community Development, Finance and Taxation 2 January 1995, Vol. 22, No. 34. Pages $514-543$. 
78. Poduska, Joseph P. 1995. "House Appropriations Committee Okays $\$ 7.2$ Billion Cut in HUD Funds" Housing and Development Reporter: Current Developments in Housing, Community Development, Finance and Taxation 13 March 1995, Vol. 22, No. 44. Pages 673-703.

Poduska, Joseph P. 1997. "Housing Groups Raise Concern About HUD's Budget Proposals for Public Housing, HOME" Housing and Development Reporter: Current Developments in Housing, Community Development, Finance and Taxation 24 February 1997, Vol. 24, No. 42. Pages 641-670.

80. Providence Housing Authority Senior Staff. 1995. Meeting to Discuss Strategic Planning at the Providence Housing Authority. Providence Housing Authority. 11 May 1995

81. Providence Housing Authority Senior Staff and Strategic Planning Teams. 1995. Meeting to Discuss Strategic Planning at the Providence Housing Authority. University of Rhode Island Whispering Pines Retreat Center at the Alton Jones Campus. 4-5 October 1995

82. Providence Housing Authority Senior Staff and Strategic Planning Teams With Robert Leaver. 1995. Meeting to Discuss Strategic Planning at the Providence Housing Authority. Organizational Futures Urban Retreat Center. 19 September 1995

83. Providence Housing Authority Senior Staff and Strategic Planning Teams With Robert Leaver. 1995 Meeting to Discuss Strategic Planning at the Providence Housing Authority. Organizational Futures Urban Retreat Center. 8 January 1997

84. Ring, Peter Smith. 1988. "Strategic Issues: What Are They and Where Do They Come From?" In Strategic Planning: Threats and Opportunities for Planners John Bryson and Robert Einsweiler (Eds.) Chicago. American Planning Association.

85. Weisman, Jonathan. 1995. Congressional Quarterly Weekly Reports. "Impact of GOP Congress Well Beyond Bills" 7 September 1995. Pages 2515-2520. 


\section{Strategic Planning: A Case Illustration}

Appendices

Environmental Scans

Environmental Scan Worksheets

External Stakeholder Survey

Internal Stakeholder Survey

Scattered Site Survey

Section 8 Landlord Survey

Section 8 Tenant Survey

Resident Surveys 
ENVIRONMENTAL SCAN: POLITICS/POLITICAL PROCESS

Introduction

Public housing is a creature of the political process. Every year the public housing program relies on the Congressional budget process for its funds. It has been this way since the passing of the Housing Act of 1937 .

Then, housing authorities relied on HUD only to pay off the construction bonds which the local authorities sold to build developments. All other operating expenses for local housing authorities (LHAs) were paid from operating income, primarily rent.

In 1968, the funding method for local housing authorities was changed. With the arrival of the Brooke Amendment, which limited the amount of rent charged residents to $25 \%$ of their adjusted family income (increased in 1981 to $30 \%$ ), housing authorities had a difficult time covering expenses. In fact, several large public housing agencies were near bankruptcy and this posed a threat to the existence of urban public housing authorities.

The Department of Housing and Urban Development responded to the financial plight of housing authorities by contracting with the Urban Institute to research and propose a subsidy system. What resulted was the Performance Funding System (PFS), which devised a complex formula to determine the amount of money a "well managed and operated" housing authority should receive after rental income was determined. In simple terms, HUD subsidized the difference between generated rental and other income and real expenses up to the authorized subsidy

Politics does have an important impact on the future of public housing. Every year public housing competes against other programs in the federal budget process for funding. The HUD budget is considered "discretionary", which is a relatively small part of the federal budget. It competes with the Veterans Administration, NASA and other independent agencies when the annual budget resolution is prepared. A good example of how this process works took place five years ago when $\$ 500$ million was at stake for either public housing or the space station. After a lengthy debate, during which all the "horrors" of public housing were matched against the glory of the space station. the funding was given to NASA.

Politics and public housing comes into play at all levels. The next several sections will review the politics of public housing and the roles played by key actors.

\section{FEDERAL LEVEL}

As cited in the introduction, the public housing program competes with all other programs in the federal budget for its funding. Even at the federal level there are various forces at work which determine the amount and distribution of funds for public housing. The primary participants at the federal level are: the existing administration, the Department of Housing and Urban Development. Congress, and the trade and professional associations.

\section{Administration}

Each year the Administration, through its Cabinet and the Office of Management and Budget (OMB), prepares an annual budget. The public housing budget is prepared by the Department of Housing and Urban Development. In recent years OMB has taken a more active role in budget preparation with the Cabinet departments. This is primarily due to the large federal budget deficit and the prevailing desire of almost everyone to reduce it. Once a budget figure has been determined, it is submitted to the Congress.

How, why and what is funded is a complex process, even in its initial stages at HUD. There are numerous constituencies at HUD that must be satisfied. Usually, the Administration in office runs their political campaign on a party platform that outlines what they propose for housing programs. However, these plans are always revised due to changing budget circumstances, need, and an assortment of other factors.

There was very little in the Clinton Administration's platform on public housing. What was there was the standard phrase.. . "provide decent housing. .." The Democratic Party platform also used standard phrases to explain their position on public housing.

The Administration is not expected to be a strong supporter of the public housing program. It is expected they will not expend a lot of political capital on a program with a small constituency. Furthermore, their emphasis has been on other programs such as homelessness, community development, HOME and enterprise communities. 
Department of Housing and Urban Development

The Clinton Administration is the first to bring experienced practitioners of public housing to HUD. HUD Secretary, Henry Cisneros, is a former mayor of San Antonio, Texas who experienced the problems and needs of an urban area. He also possesses a doctorate in urban affairs. Joseph Shuldiner, Assistant HUD Secretary for Public and Indian Housing, is the first assistant secretary to actually have operated a public housing agency. He served as Executive Director of the New York City and Los Angeles housing authorities. Mr. Shuldiner brings to the position an intimate knowledge and of the workings of public housing and is very sensitive to our needs.

The HUD Department has developed several initiatives since coming into office. Many deal with the non-housing needs of our residents. Programs such as Family Investment Centers and Youth Build provide for services that will promote economic independence for residents. The department also continued to fund initiatives (Family SelfSufficiency, Public Housing Drug Elimination Program. Youth Sports Program) that originated in previous administrations.

The existing HUD team was also anxious to invite the public housing community in reforming HUD. Task forces were established to review regulations governing housing authorities to determine if they were an unnecessary hindrance and could be reformed or eliminated. The task forces were made up of public housing members (staff and residents) and HUD field representatives. Some of the more important regulatory changes were suggested by HUD staff members. The department was very open in their willingness to deal with the profession and went so far as to consider consultations with industry representatives before initiating new efforts.

HUD Reinvention

HUD's so-called blueprint for change, or their "reinvention," is a dramatic change in the way HUD does business with local housing authorities. It proposes to shift almost all responsibility for operating public housing to the local community. Although still going through changes, the reinvention consists of three principal stages: deregulation. block grants, and "voucherization."

\section{Stage 1: Deregulation}

This stage has HUD eliminating all but statutory requirements and letting housing authorities become creative in the operation of their authorities. Previously required handbooks and operating notices would no longer determine the day-to-day operations of the PHAs.

\section{Stage II: Block Grant}

At this stage, HUD would create 2 public housing and 1 Section 8 block grants to fund housing authority activities. Presumably, PHAs would determine how the funds are distributed for eligible programs. The two public housing block grants would be: operating subsidies fund and capital fund. The Section 8 block grant would be called the housing certificale fund. The public housing block grants would consolidate all the current programs funded for public housing into these two categories. The Section 8 block grant would do the same.

\section{Stage III: Voucherization}

This stage is rather dramatic, even for HUD. At a time yet to be determined (probably within 3-5 years), PHA's would lose their subsidies and direct grants. All existing residents would be supplied with vouchers. They could remain in public housing or they could move to private market rate housing. LHAs would then have to compete for tenants with private property owners. The income for day-to-day operations, programs and physical improvements would be derived from rents.

It is fairly clear that HUD did not give this plan much initial thought. This is validated by the number of changes from the initial presentation. Originally, the plan was supposed to be completed in three years.

$H \cup D$, after listening to objections from the professional housing associations, has modified the plan several times and certain elements have been eliminated entirely.

Presumably, the plan was devised in direct response to last November's election. Rumor has it that OMB was suggesting to eliminate HUD entirely or dramatically alter its function. Supposedly, Secretary Cisneros was instructed to prepare a plan in a short period of time for the budget planning team to review. The secretary assembled his assistant secretaries on a Friday afternoon and told them to have a plan to reinvent HUD by Sunday afternoon. It's been reported that the secretary slipped the reinvention plan under the door where the budget planning team was meeting and HUD was saved from extinction. Whether or not this story is true is not important. The department and the Administration are actively responding to the elections and the mood of the voters. 
What will be the end result of HUD's reinvention is unknown. So many changes have been made with the original plan that it's difficult to keep up. More importantly, the reaction of Congress to the reinvention plan and what will take place in future budget packages has a profound effect on the plan's ultimate design.

\section{Congress}

Last November a seismic shift took place in the political environment of this country. The Republican Party won both houses of the Congress for the first time in forty years. This will have a significant and lasting impact on public housing for several reasons. First, the House of Representatives controls all funding bills. The House is led and controlled by a group of conservatives bent on changing the way the government deals with the poor. Public housing is not a favorite program of the leadership and nor of the newly elected House members whose mission was to cut back on government programs. Second, the House has proposed eliminating the Federal deficit in seven years which is no small task when you consider the size of the debt. Third, public housing maintains a very negative image in the eyes of the public with no core constituency. All these factors combine to make the future of public housing very bleak.

The Congress has not welcomed the HUD reinvention with open arms. Leading Democrats have been particularly critical of the proposal, including Representatives Joseph Kennedy and Barney Frank of Massachusetts who serve in key minority positions on the committees which will consider the legislation. Several key ranking Republicans, such as Representative Lazio of New York and Senator Bond of Missouri have also expressed reservations over the proposed reinvention, particularly voucherization.

\section{Professional Associations}

The Providence Housing Authority, as well as the 3,200 housing authorities nationwide, is a member of at least one professional association that advocates housing. The PHA belongs to NAHRO (National Association of Housing and Redevelopment Officials) and CLPHA (Council of Large Public Housing Authorities). Both NAHRO and CLPHA have experienced professional staffs with access to key members of the Administration, Congress and HUD. There are numerous other professional associations that represent housing authorities' interests before Congress and Federal agencies

Each of these organizations monitor federal legislation relating to the housing industry and to public housing in particular. Every piece of legislation submitted before Congress or any program proposal submitted by HUD is examined for its impact on local housing authorities. Papers are prepared which discuss such impact and these are sent to housing authorities throughout the country as well as to key Congressional staffers. Many of these organizations are well respected players in the "dance of legislation." Several of the key players in these professional organizations were members of Congressional staffs or worked at HUD. Their information network, testimony before Congressional committees, and their influence at HUD all create an impact on their legislation. The current administration at HUD has been very accommodating to the professional housing industry. Members have been asked to serve on numerous task forces examining every aspect of HUD operations. Evidently, the atmosphere has changed at HUD since the Jack Kemp administration when public housing officials were disdained and our professional associations ignored

\section{STATE LEVEL}

\section{Almond Administration}

Governor Almond never presented a comprehensive housing plan during his campaign for governor nor since his inauguration. His administration clearly defers to the Rhode Island Housing and Mortgage Finance Corporation (R I Housing) for a housing agenda. R I Housing offers numerous programs for first time home buyers, as well as programs for housing rehabilitation and assistance to nonprofit housing associations. R I Housing also administers the Section 8 and HOME programs for nonentitlement communities throughout the state. It is not expected that the Almond Administration will offer any programs to assist public housing directly. With the state's financial condition being so bleak, it is not expected to initiate any dramatic new housing programs. One program that is apparently affected by the administration's budget is the Department of Elderly Affair's Elderly Security Program. Proposed reductions in the budget will reduce the funds available for security by one-half from $\$ 240,000$ to $\$ 120,000$. The DEA has informed us that, if the cuts are passed, we will receive only $\$ 77,000$ this year compared to the $\$ 130,000$ last fiscal year. DEA, recognizing the quality of our program and the real need for elderly security, still intends to give us the bulk of their allocation.

\section{General Assembly}

The R I General Assembly is not expected make any substantial alterations on public housing operations through the introduction of legislation. Their action on the budget proposal, however, could affect us in several ways. The 
PHA has been successful in applying for and receiving state grants from the Departments of Elderly Affairs (Elderly Security - \$130,000), Substance Abuse (Service Coordinators - \$47,500), and Health (Teen Pregnancy Prevention Program \$40.000). Should reductions in state spending result in substantial reductions in those departments' budgets, the funds we receive for several programs may be in jeopardy. Another factor concerns so-called "legislative grants." These are special grants requested by members of the General Assembly for organizations in their districts. Over the last several years, several of the elderly/disabled developments have benefited from these legislative grants. Funds were used to purchase recreational equipment and furniture for community rooms. The state's fiscal condition will probably preclude any legislative grants this year.

\section{LOCAL (MUNICIPAL) LEVEL}

The City of Providence is experiencing severe financial difficulties. The city faces a budget deficit in excess of $\$ 40.0$ million in FY 1996, unless spending reductions are implemented and/or additional revenues are found. There are various reasons for this shortfall but it's primarily due to the city's shrinking tax base and the increase in tax-exempt property.

Over the last five years, the value of taxable property in the city has declined by $\$ 100.0$ million, while the value of tax-exempt property has grown by $\$ 425.0$ million. If fully taxed, that $\$ 425.0$ million in value would yield $\$ 12.0$ million in taxes every year.

The city provides little funding for the PHA. Currently the only funds they provide are for Commissioner's compensation ( $\$ 75,00$ a meeting for expenses) and approximately $\$ 25,000$ as a match for state funding for the elderly/disabled security program. We cannot expect any additional funds from the city, unless it's a pass-through of federal funds like community development or HOME funds. The demand on these funds is so great that it's unlikely we will receive any assistance.

\section{Mayor}

Mayor Cianci is very supportive of the housing authority. He personally asked the Executive Director to remain at the PHA when he won election in 1990. Although the city's finances preclude any major infusion of funds from the city, the mayor's supportive comments and encouragement are helpful. The mayor has also allowed the PHA staff to run their own operation with little, if any, interference for practical political purposes.

\section{City Council}

The Providence City Council has little impact on the housing authority's operations. They have not allocated any funds to the PHA beyond the one program for the elderly residents and compensation for Commissioners. Two City Council members serve on the PHA Board according to state law. They are appointed every year by the council.

The 15 City Council members primarily interact with the PHA through their advocacy efforts for constituents requiring public or Section 8 housing assistance or residents residing in developments in their districts. Most requests are to provide constituents with emergency housing, which the PHA is unable to provide. The council members also have been occasional critics of our scattered site public housing program. Echoing the complaints of their constituents, several have asked that the units not be built in their wards. One council person personally intervened with the zoning board to prevent a minor and common zoning variance.

\section{City Departments}

The PHA interacts with a number of city departments, primarily due to service requests, but occasionally in concert with them for planning purposes. This is particularly true in the preparation of the HUD-mandated Comprehensive Housing Affordability Strategy (now known as the Consolidated Plan). The PHA's Executive Director meets biweekly with city department directors at the mayor's directors meeting. Other than an occasional request from the public works department or department of Inspections and Standards, little more is provided by the city.

ENVIRONMENTAL SCAN:

JOB TRAINING, EMPLOYMENT AND SELF-SUFFICIENCY (EXTERNAL)

Introduction:

As of April, 1995 the Providence Housing Authority is housing 840 families headed by single women on AFDC, representing $36.4 \%$ of its client households. The Authority's commitment to assisting these women in achieving economic independence through employment is manifested through several programs and policies. In the most direct way possible, the Authority makes a strong commitment by employing residents in its own operations 
wherever possible. We demonstrate our understanding of the complex and interrelated service needs of low income single mothers seeking to leave public assistance and continuously seek to offer a comprehensive package of services to meet those needs.

The Family Self Sufficiency Program is the PHA initiative most directly targeted to assisting heads of household to reach levels of income adequate to move from government dependence and into the world of work. FSS entails fiveyear contracts of participation between the Authority and participants. The PHA offers case management and advocacy services and several enrollment incentives. Currently, there are 76 active contracts. (Please note. current FSS enroliment includes 35 Section 8 families.)

\section{FORCES/TRENDS}

At the heart of any discussion of welfare-to-work initiatives in Rhode Island are two adverse trends:

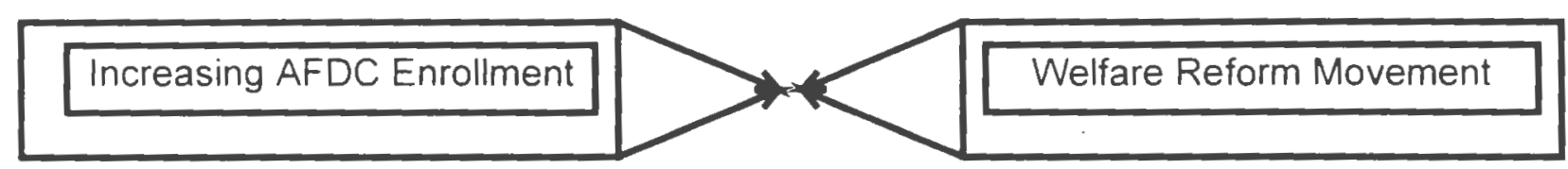

The number of Rhode Island families enrolled in the state's AFDC program has grown in each of the past five years, now totaling roughly 22,000 (about 42,000 children). In 1990, the state's caseload was about 16,000; there has been a $40 \%$ increase in five years. Local (and, to some degree, regional) job loss accounts for much of the increase, especially reductions in the banking, defense and manufacturing industries. Nationally, there has been a great deal of discussion about reforming welfare. And changes entailing limited enrollment terms and mandatory work requirements are most popular, at least in the press.

After taking office in January of 1995, Governor Almond indicated that he will not address changes to the State's welfare system until after January, 1996. Several states, however, have already moved to limit the amount of time parents can collect AFDC payments, have instituted mandatory work requirements and/or have imposed a cap on benefits determined by the number of children a woman has at the time of initial program enrollment.

In an environment of increasing caseloads and decreasing job availability, term limits and work requirements are only feasible if they are accompanied by an aggressive strategy for developing placements and a strong network of necessary supportive services, especially childcare and transportation.

\section{People}

Viewed through the broadest possible lens, the welfare-to-work initiative affects just about everyone in the state. Groups most directly involved are:

AFDC Recipients: About 3.5\% of the state's 22,000 AFDC households live in PHA properties. Ninety-seven percent of all AFDC households are headed by women and that is consistent with the demographics among our residents. Statewide, $60 \%$ of recipients are White, $15 \%$ are Black and $22 \%$ are Hispanic; among our population, $6 \%$ are White, $37 \%$ are Black and $57 \%$ are Hispanic.

Forty-six percent of all AFDC parents become eligible for the first time before their 22nd birthdays, when the probability of chronic dependence is higher. A recipient is classified as "chronically" dependent when one of the following conditions exists:

1. The most recent duration on AFDC is five years or longer

2. There have been four or more intervals on AFDC

3. There have been two or more intervais on, with the most recent duration being at least three years

Almost $60 \%$ of all recipients who came on AFDC before their 22 nd birthdays became chronic, as compared to $39 \%$ of those who came on after the age of 22. Clearly, there is a correlation between earlier parenthood and greater difficulty obtaining and maintaining an income over the poverty level. Equally obvious is the need for welfare-to-work programs that are evaluated by a more stringent standard than just rates of placement. Many women leave AFDC each year for employment, but most of them return to welfare. There is no single reason for this, although the fact 
that they are only able to obtain minimum wage jobs without benefits (especially health insurance for themselves and their children) or any prospect of advancement is frequently cited. AFDC recipients are most likely to obtain employment which can best be described as "tentative," meaning that neither the new employee nor the employer are strongly committed to a permanent placement.

The Working Poor: We are housing, in the family developments, about 225 families who report compensatıon for employment as the primary source of income. Considering that the average annual income in the family developments is only $\$ 8,907$ for a family of more than three people, it is safe to assume that these residents are working at very low wage jobs. Most of the resources in the state available to welfare-to-work efforts are focused on recipients. Those attempting to transition oft welfare and who have secured employment are generally not afforded the same level of support.

There are some resources to assist working poor in transition, including: Pathways-funded childcare subsidies (less available than for those in training) and extension of Medicaid and food stamp benefits for the family for up to 12 months following case closure, provided they don't earn too much money. Under RITE care regulations currently in effect, the children under age six are covered up to $250 \%$ of poverty; however, coverage for the head of the household (unless she is pregnant) and older children drops off much sooner. Also, there has been criticism of the program enroliment procedures, through which the AFDC population selects "primary care providers" from among local HMOs. The providers generally perceived as "better" (Harvard Health, for example) placed a cap on the number of enrollees they would accept. Provider designations were determined last year during income recertifications so the degree of choice a recipient received was entirely a function of her AFDC "anniversary" date.

Elected Officials: Currently, we are fortunate in this state to be represented in Washington by four elected officials who resist the politically expedient hostility toward AFDC-dependent mothers and children witnessed in other parts of the country. Congressmen Kennedy and Reed and Senators Pell and Chafee have all demonstrated an awareness of the complexities surrounding effective welfare reform, especially the extent to which well-funded supportive services (childcare, healthcare and transportation) are essential to the success of any reform effort.

Media: This is where the discussion of the future of public assistance programs is taking place and, in the past year, there have been no fewer than 20 local print and broadcast "news" stories which could be categorized as undermining serious welfare reform efforts in that they attempt to raise questions about the integrity of the programs and the recipients. Improving the public's perception of the AFDC population is instrumental to shoring up the political will essential to effective reform.

TaxpayersNoters: It's difficult to read public sentiment on welfare reform, although the 1990 and 1994 elections indicate that promises to "end welfare as we know it" garner votes. Certainly, the media is playing into taxpayer discontent in its zeal to "expose" government "giveaway" programs. Work requirements are a popular idea; significant public expenditures for the support services necessary to make work requirements feasible (training. education, childcare, job creation) are not.

State Government/Quasi Public Entities: Many of the resources necessary for successful self sufficiency programs are fragmented among too many administrative entities, including: The Department of Human Services (overall jurisdiction over AFDC, Medicare/Medicaid (shared with Department of Health), and Pathways to Independence. which provides case management, childcare subsidies, transportation allowances and contracts with an average of six providers per year for ESL and adult basic education programs); The Department of Employment and Training (coordinates public/private training initiatives, works with recipients of unemployment insurance benefits to achieve re-entry into the job market, tracks and analyzes employment statistics and trends; provides some case management services to AFDC population); The Department of Economic Development (negotiates to attract new business and job opportunities to the State, provides technical assistance to existing businesses to avoid job loss): The JTPA's and the Private Industry Councils (there are three in the state -- Providence/Cranston, Northern Rhode Island and Balance of State -- which administer federally funded training, re-training and technical assistance programs). The Department of Education (oversees adult basic, vocational and ESL programs; grant-funds special projects; runs the state's post secondary education system); The Department of Health (grant funds special projects; partial oversight responsibility re: Medicare and Medicaid); Rhode Island Public Transit Authority (intermittently manages transportation assistance programs for AFDC recipients; designs public transit system in the state); Office of the Attorney General (funds crime prevention projects); Department of Corrections (funds rehabilitation and education and counseling programs); Private Foundations and Public Private Partnerships (these include foundations and organizations like The Human Resource Investment Council. The Small Business Development Center and the Chambers of Commerce). 
These represent only the central administrative entities in the State. Each of these is party to a network of relationships entailing:

- Non-profit service providers

- Religious-based service providers

- Day care providers

- Local school boards and school departments

- Proprietary schools

- Private industry seeking to access public job training support funds

- Public housing agencies and RIHMFC

- Neighborhood community centers

- Neighborhood health centers

- Public libraries

- Neighborhood/community groups and task forces

- Hospitals, mental health treatment and counseling providers

Clearly, this fragmentation of adult basic education, post secondary education and support, job training, childcare. transportation and case management creates of system where the apportioning of public funds between administrative and direct service expenses is not in the clients' best interest. However, a dilemma arises when one considers consolidation of existing services. Efforts to reduce administrative costs may force a (possibly severe) reduction in the degree of specialization/neighborhood/special population specific service design and delivery. The challenge is to provide consolidation while avoiding uniformity. Also, each state department or "quasi" agency as well as each direct service provider has staked out its own funding turf and many of them retain sufficient political influence to guard it. Consolidation is a daunting objective.

Pathways to Independence (Rhode Island's JOBs Program) is the state program which provides the greatest number of services directly targeted to moving AFDC recipients into the world of work and also most closely monitors program enrollments. Pathways reported the following for fiscal year 1994 :

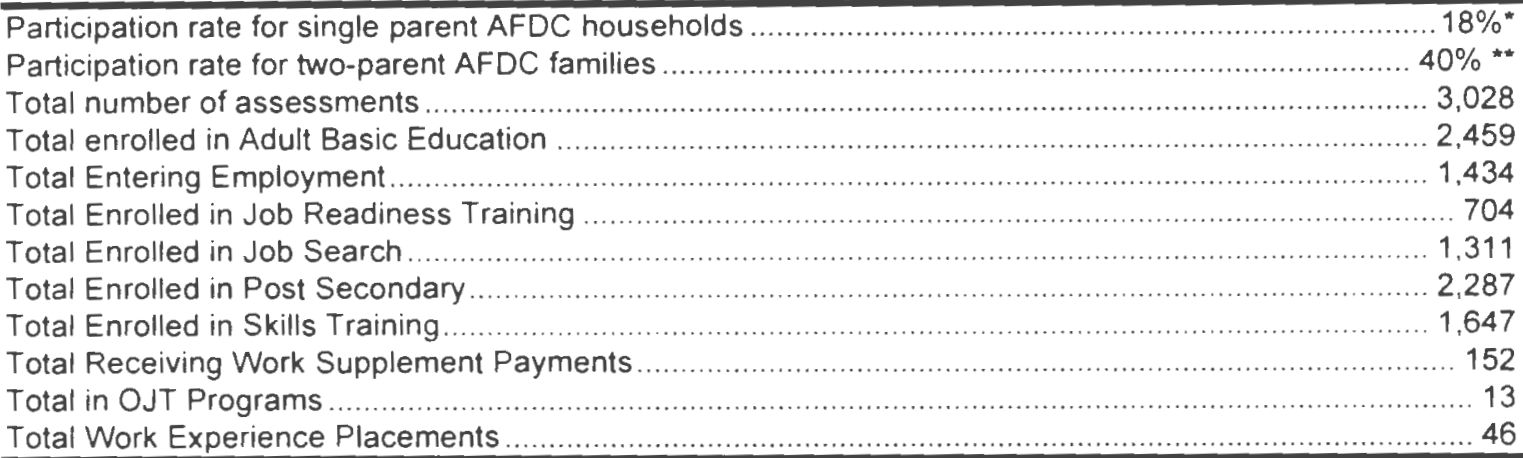

* Federally mandated participation rate (to receive full federally match) for 1995 is $20 \%$

** Federally mandated participation rate for 1995 is $50 \%$, moving $1060 \%$ in 1996 and $70 \%$ in 1997

\section{Economic}

Without the creation of significantly more full-time (40 hour per week) lower skill jobs which provide wages of about $\$ 7.00 /$ hour and family health benefits, the prospects for a successful welfare-to-work program are dismal. The avowed priority of the Rhode Island Department of Economic Development is the development of higher paying. higher skilled jobs, the sort not traditionally filled by single parents transitioning off AFDC. However, with close case management and a solidly supported training plan of three to five years, some AFDC recipients may successfully make the transition into the kinds of jobs the state is working to create. DED estimates that the kinds of jobs it considers ideal would require a minimum of a high school diploma (not, in most cases, a GED) and two years post secondary training. Of course, given the swelling of the case load in the most recent years, it is more than likely that workers displaced from other industries who have already been trained will fill those jobs. Bear in mind that estimates of the ratio of available jobs in the state which are filled without involvement of any of the self sufficiency related services network already identified range from $80 \%$ (DED) to $97 \%$ (DHS). 
A proactive job training program ought to aggressively train people for projected employment growth industries and. as of today. there is agreement among the central administrative entities as to what those are. Travel and Tourism, Financial Services. Food Services. Transportation and Geriatrics are industries which should be looking to hire more people over the next three to five years. (Again, bear in mind that the state's job training network poured its all about five years ago into preparing workers for the Bio/technology industry which, by all expert admissions. "fell flat".)

The State and Federal governments are also able to provide important indirect supports to job creation efforts, including the designation -- especially for tax purposes -- of "opportunity" and "empowerment" zones through which private industry employers receive financial and other incentives for creating new jobs. The "zone" concept. however, often overlooks a consideration pertinent to the issue and that is that people living in low income areas do not have to work in the same neighborhood to improve their income. Zone designations have to be meticulously worded and monitored to ensure that they function to create jobs for low income people which did not previously exist. Additional incentives to enlist private industry support for self sufficiency efforts are tax credits for employers who provide daycare for employees, special grants for training to improve skills and the Rhode Island Supportive Work program, through which the AFDC payment is deferred to an employer for up to six months provided that the former recipient is then offered a full time position which includes health insurance benefits

\section{Social}

The job training/self sufficiency services delivery industry is rife with stories of bias against the AFDC population and, clearly, there are myths about a veritable army of non-white single women who procreate irresponsibly for the sake of an additional $\$ 78.00$ a month. In fact, a Rhode Island AFDC recipient is most likely to be white and to have one child whereas a PHA client is more likely to a member of ethnic minority group. The negative stereotype remains a very stubborn piece of our "urban legend". Experience administering the PHA's FSS program along with the reports made by case workers employed by DHS and DET verifies that women seeking jobs in order to transition off AFDC have a difficult time obtaining employment, even when they have received appropriate training. Placement rates through articulated agreements with employers specifying numbers of enrollees to be offered employment are higher than rates for individuals seeking placements on their own. Over the past 10 to 20 years, however, popular perceptions of single mothers have improved.

In Providence, the percentage of both the overall and the AFDC population which is non-white continues to grow dramatically. A decided tension is emerging, as mandatory work requirements are discussed, between those who argue that only culturally appropriate service delivery will be effective and critics who insist that the onus of achieving economic independence is on those who choose to immigrate to this country. The development of a comprehensive and effective policy becomes that much more difficult in a politically contentious environment.

What is established are the long range benefits of self sufficiency programs that work. Children raised in households with an adult or adults who work are much more likely to become working adults themselves. If we are interested in public policy that engenders a work ethic, than we would be best advised to fully fund self sufficiency programs sooner rather than later.

A social issue which bears discussion concerns somewhat of a public policy and public perception "blind spot" about the responsibilities of both parents to contribute to the support of their children. The Department of Human Services makes a concerted effort to identify fathers of children on AFDC and to receive and enforce child support judgments. However, most mothers of children who receive AFDC benefits on their behalf do not report the names of the fathers simply because they do not perceive that it is in their best interest to do so. Unreported fathers may continue to provide valuable and necessary financial and personal support and many women are reluctant to jeopardize these already precarious relationships. About $20 \%$ of the AFDC population has, at any given time, court ordered child support payments which they cannot collect either because the father cannot be located or because he has no income with which to make the payments. Federal regulations governing both the AFDC and JOBs programs mandate more stringent work requirements of two parent families, effectively discouraging women from living in (or acknowledging that they live in) them.

Just as some would argue that the relaxation of the stigma of single motherhood has created an increasingly expensive social problem, others make the point that the lack of social condemnation of "deadbeat dads" contributes equally. Mandatory work requirements effectively force single mothers to meet the financial obligations of both parents. A realistic self sufficiency program should require her to contribute her share, and may consider some compensation for her labor as the custodial parent in determining what that share is. An equitable policy feature -- if we are considering limiting public assistance to the number of children a women has when she seeks such assistance -- would be to also deny benefits to fathers (and any other children they subsequently have) who fail to make child support payments. 
Technology

The possibility of better coordination of existing training, placement and case management services has been substantially enhanced over the past two years by technological advances. For a small state, Rhode Island has an impressively advanced telecommunications industry. In the City of Providence, installation of fiber optic cables should allow service providers to communicate with one another with greater speed and accuracy This may mean that low income people will be able to access services sooner and experience far less of the running from one provider to another that has discouraged their efforts in the past. Twice in the past year, the PHA has been party to funding applications designed to enhance its technological support for service coordination: One application, submitted to the United States Department of Labor, involved the PHA, DHS, CCRI and seven non-profit providers in Providence in a computer link up for case management purposes. Unfortunately, it was not selected for funding. The PHA is the lead applicant in a proposal for Section 8 Housing Counseling funds which includes a computer network between Providence and six metropolitan area public housing agencies. That application is pending.

\section{CLIENTS/CUSTOMERS}

No welfare-to-work initiative can succeed unless the client population buys into it. In both perception and reality, the recipient must be convinced that they will be financially better off if they work.

DHS has proactively developed, as a Pathways Program component, its "Work Pays" counseling effort. Case managers are able to demonstrate to recipients the substantive ways in which the quality of their lives will improve as more of their income is from empioyment. An important piece of the "Work Pays" pie is the IRS Earned Income Credit which, when properly applied, effectively increases the minimum wage to $\$ 6.00$ an hour. However, the level of awareness of the EIC is low and most clients do not realize that they can collect the credit from their employer throughout the year.

The PHA is able to offer additional incentives to its clients to encourage them to seek economic self sufficiency. FSS includes an escrow savings account feature, through which additional rent paid as a consequence of increased earned income is held in an interest bearing savings account and refunded to the participant following the completion of the contract. The Authority is currently managing nine escrow savings accounts. As a short term enrollment inducement, the Authority has designated certain units of scattered site housing for FSS participants. This has been a very effective means of generating interest in the program. Furthermore, the Authority has HUD approval to give preference to FSS participants in selecting buyers for scattered site houses sold through our approved $(5)(h)$ homeownership conversion program.

Again, these incentives are most effective in working with an AFDC recipient moving to employment. A head of household working at a low wage job has far fewer special incentives for advancement, although many of them have moved into scattered sites after enrolling in the program.

\section{SUPPORTERS}

Drumming up support for welfare-to-work initiatives is a challenge shared by both recipients and service providers. The national debate around welfare reform cooled considerably after various federal departments (including OMB) took at look at the price tag for comprehensive childcare assistance and job development programs. Realistically, job creation in the private sector is a much more palatable programmatic model although we are again faced with the difficulty of creating jobs that pay over poverty levels for people with low skill levels. The most significant labor market shift over the past ten years has been in the growth of "high skills, high pay" jobs.

One benefit of the amount of the attention that has been paid to welfare reform is a general increase in the level of awareness of the degree to which chronic welfare dependence is symptomatic of larger social problems. People who are poorly prepared at the secondary educational level turn into adults with low skill levels. Businesses seeking to select a site for facilities that create jobs consider the relative educational levels of the local labor market. Public school systems remain mired in a liberal arts. Post secondary preparation curricula does not translate into employment skills for those who do not pursue a college education. Most local school boards and public school departments remain strongly biased in favor of students who go on to college, despite the fact that only about a third of high school graduates in the country do so. Early parenthood makes the prospect of achieving economic independence through employment even dimmer. Again, in the first two thirds of this century, a thriving manufacturing industry was able to absorb much of the low skilled labor force.

Locally, Johnson and Wales University is an example of an institution which has responded well to labor market shifts and has maintained public support. Growth in service industries (food services, hospitality, travel and tourism), 
coupled with marketing itself as a traditional academic institution have combined to make $J$ and $W$ widely respected for its ability to train and place students.

\section{COMPETITION}

It is to the PHA's advantage to offer services to clients that both encourage and assist them to achieve economic independence through employment. Many of the ills of public housing are statistically associated with long term public assistance dependence, including crime, births to young mothers, abuse of alcohol and drugs, vandalism and low levels of voter participation. As various federal programs and policies designed to increase the rates at which people leave AFDC are considered one thing is clear and that is that those agencies best able to achieve higher rates of successful employment placements will be first in line for federal assistance.

Traditionally, the Department of Human Services has held sole jurisdiction over the AFDC program, including the JOBs component. FSS participants report that, despite the array of services offered through Pathways, it is the childcare subsidy that they find most desirable. However, Pathways is not able to offer housing subsidy and from a strictly bottom line analysis of the household budget, that is a more valuable benefit. The PHA could conceivably "own" a substantial share of this market if it could offer no cost childcare to adults in training while they receive housing subsidy. If we could further enhance our ability to directly access placements, we would have more of the significant components in place than any other provider in the state. The Authority should be dealing directly with employers and offering them what incentives it can (for example, free transportation for workers or custom-designed training programs) in exchange for placements.

Block granting of JOBs program funds to states may work to the Authority's advantage, depending on how the State decides to apportion the funds.

ENVIRONMENTAL SCAN:

HOMEOWNERSHIP/DEVELOPMENT OPPORTUNITIES (EXTERNAL)

\section{FORCES/TRENDS}

\section{People}

The PHA has various individuals and organizations that affect our desire and need to diversify. If the Authority is planning to develop and rehabilitate properties for homeownership opportunities, the major players in the field are: HUD, RIHMFC, PPHC, city/suburban non-profit agencies, lending institutions and the City of Providence.

HUD's role is as a regulatory agency as well as a funding organization. If the de-regulation of HUD takes place, the PHA may be able to take advantage of some existing public housing homeownership programs such as $5(\mathrm{~h})$ and the HOPE I program. With these programs, the PHA may be able to explore other forms of owning such as multi-family sales and condominium ownership. Presently, the PHA can participate in HUD homeownership funding programs as a non-profit developer through the FHA disposition of properties, the $203 \mathrm{~K}$ rehabilitation program, the HOME program and others.

RIHMFC currently administers the HOME and other funding programs and guarantees first mortgages for buyers. As a regulatory agency, buyers and developers must conform to RIHMFC's mortgage qualifying guidelines. RIHMFC provides first and second mortgage financing for profit and non-profit developers. Low income housing tax credits are available through them for rental housing that is developed. They also provide home buying seminars and technical assistance through professional seminars that they sponsor. The PHA can work with RIHMFC to make special concessions to the potential buyers so as to ease the sometimes rigorous standards.

The Providence Plan Housing Corporation holds a great key in the City of Providence. They provide funding to buyers in the form of down payment and closing cost assistance and run a large scale housing development program that specializes in the rehabilitation and sale of single and multi-family housing. They also administer the HOME funding program in the city. If PPHC's future is in jeopardy, the Authority may be able to tap their market of low income buyers and provide some of the programs that PPHC currently operates. At the same time, if PPHC continues their mission, the PHA can work with them to develop a large pool of potential applicants for their properties as well as the PHA's. 
Non-profit organizations participate in the majority of funding programs available in the City through HUD. RIHMFC and PPHC. They are the strongest competition to PPHC that the PHA faces if the Authority plans to delve into the low income homeownership market.

Another body the PHA must work with in order to develop its homeownership potential is the City of Providence. Due to the current high tax climate and the needed mayoral support, the City can either be an obstacle or an enabler Further, the City administers CDBG money that the PHA could garner. If the PHA

plans to put houses back on the tax rolls or develop or rehabilitate properties that are City owned or abandoned, the PHA could provide an increase in the tax base. It would be beneficial for the City to work with the PHA and its buyers to provide tax concessions that are agreeable to both parties.

Lending institutions would interact with the PHA as a source of project funding and buyer funding. Due to aggressive CRA requirements for banks, large financial powers must have money available for communities. This would affect both the PHA's ability to borrow based on development or rehabilitation, and the buyer's ability to borrow for first mortgage financing. Many banks also provide training and technical assistance for the low income buyer. They also channel federally funded programs such as the Federal Home Loan Bank's Affordable Housing Program and others through their branches. Down payment and closing cost assistance is sometimes available along with a host of low to moderate income borrowing programs.

\section{Changes}

Currently, the PHA relies heavily on the HUD subsidies of the public housing and Section 8 programs. If deregulation is to occur, and the money supplied by HUD comes in other forms (Block Grants or Certificate issuance), the PHA will be forced to seek alternative sources of funding to keep it running. Development could be a profitable business venture through profit or developer's fees in the non-profit process.

Welfare reform will certainly have an impact on any development activity proposed by the PHA. On the positive side, reforms may encourage the current recipients to strive for work, therefore making them stronger candidates for homeownership. If it affects the public housing population in this manner, the PHA may be able to have a larger pool of qualified buyers. If public housing becomes an oasis for the most destitute client, the PHA may see its working poor population want to consider other forms of housing, including homeownership. If the PHA continues to serve the poorest populations the need for alternative forms of income is definitely necessary due to dwindling rental income.

Changing interest rates and rising taxes will consistently provide a fluctuation of participation in development programs. If interest rates and taxes increase, the buyers generally suffer, leaving less and less qualified buyers. At the same time it is more difficult for the developer if borrowing money becomes more expensive while the pool of buyers decreases.

\section{Technology}

Changes in technology can provide the ease necessary in new construction and rehabilitation. Modular housing and other construction techniques make the cost of creating affordable housing less expensive. The use of construction managers rather than general contractors can decrease the cost of any job, if correctly estimated at the outset. Computer technology aids in the design of housing.

The use of computer technology can pinpoint directly the qualified buyers the PHA currently houses. The information management systems give the PHA the upper hand in knowing its market. If the PHA is to rely solely on its current rental population for homeownership candidates, the information systems can target any person who would be surface qualified to participate, up to and including accessing credit information through the use of on-line hook-ups to credit agencies.

\section{CLIENTS/CUSTOMERS}

The Housing Authority knows its clients very well. They are public housing residents and Section 8 recipients. There are currently 1,340 families (not including 978 elderly families) in public housing and 2,353 Section 8 recipients. If the PHA was to base its potential market only in these populations, and a very conservative average of 1 in 50 buyers may qualify, an approximation of qualified buyers that we currently house is seventy four. But that does not include the remaining working poor in the City of Providence and surrounding communities. The potential to tap into those markets with the appropriate products is overwhelming. The relationship the PHA holds with the network of other public housing agencies in other cities is strong allowing the Authority to use those populations as well. The 
working poor need to be identified, but the numbers can be found by completing extensive market studies which the PHA has the capacity to periorm.

\section{SUPPORTERS}

The supporters of the programs, if developed by the PHA, would first be the residents. The holistic approach to servicing the residents by providing economic empowerment programs and encouraging their move to permanent homeownership is the goal of the PHA. The residents must be aware that the opportunities are available to them if they work with the Authority to achieve this objective.

Other supporters may include the funding agencies: RIHMFC. PPHC, the City, HUD and banks. Due to the inability of the non-profits to timely build, rehabilitate and sell projects, these agencies would support a capable candidate in the market. The outstanding working relationships that the PHA holds with these agencies can work to the favor of the PHA's programs

\section{COMPETITION: STRENGTHS/WEAKNESSES}

In the City of Providence in 1994, according to the statewide Multiple Listing Service, there were 823 properties sold at an average price of $\$ 66,657$. The median price was $\$ 74,000$. The Providence Plan Housing Corporation has statistics of 75 properties; their own and the local CDCs (non-profits). Out of these properties, 13 have closed with an average sales price of $\$ 63,425$, and 36 are under Purchase and Sales Agreements or Intents to purchase at an average of $\$ 76,329$. The average sales price of 75 houses is $\$ 71,704$. Currently, the average price (Fair Market Value) of the properties the PHA is selling is $\$ 70,600$, with a median of $\$ 73,000$ (5 properties.) The actual sales price of the PHA's properties and other sales in the city are comparable. If the PHA is able to provide the same or better service than that of PPHC or the local non-profits, the PHA remains highly competitive with these agencies.

The current RI Housing Mortgage rates (May 11, 1995) range from a low of $5.875 \%$ to a high of $7.375 \%$, giving low income buyers a good opportunity to take advantage of low interest rates. There is an expectation that there will be a slight dip in the rates in the coming year.

The strongest competition that the Housing Authority faces is PPHC and other non-profits. Not only does the PHA have to worry about in-town agencies, but suburban agencies as well. They are able to draw clients from their communities and draw the PHA's residents to their projects. Suburban non-profits help city dwellers to re-locate to sometimes nicer communities. The non-profits are well known in their community and have the support of HUD, RIHMFC, PPHC and other funders.

Their weaknesses include the lack of expertise, their reliance on outside consultants and the lack of depth in their applicant pools. Rarely do you find a non-profit who has the capability to build quality housing on schedule and also conduct aggressive marketing techniques. Their technological capabilities are not as powerful as the PHA, and they do not know their client base as well as the Authority knows its residents. The combination of the PHA's grant writing, modernization and development and marketing skills make the PHA a good challenger to the low to moderate income homeownership market.

ENVIRONMENTAL SCAN: FINANCE AND ACCOUNTING (EXTERNAL)

\section{FORCES/TRENDS}

\section{People}

Politicians, government employees, judges, and vendors are examples of people who have an impact on the PHA. While vendors can effect operations by their prices and fexibility of credit terms, politicians, government employees and judges have a far greater influence on the survival of the organization. A political ally in Congress can head off proposed cutbacks in subsidized housing and lend support for any funding that may be available. Local politicians will become more influential and helpful if and when funding decisions are made at the state or city level. The reinventing of HUD will certainly impact on daily operations. Less government control will mean greater autonomy over the day to day operations. Finally, the judiciary impacts on operations by the decisions it renders. Laws governing occupancy and other facets of housing play a role in the relationship between tenant and landlord. The relationship could easily be changed depending on the judiciary's interpretation of the law. If, for example, the 
eviction process is extended by one month, this action would impact not only the amount of rental income collected but also the amount of subsidy earned. Both income components are calculated at the beginning of the year, but are affected after the fact by third party decisions

\section{Economic}

As the federal deficit increases. Congress is now seriously looking for programs to reduce or cut. In most cases, social and non-entitlement programs are the first to feel the effects of deficit reduction. In the last two years, the PHA has been the target of these reductions. For fiscal year ending ' 95 and ' 96 , eligible subsidy was reduced by a combined $9 \%$ for both years or a total of $\$ 504,254$. State and city governments have also felt the squeeze. The State of Rhode Island changed General Public Assistance (GPA) requirements. This change not only affected those individuals previously entitied to benefits, but it also affected this agency. As a result, we now have $10 \%$ of the total tenant population on zero base rent and are now collecting on average two dollars less per month per tenant in rents

\section{Social}

Changes in mores, coupled with influx of immigrants continues to outpace the ability of the authority to provide housing for those in need. Some of the changes are increased numbers of unwed, uneducated, and unskilled people who qualify for public housing

\section{Technology}

Advances in technology will improve the PHA's capabilities in some areas. Energy conservation and security will be two areas impacted.

Of particular interest will be the UNITY Monitoring System installed by USA Electronic Systerns. The new computer system monitors heat sensors, boilers, valves, and alarm systems throughout the agency. The new system breaches two critical areas under management control by providing the necessary tools for one person to control heat and security at one location

\section{CLIENTS/CUSTOMERS}

Elderly, low income, disabled, and families are the PHA's clients/customers. They are "buying" - with the government's help - a decent place to live. The decision to seek housing through the PHA is brought about by their financial inability to afford housing on the open market. The waiting list for both public and Section 8 housing has a combined total of 2,200 applicants anticipating subsidized housing.

\section{SUPPORTERS}

The primary financial supporter of the PHA is the federal government. Through the operating subsidy and Section 8 housing assistance payments, they provide funds to those in need of housing. Funding is provided annually through the budget process and is subject to changes pending government increases or decreases. The PHA also receives funds from the State of Rhode Island, City of Providence and private contributions. With decreasing federal funding anticipated, the Authority will examine increasing its source of funds from fees earned and private foundations

\section{COMPETITION}

Competitors up until now have been other housing authorities and private concerns who have received special funding and favorable tax treatment as an incentive to build or rehabilitate existing housing. Changes in the Section 8 program have also widened the level of competition. With portability, a tenant now has a greater choice of where to live. No longer are people tied to a particular location.

ENVIRONMENTAL SCAN:

\section{HOUSING MANAGEMENT (EXTERNAL)}

\section{FORCES/TRENDS}

\section{People}

The primary and most influential external organization having direct impact on the PHA is the federal Department of Housing and Urban Development. HUD provides most of the funds for the Authority's operations and practically all 
of the department's. HUD also has a great influence on our operations through its regulatory powers. Changes proposed by HUD will effect our future substantially. If HUD's reinvention and "voucherization" occurs, a new era in public housing will begin. Voucherization permits public housing residents to determine where they want to live. At a date to be determined. HUD will issue vouchers to every current public housing resident. They may remain in public housing or they may move to private housing. Rents would be subsidized in either case. The PHA would no longer receive a subsidy from HUD; rather, they would have to compete for residents.

Another significant factor affecting public housing is the Congress. The Congress, with the Administration's concurrence, has already rescinded funds for this program year from our budget. Fortunately, operating subsidy, which seriously effects the department, was not reduced. Next year's budget, however, calls for a $22 \%$ reduction in operating subsidy. This will have a significant impact on our operations.

Numerous other external organizations have an impact on our operations, particularly those institutions that involve resident services, law enforcement and the courts. An example of how government regulatory changes affect the PHA was realized last year when the state government changed the rules for eligibility for General Public Assistance (GPA). As a result of the change, over two hundred residents who had previously received GPA, were no longer eligible. Prior to this change, approximately $1 \%$ of our residents paid zero rent. Since the change, more than $12 \%$ of the rent roll is now paying zero rent.

The judiciary plays a role in our operations by deciding whether or not a resident who violates the lease (mostly for non-payment of rent) is allowed to remain in public housing. Several judges in the state district court system have stated their belief that public housing is the "...housing of last resort..." There is, obviously, no legislation or regulation citing public housing as the housing of last resort. Until this attitude is changed, evictions become more difficult and unsatisfactory residents continue to disrupt developments

\section{Economic}

Over the last 10 years, unemployment in the State of Rhode Island has fluctuated from $5.3 \%$ to $7.1 \%$. In the city of Providence, it's always been a few percentage points greater. Unemployment has a direct impact on the number of families in

need of subsidized housing. The loss of manufacturing jobs in the state and city has contributed to the higher unemployment rates in recent years. Recent data indicates that there isn't necessarily a correlation between unemployment rates and the number applicants for public housing. Even in the 1980s, during periods of very low unemployment, waiting lists for public housing continued to grow. The most significant correlation for public housing is the increase in single parent households, primarily female headed of households. The increasing rate of births to single young women is the most significant factor in the growth of public housing waiting lists.

\section{Social}

Welfare reform and its impact on families and family structure could substantially influence the future of public housing. Some of the changes that have been suggested by the Administration and Congress may truly change "welfare as we know it." One of the proposed changes involves limiting the amount of time people are eligible to receive benefits. Although public housing hasn't been mentioned specifically, it is logical to conclude that housing will be considered part of a larger welfare package. Another idea being considered is to not increase the amount of assistance for each additional child born out of wedlock. Still another proposal requires women younger than 18 to live with their parent(s) in order to qualify for assistance for the child. Some proponents of these proposals believe these changes will affect the illegitimacy rate, particularly for young women, and will not "enable" them to have children without considering the consequences. It remains to be seen if any of these proposals will actually be carried out and if they will be successful.

\section{Technology}

Increased computerization, particularly networking (wide area network) with all of our developments, will allow for instant access to current information. Plans have already been initiated to computerize waiting list information and the ability to compute rents. Use of a wide area network (WAN) would also allow the department director to provide information to the various developments instantaneously. Information such as socioeconomic data, rents receivable and security data would all be available for the site manager to review.

While not necessarily new, security surveillance cameras offers a technological advancement at our high-rise developments. Security cameras are mounted at strategic locations in the building's lobby to monitor activity at each site. If an occurrence should take place, security personnel as well as the police may review the tapes. 
A technological innovation that the Authority will examine in the near future is mini hand held computers with a HQS inspection program. The site manager would enter the development and unit number, date of inspection, and go through the electronic checklist to determine if the unit passed inspection. At the end of the round of inspections, the data would be downloaded to the PC with work order requirements forwarded to the Facilities Management

Department.

\section{CLIENTSICUSTOMERS}

Our primary customers/clients are low-income families in need of housing. Every citizen in the city, or eisewhere for that matter, is eligible for public housing if their income is $50 \%$ or less of the median family income for the area.

At present, the PHA houses 2,318 low-income families (this will grow to 2,640 families when modernization and development is completed), of which $53 \%$ are housed in our family developments and $47 \%$ are housed in the elderly developments. The racial composition at our developments is $30 \%$ White, $29 \%$ Black, $41 \%$ Hispanic and less than $1 \%$ for the Asian and Native American populations. The greatest increase in population has been among Hispanics, both at the family and elderly developments. Fifty-eight percent of the families residing in public housing family developments and approximately $64 \%$ of the PHA waiting list are Hispanics.

Our clients/customers are also the elderly and the disabled (physically and mentally impaired). As of July 1. 1995. $51 \%$ of our high-rise population was non-disabled elderly, while $49 \%$ were disabled ( $22 \%$ mental impairments, $27 \%$ physical impairments). The mixing of elderly with younger disabled residents has caused problems with the clash of lifestyles and remains one of primary concerns.

\section{SUPPORTERS}

Our supporters are people and organizations who assist low-income people to find shelter and to deal with their social well-being. Many organizations work with PHA staff to assist in the placement of families in need. We are selected by them because of our size, reputation and the services that we provide our residents. An incomplete list of supporters would include practically every social welfare agency in the city and state, nonprofit social service centers, job training facilities, etc.

\section{COMPETITION}

There are 39 cities and towns within the State of Rhode Island which also provide subsidized housing to the community either through their own housing authorities or through the offices of Rhode Island Housing and Mortgage Finance Corporation. Their ability to provide subsidized rents makes them a competitor. The PHA currently administers $7 \%$ of the subsidized housing market in Providence. What separates the Providence Housing Authority from many other competitors is that we provide elderly and family housing. We are located in the capital city which is the central location for many supportive services. We are also one of the largest property managers in the state.

Our other competition is from the low end of the private housing market. Although the number of affordable units is limited, some residents trade off the additional cost of housing for other considerations such as, security, neighborhood, and other amenities.

ENVIRONMENTAL SCAN:

FACILITIES MANAGEMENT (EXTERNAL)

\section{FORCESITRENOS}

\section{People}

The department is affected by numerous agencies and individuals, including: HUD and other regulatory bodies, residents and their friends, other PHA departments, unions, politicians, law enforcement agencies, neighbors, media and vendors.

HUD and other governmental agencies make and enforce the rules we live by. Disruptive residents and their guests cause thousands of dollars in damage. Housing management and other departments make decisions with little or no knowledge of how it affects our daily operations. Better screening of new and transfer residents is required. 
Enforcing lease provisions, such as those regarding pets, boarders and lodgers and residents' responsibility to keep units clean is necessary in order to make living conditions more desirable. Attempting to solve resident problems with phone calls to dispatch only shifts the burden, rather than curing the problem. Scattered Sites present special maintenance problems, compounded by travel time to and from the sites. Unions need to work with us in identifying troublesome employees in order to weed them out, rather than defend them. The occasional phone call from politicians around campaign time seeking special services for their constituents disrupts planned maintenance activities.

The Providence Police Department could have a major positive affect on Facilities Management's operations. Unfortunately, crime in the developments causes us to struggle trying to keep up with vandalism. If crime continues to go unchecked and budget reductions are initiated, it will not be long until we revert back to the way it was fifteen years ago. The majority of our neighbors have resigned themselves to living in developments that experience these problems and, except for a few, they have a fatalistic view about us

The local media frequently reports on the negative events taking place in public housing and does not attempt to seek the root cause of a problem. Their stories could prove helpful if they spoke directly with department spokesmen. Instead, they seek sensational stories that affect our reputation, as well as the Authority's overall.

\section{Economic}

The economy has a major impact on public housing. When the economy is not expanding and no new jobs are created, poverty tends to increase. As long as there are poor people, there will be a need for subsidized housing. However, even in good economic times there's been a need for public housing. Many residents of public housing are very low-income with little education and few employment skills. Others lack either the initiative or have given up seeking work out of frustration. Still others do not work because public benefit programs (subsidized housing, food stamps, fuel assistance, medical coverage, etc.) compete with the entry level employment for which these individuals are qualified.

There are obviously exceptions to this majority. PHA socioeconomic data indicates approximately twenty percent of the resident population works. Few work at well-paying jobs or they probably wouldn't choose public housing. In the past. a strong. growing economy would lead to new opportunities in the job market, but as stated above, many of our residents do not have the skills for the new job market.

The economy also has an affect on the federal budget and funding of housing authorities. The new Congress is attempling to reduce the federal budget deficit by cutting programs outright or reducing them substantially. Proposed cutbacks in public housing have been planned for next fiscal year.

\section{Social}

Many of our residents, or at least enough of them to have an impact, exhibit antisocial behavior which affects the quality of life in our developments. The increase in the number of single parent households (overwhelmingly female) contributes to less disciplined children who cause malicious damage to PHA property. Vandalism work orders record the amount of blatant disregard for acceptable behavior at our family developments. The drug culture is accepted by many as an everyday occurrence and this too leads to other problems beyond the ability of the department to handle. Perhaps welfare reform at the national level will improve the situation.

\section{Technology}

Labor saving devices mean we can do more for less, but this technology requires us to hire only skilled people or people who can be trained quickly. (Technology is covered more extensively in this department's Intemal Environmental Scan)

\section{CLIENTS/CUSTOMERS}

Our primary customers are low-income individuals and families. The PHA is home to just over 5,000 residents. Average household size is 2.23 persons authority-wide (3.23 at family developments, 1.11 at elderly/disabled developments). The average age of residents in family developments is 21 years; 56 years in the elderly/disabled developments. Authority-wide, the average age is 29 years. Hispanics are the largest racial group in our developments with $42.2 \%$ of the total. Whites constitute $29.4 \%$ and African-Americans $28.6 \%$. Average income for all families at the PHA is $20 \%$ of the average city income $(\$ 7,587$ compared to $\$ 37,692)$. The average income at family developments is $\$ 8,813 ; \$ 6,206$ at elderly/disabled developments). Approximately $90 \%$ of the heads of household at the family developments are females. Fifty percent of the residents in the six elderly/disabled developments are either physically or mentally disabled. 
Should HUD be successful in getting their proposed "voucherization" initiative passed, we may very well lose a number of our existing customers to the private housing market. We will have to then compete with the private sector for our customers. Our only source of income from HUD will be rental subsidies from residents who decide to stay in public housing and those families and individuals who choose to pay rent at one of our developments.

\section{SUPPORT}

Support comes from many sources, but the PHA is primarily supported financially by the Department of Housing and Urban Development through subsidies and grant assistance provided by taxpayers. Support is also received from local law enforcement agencies who patrol PHA developments. A greater law enforcement presence would contribute positively to the environment at our development.

More support is needed from local judges who believe "public housing is the housing of last resort." Every time they prohibit an eviction, the wrong message is sent to other residents saying that this is a place where the rules do not have to be followed. Judges must become aware of the unique problems experienced by public housing residents. If disruptive residents are allowed to stay, the lease-abiding residents who pay their rent on time will seek shelter elsewhere. The "housing of last resort syndrome" must be addressed

More support is needed from the City of Providence. Under the Cooperation Agreement with the city, services are supposed to be equal to those received by unsubsidized properties. Even basic street sweeping and sewer cleaning would be helpful. Financial support would be the most appreciated, but with the city experiencing difficulties of their own, this is an unlikely scenario.

\section{COMPETITION}

\section{Housing}

Our major competitors are other housing authorities, privately owned and operated assisted (subsidized) housing. our own Section 8 housing department, and the private housing market in the greater Providence metropolitan area. They currently compete with us for customers (residents). Privately owned assisted housing, particularly for the elderly, is the greatest threat because they offer amenities that are not available to public housing authorities at the same rent schedule. Another advantage for private, elderly, assisted housing is the size of the units. Most privately owned facilities are one bedroom in size compared to our efficiency (one room) units.

Even some units in the private market compete with public housing, provided the rent is not too high. This is the case in certain areas of the city, particularly the Southwest side of the city. As the housing market goes into a recession, demand for certain units decreases, making rents more affordable. Tight housing markets always make public housing an attractive alternative.

The Section 8 certificate and voucher programs also compete. These are, perhaps, an even greater threat since they are portable, meaning they allow you to live outside the city's legal limits. If and when HUD's "voucherization plan" goes into effect, all our residents will have the option to move to other housing and have it paid for (within limits) by HUD.

\section{Department Services}

The department's greatest competition will come from the private sector where labor costs are generally lower, productivity is higher, and the workforce is not organized. Clearly, in some circumstances, this will be beneficial to the housing authority. As cited earlier, an analysis of painting operations clearly indicates a clear advantage for the housing authority in privatizing. Other areas as well may, under the right circumstances, result in significant savings for the Authority.

Lack of cooperation by some residents when contracting out creates a weakness for our department. Add-on costs such as residents not being home, litter and vandalism can drive up costs to a point where on-site personnel are preferable, for the sake of convenience and flexibility.

ENVIRONMENTAL SCAN:

MODERNIZATION \& DEVELOPMENT (EXTERNAL) 
The Providence Housing Authority is affected most deeply by Congress/HUD as they prepare to make decisions regarding the funding for public housing. If the decision is made to change to block grant funding targeted through cities, then the manner in which city government will administer and disperse funds will also impact our programs. Although the objective of Congress/HUD is to make funding available to provide adequate housing and community service programs to low income families and elderly, the current political and economic situation could cause this objective to change radically. The current emphasis on balancing the budget and reducing government spending may result in a loss in funding which would clearly reduce the level of services the PHA is currently able to provide. Community service programs, although almost entirely funded by grants apar from HUD, would be competing for a shrinkıng pool of funds. This would also place more demand on the CGP budget where management improvements are aliowed to be funded up to $20 \%$ of the budget. If the present plans for reinventing HUD are implemented, we will have to compete with the private market for our current tenants.

\section{Social Impact}

With congressional cost cutting, the Modernization and Development Department will be faced with additional constraints on our ability to modernize and maintain our units. The changing population of our developments to a Hispanic base, the rise in violence and lack of a traditional two parent family coupled with society's increasingly critical attitude toward government spending are all going to affect our Department as well as the Authority as a whole. The social and economic problems seem to be growing as the funding available to address these problems is shrinking. Technological improvements, especially in the computer field, may offer some help by reducing costs, allowing for greater communication between developments and allowing us to provide one stop shopping for services. But the primary outlook seems to be one where we will be required to do more with less.

Our current resident base is primarily elderly, low income single parent families and the mentally and physically disabled. Most are on some form of public assistance. The general lack of education and training in conjunction with a poor job market leaves these people with few other aiternatives and contributes to a generational dependency on public housing. The original ideal of providing transitional housing for the working poor has been supplanted by a reality of public housing seen by the general public as housing of last resort. Their decision to move into public housing is really a non-decision, where they are driven by financial need and lack of choices.

\section{Community Impact}

Although there is support for the Housing Authority from other community organizations, churches and some city officials, there is a greater need now for an economic commitment from the Community Development Block Grant Program as well as targeted grants from government and private foundations. While these organizations are concerned for the population and aware of the need for low income housing with extensive social services, there is also a concern that this population will move outside public housing. If, in fact, our funding is cut so severely that we are unable to maintain the physical condition of our housing and our units become less marketable, the perception and support for public housing could change. If the voucher system goes into effect and the more desirable and self sufficient of our residents move to private sector housing. the Housing Authority could be seen as only a holding area to keep this population contained. There may also be problems as the various community service organizations, including our Community Service Department, have to compete for a piece of an ever decreasing pie. Even now our residents are sometimes used as a statistic to provide funding for other community organizations, but then may not receive their fair share of the program services provided by the grant

\section{Competitive Forces}

The primary advantage of our competition is that they are not associated with public housing and therefore do not carry the attendant stigma both real and perceived. Also, non-public housing developments often have more amenities available because they have not been saddled with the design/development restrictions incumbent on public housing agencies. These units may also be located in neighborhoods that prospective residents find more desirable. However, as we move into this more competitive environment, we also have several advantages over other low income housing providers both subsidized and private. We have a large stock of housing, mortgage free, the majority of which is in reasonably good condition. We have a good working and ever-improving relationship with our residents. Generally our staff shows compassion and concern for the tenants, reflected in the many programs available through the Community Services Department.

\section{Effect of Budget Cuts}

If the potential budget cuts go into effect, it will certainly mean that the comprehensive modernization at Codding Court will have to be done over a longer period of time. The funding available from the CGP will be targeted to the most serious and expensive problem areas such as heating systems and roofs. Unfortunately, what may suffer in the next five to ten years are the improvements which affect the appearance of the developments such as 
landscaping and creation of tot lots and play areas. Bath and kitchen modernization will have to be accomplished over a longer period, possibly one unit at a time as turnover occurs. We will be much more dependent on our own Facilities Management staff to trouble shoot and maintain our buildings until more extensive modernization can take place. However if, as is predicted, the budget cuts are accompanied by a deregulation of HUD and possible changes in the Davis-Bacon wage laws, this will allow us to get more output for less money and may mitigate to some extent the loss of funding. Where presently we are encumbered by regulations which are time consuming and weighted toward expensive labor, regulatory changes may allow us to make immediate changes in our planned improvements without the extra layer of HUD approval. We could immediately address problems as they arise. This ability will put us on a more even footing with the private sector if we are indeed forced to compete through voucherization.

\section{Future Strategy}

As funding decreases, the demand on the Comprehensive Grant Program to fund a larger share of our social service programming will grow. At the same time, we will be competing more with other subsidized housing and the private marketplace. This makes a partnership with our residents increasingly important. We will have to strive to be a much more consumer friendly organization that stresses service. Staff will have to buy into the program or be asked to leave. In addition, we will have to get better at attracting other sources of funding and in providing the greatest return possible, both in the quantity and quality of the product we deliver.

ENVIRONMENTAL SCAN:

COMMUNITY SERVICES (EXTERNAL)

\section{FORCES/TRENDS}

\section{People}

The PHA is a creature of the federal government and our fortunes ebb and flow along with those of the Department of Housing and Urban Development. Under the current HUD reinvention, public housing has, so far, fared relatively well. Although modernization funding has sustained cuts, operating costs appear to be intact for this fiscal year. Drug Elimination Program funding for families has so far survived reductions this year; however, most Congressional budget proposals for next fiscal year eliminate the program entirely. Support for the elderly/disabled developments has always been elusive, but we were recently awarded a Senior Service Coordinators grant for more than $\$ 600,000$. This grant program is also proposed for elimination next year.

As HUD deregulates housing authorities, the impact of both state and city policies on public housing will increase. If funding is delivered through a block grant, as has been proposed in some quarters, the state and city may assume greater roles in dispersing funds for housing services. There has been discussion of letting housing authorities administer block grants, which would be the best scenario for us. Nevertheless, under any of these options, the Authority will need to become more responsive to local governments and agencies as they replace HUD, to some degree, as regulatory agencies and sources of funding.

The state entities closely connected to the Department of Community Services now are: Elderly Affairs; Health; Mental Health, Retardation and Hospitals; Substance Abuse (recently consolidated with the Health Department); Education, and Human Services.

The local agencies and organizations working most closely with the department are: the Providence community centers such as, the Smith Hill Center and Federal Hill House; the Mayor's Council on Drug and Alcohol Abuse; Project H.O.P.E.; The Providence Center; ProCap; Dorcas Place; International Institute: All Children's Theater, and Women's and infants Hospital.

Local private foundations from which we have or will seek funding include The Rhode Island, Champlin, bank foundations.

\section{Economics}

Since 1990 the Department of Community Services has received $\$ 3,221,995$ in local, state and federal funding. Most of the funds are grants from the Department of Housing and Urban Development. The federal budget cuts slated for housing authorities and other social services agencies will have a profound impact on all our services. The Authority will need to re-engineer and re-focus our efforts to survive. Under HUD's proposed voucherization, we will be responsible for 100 percent of our funding. 
As our funding nets are cast over larger areas, the Authority must increase its awareness of state legislation. agencies and local politics. Federal and state legislatures have adopted an anti-city bias resulting in fewer dollars going to urban areas. As state government assumes a greater role in doling out federal funds, the need to educate legislators about the role of cities and the importance of support for urban initiatives, particularly public housing, is imperative.

In the city, involvement in housing efforts such as the Providence Plan has to be closely coordinated with the Authority. Perhaps joint development projects, either for special populations like FACTS House (housing for persons with AIDS) or structured housing programs for those individuals and families deemed not capable of living in our traditional housing units, (a kind of "housing of last resort" whereby if the tenants cannot be "rehabilitated" to live according to established standards they can be denied benefits and removed from housing). Other housing development options include more transitional housing for homeless people or sheltered housing for substance abusers and their children, or any number of models. The Authority needs to collaborate with the city, not become a competitor.

Another entity which needs addressing is the court system. The courts and judges must better understand our position that our units are not the "housing of last resort". The courts, city and the Authority must work together to establish what is in fact "housing of last resor", where is it offered and who offers it. The legal system needs to understand our mission and how the Authority fits into the breadth of housing availability.

\section{Social}

An Increasing Hispanic/Latino population, more people with very low or no income, more young and very young girls having babies are part of today's scenario. All three increases are borne out by Authority statistics gathered over the past three years. (See INTERNAL SCAN) Not noticeable in current Authority statistics, but through state-wide data is the increasing numbers of elderly. The number of $75+$ persons in Rhode island will increase 42 percent between 1990 and 2005 , to almost 100,000 . New forms of financing aging-in-place must be explored because nursing homes are 100 expensive an option for an already overwhelmed health system.

Funding appears to be moving away from the elderly toward children and family self-sufficiency. There is an effort to help those who can move into society and be responsible for themselves. This, for obvious reasons, does not encompass the elderly and disabled populations which, in most instances, are neither employable or able to fend for themselves. The mentally and physically disabled people fare even less well than the elderly.

In its recent restructuring, the Rhode Island Foundation has eliminated both the elderly and the disabled as priorities. The Providence Center has recently dismantled its elderly program (only 15 percent of the population that needs care is currently being attended to by TPC). Project H.O.P.E. has sustained major cuts affecting our meal sites and Elders-at-Risk programs (there has never been a disabled peoples' nutrition program). For the near future, elderly, as well as mentai health programs will suffer severe cuts, but as the large baby boomer population grows older and Social Security becomes a less secure option, attention will focus again on the elderly (and we hope the disabled) as a budget necessity.

It is as though the efforts to work with different populations stem from different focuses: for children it is socialization training, for adults it is employment and self-sufficiency, for the elderly it is delivery of health care and for the disabled it is how and where will they live.

The Providence educational system does not appear to be working. The children in our programs can barely read, write or do arithmetic. It would be in the best interests of our residents to see a third party contractor or the Authority itself provide an on-site school for public housing children. Perhaps in the future. when school vouchers become more attractive, we will see this become a reality. Our social problems are never going to solved without an educated citizenry. The city's school department does not, in any way, seem to be in the process of providing it. Truancy is rampant. One only needs to drive through one of our family developments on any school day to see this. Parents are only notified of absences on the fifth consecutive day. Further, the curriculum does not instill manners and respect for self and others. Without these basic social graces and civility, it will be very difficult for these children to function in society and the world of work.

Technology

Technology will be of great use particularly in streamlining the day-to-day functions of communicating and gathering and organizing information. We need to train employees in accessing and arranging information for the purposes of improving programs and identifying sources of funds. 
Technology in the area of improved forms of birth control must become a priority. In a recent Providence Joumal article it was stated that over 70 percent of men interviewed were not willing to be responsible for using condoms during sex. Although condoms, when used, are an excellent way to prevent sexually transmitted diseases, as well as preventing pregnancy, getting people to use them is difficult. Alternative approaches to birth control will most likely be developed, for use by both genders, that will be more user friendly.

Technology in the field of geriatrics, whereby elders will be able to live independently longer and be healthier, and psycho/pharmaceutical drugs that will help control many mental illnesses will be welcomed as they will improve the quality of life for our residents.

\section{CLIENTS/CUSTOMERS}

Our customers are existing and perspective residents. They are children, adults, the elderly and disabled. For the most part, they are very low income people. Currently the Authority shelters 1,219 households in family developments. This is 18 percent of the 6,461 low income families residing in Providence. There are 421 elderly residents over the age of 65 . This is 10 percent of the city's 3,835 low income elderly. It would be profitable to be able to expand the spectrum of incomes to include a percentage of low and moderate income people. Deregulation and a different perspective on our mission will have to come first.

If public housing is to be privatized, the Authority must stan making decisions now on how to attract residents to our developments. What will they buy? Probably a secure setting, services, space and an attractive and friendly atmosphere. The Authority will be responsible to produce these amenities, which in some cases, will severely tax the budget.

Our greatest difficulty now is drawing residents from the elderly population and that will remain the case even with voucherization if the issues that keep people from wanting to live in public housing are not addressed. Nevertheless, with a 42 percent increase in the elderly population between 1990 and 2005, and a projection of 100,000 elderly people residing in Rhode island, the population will exist to be approached with a good product and a convincing marketing plan consisting of videos, visits to the sites, brochures, etc.

\section{SUPPORTERS}

Our supporters include almost every social service agency in the City of Providence and many state-wide agencies The Authority offers housing for every kind of low income person currently ( 30 percent of the low income population of Providence) and agencies know where to find us. If the Authority disappears, there will be a void not easily filled. Nevertheless, we need to learn to collaborate in a more sophisticated manner; perhaps look at a broader spectrum of state-wide services. The Authority is looked upon as the "provider" of housing and therefore needs to assume that role in a more aggressive way.

\section{COMPETITION}

The Authority's major competitors are private and HUD assisted housing. Within the Department of Community Services Family Unit our major competitors for the provision of services are neighborhood community centers, recreation programs, schools and city programs. Actually, these are not really considered competitors by us. If we get a child to attend City Arts summer program, we consider that a success and the more our residents interact with available programs outside the Authority the better it is. Job training programs might be competition for the adults. but our Family Investment Center will only supplement opportunities available now. Our biggest competitors for the hearts and minds of the family residents are inertia, alcohol, TV and drugs.

The real competitors for the housing of the low-income elderly and disabled are the other housing providers, mostly Section 8 HUD-assisted, who can lure our elderly residents away with promises of greater safety, space and an attractive setting. Competitors for services for the elderly/disabled consist of organizations like the Westminster Senior Center. We say this because their staff feels we are pulling Dexter Manor participants away from their programs with such offerings as the Dexter Manor Senior Health Clinic. Representatives of other service agencies working with our residents state that they in no way are able to fulfill the needs of our residents and can use any support we offer. Our Services Coordinators reach far and wide to find sufficient services to cover the requirements of the elderly/disabled population. Again, we really don't consider these other service providers as competitors, but, rather as collaborators in an effort to improve the quality of life for our residents. 
The Providence Housing Authority fills an essential niche in the provision of housing in both Rhode Island and Providence and it should continue to do so even in the eventuality of voucherization. Resources are scarce to the point of forcing funding sources and service agencies and residents to work collaboratively in providing suitable housing and services to the low-income population of Providence. How this is done, how broad the coverage, how extensive the services will be is all to be determined. There is planning to do and work to be done if we choose this assignment, but this is a most formidable organization which is up to the task.

ENVIRONMENTAL SCAN: RENTAL HOUSING (EXTERNAL)

\section{FORCES AND TRENDS}

\section{People}

The Rental Housing Department deals with Section 8 applicants, Section 8 recipients, property owners, real estate agencies, and property management firms. The applicants and recipients are our primary clients. Property owners and their agents provide units in the private market for our customers. Also, property owners affect us by setting the price for rental units in the city. We either agree to rent at the price established or to deny the Section 8 recipient permission to lease the unit. All units also have to meet acceptable housing quality standards or be denied approval. Property owners consistently seek the highest rent possible for several reasons. The principle reason is obvious: they are attempting to maximize their return on their investment property. Some landlords believe renting to Section 8 residents is a risk and therefore want a higher compensation than they would expect to charge to market rate renters. While this is perhaps true with some of our clients (we do pay damage claims frequently), it is unreasonable and not acceptable. This type of situation is avoided by dealing firmly with the owners and explaining the rules of the program.

The changes proposed by HUD and the Congress will have a major impact on some Section 8 recipients, particularly when some Section 8 contracts are not renewed. Some recipients could be literally put out of their homes when they no longer receive a housing subsidy.

\section{Economic}

The economy is no longer the principal cause in the increase in the number of Section 8 applicants. Most of our new clients are young, single-parent mothers who are too poor to afford housing in the private market. Eighteen percent of the households in Providence are below the poverty level and qualify for federal housing subsidies. In the past when the economy improved, recipients would return their certificates or vouchers after obtaining a job. Today the public assistance in all its various forms, (housing, income maintenance, food stamps, fuel assistance, etc.), directly competes with entry level private employment.

\section{Social}

Many factors in society affect our services. The continuing increase in illegitimate binths and the migration of lowincome people to the city increases the number of families seeking housing assistance. Also, there is a certain "supply creates its own demand" syndrome in Providence. With 2,300 units of Section 8, we are the largest provider of subsidized units in the state. This itself draws people to our waiting lists. Other social service agencies and public transportation is also a draw to the city. A general improvement in the state and national economies would usually affect the number of people receiving assistance. But, in the last two decades, employment rates for lowincome

people have not risen dramatically even during business cycle booms. Considering the age of new recipients (mostly young single mothers), a shortage of clients will be highly unlikely.

\section{Technology}

Ongoing updating of the Section 8 Program computer software capabilities is required. At present, the HUD package Form 50058 (recipient socioeconomic data) is complete. During the next several months the department will work with the new Management Information Services manager to complete the PC-based waiting list. Presently, to determine where a applicant is on a waiting list requires a review of cards in a file system, rather than entering a name in a computer for retrieval. A new system would also allow the automatic printing of letter notifications to recipients informing them of inspection and recertification dates.

\section{CLIENTS/CUSTOMERS.}


Our clients are all low-income residents of the City of Providence whose family income is $50 \%$ or less of the city's median family income. Sixty-four percent of the recipients are minority (33.7\% Afro/American, $26.1 \%$ Hispanic, $3.6 \%$ Asian) and thirty-six percent White. Section 8 recipients live in all but one census tract of the city. The largest group of Section 8 families is in the Elmwood neighborhood with 216, comprising $10 \%$ of the total.

Our waiting list is predominantly Hispanic, reflecting the increasing number of Hispanics in the city generally. Fortyeight percent of the waiting list is Hispanic, twenty-six percent African-American, and sixteen percent White. Fiftynine percent (548) of the 930 applicants and families on our waiting list qualify for one of three federal preferences for admission. Fifty-seven percent (527) of this number qualify for federal preference because they pay more than fifty percent of their family income in rent.

\section{SUPPORTERS}

Our primary support is from the federal Department of Housing and Urban Development. It is they who provide the rental subsidies which we administer. Other supporters include Rhode Island Housing and Mortgage Finance Corporation (RIHMFC), the city's Department of Planning and Development both of whom we have worked with to build and support affordable housing, particularly single room occupancy (SRO) units. We have worked closely with the Planning Department on the Rental Rehabilitation Program, a low-interest loan program for owner occupied property. In return for seeking a loan and repairing rental units, they receive a project-based rental subsidy administered by the housing authority. Property owners and their agents are also strong supporters, since they supply housing which is subsidized.

Support, cooperation and collaboration will continue with RI Housing and the city; however, with changes in fair market rents (FMRs) we may lose some of the property owners participating in the program. An increase in irresponsible applicants/recipients who damage property will also affect the number of property owners willing to participate in the program.

\section{COMPETITION}

Our competition consists of other housing authorities administering Section 8 and public housing programs, private Section 8 and other assisted housing developments, and privately owned rental units on the lower end of the rent scale. They compete by offering subsidized (except for the later) housing units to our clientele. There are approximately 67,000 housing units in the city of Providence of which $12 \%$ is subsidized.

ENVIRONMENTAL SCAN:

SECURITY (PUBLIC HOUSING UNIT) (EXTERNAL)

\section{FORCES/TRENOS}

\section{People}

The main people and organizations that have an impact on the housing unit are the residents of public housing and the management and staff of the PHA. Both management and staff, along with the residents, are equally influential

The officers are affected by the problems of crime reported to them by management and residents of the PHA. A serious problem in a development can indicate that a major operation is needed to address the problem or just an increase in visibility will solve the problem. In essence, the tactics needed to address the problem are dictated by the type of problem reported to the police and the type of police action needed to satisfy those making the demand. These groups influence the Public Housing Unit because it is the basic mission of the unit to address the needs and demands of the housing authority and to address the security needs of the residents of public housing. Both the residents and staff of the PHA rely on the Public Housing Unit to solve the problems of crime in the developments. thus providing the resident with a safer environment in which to live.

A reduction in daily patrol coverage, due to budget cuts, will greatly reduce the effectiveness of the unit in combating crime in the developments. Currently the officers are accessible to the housing residents from 12 noon to $1: 00$ am. Should this situation change, a re-deployment of manpower to cover these hours would reduce the total number of men on the street for any given time. If the officers are restricted to work a 5 PM to am shift, to supply the most manpower for the highest crime times, they would loose contact with the management and staff of the PHA. This would also restrict the ability to follow-up on serious crime investigations. The primary impact of a reduction in hours 
would be the officers would loose contact with the residents of the PHA and would give the "crooks" more time to ply their trade while there are no "cops" around.

\section{Economic}

Originally, funding for the overtime expenditures for the Public Housing Unit came through the Comprehensive Improvements Assistance Program (CIAP). Currently it is funded through the Comprehensive Grant (CGP) program. The PHA is now in our fourth year of Comp. Grant funding, and HUD budget cuts have reduced our 704 CGP budget from $\$ 5.3$ million to $\$ 4.2$ million. Additional cuts are expected to reduce next years CGP funding as well. These reductions appear to be a trend, and it is not expected that the funding will be restored to the original levels in the near future. In this past round of cuts, the PHA did not reduce funding for the Public Housing Unit. This program was considered too important to reduce funding, so other line items were cut or reduced. Still,

Increasing rates of spending for the PHU and decreasing funding from HUD creates a problematic situation

Another area of concern is the cuts in state funding for the security guards in the PHA's elderly/ disabled high-rise developments. The Department of Elderly Affairs has seen drastic cuts $(40 \%)$ in funding for this program, and while the PHA will still receive a large share of this money, it is expected that funding for this program will be cut in half. Should it be deemed necessary to augment this funding, Comprehensive Grant Program funds would appear to be a likely source. Increasing spending for security programs paid for through CGP funding will necessarily affect the PHA's ability to perform in other areas.

\section{Social}

The increasing acceptance of the drug-related culture affects the PHU's ability to perform its primary role of providing security services. The need for funds to pay for drugs increases the amount of crime in an area. particularly car thefts, breaking and entering, larcenies, and other crimes where stolen goods can be converted to cash to purchase drugs. The drug culture also affects the living environment in public housing. Public housing developments have become identified as a location to purchase drugs. As a result of this there tends to be a tremendous amount of loitering in the developments to provide for drive buy purchases of drugs. We have consistently stopped for questioning numerous cars with passengers who do not live in the developments who are seeking drugs. This behavior impairs the environmental condition at certain developments.

Another social problem that may impair the performance of the PHU in executing its duties is the loss of respect for authority, particularly law enforcement officers. The recent Mark Furman incident at the OJ Simpson trial, the Strand Theater incident in Providence, and the Rodney King affair have all tainted law enforcement. Fortunately, the PHU has a good reputation with the people we serve. This, however, could change as incidents like those mentioned are interpreted to suit the needs of certain parties. Crime in the housing developments will probably be on the rise due to the increase in population. Police, along with management, must work to rid housing of trouble tenants and once a problem is cleared up all steps must be taken to prevent the problem from returning.

\section{Technology}

The primary addition to the PHU was the computer provided by the housing authority. This has provided the housing unit with a more efficient method of keeping a record of the unit's daily, monthly and annual activities. Through these reports, the officers and PHA can keep track of the problem areas and also the results of police operations in a problem area. The computer has also provided the officers with a data base of the criminals who reside in or frequent the area. On several occasions other departments of the Providence Police Department, state and federal law enforcement agencies were provided information through this data base system.

\section{CLIENTSICUSTOMERS}

Our primary clients are, and should be, the residents, staff and management of the PHA. who require our security services. The PHU attends staff meetings on a weekly basis at the PHA and meets frequently with the PHA Executive and Deputy Directors to discuss problems and strategies. The unit also frequently attends meetings with resident associations and development crime watch groups.

Budget cuts may cause a reduction in the level services now being provided. An increase in funding would provide for an increase in services and the hours of coverage. Through the fear of crime, real or perceived, the demand for police services are constantly required and sometimes demanded.

\section{COLLABORATORS/COMPETITORS}


Collaborators are the management, staff and residents of the Providence Housing Authority. Again, the Public Housing Unit provides the major source of law enforcement for the PHA, thus there are no real competitors. The only collaborators should be the management, staff and residents of the PHA. There are no real long-term competitors for the Housing Unit. As to the competitors, most other law enforcement agencies have come into the developments, conducted short term operations or investigations, and then move out.

Other important collaborators in providing security services to the PHA are the Providence Police Department's Police Reservists, the PHA's Security Guard Force, and the residents' crime watch groups at some developments.

The Public Housing Unit generally receives the full support of a majority of the residents living in PHA developments. This isn't expected to change. There is a reluctance of some residents to provide intelligence (information) on illegal activities due to fear of retribution. There is also a minority of residents who have come to accept the counter-culture and are not supportive of police operations. Fortunately, this group is a minority. It's gratifying to see that the residents have expressed their concern with crime related issues in the PHA's recent Needs Assessment. Our goal is to address those needs with the resources we currently have available at our disposal or seek additional resources.

\section{COMPETITION}

Again, there are no major competitors, most of the law enforcement services are provided by the housing unit with occasional assistance from other federal, state and local law enforcement agencies. Not to be forgotten are the Police Reserves, PHA Security Guards, and the resident crime watches. However, these groups are more collaborative than competition.

These agencies pose no problems to the housing unit, but they do offer assistance and support in attacking major problems, such as drugs, in the developments. The major shortcoming of these agencies is that the operations are usually short term, the results are tallied and then they pull out of the area. Unfortunately this usually results in the problem, usually of a narcotics nature, in returning within a short period of time after the operation is mounted. 
ENVIRONMENTAL SCAN:

PERSONNEL, TRAINING, INSURANCE AND RISK MANAGEMENT

\section{PERSONNEL}

\section{Staff and Employment Trends}

Over the past five years, the number of staff members employed by the Providence Housing Authority has increased by $19.5 \%$, growing from 210 to 251 full and part-time employees. Most of the increase is from part-time personnel, particularly in the Community Services Department, which employs a considerable number of part-time resident assistants and youth sports staff members funded from grant programs. All our security guards for the elderly/disabled developments are also part-time ${ }^{1}$ personnel.

The years of experience that the staff has acquired either from working at the PHA or elsewhere adds to the organization's level of strength. There is high esprit de corps in most departments. Another strength of the staff is their racial, ethnic and gender diversity. Hence, the organization reflects the diversified community of Providence.

Skill levels at the PHA are varied. The staff consists of numerous skilled technicians who are able to perform any function required by their given position. Some individuals in supervisory positions need improvement in performing their roles.

Since FY 1986, the budgeted staff size of the Authority has increased $55 \%$ from 109 to 169 staff positions. The increase over the last five years has been $12 \%$ from 151 to 169 . The greatest increase over the last ten years has been in the category of Administrative Non-Technical which increased from 42 positions in FY 1986 to 83 positions in FY 1995. a $97.6 \%$ increase. This sizable growth can be attributed to the increase in grant-funded positions awarded to the PHA to operate programs in the Modernization and Development, Community Services, Facilities Management, and Rental Housing Departments. The positions in the category of Maintenance (Facilities Management non-supervisory) increased 55\% (60 positions) from FY 1986 to FY 1995 and $12 \%$ (18 positions) over the last five years.

Personnel at the PHA are compensated at rates comparable to staff members working for the City of Providence. Until recently, local housing authorities were required to have wages comparable to the rates of local government personnel. HUD recently dropped this requirement from the regulations. Salaries for non-management personnel at the PHA are comparable to the private sector, however, benefits are substantially higher. Management personnel are compensated at rates either equal to or slightly below private sector salaries.

Due to costly liberal employee benefits, the PHA has not always "staffed up" to its authorized complement. This is particularly true for the Facilities Management and Housing Management Departments. Rather, these departments employ a number of temporary personnel. This is advantageous for the PHA for several reasons: (1) it is less costly. (2) it gives the department senior staff an opportunity to judge the quality of the temporary employee's work, (3) if the temporary employee isn't suitable, they can be released without a burdensome process.

\section{Benefits}

The PHA offers a generous benefit package including health (medical and dental), pensions, sick days, holidays and vacations. The average fringe benefit package has increased $25 \%$ over the last five years from $\$ 7,641$ to $\$ 9,566$. The FY 1996 Annual Operating Budget allocates $\$ 1.3$ million for employee benefit contributions.

Benefits at the PHA are substantially higher than private sector compensation. Total benefits, as a percentage of salaries, for the four unions employed at the PHA are: Teamsters (37\%), Laborers (44\%), Carpenters (43\%), and Painters (42\%). Included in the PHA's benefit determination is: pension payments, legal fund costs (laborers only), health care, FICA and SUTA, longevity, and auto allowance (if applicable).

\section{Heaith}

Health care expenses are our primary concern due to the cost to the Authority. The FY 1996 operating budget contains $\$ 795,576$ allocated for health benefits for full-time personnel, approximately $8.5 \%$ of the entire operating budget. The average family health policy (medical and delta dental) costs the Authority $\$ 538$ a month; $\$ 274$ a month for single coverage. The PHA offers one of four plans to its employees. They range in cost from $\$ 516$ a month for

\footnotetext{
'The PHA has two classifications of part-time personnel. Some personnel are full-time part-time personnel meaning they work 35 or 40 hours a week but are not eligible for benefits. Other part-time personnel work as little as a few hours a week
} 
family coverage (\$214 single coverage) for Blue Cross Classic to $\$ 393$ a month ( $\$ 157$ single coverage) for Harvard Community Health. Delta Dental costs an additional $\$ 55$ a month for family coverage and $\$ 18$ a month for single policy.

Health care costs have steadily risen more than the inflation rate. Five years ago the PHA paid $\$ 399.99$ for family Blue Cross coverage. This year the cost for the same coverage is $\$ 516$, a $29 \%$ increase in five years $(5.8 \%$ annual average increase). Similar increases were experienced for the other health coverage packages offered to employees.

\section{Pensions}

The PHA currently provides two pensions for its employees. Each union member has their individual union's pension and there is an Authority-wide pension plan with Mutual of America. The contribution rate for each union is negotiated separately; there has not been an increase in several years.

The weekly contribution amounts for each union is as follows:

\section{PHA Pensions}

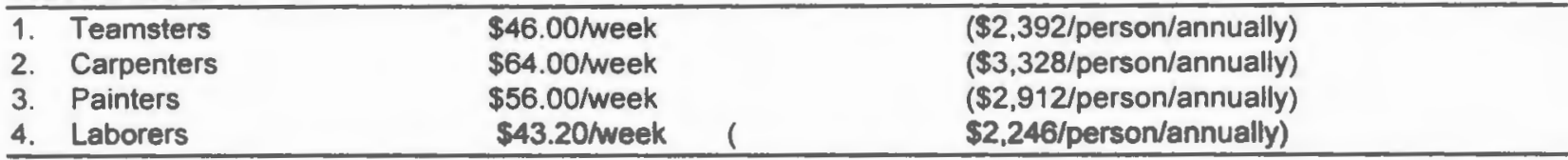

Pension payments by the PHA in FY 1996 are budgeted for $\$ 603,534$ of which $\$ 386,713(64 \%)$ go to the union pension funds and $\$ 216,821(36 \%)$ go to Mutual of America.

\section{TRAINING}

Training is emphasized at the PHA. Over the last five years (FY 1991-FY 1995), employees have attended 13.985 hours of training, an annual average of 2,757 hours. In FY 1995, 4,073 hours of training was conducted, an increase of 433 hours $(12 \%)$ from the previous year and $155 \%$ more than five years ago when 1,597 hours of training was conducted.

The training programs conducted by or contracted for by the Authority has varied considerably. In the past fiscal year emphasis was placed on planning, team building and computer training. Each year a training needs assessment analysis is undertaken to determine staff needs through the use of written surveys and discussions with department directors. Every effort is made to accommodate requests from

\begin{tabular}{|c|c|c|}
\hline FISCAL YEAR & HOURS & PCT. INCREASE \\
\hline FY 1995 & 4,073 & $+12 \%$ \\
\hline FY 1994 & 3,640 & $+41 \%$ \\
\hline FY 1993 & 2,580 & $+23 \%$ \\
\hline FY 1992 & 2,095 & $+31 \%$ \\
\hline FY 1991 & 1,597 & \\
\hline TOTAL & 13,985 & \\
\hline
\end{tabular}
staff for third-party training, including courses at local colleges when the instruction is work related.

Several assessment instruments administered this past Summer indicate a need to increase team building within some departments. Further assessments of the instruments will be conducted to determine the type of training necessary to strengthen team weaknesses. The Authority will conduct more testing and use more instruments to isolate and target our training needs.

The PHA is fortunate that Management Improvement funds, under the Comprehensive Grant Program, allows funds to be used for staff training. Over the past five years, the PHA has set-aside $\$ 145,155$ for training purposes. The training allocation is used for in-house training materials, contracting with third-parties, purchasing books, video and audio tapes, and consultants who serve as training facilitators.

Training for management and labor at the Authority has been a huge success and was instrumental in turning the agency around from a troubled housing authority to a well-managed one. However, the Authority cannot afford to rest on its reputation. Circumstances change too quickly. Staff skills should be in a state of constant renewal if the Authority is to remain successful.

\section{INSURANCE}

The housing authority carries five different types of insurance coverage. Two particular types, Workers Compensation and General Liability, are costly. Both, however, have experienced significant reductions over the last five years due to initlatives undertaken to reduce risk. 


\section{General Liability}

General liability premiums have been reduced $10 \%$ over the last five years and $34 \%$ since FY 1990 . After experiencing a dramatic reduction from FY 1990 to FY 1994, it increased by $\$ 12.000(10 \%)$ last year. Losses have been reduced $82.8 \%$ in the last five years. Much of this loss reduction and a corresponding decrease in our general liability premium is attributable to our Safely Plan. The Plan consists of a number of initiatives that reduce the exposure to risk through a Safety Program.

The PHA's Safety Program has been in existence for seven years. Its purpose and goals are to provide training for Authority personnel and residents of public housing in risk management. A Safety Committee consisting of volunteer staff members from each of the departments establishes its annual agenda of activities. In FY 1995 the Safety Committee undertook the following activities:

- Conducted Vehicle \& Fire Safety Training

- Conducted Fire Safety Poster Contest for residents

- Updated the annual Risk Control Plan and Safety Manual

- Continued the self-inspection program and safety checks

- Sponsored and conducted CPR training for staff members

- Updated the Vehicle Safety Policies and Procedures Handbook

- Conducted semi-annual Fire Safety Education visits

- Updated accident reporting procedures and forms

- Conducted monthly meetings with risk control personnel

\section{WORKERS COMPENSATION}

Workers Compensation is an other area the Authority has been successful in addressing. Since FY 1991, the number of employees (full and part-time) covered by our Workers Compensation has increased 20\%, while our premium costs have been reduced $45 \%(\$ 502,130$ to $\$ 274,100)$, and our costs per employee has been reduced $55 \%(\$ 2,391$ to $\$ 1,075)$.

In 1993, the Authority developed a Risk Management Plan designed to curtail the sources of Workers Compensation high costs. The Plan:

- Established a Safety Committee

2 Conducted safety awareness training and injury prevention activities

(3) Responded swiftly to correct all reported safety problems

(1) Investigates and documents all accidents

- Provider medical delivery system

- Case Management

(7) Created a policy of offering "light duty" to injured personnel.

The objective of the Plan is to deliver care to the injured employee, assist them through the recovery process and facilitate an easy and timely return to work.

The cost savings of $\$ 17,573$ in General Liability and Property Insurance, coupled with the savings of $\$ 228,030$ in Workers Compensation premium has resulted in a premium savings of $\$ 245,603$ over a five year period.

\section{FUTURE STRATEGIESICONSIDERATIONS}

\section{Personnel and Benefits}

The PHA's personnel costs continue to rise, even though salary increases have remained at the Consumer Price Index (CPI) level for the last five years. Benefits, however, have risen more than the HUD inflation factor and affect the PHA's Operating Budget. Although we've been successful in reducing our Insurance expenses (see above), the cost is still substantial.

The PHA must examine ways in which to reduce operating costs. This can be accomplished in a number of ways, including direct reduction in employee benefits or contracting for some services.

The Authority offers a very generous benefit package which is considerably higher than that offered by the private sector. Total benefits, as a percentage salaries, for the four unions employed at the PHA are: Teamsters (37\%), Laborers $(44 \%)$, Carpenters $(43 \%)$, and Painters $(42 \%)$. 
The PHA currently offers its employees three pension plans, if one considers Social Security to be a pension plan. Each employees union has a pension and each employee receives contributions to Mutual of America pension plan The Authority may consider reducing or eliminating one of the two option pension plans (Social Security is not optional, although the Providence Police Department do not contribute to Social Security and there may be an opt out). The PHA's contribution to Mutual America alone totaled $\$ 216,821$ in FY 1995. Another option may be to totally fund the union plans and agree to administer voluntary contributions to Mutual of America. Any number of options and variables would save the PHA funds. Considering HUD's future funding scenarios and the Congress' antipathy to the public housing program, it is imperative to reduce our overall costs

The PHA offers four medical plan options for its employees. These range in cost from $\$ 515.81 /$ month for a Blue Cross Classic family coverage ( $\$ 214.35$ single coverage) to $\$ 392.64 /$ month ( $\$ 157.06$ single) for Harvard Community Health plan, a $31.4 \%$ difference! A majority of the PHA staff (73\%) utilizes Healthmate, which costs $\$ 493.74 /$ month The PHA pays $100 \%$ of an employee's medical family or single coverage.

The PHA, in an effort to reduce its costs, has several options:

1. It could offer a flat rate for medical benefits and allow its employees to shop for the best bargain.

2. We could agree to fund at a certain level with employees paying the difference-a sort of co-payment plan

3. We could offer the least inexpensive, but comparable medical benefit plan, such as Harvard Community Health. If employees wanted an other more expensive plan, they pay the difference.

4. We could offer to pay for single coverage with employees paying the difference for family policies.

5. Pay a one time cash bonus to employees to switch to a less expensive plan

6. Require a co-pay for delta dental coverage

7. Initiate a different policy plan for new employees after a certain date

8. A combination of several options

Option \# 3 alone would save the PHA more than $\$ 200,000$ and a number of the other options would save a significant sum. Further examination of these options should take place with management, staff and their union representatives.

Contracting out, also known as privatization, could also save the housing authority a significant sum. A recent analysis of our paint crews indicates a savings of more than $\$ 250,000$ if we switched to private contractors. The analysis compared costs, the amount of work, and quality of work between our unionized paint work crews and private firms. The private firms were substantially faster, half the cost, and quality was comparable. Other areas for consideration are landscape work, community services, security and inspection services. Obviously, existing union contracts would have to be considered, but the bottom line for the PHA is to get quality work performed at the least expensive price

\section{Training}

Training will continue to play an important role at the PHA. In the future, with limited funds, we will have to target our training programs more by undertaking training needs analysis. Identifying and targeting training needs to solve specific staff problems is important.

Safety training has been successful and has contributed to the decrease in our insurance costs. This type of training must continue, particularly in those areas requiring further improvement. The Safety Committee members should be given instruction and "deputized" to serve as instructors in their departments.

The Housing Authority Insurance (HAl) and the Housing Authority Risk Retention Group (HARRG) are excellent partners to work with for safety training. In addition to frequent training sessions and voluminous literature on the subject of safety, they have recently initiated a satellite training program subscribed to by the PHA. This System will be interactive and allow the PHA staff to participate in training programs conducted from sites around the country. This is an outstanding new feature to our training program.

The PHA has for some time offered in-house training on a variety of topics including: Strategic and operational planning, principles of management, performance management, goals and objectives, problem solving, leadership. and a host of other relevant training programs. This too will continue and a curriculum with supporting manuals will be developed. We are contemplating required course work for promotions and continuous. education credits for all staff members, particularly senior management staff. A Career Ladder Program has, already, been developed for our Facilities Management Department and will be improved on. Our next step will be a similar program for Management Department staff and a Senior Executive Training Program. 
While funds are available from the Comp Grant Program, it is not imperative to find substitutes for the training we currently offer. The PHA has always been frugal in its training costs

\section{Insurance}

Insurance costs will continue to be costly for the PHA, even though significant reductions have been realized over the last five years. The PHA must continue to seek methods in which to lower our insurance costs. The best methods for doing it is through competitive price seeking and risk management. Again, the PHA has been successful at both and constantly seeks ways to improve our risk management program.

It must continue to be proactive in the area of Risk Management and Risk Control by:

1. Continuing its Employee and Tenant Insurance Educational Programs

2. Annual inspection of all PHA property

3. Updating Safety Manual

4. Transferring risk, when possible

5. Monitor losses by identifying trends, cause and effect, and solutions

Providence Housing Authority staff members will have specific risk duties and responsibilities associated with their positions. However, residents and contractors must also share in risk control activities to maintain an effective program.

The PHA will also seek other methods to lower our costs by: (1) examining the feasibility of self insurance, (2) lowering Workers Compensation costs by contracting for some services.

ENVIRONMENTAL SCAN: JOB TRAINING, EMPLOYMENT AND SELF-SUFFICIENCY (INTERNAL)

\section{RESOURCES}

\section{People}

The Providence Housing Authority's Comprehensive Social Service Needs Assessment allowed public housing residents to influence the design and delivery of non-housing services by expressing their opinions around a wide range of quality of life issues. Adult heads of household living in PHA properties identified issues directly related to the achievement of economic independence through employment as their three greatest quality of life deficiencies: lack of employment opportunities, lack of job training and lack of formal education. Clearly, this is an area of advocacy and service provision in which the Authority can rightfully engage.

At the higher levels of administration, and at the Board of Commissioners level, there exists a well-informed understanding of the pervasive need for improved access to training and job opportunities. However, translating that understanding into programs, policies and procedures that actually improve the numbers of public assistance dependent pubic housing residents achieving economic independence is problematic.

Currently, the PHA has one employee explicitly charged with administering the Family Self Sufficiency Program, the only PHA program which requires residents to move toward financial independence via an articulated route and within a defined period of time. The Authority also sponsors, through the Department of Community Services, a number of programs and services which address issues related to self sufficiency, including teen pregnancy prevention, living skills, and computer literacy.

Overall, PHA staff resources are concentrated in housing management and building maintenance. Although Community Services is the fastest growing department in the agency, relatively few of its resources are categorically focused on job-specific employment skills training, job creation or direct placement and case management geared to ensuring successful transition from AFDC. The department does have a strong track record providing employment opportunities (and associated on-the-job training) for residents in its own operations.

The Authority is currently in receipt of a HUD Family Investment Center Program grant which provides for the rehabilitation of an FSS center and funds, for five years, two additional case managers. Included in the Family Investment Center services are: 
- ESL classes (both pre-employment and employment support groups)

- GED and basic employment skills training

- Computer skills development

- Development of five year contracts for the achievement of economic independence through employment

- Advocacy services

- Placement development

- Employment support

\section{Economic}

Despite the focusing of national attention on the need for reform of public assistance programs (especially AFDC), federal resources in suppon of welfare-to-work programs have not expanded. In fact, the discussion is now polarized between those who believe that reducing welfare enrollment by limiting benefits is the best option and those who argue that a stronger commitment to job development, case management and supportive services (especially childcare) is the best way to increase the number of recipients moving to economic independence.

Many of the HUD-funded efforts in support of residents seeking to achieve economic independence have been either completely defunded or substantially reduced. These include both the Family Investment Center and Section 8 Counseling programs. Defunding of the Public Housing Drug Elimination Program is a strong possibility if the President does not veto the 1996 HUD Appropriations bill.

Until there is a resolution of the future of federally supported programs for low income single parents, Providence (like all large public housing agencies) is left with a mandate from HUD to administer a Family Self Sufficiency Program but with no additional funding for related services.

\section{Information}

The PHA has improved, via administration of FSS, its overall awareness of available job training and related support service resources. Also, the agency is now well positioned to provide its decision makers with descriptive information about the experiences of its FSS population.

The Authority has been party, in the past year, to two collaborative funding applications designed to coordinate and improve client access to pertinent information via electronic networks among service providing agencies.

\section{Competencies}

The Authority is potentially an outstanding provider of the coordinated case management necessary for a successful welfare-to-work program. Proactive case management (closely monitored attendance, intervention in crises likely to derail completion of training or sustained employment) is a programmatic element frequently missing from larger scale efforts. For example, about $50 \%$ of FSS participants have accessed the federal Pell grant program. which provides post secondary tuition grants, as part of their employment training effort. As administered by the Rhode Island Department of Education, the program succeeds in its outreach and enrollment objectives: however. resources to monitor the academic performances and retention efforts are severely limited.

\section{PRESENT STRATEGY}

Thus far, the PHA's strategy has focused on outreach and coordination of existing job training and employment support resources to a limited number of AFDC recipients. (Please note: FSS enroliment is not limited to the AFDC population: an equally emphasized program objective is assisting the under employed to improve their income.) As of 06/31/95, there are 68 public housing and Section 8 heads of household with active contracts and another nine participants in Operation Bootstrap, which does not entail a contractual commitment.

The shortcoming of the existing strategy is the lack of job development activities and the fact that the program does not represent an aggregate increase in services. We are currently assisting people to access existing services to train for jobs in the existing employment market.

We are on the brink of reorganizing to improve our capacity to administer a broader FSS effort, pending the implementation of the Family Investment Center initiative, which includes strong placement development and employment support components.

\section{PERFORMANCE}


Among public housing agencies. Providence has the longest running FSS program in the state. It was the first agency in Rhode Island with a HUD approved program administrative plan and is the only local agency to have voluntarily instituted a program larger than that required by HUD.

The Authority also has a strong record of employing residents in its own operations.

\section{TRENDS}

The future of FSS is cloudy, although it is obvious that the Authority will be required to perform on existing contracts. It has been nearly three years since HUD headquarters issued any additional guidance on program administration or developed initiatives specifically designed to encourage agencies to expand their programs. Currently, public housing agencies are required to increase the number of FSS enrollments in proportion to any new units (public housing or Section 8) funded.

Beyond FSS, the resolution in Washington of the controversy around reforming welfare will markedly influence job training, job development and related supportive service funding.

\section{SHARE OF THE MARKET}

As was outlined earlier, the PHA's effort does not substantially increase the number of people served. Through community center based and related services we are able to reach:

1. Adult heads of household not currently accessing JOBS/JTPAJPell Grant resources and

2. Younger residents at risk of becoming the next generation of chronic public assistance dependents.

The statewide welfare-to-work program (Pathways to Independence) serviced approximately 3.500 heads of household in fiscal 1994. The Authority worked with 39 FSS enrollees during that fiscal year, $75 \%$ of whom were also Pathways clients.

\section{STABILITY}

This is the PHA's greatest positive attribute as a job training/employment support service provider. Many of the limited resources are apportioned throughout the state via contractual relationships to small non-profits which often, in turn, need to rely on those resources as sources of operating overhead revenue. The Authority strives to ensure that a greater share of the service dollar reaches the client because we are able, in varying degrees, to cover overhead (including staff) from other sources. Moreover, we can potentially offer more regular and comprehensive case management because we are also the housing provider.

Furthermore, the Authority can make the case for targeting limited resources to public housing residents on the basis of existing rental assistance. In other words, trainees with stable housing are more likely to succeed in their training and in subsequent placements. This is because the lack of decent and/or affordable housing is stressful enough to thwart the success of programs targeted at those whose lives are unstable.

\section{EFFICIENCY}

The Authority, with its limited staff resources, has clearly demonstrated its ability to manage FSS according to HUD specifications with limited staff resources. Also, the Authority is refreshingly unencumbered as a job training and placement agency. Program decisions at PHA-sponsored programs could be made solely on the basis of the caliber of the training and the rates of placement at wages sufficient to move a family off public assistance. The somewhat moribund job training landscape in Rhode Island is, at least in part, explained by some providers being assured of funding over a period of years on the basis of success measured in program completion rather than placement of an objective assessment of skills achieved in training.

\section{FLEXIBILITY}

The Family Investment Center was designed with strong emphasis placed on its capacity to respond to employer needs for specific training programs. 
ENVIRONMENTAL SCAN: FINANCE AND ACCOUNTING (INTERNAL)

\section{RESOURCES}

\section{People}

Overall, the staff at the PHA consists of highly competent who personnel hired to perform specific duties based on their abilities. In the Accounting and Finance Department, all personnel have the necessary experience and educational requirements necessary to perform their duties at a high level. Training opportunities such as seminars workshops and $\mathrm{PC}$ instruction are available both in-house and nationwide. Compensation is on a level comparable to other government agencies with benefits being slightly better at the PHA. It is this, alorig with other non-monetary factors, that has enabled this agency to maintain a highly trained, motivated and stable work force

\section{Economic}

Since Congress changed the method by which subsidy is distributed to Housing Authorities, the Providence Housing Authority from the inception of PFS (Performance Funding System) was hindered by a low expense level rating. In 1976 (PFS inception), the PHA had a massive lay off and instituted other cost saving measures to off-set major budget problems. The existing expense level of $\$ 61.19$ per unit, was too low to effectively operate the agency This was not the intent of HUD but unfortunately the low PFS level for the past 19 years has done nothing but hamper this agency from maintaining a minimum reserve level as required by regulation. Under PFS, a housing authority must maintain a minimum reserve level equaling $20 \%$ of $1 / 2$ of the total operating expense for the upcoming budget year If the minimum reserve level is not maintained, then HUD will classify the PHA as financially troubled.

Due to the inadequate funding under the Performance Funding System, the PHA has run deficits in the public housing program for a number of years. Fortunately, the surplus generated from excess Section 8 administrative fees has been applied to the public housing program. Despite this, over the last 5 years, the PHA has taken full advantage of all funding sources and has improved its financial picture. This trend must continue since it is apparent that proposed legislation to reduce funding is inevitable and no program is safe from legislative review.

The department actually administers several budgets in addition to the Annual Operating Budget. The FY 1995 Annual Operating Budget totaled $\$ 9.3$ million, only $23 \%$ of the aggregate amount of funds administered by the department. The consolidated budget, which includes all funding sources, totaled $\$ 40.9$ million in FY 1995 . Other budgets include: Section 8 - $\$ 18.5$ million (46\%), Modernization and Comp Grant - $\$ 6.1$ million (15\%), Development $\$ 5.7$ million (14\%), and other HUD, state and local grants - $\$ 1.1$ million (2\%).

The amount of funds the housing authority receives depends on several factors including the success of our grant writing and the formula used to allocate resources. Several HUD programs, particularly the Comprehensive Grant Program, are formula-based. Others, like Public Housing Drug Elimination Program. Youth Sports, Service Coordinators, Family Investment Centers are competitive grants. It's easy to see how the aggregate, consolidated budget can fluctuate from year to year.

Over the last four years the PHA's Consolidated Budget has averaged $\$ 38.17$ million. During that period FY 1994 was the highest with $\$ 45.4$ million and FY 1992 was the smallest with $\$ 33.1$ million. Again the Operating Budget only comprises from $20 \%-25 \%$ of the aggregate budget administered.

Our operating reserve, unadjusted and adjusted, has improved considerably. This fiscal year that ended on 30 June 1995 was our most successful in five years. We ended FY 95 with an adjusted operating reserve of $\$ 517,747$ after Section 8 reserves were credited. Without the Section 8 reserve credit, our unadjusted operating reserve was $\$ 189,173$. With a deficit, it is considerably better than last year's $-\$ 419,095$ deficit. Over the last five years, our unadjusted operating reserve averaged $-\$ 509,996$. Fortunately, the annual average surplus in our Section 8 administrative fee has been $\$ 552,498$.

\section{Information}

The information system at the PHA has been one of our strongest attributes. This system has an interconnected PC network in place, as well as the IBM system 36 (for general ledger and its related AVR, AVP and payroll functions). Constant upgrades are necessary if we are to maintain our competitive edge by accumulating and generating the necessary data to provide the means to be a proactive rather than a reactive agency. Current plans call for networking our entire system and phasing-out the IBM-36 system and purchasing existing public housing software packages. 


\section{Campetencies}

Budget and financial management functions are performed in a highly competent manner as detailed in the annual audit of the PHA. The labor force is highly qualified, dedicated and trustworthy. Optimum use of PHA resources has been utilized in maintaining a decent and safe living environment for its tenants, as well as a good perception from the outside (i.e. public relations). In order to maximize full rental income potential, some improvement is necessary in the turnaround of vacant aparments. Competence in job performance at the PHA is managed on a departmental level in conjunction with the respective unions.

\section{PRESENT STRATEGIES}

As a result of the federal deficit and cuts associated with deficit reduction, the PHA should plan for a future of relying less on federal funding and more on alternative sources of funding as a strategy to complete the overall mission. There are no immediate shortcomings since the budget and fund allocation process takes us into FY 1996.

\section{Department}

The Finance and Accounting Department is well organized and prepared to meet the mission of the PHA, mainly due to competence and stability of staff. The current staff has worked together as a unit for nearly 7 years without an increase or turnover in personnel.

\section{PERFORMANCE}

\section{Results}

The performance of the PHA has been outstanding over the last 5 years. This was recognized by HUD and resulted in being taken off the list of "troubled housing authorities." Couple this with the return of Chad Brown to PHA management and we are probably without doubt the best run housing authority in the state. The Finance and Accounting Department based on financial audit reports has also performed well. This is not unusual since we are the only department scrutinized on an annual basis by an Independent Accounting Firm. In order to comply with the Audit Guide and General Accepted Accounting Policies, established goals, standards, and procedures must be in place. Over the last four years, the annual audit uncovered only four insignificant findings that resulted in minor changes to departmental procedures. For the most part, the mission is being achieved on an on going basis. But there is more to accomplish. We must obtain adequate funding, increase the reserve level, build and sell low income housing and finally build low income rental housing financed with PHA funds.

\section{TRENDS}

Over the past several years, the trend in public housing has been an increase of social services (counseling, living skills, etc.) These services, however, are almost totally dependent on HUD funding such as Drug Elimination Programs which may be the victims of drastic cutbacks on Capitol-Hill. All these programs have increased the administrative burden on the department without an increase in staff. Newer, quicker methods of drawing down grant funds from HUD, through the U. S. Treasury, (the new LOCCS System) has improved our vendor payment schedules and actually reduced time consuming manual forms. With a reduction in funds and the elimination of several of our major programs, many of these duties will be reduced.

\section{STABILITY}

The PHA was established in 1939 (56 years and counting). Programs have come and gone during this period, but public housing remains. As cited elsewhere, the staff has been together as a unit for 7 years.

\section{EFFICIENCY/FLEXIBILITY}

The Providence Housing Authority has been on deficit reduction mode for an extended period of time. Cost-effective utilization of resources has been a necessity due to limited funding and the consequent low reserve levels. Constant changes in HUD regulations and procedures have occurred over the years and the PHA has shown the flexibility to adapt to those changes. Key competitive advantages are experienced leadership. staff, positive public relations and recently modernized units. These advantages will serve the PHA well to offset disadvantages that may occur with proposed legislation from Washington.

ENVIRONMENTAL SCAN:

HOUSING MANAGEMENT (INTERNAL) 


\section{RESOURCES}

\section{People}

The Housing Management Department consists of 37 staff members whose skills in the housing management field range from very experienced to the inexperienced. The staff brings an average of 11 years of professional housing knowledge to the organization

Managers are the key to successful property management. They are required to be well versed in all federal public housing regulations, policies and procedures, as well as our own praclices. In addition to managers, there are 11 Management Aides, one Acting Management Aide, two Occupancy. Specialists, one Administrative Assistant, three Clerk Typists, one Clerk Stenographer, one Receptionist and eight Temporary Clerks who work full or part-time. The Temporary Clerks are trained to assist the permanent staff by answering telephones and providing general customer service. Due to their lack of experience in handling the special problems of the numerous people we serve, the temporary personnel are considered to be our department's primary weakness.

Training is an ongoing process for the permanent staff. The department's goal is to have $100 \%$ of its personnel certified as a Public Housing Manager (PHM) by the National Association of Housing and Redevelopment Officials (NAHRO). At present. $73 \%$ of the staff is certified as a PHM. Additional training on policies and procedures is also provided by the Director of Housing Management within the department, who keeps the staff informed on new regulations from HUD as well as changes to internal policies

\section{Economic}

Over the past ten years, the Housing Management Department has experienced an increase in the number of employees while undergoing a change in the overall responsibilities of the staff. Eleven years ago, the department was responsible for development management, security and resident services functions with a total of 18 staff members. Through the years, our staff has become larger and more specialized. Our security force has increased from one full-time employee to a separate division with security guards and city police officers who supervise the day to day security program. Resident services were provided by the Management Aides and Managers of our developments. And these same staff members were still required to complete all the appropriate management work, such as recertifications, unit inspections and other management functions, for which they are responsible today. This signified limited services for our residents. Resident Services are now provided by a separate department.

The amount of funding provided to the department for operational use is adequate to accomplish the current mission of the department. Future funding is bleak, however. Congress is proposing a $22 \%$ reduction in operating subsidy to public housing authorities. This will substantially impact this department, since $100 \%$ of the staffs budget is from the annual operating budget. It remains to be seen what impact "voucherization" will have on the department. If all our residents are issued vouchers, as is called for in HUD's proposal and the residents remain in our developments. the impact shouldn't be too severe, particularly if the rent structure is high enough.

Other trends for the future are influenced direclly by the Department of Housing and Urban Development (HUD), the Congress and changes made to the Code of Federal Regulations. These regulations govern our operations; therefore, any changes could affect the manner in which we provide housing. We have little control over the external factors which directly affect HUD. In the future it will be important for the Providence Housing Authority and other such professional advocacy organizations to help create positive changes to the Code of Federal Regulations that will enhance public housing operations.

\section{Information}

The Director of Housing Management conducts weekly meetings and requires written reports to be submitted to monitor the activities of each development. These reports provide information on the number of vacancies, unit turnaround time, resident/manager conferences, transfers, unauthorized vehicles tagged and towed, legal attachments sent to residents, applicants on waiting list, home visits, and other information pertaining to the development and waiting list. This information enables the department to identify any potential or existing problems and also provides a data base for future reference.

Each of the developments have recently been equipped with new, powerful, personal computers with the latest Microsoft Word software. Long-term plans call for linking each development to a wide area network (WAN) at the central administrative offices. This will allow information that is currently transported by hard copy to be sent electronically. 


\section{Competency}

There is a periodic review of the Goals Management Performance/Monitoring Plan. Monitoring these goals helps determine the status of our organization in comparison to industry wide standards. These goals provide a plan of action to be achieved at the end of a specified period of time. The plan which is currently in effect has a three year time period. We can improve our competencies by getting input from all levels of staff when planning for our future. It is important for us to not just ask for input but to require it. Presently, the department is meeting all its goals and performance standards.

Firm, fair, and consistent management is the goal of the Housing Management Department. Currently. the PHA maintains 2.555 units. The department conducted a total of 33,198 management conferences this year. Rent collections have averaged $97 \%$. The Department issues approximately 468 legal notices on a monthly basis. These notices begin the legal process for eviction if the resident does not cure or pay rent on time. In FY 1995 there have been 221 eviction actions generated but only 42 physical evictions.

Department staff require more training in effective report writing and planning. This is perhaps our weakest area And customer service is also an area in need of improvement.

\section{PRESENT STRATEGY}

\section{Overall}

The Housing Management Department achieves its PHA mission by maintaining firm, fair and consistent management techniques. This applies to staff and residents' needs which are addressed once identified. However, the resolution of those needs are guided by the PHA's established policies and procedures.

\section{Department}

The department has a time tested structure that has proven to be effective. All required functions are completed on time. but this does not mean there is no room for improvement. Under our current organization. Management Staff gets territorial and many resist suggested transfers to new work sites. Staff members are also limited by their work assignment to learn only what is currently required of them at a particular development. Interdepartmental cross training would be helpful in broadening management staff's range of knowledge. It could also be a positive step to take a team approach, such as creating a recertification team responsible for all PHA resident certifications and an inspection team to inspect all PHA units. Employees could be assigned to a team for a specified period. which would add to their training experience.

\section{PERFORMANCE}

\section{Results}

Management meets or exceeds most established industry standards. A large part of our success has been employee and resident education. We ensure that our goals are known by all staff members and that they understand what is necessary to achieve them. Residents are trained on lease requirements and what is expected of them to maintain a successful managementresident relationship.

\section{TRENDS}

In the past five years, the Housing Management Department has maintained an annual average of $98 \%$ occupancy, $7 \%$ tenants account receivable. In FY 1995, 33,198 management conferences were held, 294 eviction actions were processed, 20 actual evictions took place, and 18 grievance hearings were held. Our concerted effort has resulted in the realization of most of our goals. The one exception to this is receivables. A few developments have difficulty achieving their goals. Our occupancy is also effected by trends in the availability of low-income housing in the state. Negative trends in either instance cause management to increase its efforts in reaching our goals.

\section{SHARE OF MARKET}

The PHA is the largest landlord in the City of Providence; our competition for residents consists of other public and private subsidized developments in and around the Providence metropolitan area.

Thirty-nine communities provide subsidized housing to qualified applicants in Rhode Island. The PHA houses approximately $7 \%$ of the total number of subsidized units. In 1994, the City of Providence had 7,672 assisted housing units, of which the PHA managed 2,540 units (public housing). 


\section{STABILITY}

The organization has demonstrated staying power through creativity over the years. The PHA has investigated numerous methods in which to provide a competitive edge in the housing community. Some resources have been provided through grants used for specific community programs, volunteers and internships. Every resource has improved the services which we provide to the residents in an effort to enhance their quality of life. The PHA has developed other means of transitioning residents out of the traditional subsidized low-income housing. Through the PHA's assistance, low-income families can take part in opportunities to become more self-sufficient through programs such as the Family Self-Sufficiency Program (FSS), and the Homeownership for People Everywhere (HOPE I).

\section{EFFICIENCY}

The organization has been cost effective in the utilization of its facilities, personnel and resources. Shifts in the responsibilities (specializations) of personnel have increased the effective delivery of services to our residents. Additional resources have allowed an increase in programs offered to residents which enhances the use of our facilities.

\section{FLEXIBILITY}

Because of the availability of funds to make physical improvements to our housing stock, the PHA has been enabled to transform itself. These changes have made our developments more attractive to prospective residents

Within the housing market, our competitive advantage is that we are a subsidized agency and are able to provide housing services to residents at lower than market rents. We are affected by economic changes in the market, however, the cost of providing services increases every year.

Public housing can maintain a competitive advantage by continued efforts to improve and upgrade our housing, customer services, and our physical property. Any changes to the Federal Regulations that restrict our capabilities and types of services we extend within our market would be a great disadvantage to our organization. However. more positively, changes which deregulate and give more decision making power to the PHA will be an advantage that will guarantee a successful future.

ENVIRONMENTAL SCAN: FACILITIES MANAGEMENT (INTERNAL)

\section{RESOURCES}

\section{People}

Ninety-percent of the Facilities Management's ninety-eight employees are blue collar workers of diverse backgrounds reflecting the city's racial and ethnic population. In recent years the department, as part of PHA policy, has made a special effort to recruit and train public housing residents for positions in the Facilities Management Department and to open positions to woman. Involving residents as part of our staff has proven to be beneficial in many ways, including building character, promoting self-sufficiency, and opening the possibility of obtaining grants for resident training.

\section{STRENGTHS AND WEAKNESSES}

Our strengths include sound leadership, diversity of skills, experience, and the ability to respond quickly to emergencies. An inordinate amount of time is spent on work orders that could be avoided with better resident cooperation (graffiti removal is the prime example), thus freeing the staff to pilot creative solutions to more entrenched building maintenance problems.

Like many organizations of this size, our major weaknesses are resistance to change and inexperienced and untrained personnel, both of which hinder us in the deployment of more independent teams. Another serious weakness is our inability to discharge troublesome employees in a timely manner, because of required documentation of their infractions. The entire staff is union, both workers and supervisors. 
More formal internal training is needed to build employee confidence. Our inability to control employee sick leave, especially 2nd and 3rd shifts, results in overtime for on-call personnel and leaves day shifts shorthanded. in the past, we had to promote and hire many people not able to meet job requirements due to outdated specifications and past practice. This situation has improved. A lower entry level position such as apartment and grounds cleaner is warranted, along with revised job specifications. These two improvements would enhance our ability to train qualified people and, in turn, lower operating expenses.

The department needs to revamp, create and initiate a new staff training program. Such a training plan and schedule will be developed for the Fall. The new program will allow a new employee to receive on-the-job training (OJT) in all of our skilled trades. It will include all our basic routine jobs, as well as skilled tasks such as carpentry. plumbing. electrical, mechanic and boiler technician. All employees are, also, encouraged to seek out job-related formal education, for which they will be reimbursed for out of pocket expenses. Employees will not only experience self-satisfaction, but will also improve their chances for advancement.

The department's average skill level is equal to private industry. We have many highly skilled employees, but half of our staff are semi-skilled or unskilled. Some of our employees are not mechanically inclined and, despite instruction from coworkers, cannot perform required lasks. These individuals should be dismissed or become part of a permanent grounds and cleaning staff paid at a lower rate than skilled and trainable personnel.

\section{Economic}

For the past ten years annual operating funds have been adequate to conduct operations at a sustainable level. The creative use of Comprehensive Improvement Assistance Program (CIAP) and Comprehensive Grant Program (CGP) funds has allowed us to replace our vehicle fleet and to purchase new equipment to improve the efficiency of our operations. Comp Grant funds have also been used to pay salaries for the department's Operations Planner and an Assistant Operations Planner, who will be hired in the Fall. Our main concern is continued funding to maintain recent improvements to our facilities, additional scattered sites will further strain our existing work force requiring additional personnel. Budget reductions, particularly operating subsidy, from Washington is our primary concern. Our greatest fear is the budget cuts which, coupled with vandalism due to drug-related crime, will result in our developments becoming "projects" once again.

\section{Information}

Our best sources of information are our own employees and residents. This instant feedback, combined with jobrelated seminars and published manuals assist us in performing our mission. Our computer-generated reporting system is also an excellent source of information, particularly for tracking the level of activity, identifying troubled areas of operation, and tracking work order numbers, time of performance and completion rates by category and development. This information is included in the Monthly Management Reports and Annual Report on Operations.

Improvements to the management information system will be forthcoming in the next six to nine months when we select new computer software for our work order system. The new system should be more user friendly and generate more customized reports. It will also be able to interact with the Finance and Accounting Department to charge residents' accounts for damages and service calls.

Another recent improvement has been the purchase of the a centrally located energy management computer which monitors all our boilers, values, and data points, including security. This addition has enhanced our energy management capabilities resulting in greater energy efficiencies and lower costs (an analysis will be undertaken in the Fall.)

\section{Competencies}

The department has a good performance record considering the number of developments we manage and maintain. The addition of the scattered sites has taxed the department's resources -- particularly personnel-- due to the number of units and their varied locations. While the PHA's made a conscious decision to "scatter" the new units for social/political reasons, the additional burden to the Facilities Management Department has not been cost effective. The amount of lawn work alone requires more time than is available, resulting in grounds maintenance not being performed to meet our current standards. Solutions to this problem will be addressed in the "strategies" section of this scan.

Employee absenteeism is also an issue influencing department operations. . We have to conduct better screening of new employees and get the unions involved in policing their own personnel. Absenteeism leads to longer completion times for all projects and, as stated earlier, requires the callback of off-duty personnel who collect overtime. 
In the past, terminating difficult people has been a problem. The process itself is cumbersome and the signal it sends to other employees is tough on morale. Some employees persist in the belief that they are entitled to their jobs whether or not they meet the responsibilities of the position, and changing this attitude is difficult. These personnel usually are dealt with through attrition rather than termination. Foremen must start documenting even the smallest infractions in order to build evidence of a need for disciplinary action. Our productive employees must take a stand and demand their peers do their share of the work. Jealousy among some employees is also a problem and generally the people with the least motivation complain the most. Internal departmental communication (for the most part) is strong. despite occasional clashes in opinion. Our goal is to delegate responsibility to small teams at the lowest possible level to promote independence and accountability.

\section{PRESENT STRATEGY}

Teamwork through quality management is our modus operandi. Our current strategy is to achieve the goals outlined in the Goals Management/Performance Monitoring Plan and the Quarterly performance indicators. Documentation, time studies and resident input will help us achieve our goals. We have recently reorganized, combining central and on-site maintenance teams to achieve our goals. Our centralized supply inventory has been reduced by using direct to site deliveries on a predetermined basis. New software for our work order system would tie-in work orders directly to inventory control and resident accounts and would have databases large enough to store such information.

Energy management is another area we are revamping after many years of neglect. New windows, boilers, an energy management computer with software, and the addition of two highly skilled personnel have already generated substantial savings.

We are planning more in-house formal training to coincide with job assignments. By doing this, classroom instruction will immediately be put to practical use. Better use of bulletin board and handouts to improve communication is also planned. A method to reward our skilled and productive people needs to be developed to encourage high performers. We should also adopt testing of all personnel prior to promotion and ask for foreman input before promoting staff to higher levels of responsibility.

The future is unclear for the department, as well as the housing authority as a whole. Budget reductions, particularly annual operating subsidies, will affect the Facilities Management Department more than any other. Ninety-eight percent of our personnel are funded through the annual operating budget. Although other grants, such as the Comp Grant may off-set some costs, the operating budget will continue to be our primary source of funding. Cutbacks on staff are inevitable. Supervisors must identify their least productive personnel now, document their shortcomings, and either demand improvement or terminate their employment. Our strategy for the future is to perform more with less.

\section{PERFORMANCE}

\section{Results}

Considering some of our weaknesses, the department achieves its primary goals, with the exception of unit turnaround time. However, response time to work orders and the percentage closed out are well within the prescribed standards. Large government agencies traditionally do not perform as efficiently as small private companies due to bureaucratic red tape, labor contracts and other long standing practices. Some phases of maintenance should be contracted out, especially ones with logistic problems, like grass cutting and exterior painting of scattered sites. Routine maintenance (tenant services) can best be handled by permanent staff due to slow response time of most senvice companies who also add extras to increase profit margins.

Our greatest need is to work better together through good communication; more training. Defining jobs and establishing time parameters are our priorities. Over the past few years, the Facilities Management Department performance has made great improvements. We all see room for additional improvement and achieving it is our common objective.

\section{TRENDS}

With significant budget reductions and the elevated labor costs of public employees, the trend has been to "contract out" (privatize) services. Labor costs for unionized public employees are considerably higher than private sector firms. An evaluation of labor costs for the PHA indicates significant savings could be realized by contracting out. The drawback of contracting out is that it deprives the agency of the flexibility of moving personnel at will. Other 
services that could be considered for contracted services include: ground maintenance and exterior building painting at scattered sites developments. It should be observed, however, that the department has, in recent years, hired technical specialists for our staff that are doing work previously contracted for with private firms. These technical specialists have saved the PHA a significant amount of funds to make their hiring worthwhile. Each situation has to be analyzed separately to determine its impact on the department's time and resources.

\section{STABILITY}

The department has some long-term employees who provide stability to our operations. Recent retirements, however, have allowed for some promotions of qualified staff. Attempts have been made to identify key, qualified personnel to fill slots through promotion. If qualified persons are not available, there is no hesitation to seek personnel from outside the department or Authority. Emphasis must be placed on hiring the most qualified for an increasingly technical career field. The department has followed a policy over the last several years of hiring entry level laborers as "temporary" employees to determine their suitability for the job. If they show initiative and a permanent position becomes available, they are hired.

No one at this time knows what the future holds for the PHA. If drastic reductions are made in the Authority's Annual Operating Subsidy by either the Congress or the Administration, it could have dire consequences for Facilities Management's operations. Ninety-eight percent of the department's personnel funding is provided through the operating budget with little chance of off-setting the costs to other programs. If the operating subsidy is reduced, the department's staff will be reduced with a corresponding reduction in the level of services.

\section{EFFICIENCY}

In the past, when funds were more plentiful, efficiency was not a prime concern of the department. Now, with budget reductions on the horizon, efficiency and effectiveness are our number one concern. An efficient and effective operation requires fewer people to perform the same amount of work. Our challenge is to perform more work with fewer people, and it can be met by weeding out inefficient and unqualified personnel, increased training, improving equipment and materials, improving planning, and hiring the most qualified personnel.

\section{FLEXIBILITY}

The department has to remain somewhat flexible to meet the demand of everyday operations. For instance, planned preventive maintenance comprises approximately sixty percent of all work orders. But, in order to meet the demand of our customers. the residents, we must be able to reallocate resources (time and material) to daily resident requests that comprise, on average, twenty to twenty-five percent of unscheduled work orders. An analysis has to be undertaken to determine the causes for so many resident requests. With plannedipreventive work orders comprising so much of our aggregate work order load, there should be fewer resident service requests. The analysis should cover the type of planned/preventive maintenance taking place and whether a re-working of the system should take place.

\section{ENVIRONMENTAL SCAN: MODERNIZATION \& DEVELOPMENT (INTERNAL)}

The Modernization and Development Department is made up of nine full time employees with various professional, clerical and technical skills as well as temporary part time clerical and technical people hired on an as-needed basis. They bring to their work a high level of skill and professionalism as well as a concern and sensitivity for the population that the Housing Authority serves. There is made available to them a wide variety of training in both their own professional area of expertise as well as numerous courses and seminars related specifically to public housing issues and regulations. Budgets administered by the department since 1987 total over $\$ 110$ million, more than $\$ 65$ million in modernization funds and over $\$ 45$ million in development projects. The Department is continually making an effort to improve and streamline its work flow in order to deal with the ever increasing volume of paper work resulting from the Comprehensive Grant Program (CGP). Although HUD is moving toward less regulation, the quantity of reports, contracts, budgets etc. that the department prepares and administers has increased dramatically over the past two years. This is a direct result of the transition from project specific modernization activities like Hartford Park and Manton Heights to the CGP where the PHA has over 400 line items in its four budgets. There is also an increased effort to broaden the focus of the Department in an effort to work more expediently with other departments and to eliminate duplication of effort, especially in the area of procurement. 


\section{Comprehensive Grant Program}

The Comp Grant Program which is managed by this Department has provided us with enormous flexibility as we are able to pinpoint specific areas in each of the developments where needs exist and to target funds to priority projects in the most cost effective manner. However, it has also meant that we are now handling an enormous number of separate contracts and purchases rather than overseeing two or three large construction projects. The result is a deluge of paperwork as we must continue to meet the numerous regulations required by HUD. With the current political and economic climate of stringency and less government involvement, we will be forced to deal with new challenges. At minimum we will be faced with a decrease in our Comp Grant funding forcing us to phase projects, extend time lines and reduce the size of some projects. It is expected that we will receive a reduction in funding for the current year of approximately $\$ 1,100,000$ and in subsequent years the reduction is estimated to be $25 \%-30 \%$ or $\$ 1,300,000-\$ 1,600,000$. In the next year or two it is expected that the CGP and other HUD programs will be replaced by block grants. This could be a positive change if it results in reduced regulations allowing us to further simplify and streamline the procurement process by taking life cycle studies into account in the purchase of equipment and material. We are purchasing more maintenance friendly products and avoiding a duplication of effort by both departments. However, there is still work to be done in record retention. There is no definitive record of the modernization work done at each of the developments, that itemizes type of work, date of work, warranty information, cost, etc. There is no tie-in between the Facilities Management work order tracking and the Modernization needs assessment. The Inventory Control System is another natural area for Modernization and Facilities Management to work together to devise a more user friendly system.

\section{Pending Physical Needs}

Many of the problems we face are a direct result of the enormous economic difficulties of our residents. Consequently, our mission can never be completely accomplished in such a climate. We have identified more than $\$ 20,000,000$ in unmet physical needs. At our current funding levels, assuming that nothing is added to the list. it will take from five to eight years just to catch up with today's backlog. The comprehensive modernization of the final three buildings at Codding Court needs to continue to bring the entire development to the same level as the recently modernized buildings. The primary unmet physical need throughout PHA developments is the poor condition of most of our heating systems in both high-rises as well as our family developments. Lack of control results in overheating in the winter and thereby causes resident discomfort and increased energy costs as well as man hours spent in trouble shooting and repair. Several high-rise buildings require major fire alarm upgrades. Comprehensive modernization on the 30 year old Dexter Manor I as well as major modernization at Roger Williams including kitchens and baths still must be undertaken. At Chad Brown/Admiral Terrace, exterior doors and kitchen cabinets must be replaced in the first two phases. And in the Phase III units, interior doors and finishes are needed. Poor ventilation in our high-rise buildings as well as old baths and kitchens also require constant repair. In addition, they present an uninviting appearance to prospective tenants should voucherization become a reality.

\section{Impact of Regulations and Cutbacks}

Davis-Bacon requirements and hazardous waste regulations have also had a major impact on the department. We have had a major increase in the number of contracts we administer. Many of the jobs are very small, resulting in a large number of new contractors without previous experience on Federal jobs. On site monitoring and payroll reviews have become virtually a full time job. This has resulted in a major increase in workload for staff and delays in closing out of projects as we target staff to this effort. We also continue to target resources toward abatement of asbestos and lead in our buildings. Over the next 12-18 months, we expect to contract for the removal of the bulk of these materials still existing in our developments.

There is no question that cutbacks in funding will affect how quickly the Modernization and Development Department addresses the backlog of modernization projects. The Five Year Plan will have to be revised and projects reprioritized. It will clearly take longer for some of the larger projects -- including Codding Court, which will have to have one additional year added to the schedule. Lower priority projects will be deferred or deleted from the plan. It becomes even more important that communication and cooperation between departments be enhanced and an increased sense of one organization working as a team be encouraged.

Development activity should not be materially effected by the funding cutbacks in Washington. Since we must complete our 240 replacement units under court order, funding should continue. However, since we are running out of possible sites for single family and duplex units, perhaps it is time for the PHA to look into structures larger than two units or other ways to produce the needed units. For example, the Department will be looking at acquisition in order to complete the 16 units for which no proposals are pending. In the next year, with the completion of the 240 replacement units, development activity will virtually cease. This will effect the job responsibilities within the department as roles are redefined. 


\section{Current Status}

The Housing Authority as a whole, and more specifically the Modernization and Development Department, have experienced a vast improvement in the last five to six years. The Goals Management system, long range planning and involvement in public housing professional organizations has resulted in an Authority that is a leader in research and planning, as well as in its ability to attract funds. However, there is more that can be done. More time and effort must be devoted to the development of policies that are efficient and ensure that departments don't work at cross purposes. For example, the selection process for residents to occupy our scattered site units needs to be improved. Although no process is foolproof, we seem to have more than our share of residents that are not respecting the property. We need to have more discussions among departments with the aim of developing better mechanisms to deal with these kinds of situations. If residents are not assuming their share of responsibility when they occupy the new units we need to know why. Do leases need to be revised? Can we learn from other PHAs about how they select and monitor scattered site residents? Is it a matter of more education and remedial training to ensure that problem residents are identified and behavior altered? Or is it that we are not reinforcing positive behavior and punishing negative behavior? We should not be tolerating any situations where tenant behavior causes us problems. Should our philosophy be to change behavior and make the individual family more self-sufficient and responsible? Then perhaps we should prepare some kind of contract with the family at a scattered site unit whereby we spell out more clearly what is expected of them. We could have regular meetings where groups of residents come together and discuss examples of good and bad behavior.

\section{Future Strategy}

The key to our survival in the difficult years ahead will be to make use of the very systems for planning which we currently have in place. However, because of the possibility that the Authority may be in direct competition with the private sector in the future, some of our current strategies need to be refined. We need to build better partnerships with the residents at all levels and need more involvement by people in the community. Greater involvement by individuals at a lower management level who are in direct contact with the residents will give us a more realistic picture of our successes and shortcomings. We may find that our goals need to be fewer, but that they need to be much more relevant to the marketing of our units. We will have to be more innovative in our programming, working with other community organizations to make the maximum use of the funds available, making use of our bonding authority, and most importantly, continuing to provide services that will enable residents to improve their selfsufficiency.

\section{ENVIRONMENTAL SCANS: COMMUNITY SERVICES (INTERNAL)}

\section{RESOURCES}

\section{People}

The department is on its own to a great extent, which can be viewed as a virtue in bad times. We are accustomed to living on the edge, we are more attuned to external opportunities, we already have a degree of team attitude because staff must share and depend on each other's good will.

This department focuses on the residents. By definition, we don't have to meet rent receivables every month or turn over apartments under 18 days. In contrast, our evaluation is based on figures representing how many residents are involved in our programs, how many youth graduated from high school and are going off to college, how many successful referrals have been made to social service agencies.

Staff has always been chosen for their interest and enthusiasm for helping public housing people. They are caring. problem solving, fun and willing to work very hard. They add a great deal to the Authority. Weaknesses include insufficient writing and organizational skills, non-business focus. As the family unit programming moves toward more academic and job emphases, we look more toward the educational professions for staff. In the elderly disabled unit we are moving away from staff trained as social workers and toward the relatively new resident services coordinator model.

\section{Economics}

The Department of Community Services has always been dependent on external funding. Currently, only nine percent of the department's salaries come from the PHA operating budget. The dollar amount we administer has 
continually increased from $\$ 232,600$ in 1990 , to $\$ 837,081$ in 1994 , a 360 percent increase. Assuming all pending grants are approved, this year's grant funding will exceed 1994 by an additional \$692,800.

Administration now is a partner in grant applications. Current interns are superb in that they are competent and committed to our goais. When and if funding procedures change and we must apply to city or state through block grants, our abilities to acquire private funding will have to sharpen because state and city governments have their own carefully cultivated agendas. We will have to fight for our share. The best scenario under the block grant alternative would be for the Authority to administer the state's or city's housing funds. This would mean the Authority would have to assume some control over the smaller PHA's and/or other housing

\begin{tabular}{|l|l|}
\hline FUNDING ALLOCATIONS \\
\hline YEAR & AMOUNT \\
\hline 1990 & $\$ 232,600$ \\
\hline 1991 & $\$ 396,127$ \\
\hline 1992 & $\$ 490,726$ \\
\hline 1993 & $\$ 576,461$ \\
\hline 1994 & $\$ 837,081$ \\
\hline 1995 & (to date) $\$ 689,000$ \\
\hline TOTAL & $\$ 3,221,995$ \\
\hline
\end{tabular}
programs. The Authority must be flexible and adaptable to such situations.

Past strategies of the Authority were based on a top-down departmental structure. Currently there is an effort to explore a more team-oriented approach. This is in no way a complete "re-engineering" of the system, but rather an experiment to see where, how and at what levels we can accomplish more and waste less throughout all areas of the Authority. The Authority will always be a strong hierarchy with the present director.

Nevertheless, openness to "re-engineering" type management styles will teach us to operate in a flexible state, allowing for teams to address outside organizations as well as internal problems. Team problem solving and team management appear to be working, especially between community services and management staffs. All kinks have not been worked out, but we are committed to coordinating and streamlining the process. With the addition of maintenance into the process and then eventually resident input, we will have begun to work at internal problems that have not been solved in the past through conventional means.

If the future produces privatization of public housing, the administration staff will lead us into the marketplace. That staff has to set aside time to explore and plan now. Administration staff is more than capable of rising to this opportunity and the department's assumption is that options are already in the works.

\section{Information}

The increasing ease with which information is gathered and aggregated for useful purposes is a great part of the flexibility of the Authority. Increased computerization, both from the complexity of programs and their availability has already made a big difference in grant preparation, budgeting and administering surveys. We should continue expansion of our computerization until everyone has a computer at his or her desk and knows how to use it.

In the Department of Community Services, greater computer abilities will allow us to speed up networking between agencies. For example, if we could sit down and send information to the Providence Center about a client without having to make the usual 20 phone calls to reach the correct person, communication time between agencies would be cut down, allowing for more time with residents. What if we could advocate with Social Security staff directly over the computer, setting up benefits for a resident within half an hour?

\section{Competencies}

Our department continually needs revamping to adjust to new information, restrictions and opportunities. As we receive and lose grant funding, as welfare reform shifts the focus to jobs, as the Spanish-speaking population continues to increase, as funding is taken away from elderly programs; all these changes make us look anew at our program.

Our goal will always be elusive; sometimes we seem to work against ourselves. For instance, we developed a very successful youth program which fully occupied youngsters during after school hours and into early evenings. Similarly, we ran a full-time summer camp. Many parents looked upon us as a free baby-sitting service and they did not have to care or get involved with their children during program time. Now we have to shift the responsibility back to the parents -- (i.e.; through mandating volunteer time from each parent). Problems also exist in the elderly/disabled buildings. We find the service coordinators devoting eighty percent of their time to twenty percent of the population and we need to reverse that percentage through our own efforts and those of assisting agencies.

If we are to manage buildings more efficiently, if we are to make public housing a "neighborhood of choice" then we must focus on educating residents so they may become responsible internal stakeholders. This is accomplishable 
through tenant associations, greater training placed on residents when they first move in, more stringent residency policies and as a part of the job preparation program. However it's done, it needs to happen. If it takes six maintenance workers full-time to pick up the trash dropped by residents, then we, as an efficient organization, are working at odds with our goals.

\section{PRESENT STRATEGY}

The Authority's performance has improved radically from the days of being on the "troubled housing authorities" list. This has been accomplished through strong administrative leadership. The Authority is among the city leaders in housing knowledge and advocacy. We should maintain and improve this position, particularly if there is a possibility that we could be the pass through for federal housing funds.

The Authorily's mission to provide decent, safe and sanitary housing units for low income people and help residents achieve self sufficiency is a task that can never be completed. We will never have 100 percent of our residents working and providing comfortably for their families and there will always be more work to be done maintaining the building stock. What we can do is collaborate with the residents, service agencies and funding sources in learning what populations need housing and build it. We should also determine who needs jobs or training and find or provide the opportunities.

Goals and objectives need to be revisited. Goals should not be along the line of turning in HUD reports on time or collecting $x$ percent of the rents. Those items should be requirements of a department. Goais are of a different nature and should not only be departmental, but should be individual. Each employee, as well as the Authority as a whole, should have requirements, goals and objectives all of which are monitored on a regular basis. This revisiting should also include performance indicators.

\section{FUTURE STRATEGIES}

Making more services available, more quality tenant involvement, more thorough security systems and improved housing stock are essential for us to market public housing in a future of privatization. To market our elderly only housing units we may need to enlarge our efficiency units to one and two bedrooms. Another possibility is to work with Aging 2000 for Medicare waivers to finance services such as housekeeping and personal care for the older residents. If we want to let residents age in place we will need floors set aside for assisted living. This may be the wave of the future in the U.S. as nursing home placements are often unnecessary and too expensive. Rhode Island currently spends approximately $\$ 275$ million a year in Medicaid and state tax dollars on long term care; a cost of approximately $\$ 30,000$ per year per bed. We also need a model for the remainder of the high-rise buildings; not abandon the disabled.

In the family developments, job preparation and personal development for adults is the direction for the future. This includes: academic remediation, enrichment, a focus on positive male role models, and substance abuse and teen pregnancy prevention for the youth, and more togetherness for parents and children.

The department needs to develop other sources to supplement our existing scarce resources such as, private money, increased collaborative fund raising, and working with schools and universities. Deregulation may lead to being able to charge for services and programs.

Public housing tenants are both our customers and our collaborators. In the future, they will assume a greater role in determining policy and management structure. Twenty-five hundred households in the City of Providence should not be overlooked. There is a certain political clout in that number which must be used to leverage financial support and city services. A PHA-wide tenants council will be a formidable collaborator in applying for national as well as local foundation support.

Tenants are half the equation in understanding what makes a development a desirable place to live. Along with staff, they can begin to assume the responsibility to protect what policies they now hold ownership to. This leads to an inter-dependent relationship with all sorts of opportunities possible. Tenant management, tenant job training. tenant-owned companies, involved tenant associations and team participation with Authority staff will be a part of the emerging pattern

The PHA is healthy, well administered, creative and a "good size". We are well positioned for change, not so large we can't adapt and not so small that we get swallowed up. So far, the organization has been able to move ahead within the tiresome restrictions placed on public housing by HUD. If we eventually end up on our own, competing in 
the private open housing market, the Authority must consider addressing our organizational structure, building stock and our management style to reflect the challenges of HUD's reinvention and deregulation..

The PHA should consider creating the Providence Housing Community Comporation working in collaboration with private and government funding sources in developing and staffing public housing developments or developing new housing for moderate-income families.

Superior, not just good, security systems must be established at every development, since this is mentioned in surveys and focus groups as the primary concern at all our developments. This will assist us in competing for residents when voucherization takes place. In the elderly/disabled developments, the apartments must be redesigned to expand efficiencies into one bedroom units and community spaces must present a more comfortable image. In the family developments the focus has to be on maintenance and upkeep, perhaps through more stringent resident policies.

The Authority will be a public entity in the shape of a pyramid of housing options with the three points being Authority staff, residents and connected agencies and providers. To carry out the collaborative mission, team work will be necessary at every connection. With what the training Authority staff is currently undergoing, we are preparing for the future.

\section{PERFORMANCE}

Our department's performance has improved tremendously over the past five years. Our funding has grown 300 percent since our first PHDEP grant. Our department is almost totally funded by grants. We have standardized our youth program to include education and enrichment components, established a Family Advisory Committee to encourage adult participation, established an Inter-Housing Authority Travel Sports League, managed to grow into a positive, hard working and supportive staff relationship, begun standardization of the new services coordinator positions. worked out relationships with schools and universities to provide our residents and their students with social work internships and made numerous other small victories.

Through observation, study and communication our department adapts to what we see as future trends. In the elderly/disabled unit the focus is less and less on traditional social work and more and more on coordinating services available in the community and on building activities which include a number of residents.

\section{TRENDS}

\section{Socio-Economic Information}

The socio-economic data that displays changing characteristics for the family development resident population reveals an increase of $8.3 \%$ children between the ages of 0 and 9 between 1991 and 1994, and a 13 percent increase of Spanish-speaking residents with a concomitant decrease of 4.2 percent of white residents and 9.1 percent of Black residents during the same period of time. Currently 57 percent of the family population is Hispanic/Latino, 37 percent Black and 6 percent White. Forty-seven percent is under 19 years old. Cultural understanding, racial conflicts, and parenting issues are all growing concerns for the future.

In the elderly/disabled developments the number of residents between the ages of 20 and 49 has increased 9.4 percent between 1991 and 1994, and the over 70 cohort has decreased 6 percent during the same time. While the disabled population has increased only 5 percent between 1991 and 1994, there has been a dramatic shift in the composition of the disabled population. From 1991 to 1994, the percent of disabled people under the age of 60 has increased by almost 20 percent. Steps have already been taken in addressing the issue of mixing old and young populations through the designation of two buildings as elderly only. How we will maintain integrity of services to both the disabled and elderly populations is a formidable challenge to us. Networking and collaboration are definite realities.

Whereas most of the Spanish-speaking family residents either have a basic understanding of English and can communicate or have a child to assist interpreting, the elderly Spanish-speaking residents, often cannot begin to exchange information with an English-speaking person. For the Spanish-speaking family residents it is imperative that they learn English to become participating members of the larger community.

For the elderly disabled Spanish-speaking population it is less imperative but nevertheless helpful to speak English. Until we can provide tutoring for residents it is necessary to employ staff who are fluent in Spanish. Our Spanish. speaking VISTA Volunteer has been welcomed with open arms by these older people who feel they have never 
understood anything and have not participated because they don't know what is going on. Our volunteer has even reached out to find nominees willing to run for positions in the tenant association in one building. She has also found elderly people, without primary medical care, to take advantage of the Dexter Manor Senior Medical Clinic. If we are to utilize the energy of residents in our future plans, this continually growing population must be brought into the fold.

\section{SHARE OF MARKET}

The department realizes that it is virtually impossible for them to provide services for every public housing resident. To date, most services have been targeted to young people. With our current funding sources we service approximately $30-35 \%$ of the youth population directly. Our Summer and FallWinter programs are limited by physical constraints (building size, room availability) and staff (coordinators, assistant coordinators, resident assistants, and contract workers). The PHA must rely on other outside agencies to absorb those residents we are unable to assist.

\section{EFFICIENCY}

The department encourages the efficient use of resources by using as many part-time personnel as possible and by attempting to purchase services materials in bulk to receive the best rates.

\section{FLEXIBILITY}

Being adaptable is a requirement in the department in order to deal with constantly changing situations. Since funding is always a concern for social services, the department must be prepared to identify and seek alternative means of funding.

We have also remained flexible to meet the changes in our market. Emphasis is now being placed on the family to encourage harmonious family development. Education is also emphasized since it is clearly the primary method of escaping poverty. Our new programs will emphasize job preparation.

ENVIRONMENTAL SCAN:

RENTAL HOUSING (INTERNAL)

\section{RESOURCES}

\section{People}

The Rental Housing Department consists of a staff of ten, primarily program representatives $(P / R)$. On a daily basis they work with applicants, participants, and property owners. The department is supervised by the Director of Rental Housing who is assisted by the Senior Program Representative and a clerk typist. All the staff members meet minimum requirements for their positions. Four of the program representatives came to the department from private property management firms already knowledgeable of Section 8 Regulations. Two representatives have had on-thejob training and have been with the Authority over nine years and the last two representatives have been promoted from within having served in the Facilities Management and Community Services Departments. The staff exhibits good work habits and successfully meet all their goals, objectives and performance indicators. All P/Rs must be skilled in executing leasings, recertifications and conducting unit inspections. At present, each P/R is assigned duties in the categories of occupancy, leasings and recertifications. Most of the staff is cross-trained to perform any department function.

Communication is one of the department's greatest weaknesses when dealing with Section 8 clients and property owners. Having to respond to complaints, damage claims, and other problems can cause a gap between the representatives and their clients. Communication breaks down when program representatives are provided information by only one of the two parties they deal with in leasing units. On numerous occasions, a property owner will contact a different $P / R$ regarding a tenant or lease problem and word fails to reach the appropriate $P / R$ dealing with that owner and resident.

The department requires continuous training to keep the staff informed of the constantly changing program regulation requirements. The staff receives interdepartmental training at staff meetings in order to keep up with current updates to the Federal Register as well as with other issues that assist them in their job performance. All 
staff members have attended the Authority's training in goais, mission, planning and policy. Specialized training is available for the representatives in housing quality standards (HQS), Certifications, and Occupancy.

\section{Economic}

The number of Section 8 units administered by the department has increased by 1,500 over the last ten years from 800 units to 2,300 units. An increase in the number of leased units results in an increase in earned administrative fees. With these additional fees, the department has been able to increase in staff size, competitive wages and updated equipment.

The entire department's personnel, equipment, and supplies costs are paid for by fees earned for operating the program. Our primary area of concern is HUD's proposed change in the formula for computing Fair Market Rent (FMR), which would decrease our administrative fee. HUD is proposing to base FMRs at $40 \%$ of the area's median rent. Presently it's at $45 \%$. This will result in a reduction of earned administrative fees. HUD is also proposing to reduce the current fee percentage earned, which is currently varied depending on the program type, to a straight $7 \%$. Based on the current year's earned fees, we would realize a $\$ 154,338$ reduction. The merging of the Certificate and Voucher Programs has brought the fees to a blended rate. The department generated $\$ 1.36$ million in administrative fees in FY 1995.

\section{Information}

Our principal source of information on the day-to-day operations of the program is provided by the staff through a series of department generated reports. Data is entered daily in the PHA's mainframe computer (IBM System 36) and the department's free-standing personal computers. Plans call for all the department's information to be downloaded to personal computers by the end of the year. Information generated by the computers is included in the Monthly Management Report and Annual Report on Operations. The information provided includes: lease rates, turnover, number of inspections and recertifications, spatial distribution of units, rent schedules, and any other data required to make informed management decisions.

The department's staff also stays informed by attending training sessions sponsored by third-party vendors -- mostly conducted by the professional associations -- and our own in-house training program. In the next few years, numerous changes will take place affecting our programs. It is not known at this time if the department will be responsible for administering the vouchers that will be issued to public housing residents under the so-called "voucherization" of public housing.

\section{Competencies}

The department meets its established goals, objectives and performance indicators either on time or ahead of schedule. The staff's primary competency is knowledge of its day-to-day responsibilities. As stated above, the staff is well trained, is experienced, and performs well together.

The department's primary weakness is planning. Not enough is being done in anticipation of the future (mostly because HUD is constantly changing their proposed changes). Contingency plans must be prepared in order to provide a smooth transition when anticipated changes are enacted.

\section{PRESENT STRATEGY}

\section{Overall}

Our overall goal is to provide leased units of housing to qualified applicants as soon as they become available. Over the last six years we have enjoyed a lease rate of $100 \%$. The only time our lease rate was not at $100 \%$ was when the Authority received a large allocation of Section 8 units. These, however, were leased soon after the applicants identified the units they desired to live in, the proper inspections were made and the leases were executed.

\section{Department}

The department's goal is pretty much identical to the overall goal stated above. In the next year we will attempt to provide speedier service to our customers, although we already perform our inspections and recertifications considerably ahead of our current goals. Efforts will be made to assist residents in identifying and leasing better units in nicer neighborhoods.

\section{PERFORMANCE}

\section{Results}


All industry standards set by HUD are being met or exceeded. Recertifications are completed 90 days prior to the expiration date. And annual inspections are implemented 60 days prior to the expiration date. Lease rates have been maintained at a rate of $96 \%$ to earn $100 \%$ throughout the year. The performance of the department was acknowledged 4 years ago when we received HUD's Award for Sustained Performance

\section{TRENDS}

The department's workload has constantly increased as the number of Section 8 units we administer has grown. Ten years ago the department administered 800 units, now there are 2,300. The additional workload has been addressed by increasing the number of Program Representatives working for the department. We also have utilized a part-time inspector who is a retired PHA employee with experience in housing inspections.

The trend for the program is unknown at this time. HUD has proposed cutbacks in the Section 8 program, including not renewing Section 8 contracts when they expire. Congress has proposed a similar scenario beginning this year. If these plans are executed, we will end up administering a decreasing number of Section 8 units. This will result in smaller administrative fees earned impacting not only the Section 8 Program but the public housing program as well (each year's Section 8 reserve has been used to make up for shorfalls in that underfunded program).

Another unknown is the impact and what role the department will play in administering the so-called "voucherization" of public housing units. HUD has proposed a phasing-in of this of this initiative whereby existing residents in public housing would receive a voucher. With the voucher they would determine where they want to live. They could stay in the public housing unit/development where they currently reside, or they could move to a private owned dwelling unit in the private housing market -- the choice would be theirs. HUD has not finalized how the program will be administered. If the vouchers and process is the same as we currently administer, we would logically oversee the program.

\section{SHARE OF MARKET}

The 2,300 units of Section 8 administered by the department comprises $3.4 \%$ of the total number of housing units, $3.9 \%$ of the 58.905 occupied units, and $6.1 \%$ of all rental units in the City of Providence. Increasingly recipients of Section 8 certificates and vouchers are exercising their right to move to other cities with their Section $8 \mathrm{~s}$. This is allowed under the portability feature of the assistance. However, residents in other cities are also moving to Providence with their Section 8 assistance. As of June 30, 1995, the department administers 222 Section 8 certificates or vouchers outside the city's legal boundaries. We currently administer 160 Section 8 certificates and vouchers from other cities, that is, families who have moved to Providence with their certificates or vouchers from other jurisdictions.

\section{STABILITY}

The department has exhibited staying power by working together and achieving all of their established goals. A majority of the staff has been together for five or more years. Only the recently hired have not been with the group as long, although two of them served in other departments at the PHA.

\section{EFFICIENCY}

The department has proven its efficiency year after year by actually earning more in administrative fees than it costs to run the department. For FY 1995 the department earned $\$ 700,000$ more in administrative fees than was necessary to operate the department. This additional amount saved the PHA from experiencing a deficit this year.

\section{FLEXIBILITY}

The department has responded well to changes in program regulations in the past and is prepared to deal with forthcoming changes.

ENVIRONMENTAL SCAN:

SECURITY (PUBLIC HOUSING UNIT) (INTERNAL)

\section{RESOURCES}




\section{People}

The Public Housing Unit (PHU), is a unit of the Providence Police Department. It consists of regular police officers from the department who are assigned exclusively to the Providence Housing Authority developments. The size of the PHU has ranged from two to seven officers.

A majority of the officers assigned to the unit have years of experience patrolling the public housing developments. Two of the officers began their career as Community Protection Officers (CPO) in the 1970s. The C.P.O.s, who were funded by a federal grant program, of that time had the sole duty of patrolling the housing developments in the city. Through the years the officers assigned to this unit have secured a knowledge of the criminal element which resides in or frequents the developments. Most important, however, is the relationship that the officers have with management and the staff of the PHA and also with the residents of the developments. Throughout the years the officers have been able to gain and maintain the trust of most of the residents of the developments.

A lack of sufficient manpower to provide 24 hour a day coverage is the primary weakness in the unit. Also, the inability to consistently follow-up on all major crimes and reports tends to hamper the impact the officers can have on crime in the area.

The officers have attended seminars pertaining to Crime in Public Housing and also Gang Violence. These seminars were conducted by professional criminologists and sponsored by the PHA. Computer training was provided also by the PHA who installed a computer in the PHU office located at Hartford Park. Some of the officers have also attended seminars pertaining to Crimes Against the Eldenly and Domestic Violence sponsored by the police department. The officers also attend the police departments in-service training programs when they are offered

The City of Providence pays for the regular salaries and benefits for the officers through the department's city budget allocation. The PHA provides money for the overtime needed for the extended patrol hours, which have averaged 100 to 125 hours per week.

All of the officers are graduates of the Providence Police Academy. The experience gathered by the original officers throughout the years has been filtered down to the newer officers of the unit. The two officers who have been with the unit the longest have over 45 years experience in public housing.

\section{Economic}

The Public Housing Unit is primarily funded by the Providence Police Department. The Department pays the salaries of the officers assigned to the PHU, however,

overtime hours are paid for by the PHA. The PHA pays for these additional hours in order to allow the members of the PHU to be assigned these hours exclusively.

In the past five years (FY 1991-FY 1995) the PHA expenditures for the PHU have averaged $\$ 127,073.93$ with a low of $\$ 109.959 .52$ in FY 1992 and a high of $\$ 145,145.78$ in FY 1995. While spending over the past five years has not risen in a consistent manner, it does appear that there is a trend towards increased levels of spending. Furthermore. for the current year (FY 1996) the rate of expenditures for overtime hours threatens to exhaust budgeted funding long before the end of the fiscal year. By August 19, (14\% of FY 1996) $\$ 26,647.48$ had been spent. This represents $21 \%$ of the average annual expenditures for the past five years. Increased expenditures along with cuts in CGP funds through which the PHU over time is paid is obviously a problem that will have to be addressed.

The PHU is also responsible for overseeing the recruiting, training and oversight of the PHA's Elderly Development Security Program. This program is funded through the R. 1. Department of Elderly Affairs (75\%) and the City of Providence $(25 \%)$. Over the last three years the program has been funded by the state at $\$ 140,000$ per annum Due to state budget constraints, the funding has been reduced by $40.1 \%$ to $\$ 77,000$. This funding reduction will have to be made up through other sources or the number of security guard hours, currently at 12 hours per evening. will need to be reduced. If the city commits to retain funding at its current rate, the PHA may be able to shift Comp Grant Management improvement funds

\section{Information}

Open lines of communication between the police. PHA's management and residents provide all those involved with a clear picture of the problems and the possible solutions. The relationship is strong enough that the PHU is sometimes considered a "department" of the PHA. As mentioned above, the PHA has provided invaluable assistance in the form of computer technology, including tenant a database of all residents and a program to database arrests and criminal identification. In the near future these databases will be improved upon and 
expanded. Plans call for a database indicating the geographical locations of all crimes plotted on site maps. This information will be useful to better determine patrol and deployment patterns for the PHU and other law enforcernent entities

\section{Competencies}

The unit seems to provide an acceptable amount of basic police services to the residents and the Authority. The officers also have a good working relationship with management and residents of the developments. Several of the officers, due to their tenure in the unit, are very familiar with the developments they patrol. They have seen an entire generation of children grow up and become adults. This familiarity with the residents and the trust and rapport they have with the residents makes it easier to obtain information on the illegal activities taking place at certain developments. The PHU as a whole and individual members of the unit have received recognition and commendations from the department for their performance

A major improvement that would heighten the effectiveness of the unit would be an extension of the hours of patrol coverage and the time needed to follow-up on the problems reported to the unit.

Incompetence, although not really a problem for the unit, is dealt with through the chain of command, the "coaching and counseling technique" and peer review. Adjustments to needs and demands of all involved are constantly being made. If team members do not "fit" in the unit they usually are transferred to other police units. There has been very little turnover in the core group of the unit over the years.

\section{PRESENT STRATEGY}

\section{Overall}

In a crime problem area, the officers have taken a "zero tolerance stand" to assist in addressing the problems. In this situation not only are arrests made but summons' are issued and numerous dispersals are made. Problem causing outsiders or residents are reported to management who will determine if further "management" action should be taken. The officers have also secured an informational network with the "good" tenants in the developments, and these tenants have greatly contributed to the effectiveness of the unit in addressing the problems.

Current strategy calls for patrol coverage of the PHA's developments for up to 16 hours a day, 7 days a week when possible. The schedule depends on the availability of unit members, the intelligence that is available to the unit, and whether or not trouble is anticipated (such as on "check day" when a majority of residents receive their public assistance and more problems usually occur).

The current shortcoming of security is a lack of 24 hour coverage resulting in a situation of "when the cops go home, the crooks come out". At times a lack of aggressiveness by management greatly impairs the impact on a problem the unit has addressed and contributes to the problem reoccurring.

\section{Department}

For the most part, all of the officers assigned to the unit participate in street operations and patrol operations. This greatly increases the visibility needed in the problem areas. Most of the administrative duties are divided between the sergeant in command of the unit and the two senior patrolmen of the unit.

An extension of patrol hours and coverage would greatly assist the officers in dealing with the problems in the developments and would allow for more time to conduct follow-up investigations.

\section{PERFORMANCE}

The Public Housing Unit is one of the most active units on the Providence Police Department. The unit was recognized for its performance in 1992 when it won the Public Safety Commissioner's Award for Best Overall Performance on the Providence Police Department. Several individual members of the unit have also received recognition for their performance in the line of duty. They also oversee the PHA's Elderly Security Program which received a National Association of Housing and Redevelopment Officials Award of Merit-Client and Resident Services in 1992. Data concerning the number of responses to calls for service, arrests and security work orders is covered in the next section.

\section{TRENDS}


The number of arrests have been increasing. In calendar year 1994, the unit made 507 arrests, the most ever made in a year by the housing unit. As of September 1995, the unit has made over 530 arrests, a $4.5 \%$ increase. Radio calls for service are also higher and this is attributed to the number of apartments that have been rehabilitated and occupied. Almost half of the Hartford Park and Manton Heights developments were vacant while modernization took place. They are at close to $100 \%$ occupancy now. Another contributing factor to the increase in arrests and the number of calls for assistance is the number of youth living in PHA developments. As of July 1, 1995 more than $50 \%$ of the population at PHA sites was less than 18 years of age. The average age of the population at family developments is 21 years. Numerous studies have indicated there is a correlation between age and crime rates, particularly certain types of drug-related crime.

Police responses to calls for service have fluctuated year-to-year. In FY 1992 there were 1,335 responses: in FY 1993, 1.644; in FY 1994, 1,557; and in the first seven months of FY 1995, 1,246 calls for service. This would project to an monthly average of 178 calls or 2,136 calls for service, an increase of $37.2 \%$. (the figure has to be projected because the Providence Police Department's Computer Bureau is unable-or unwilling-to provide this information anymore)

The trend in arrests has increased substantially. In FY 1994 there were 252 arrests by the PHU; in FY 1995 there were 496 , a $96.8 \%$ increase! Over the three fiscal years prior to this past fiscal year, the average annual number of arrests was 263. FY 1995's arrests exceed the three previous years' average by $88.6 \%$. The increase in arrests can be attributed to several factors: (1) the percentage of population less than 18 years of age, (2) the increase in the number of occupied units, and (3) more aggressive patrolling by the PHU with greater size unit.

Felony and narcotics arrests also increased from the previous year. In FY 1994 there were 26 felony and 64 narcotics arrests. In FY 1995 the same categories were $30(+15.4 \%)$ and $94(40.6 \%)$ respectively.

PHA Security Work Orders followed the same trend as arrests. Total Security Work Orders rose $38.6 \%$ in FY 1995 from 1,715 to 2.378. Code \# 3 security work orders (criminal) rose $115 \%$ from 647 in FY 1994 to 1,390 in FY 1995

It is predicted that there will be a general increase in crime in PHA developments. Most of the criminal activity will be drug-related. Consistent follow-up by the police to manage problem tenants, a more aggressive stand by management to rid the developments of problem tenants, and also an extension of patrol hours are needed to keep the crime rate down

\section{SHARE OF THE MARKET}

The Public Housing Unit has the primary responsibility of patrolling public housing developments. They patrol an average 10-16 hours per day. On their off hours, regular police from the area's patrol post respond to PHA developments. An earlier analysis, when that information was made available in January of this year, indicated that the PHU responded to $80-85 \%$ of all calls in public housing. Other law enforcement agencies include the R. I. State Police, F.B.I. Attorney General's Drug Task Force, Bureau of Tobacco and Firearms, and HUD's Office of inspector General (Investigations). The PHU provides the bulk of the security services including supervising the PHA's EIderly Developments Security Guards throughout the night.

\section{STABILITY}

Historically, the housing developments have been patrolled by 4 entities that were responsible for law enforcement, even though some were not regular Providence policemen at the time The CPO and HSF Programs were both LEAA funded programs. The organizations were:

1. The Community Protection Program (1971 - 1977)

2. The Housing Security Force (1977-1982) The HSF was disbanded in 1982 and seven Housing Security Officers were absorbed by the Providence Police Department. These officers still provided protection to PHA developments in 1982 and 1983.

3. PPD Neighborhood Response Team (1985-1989) Four officers assigned to patrol the developments.

4. Public Housing Unit (1990-present) A separate unit is created to patrol public housing developments. The strength of the unit has fluctuated from two to seven officers.

\section{EFFICIENCY}


In most major cities public housing developments are patrolled by Housing Authority Police Forces. In Providence, the PHA has only had to absorb the cost of the extended hours of coverage and some of the equipment needed by the officers of the PHU. Having a unit dedicated to patrolling public housing is far more efficient than allowing the area's patrol car to respond to all calls for service. By having a special unit deal with public housing problems using the Community Police model, the responsibility is much more clearly defined.

\section{FLEXIBILITY}

The officers have had many environmental changes to adapt to over the years. The most notable was the pervasive "ghetto" atmosphere before the developments were renovated and cleaned up of the criminal problems. That "ghetto" atmosphere has been eliminated and the officers find themselves dealing with a greater majority of lawabiding citizens than criminals

The organization must examine its physical, financial, personnel, and other resources used to determine what type of new services to provide to clients, the PHA and its residents. It appears that the housing unit has been able to keep ahead of other PHA police organizations with methods of patrol and other police tactics used in dealing with crime in public housing. Only by being able to quickly address new problems or having the flexibility to address these problems can the unit maintain its tactical advantage in the developments. 
THE FOLLOWING WORKSHEET WAS USED FOR THE PROVIDENCE HOUSING AUTHORITY'S STRATEGIC PLAN 2000

\section{EXTERNAL ENVIRONMENTAL SCAN WORKSHEET}

An external scan focuses on those factors external to the organization which can influence funding and participation. The Bryson Model identifies three areas for which information must be obtained

Forces/Trends (People, Economic, Social, Technological), Clients/Customers, and

Competitors/Collaborators

FORCES/TRENDS

People:

Who are the people and/or organizations that have an impact on the organization? In what ways do they affect the organization?

Which are the most influential?

Why do they have an impact on this organization?

What are their objectives and reasons for their concern with the organization?

What could cause this situation to change?

relationship

What impact will changes have on an organization's publics and their

Economic: with it?

What forces or trends in the economy will affect what we provide/perform? Will the economic situation remain stable or change having a direct impact on

the delivery of our services?

Social:

What changes in society will have an affect on our services?

What are the projected trends for the future?

Technology:

What forces/trends in technology will affect the method in which we

CLIENTS/

CUSTOMERS:

provide/deliver our services?

Who are our clients? Who should they be?

What are they "buying"?

What could cause this situation to change?

Why do they "buy" or participate?

How do they make decisions to "buy" or participate?

COLLABORATORS/ COMPETITORS:

Who are they?

Who should they be?

What are they supporting?

What could cause this to change?

Why do they provide support?

When do they provide support?

How do they make decisions to provide support?

COMPETITION: Who are the major competitors?

How do they compete?

What are their strengths and weaknesses that will pose problems and

opportunities? These may include: costs and fees, access to clients and supporters, image, type of client base, personnel, and other resources. 


\section{THE FOLLOWING WORKSHEET WAS USED FOR THE PROVIDENCE HOUSING AUTHORITY'S STRATEGIC PLAN 2000}

\section{INTERNAL ENVIRONMENTAL SCAN WORKSHEET}

An internal environmental scan, also known as situation analysis, is an assessment of an organization's present position in its current environment. This involves the identification of present and potential problems and opportunities in the organization.

To assess the performance of their organizations, managers must ask themselves questions which relate to critical areas of performance.

\section{RESOURCES:}

People: Who are the people that work for the organization?

What strengths do they bring to the organization?

What are their weaknesses?

What type of training is available?

How are they compensated?

What is their skill level to perform their mission?

Economic: What have been the financial trends over the last ten years?

What areas of concern are there?

What areas of funding are we secure in?

What trends do we anticipate for the future (1-3-5 years)?

Information: What resources are currently available to provide information to decision-makers? What are the likely trends in the next 3-5 years?

What improvements can be made to the system?

Competencies: What does the organization do well?

Where is there need for improvement?

How are incompetencies dealt with?

\section{PRESENT STRATEGY:}

Overall: What strategies are undertaken to complete our mission?

What are the shortcomings of existing strategy?

Department: Is the department organized to meet the mission?

Are there changes that could be made to improve performance?

\section{PERFORMANCE:}

Results: What has been the performance of the organization as measured against industry standards?

What has performance been compared to established goals and objectives?

Has the mission been achieved?

What more needs to be accomplished?

What has been the past performance over the last $3-5$ years?

\section{TRENDS} support?

What are the significant trends in the organization's programs, services, participation, and 


\section{SHARE OF MARKET}

How much of the market does the organization have in relation to competitive organizations?

\section{STABILITY}

Has the organization demonstrated "staying power"?

\section{EFFICIENCY}

Has the organization been cost effective in the utilization of facilities, personnel, and other resources?

\section{FLEXIBILITY}

Has the organization been able to adapt to market and environmental changes?

The organization must examine its physical, financial, personnel, and other resources used to provide services to clients. Two critical questions are

1. What key competitive advantages does the organization have?

2. How can the organization maintain its competitive advantages and overcome its competitive disadvantages?

\section{AREAS FOR ENVIRONMENTAL SCANS (SITUATION ANALYSIS) AT PHA:}

1. Political

2. Financial/Economic

3. Organization

4. Personnel

5. Physical Properties 
THE FOLLOWING QUESTIONNAIRE WAS USED FOR THE PROVIDENCE HOUSING AUTHORITY'S STRATEGIC PLAN 2000

\title{
PROVIDENCE HOUSING AUTHORITY STRATEGIC PLANNING PROCESS $-1995-$
}

\author{
EXTERNAL STAKEHOLDER ANALYSIS
}

\section{INTRODUCTION}

The Providence Housing Authority is in the process of updating its strategic plan. Part of this process involves receiving input from external sources that are involved in or affected by the operations of the Providence Housing Authority.

The following booklet begins with a brief description of the strategic planning process. The remainder of the booklet is designed to elicit your opinions and observations regarding the Providence Housing Authority. We would greatly appreciate your assistance in providing us with the necessary information for updating our strategic plan. Your participation in this process by completing this survey will greatly enhance our ability to plan and implement effective strategies that will meet the needs of those we exist to serve. Your help is appreciated as we prepare to met the challenges of providing the highest level of services possible within the context of a changing social environment. 


\section{THE STRATEGIC PLANNING PROCESS}

Strategic planning is defined as a process by which an organization envisions its future and develops the procedures and applications to achieve that end. When done correctly, strategic planning is an ongoing function that drives the organization to do better and helps to create its future

Strategic planning places emphasis on:

- Action

- Consideration of a broad and diverse set of stakeholders

- Attention to external opportunities and threats

- Attention to internal strengths and weaknesses

This process will guide the Providence Housing Authority by identifying issues and creating strategies to address these issues. This process will help to define both our mandated role as well as a vision for our potential role as social service provider. Many organizations mistakenly assume that their activities are limited by their mandated role. Part of this process expands the scope of the agency's role to include additional social service roles. This full range of opportunities is then narrowed to include only those activities that fall within the proper role of the organization within the larger community. The resulting outcome is the formulation of the mission statement. The following graphic depicts this process.

\section{STAKEHOLDER ANALYSIS}

Stakeholder analysis is an important component of the strategic planning process. The stakeholder analysis is important because the strategic planning process involves identifying and resolving issues, examining possible futures and the implications of current actions and environmental conditions (both internal and external) and asks questions about the appropriate role of the organization. In defining the organization's mission statement, the members of the strategic planning process should gather and consider input from the stakeholders.

A stakeholder is defined as "any person, group, or organization that can place a claim on an organization's attention, resources or output, or is affected by that output." The key to an organization's success lies in the satisfaction of its stakeholders. Organizations often fail to meet with success because they create an atmosphere in which stakeholders feel the organization is working against their interests.

Question 1.

What is your relationship to the Providence Housing Authority?

Question 2.

How long have you been involved with activities related to the Providence Housing Authority and its operations? 
Question 3.

In what ways does the Providence Housing Authority and its operations and activities affect you?

Question 4.

In what ways do you affect the operations and activities of the Providence Housing Authority?

\section{MANDATES}

In preparing a strategic plan, the organization should consider both informal and formal mandates. Mandates are the external expectations placed upon the organization. It is important to note that mandates need not completely define its mission. Two fundamental mistakes that organizations often make are to see themselves as more constrained by mandates than they really are, and to assume that if they are not explicitly told to do something, then they are not allowed to do it. As the strategic planning process deals with questions concerning the agency's proper role in the community, the agency's mission statement often goes beyond the stipulations required by formal mandates (legislation, ordinances, charters, articles, and contracts.)

Question 5.

What do you expect from the Providence Housing Authority in terms of programs and services?

Question 6. What do you see as the Providence Housing Authority's mandate? (What do you think the PHA's legal responsibility is within the city of Providence?)

\section{MISSION}

An organization's mission provides the social justification for its existence. This mission statement is used to define the organization's purpose, direction and future. The mission is broader than the mandated obligations but is more refined and directed than the potential ideals.

Question 7.

Given what you have read, heard, and concluded from your own experiences, what are the most pressing needs to be addressed by the Providence Housing Authority?

Question 8

Think beyond what you consider possible. If the Providence Housing Authority were to become the perfect agency, what characteristics and attributes would you use to describe it? What characteristics and attributes would you use to describe the ideal public housing development? 
Question 9.

What do you see as the proper role of the Providence Housing Authority in the city of Providence?

Question 10.

Please write a statement summarizing your ideas of the Providence Housing Authority's primary goals and core values

V. SWOT

SWOT stands for strengths, weaknesses, opportunities and threats. The strengths and weaknesses represent what the organization faces internally and the opportunities and threats are derived from external sources.

Question 11.

In what ways is the Providence Housing Authority a unique organization for the city of Providence?

Question 12.

How would you rate the overall performance of the Providence Housing Authority?

Outstanding Above Average Average Below Average Unacceptable

Question 13.

Given your views of the perfect agency, where is the Providence Housing Authority now? Paint a truthful picture of the PHA. What aspects of the PHA's operations are unacceptable? Which are excellent?

Question 14.

Are there any external opportunities that you see that might help the Providence Housing Authority better meet the needs of the citizens of Providence?

Question 15.

Do you see any external constraints that hinder the ability of the authority to carry out its overall mission as you understand it to be?

Question 16.

What factors/forces are operating at the local, state, regional, national, and global context that will impact the Providence Housing Authority and its public housing developments? 


\section{PROVIDENCE HOUSING AUTHORITY STRATEGIC PLANNING PROCESS}

$-1995-$

INTERNAL STAKEHOLDER ANALYSIS

The Providence Housing Authority is in the process of updating our strategic plan. Part of this process involves receiving input from internal sources who make possible the operations of the Providence Housing Authority

The following sections of this booklet begins with a brief description of the strategic planning process. The remainder is designed to elicit your opinions and observations regarding the Providence Housing Authority. Your input will provide us with the necessary information for updating our strategic plan. Your participation in this process by completing this survey will greatly enhance our ability to plan and implement effective strategies that will meet the needs of those we exist to serve. Your participation is vital as we prepare to meet the challenges of providing the highest level of services possible within the context of a changing social environment. 
PART ONE:

THE STRATEGIC PLANNING PROCESS

Strategic planning is defined as a process by which an organization envisions its future and develops the procedures and applications to achieve that end. When done correctly, strategic planning is an ongoing function that drives the organization to do better and helps to create its future.

Strategic planning places emphasis on:

- Action

- Consideration of a broad and diverse set of stakeholders

- Attention to external opportunities and threats

- Attention to internal strengths and weaknesses

This process will guide the Providence Housing Authority by identifying issues and creating strategies to address these issues. This process will help to define both our mandated role as well as a vision for our potential role as social service provider. Many organizations mistakenly assume that their activities are limited by their mandated role. Part of this process expands the scope of the agency's role to include additional social service roles. This full range of opportunities is then narrowed to include only those activities that fall within the proper role of the organization within the larger community. The resulting outcome is the formulation of the mission statement. The following graphic depicts this process.

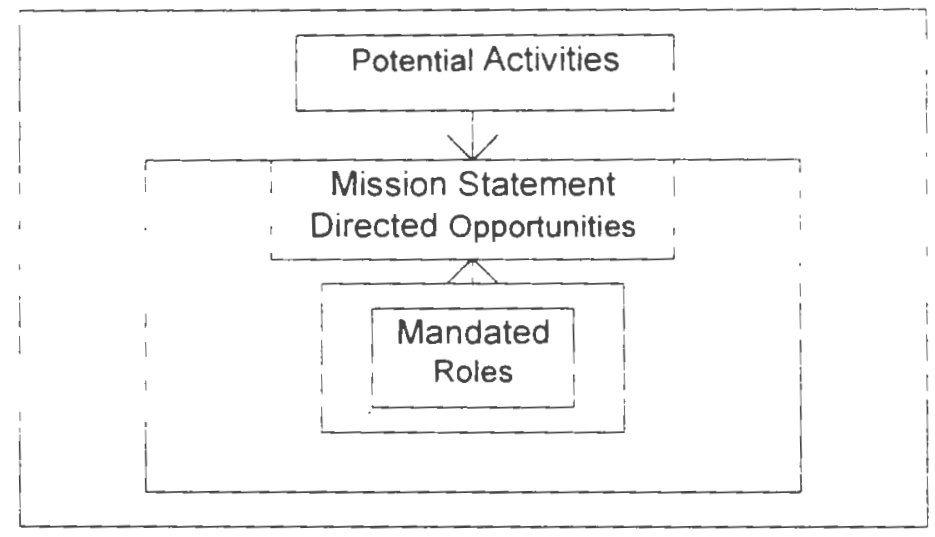

PART TWO:

STAKEHOLDER ANALYSIS

Stakeholder analysis is an important component of the strategic planning process. The stakeholder analysis is important because the strategic planning process involves identifying and resolving issues, examining possible futures and the implications of current actions and environmental conditions (both internal and external) and asks questions about the appropriate role of the organization. In defining the organization's mission statement, the members of the strategic planning process should gather and consider input from the stakeholders. 
A stakeholder is defined as "any person, group, or organization that can place a claim on an organization's attention, resources or output, or is affected by that output." The key to an organization's success lies in the satisfaction of its stakeholders. Organizations often fail to meet with success because they create an atmosphere in which stakeholders feel the organization is working against their interests

A separate external stakeholder analysis is currently being conducted to help us define the expectations and needs of the larger Providence community.

Question 1.

What is your (or work group) role at the Providence Housing Authority?

Question 2.

How long have you been responsible for current responsibilities at the Providence Housing Authority and its operations?

Question 3.

In what ways do you affect the operations and activities of the Providence Housing Authority?

PART THREE:

MANDATES

In preparing a strategic plan, the organization should consider both informal and formal mandates. Mandates are the external expectations placed upon the organization. It is important to note that mandates need not completely define its mission. Two fundamental mistakes that organizations often make are to see themselves as more constrained by mandates than they really are, and to assume that if they are not explicitly told to do something, then they are not allowed to do it. As the strategic planning process deals with questions concerning the agency's proper role in the community, the agency's mission statement often goes beyond the stipulations required by formal mandates (legislation, ordinances, charters, articles, and contracts.)

Question 4.

In terms of programs and services what do you think the Providence Housing Authority's responsibilities are to the people of Providence? List three primary and three secondary programs or services in order of importance.

Question 5.

What do you see as the Providence Housing Authority's mandates (What do you see as the legal responsibility of the PHA to the people of Providence?)

PART FOUR: 
An organization's mission provides the social justification for its existence. This mission statement is used to define the organization's purpose direction and future. The mission is broader than the mandated obligations but is more refined and directed than the potential ideals.

Question 6.

What do you see as the proper role of the Providence Housing Authority in the city of Providence?

Question 7.

What needs within the city does the Providence Housing Authority exist to fill?

Question 8.

What needs are we not meeting? List three.

Question 9.

Given what you have read, heard, and concluded from your own experiences, what are the most pressing needs to be addressed by the Providence Housing Authority?

Question 10.

Given your views of the perfect agency, where is the Providence Housing Authority now? Paint a truthful picture of the PHA. What aspects of the PHA's operations are unacceptable? Which are excellent? List what we do well. List what we need to concentrate on for improvement.

Question 11.

Think beyond what you consider possible. If the Providence Housing Authority were to become the perfect agency, what characteristics and attributes would you use to describe it? What characteristics and attributes would you use to describe the ideal public housing development?

Question 12.

If you had to write the mission statement for the Providence Housing Authority what would it be? This statement would summarize what the Providence Housing Authority's over-all goals and core values are, and what role the PHA envisions for itself within the city. (Keep this to one or two paragraphs.

PART FIVE: SWOT

SWOT stands for strengths, weaknesses, opportunities and threats. The strengths and weaknesses represent what the organization faces internally and the opportunities and threats are derived from external sources. 
Question 13.

In what ways is the Providence Housing Authority a unique organization for the city of Providence?

Question 14.

How would you rate the overall performance of the Providence Housing

Authority?

$\square$ Outstanding $\square$ Above Average $\square$ Average $\square$ Below Average

Unacceptable

Question 15.

What do you see as the Providence Housing Authority's strengths? List five with one being the greatest strength.

Question 16.

What do you see as the Providence Housing Authority's weaknesses? List five with one being the greatest weakness.

Question 17.

Are there any particular operational constraints that hinder your ability to provide services?

Question 18.

Are there any external opportunities that you see that would help the Providence Housing Authority better meet the needs of the citizens of Providence?

Question 19.

Are there factors/forces are operating at the local, state, regional, national level that will impact the Providence Housing Authority and its public housing developments? List several.

Question 20.

Do you see any external constraints that hinder the ability of the authority to carry out its overall mission as you understand it to be?

Question 21.

What barriers will hamper the achievement of the vision? Consider broad social and economic barriers as well as regulatory and procedural ones. What impact does each barrier have on maximizing the quality of Public Housing here in Providence? 
Question 22.

What federal, state, and local procedures get in the way of implementing the vision for public housing?

PART SIX:

STRATEGIC ISSUES

A strategic issue is defined as a fundamental policy choice affecting an organization's mandates, mission, values, service level, cost, financing. organization and management.

Question 23.

What important issues should we address, what are these issues and what would it look like at the PHA if we failed to address them? List at least three, but no more than five

Question 24.

What are some practical alternatives, dreams or visions through which we might address this issue?

Question 25.

What are the barriers that would prevent us from addressing these issues?

Question 26.

What are some proposals we might pursue to address these issues and overcome these barriers?

Question 27.

What actions would existing staff and management have to take to implement these proposals and in what time frame? 


\section{PROVIDENCE HOUSING AUTHORITY RESIDENT SURVEY}

\section{SCATTERED SITE}

The Providence Housing Authority is conducting a survey to evaluate the programs and services offered to public housing residents. This information will be used to update the strategic plan. Your response will help us to improve these services and programs. To keep responses confidential. please do not include your name

Please rank the following programs and services by circling a number, one (1) being poor and five (5) being excellent.

SECTION ONE: GENERAL INFORMATION.

$\frac{\text { 1. Gender. }}{\text { MALE }} \begin{array}{cc}\text { FEMALE } \\ 1\end{array}$

$\begin{array}{ccrcc}\frac{2 . \text { Age }}{\text { 2. AgER } 18} & 18-24 & 25 \cdot 34 & 35-50 & \text { OVER 50 } \\ 1 & 2 & 3 & 4 & 5\end{array}$

3. RaCe.
AFRICAN
AMERICAN HIITE HISPANIC $\begin{aligned} & \text { ASIAN/ } \\ & \text { PACIFIC } \\ & \text { ISLANDER }\end{aligned}$ OTHER

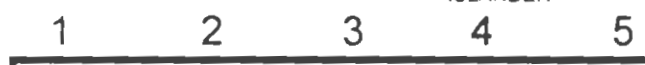

Section TWo: Management.

1. Overall level of service by the Management.

\begin{tabular}{ccccc}
\hline POOR & FAIR & GOOO & VERY GOOD & EXCELLENT \\
1 & 2 & 3 & 4 & 5
\end{tabular}

2. Quickness of response to resident problems.

POOR FAIR GOOO VERYGOOO EXCELLENT

$\begin{array}{lllll}1 & 2 & 3 & 4 & 5\end{array}$

$\frac{\text { 3. Level of follow up for resident concerns. }}{\text { POOR FAIR }}$

$\begin{array}{lllll}1 & 2 & 3 & 4 & 5\end{array}$

4. Level of fairness in rent collections.

$\begin{array}{ccccc}\text { POOR } & \text { FAIR } & \text { GOOD } & \text { VERY GOOD } & \text { EXCELLENT } \\ 1 & 2 & 3 & 4 & 5\end{array}$

\section{Explanations of PHA rules by} management. POOR FAIR GOOD VERY GOOD EXCELLENT $\begin{array}{lllll}1 & 2 & 3 & 4 & 5\end{array}$

6. Handling of annual inspections. POOR FAIR GOOD VERYGOOD EXCELLENT $\begin{array}{lllll}1 & 2 & 3 & 4 & 5\end{array}$

$\frac{7 \text { Overall concern for residents well being. }}{\text { POOR FAIR }}$

$\begin{array}{lllll}1 & 2 & 3 & 4 & 5\end{array}$

8. Level of communication between management and residents.

\begin{tabular}{ccccc}
\hline POOR & FAIR & GOOD & VERY GOOD & EXCELLENT \\
1 & 2 & 3 & 4 & 5
\end{tabular}

Section Three: MaIntenance.

1. Overall maintenance of vour home

POOR FAIR GOOD VERY GOOD EXCELLENT

$\begin{array}{lllll}1 & 2 & 3 & 4 & 5\end{array}$

2. Maintenance and upkeep of yard.

\begin{tabular}{ccccc}
\hline POOR & FAIR & GOOD & VERY GOOD & EXCELLENT \\
1 & 2 & 3 & 4 & 5
\end{tabular}

3. Utilities (heat and electricity).

\begin{tabular}{ccccc}
\hline POOR & FAIR & GOOD & VERY GOOD & EXCELLENT \\
1 & 2 & 3 & 4 & 5
\end{tabular}

4. Response to work orders. $\begin{array}{ccccc}\text { POOR } & \text { FAIR } & \text { GOOD } & \text { VERYGOOD EXCELLENT } \\ 1 & 2 & 3 & 4 & 5\end{array}$

$\begin{array}{lllll}1 & 2 & 3 & 4 & 5\end{array}$

5. Quality of painting of home.

\begin{tabular}{cccccc}
\multicolumn{1}{l}{ POOR } & FAIR & GOOD & VERY GOOD & EXCELLENT \\
1 & 2 & 3 & 4 & 5
\end{tabular}

6. Pest and rodent control. POOR FAIR GOOD VERY GOOD EXCELLENT

$\begin{array}{lllll}1 & 2 & 3 & 4 & 5\end{array}$

7. Lawn care. 

POOR FAIR GOOD VERYGOOD EXCELLENT
12
3
4
5

SECTION FIVE: SECURITY.

1 Overall security at your home.

\begin{tabular}{ccccc}
\hline POOR & FAIR & GOOD & VERYGOOD & EXCELLENT \\
1 & 2 & 3 & 4 & 5
\end{tabular}

\section{SEction Six: Site ANo NeIgHBorhood Information}

1. How long have you lived in PHA housing?

2. How many years have you lived in Scattered Site housing?

3. If you answered both questions 1 and 2, which living arrangement do you prefer, Scattered Site or large public housing developments? Why?

4. How do you feel your scattered site house fits in with the rest of the neighborhood?

5. Are there services you require which are not available in your neighborhood?

6. Do you or your children participate in social service or recreation programs in your neighborhood?

6. Do you feel welcome in your neighborhood?

7. Do you plan to move from your home soon? Why?

8. Are there things that the PHA should be doing to assist you that they are not?

\section{PLEASE RETURN TO:}

Providence Housing Authority Strategic Planning Committee 100 Broad Street Providence Rhode Island 02903 $751-6400$ ext. 285 


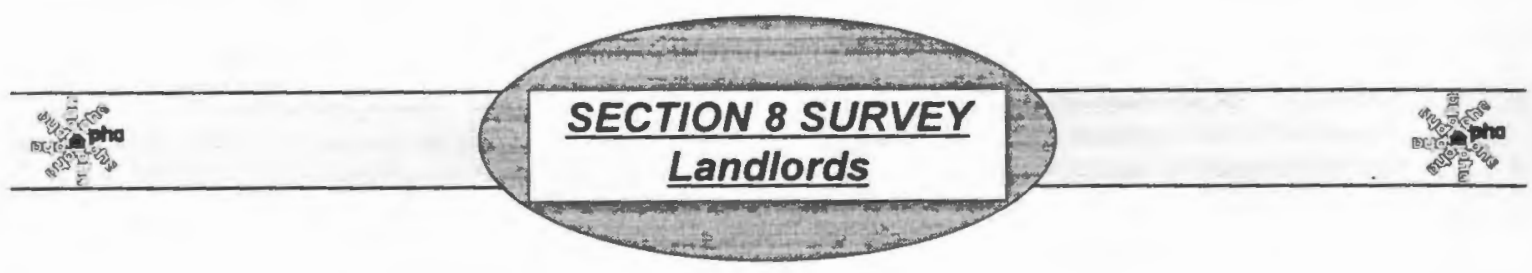

Question 1: How many years have you participated in the Section 8 program as administered through the Providence Housing Authority?

Question 2: How many section 8 units do you currently own or manage?

Question 3: Did you receive an information package from the PHA regarding guidelines and regulations when you began participating in the program?

Question 4: Was this package helpful in providing you with the information necessary to participate successfully in the Section 8 program.?

Question 5: Is there anything you would add to this informational package?

Please rank the Providence Housing Authority etaff In their ablity.to serve you in the following areas.

Question 6: Finding tenants

POOR FAIR GOOD VERYGOOD EXCELLENT

12

Question 7: Annual inspections and recertifications

POOR FAIR GOOD VERYGOOD EXCELLENT

12
Question 8 Intervening with problem tenants

POOR FAIR GOOD VERY GOOD EXCELLENT

$\begin{array}{lllll}1 & 2 & 3 & 4 & 5\end{array}$

Question 9 Overall opinion of the PHA staff POOR FAIR GOOD VERYGOOD EXCELLENT

12

3

4

5

Question 10 What changes, if any, would you recommend to improve the Section 8 program in Providence? 


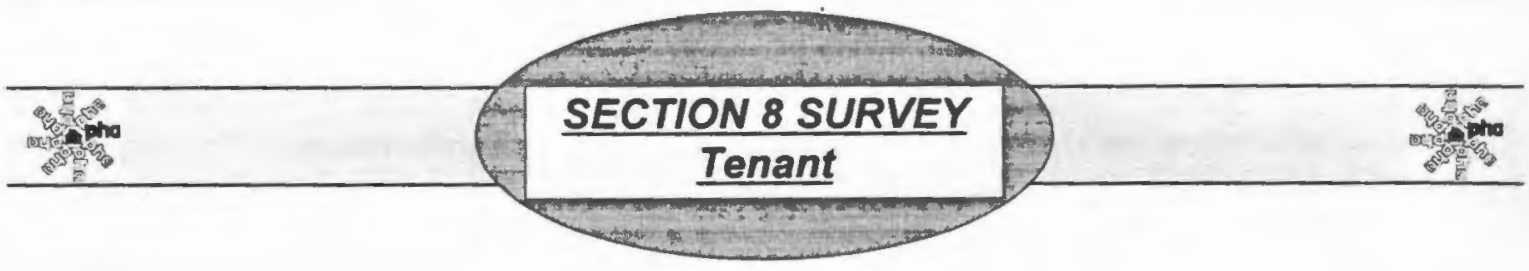

Question 1: How many years have you participated in the Section 8 program as administered through the Providence Housing Authority?

Question 2: How many times have you moved since you entered the Section 8 program and for what reasons?

Question 3: Did you receive an information package from the PHA regarding guidelines and regulations when you began participating in the program?

Question 4: Was this package helpful in providing you with the information necessary to participate successfully in the Section 8 program.?

Question 5: Is there anything you would add to this informational package?

\section{Please rank the Providence Housing Authority staff in their ablity to serve you in the following areas.}

Question 6: Finding Section 8 Apartments

POOR FAIR GOOD VERY GOOD

EXCELLENT

1

Question 7: Annual inspections and recertifications

POOR FAIR GOOD VERY GOOD EXCELLENT

12
Question 8 Intervening with problems with your apartment

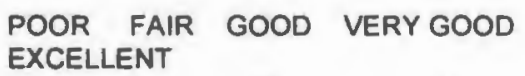

Question 9 Overall opinion of the PHA staff POOR FAIR GOOD VERYGOOD
EXCELLENT $\begin{array}{lllll}1 & 2 & 3 & 4 & 5\end{array}$

Question 10 Are there things that the PHA should be doing to assist you that they are not?

Question 11 Does the ability to select a Section 8 apartment outside of the city of Providence affect where you choose to live? If so, why? 


\section{PROVIDENCE HOUSING AUTHORITY RESIDENT SURVEY}

\section{ELDERLY DEVELOPMENTS}

The Providence Housing Authority is conducting a survey to evaluate the programs and services offered to public housing residents. This information will be used to update our strategic plan. Your response will help us to improve these services and programs. To keep responses confidential. please do not include your name.

Please rank the following programs and services by circling a number, one (1) being poor and five (5) being excellent.

SECTION ONE: GENERAL INFORMATION.
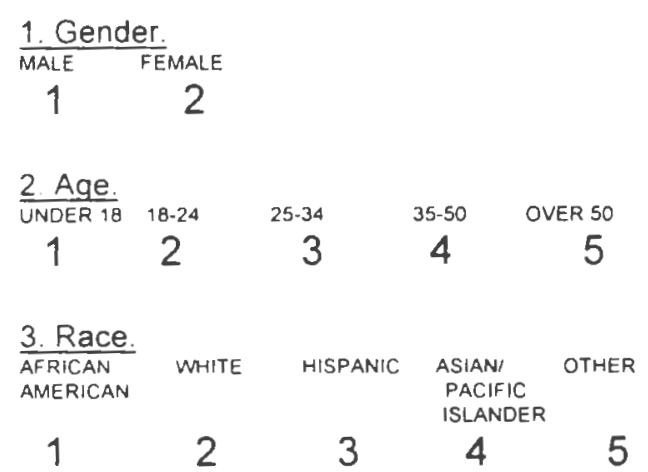

4. How many years have you lived in PHA

\begin{tabular}{llccc}
\hline \multicolumn{2}{l}{ Housing? } & & & \\
\hline UNDER 1 & $1-3$ & $3+-5$ & $5+-10$ & OVER 10 \\
YEAR & YEAR & YEAR & YEAR & YEAR \\
1 & 2 & 3 & 4 & 5
\end{tabular}

\section{SECTION TWO: MANAGEMENT.}

1. Quickness of response to resident problems. POOR FAIR GOOD VERYGOOD EXCELLENT

$\begin{array}{lllll}1 & 2 & 3 & 4 & 5\end{array}$

2. Level of follow up for resident concerns.

$\begin{array}{ccccc}\text { POOR } & \text { FAIR } & \text { GOOD } & \text { VERY GOOD } & \text { EXCELLENT } \\ 1 & 2 & 3 & 4 & 5\end{array}$

3. Level of fairness in rent collections.

\begin{tabular}{ccccc}
\multicolumn{1}{c}{ POOR } & FAIR & GOOD & VERY GOOD & EXCELLENT \\
1 & 2 & 3 & 4 & 5
\end{tabular}

4. Explanations of PHA rules by management.

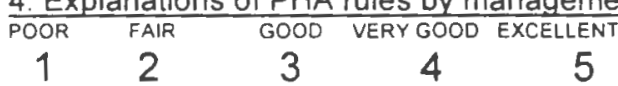

5. Handling of annual inspections.

\begin{tabular}{cccccc}
\hline POOR & FAIR & GOOD & VERYGOOD & EXCELLENT \\
1 & 2 & 3 & 4 & 5
\end{tabular}

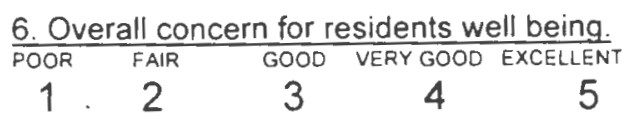

7. Level of communication between management and residents.

POOR FAIR GOOD VERYGOOD EXCELLENT

$\begin{array}{lllll}1 & 2 & 3 & 4 & 5\end{array}$

8. Overall level of service by the Management. POOR FAIR GOOD VERY GOOD EXCELLENT

$\begin{array}{lllll}1 & 2 & 3 & 4 & 5\end{array}$

SECTION THREE: MAINTENANCE.

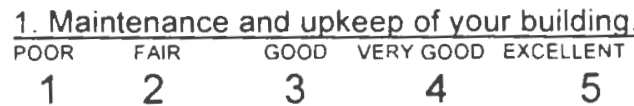

2. Maintenance and upkeep of grounds. \begin{tabular}{ccccc}
\hline POOR & FAIR & GOOD & VERY GOOD & EXCELLEN \\
1 & 2 & 3 & 4 & 5
\end{tabular}

3 Maintenance of hallways.

\begin{tabular}{ccccc}
\hline POOR & FAIR & GOOD & VERY GOOD & EXCELLENT \\
1 & 2 & 3 & 4 & 5
\end{tabular}

4. Utilities (heat and electricity).

\begin{tabular}{ccccc}
\hline POOR & FAIR & GOOD & VERY GOOD & EXCELLENT \\
1 & 2 & 3 & 4 & 5
\end{tabular}

5. Response to work orders.

\begin{tabular}{ccccc}
\hline POOR & FAIR & GOOO & VERY GOOD & EXCELLENT \\
1 & 2 & 3 & 4 & 5
\end{tabular}

6. Quality of painting of apartments.

\begin{tabular}{|c|c|c|c|}
\hline POOR & FAIR & $\mathrm{GOOD}$ & VERY GOOD \\
\hline 1 & 2 & 3 & 4 \\
\hline
\end{tabular}

7. Pest and rodent control.

POOR FAIR GOOD VERY GOOD EXCELLENT




\section{$\begin{array}{lllll}1 & 2 & 3 & 4 & 5\end{array}$}

Section Two: Maintenance. (Continued)

$\begin{array}{ccccc}\text { 8. Snow removal. } & & & \\ \text { POOR } & \text { FAIR } & \text { GOOD } & \text { VERY GOOD EXCELLENT } \\ 1 & 2 & 3 & 4 & 5\end{array}$

$\frac{\text { 9. Graffiti removal and prevention. }}{\text { POOR FAIR GOOD VERYGOOD EXCELLENT }}$

$\begin{array}{lllll}1 & 2 & 3 & 4 & 5\end{array}$

10. Trash removal.

POOR FAIR GOOD VERYGOOD EXCELLENT

$\begin{array}{lllll}1 & 2 & 3 & 4 & 5\end{array}$

$\frac{11 . \text { Laundry services. }}{\text { POOR FAR GOOD VERY GOOD EXCELLENT }}$

$\begin{array}{lllll}1 & 2 & 3 & 4 & 5\end{array}$

12. Overall maintenance of your Development.

$\begin{array}{ccccc}\text { POOR } & \text { FAIR } & \text { GOOD } & \text { VERYGOOD EXCELLENT } \\ 1 & 2 & 3 & 4 & 5\end{array}$

SECTION FouR: PHA COMMUNITY SERVICES. (SOCIAL PROGRAMS)

$\frac{1 \text { Community room activities. }}{\text { POOR FAIR }}$

$\begin{array}{llllr}1 & 2 & 3 & 4 & 5\end{array}$

2. Job training services.

$\begin{array}{ccccc}\text { POOR } & \text { FAIR } & \text { GOOD } & \text { VERY GOOD } & \text { EXCELLENT } \\ 1 & 2 & 3 & 4 & 5\end{array}$

3. Education services for adults.

$\begin{array}{ccccc}\text { POOR } & \text { FAIR } & \text { GOOD } & \text { VERY GOOD } & \text { EXCELLENT } \\ 1 & 2 & 3 & 4 & 5\end{array}$

$\frac{\text { 4. AIDS/STDS education. }}{\text { POOR FAIR GOOD VERY GOOO EXCELLENT }}$

$\begin{array}{lllll}1 & 2 & 3 & 4 & 5\end{array}$

5 . Substance abuse prevention programs. POOR FAIR GOOD VERY GOOD EXCELLENT

$\begin{array}{lllll}1 & 2 & 3 & 4 & 5\end{array}$

6. Recreational Activities for adults.

\begin{tabular}{ccccc}
\hline POOR & FAIR & GOOO & VERY GOOO & EXCELLENT \\
1 & 2 & 3 & 4 & 5
\end{tabular}

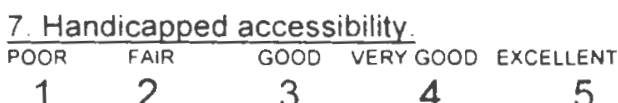

8. Access to medical care

\begin{tabular}{ccccc}
\hline POOR & FAIR & GOOD & VERY GOOD & EXCELLENT \\
1 & 2 & 3 & 4 & 5
\end{tabular}

9. Overall level of community services.

POOR FAIR GOOD VERY GOOD EXCELLENT

$\begin{array}{lllll}1 & 2 & 3 & 4 & 5\end{array}$

10. Overall community services for adults. POOR FAIR GOOD VERY GOOD EXCELLENT

$1 \cdot 2 \quad 3 \quad 4 \quad 5$

SECTION FIVE: SECURITY.

1. Police response time to calls.

POOR FAIR GOOD VERYGOOD EXCELLENT

$\begin{array}{lllll}1 & 2 & 3 & 4 & 5\end{array}$

2. Level of concern shown by police.

POOR FAIR GOOD VERYGOOD EXCELLENT

$\begin{array}{lllll}1 & 2 & 3 & 4 & 5\end{array}$

3. The effectiveness of PHA security guards. POOR FAIR GOOD VERY GOOD EXCELLENT

$\begin{array}{lllll}1 & 2 & 3 & 4 & 5\end{array}$

4. Overall security at your development. POOR FAIR GOOD VERY GOOD EXCELLENT

$\begin{array}{lllll}1 & 2 & 3 & 4 & 5\end{array}$

SECTION Six: TenantS Association

1. The degree to which your Tenants Association represents your concerns. POOR FAIR GOOD VERY GOOD EXCELLENT

$\begin{array}{lllll}1 & 2 & 3 & 4 & 5\end{array}$

2. The level of communication between you and your tenants association. POOR FAIR GOOD VERYGOOD EXCELLENT $\begin{array}{lllll}1 & 2 & 3 & 4 & 5\end{array}$

3. The overall effectiveness of your tenants association

POOR FAIR GOOD VERYGOOD EXCELLENT

$\begin{array}{lllll}1 & 2 & 3 & 4 & 5\end{array}$

PLEASE RETURN TO:

Providence Housing Authority Strategic Planning Committee 100 Broad Street Providence Rhode Island 02903 


\section{PROVIDENCE HOUSING AUTHORITY RESIDENT SURVEY}

\section{FAMILY DEVELOPMENTS}

The Providence Housing Authority is conducting a survey to evaluate the programs and services offered to public housing residents. This information will be used to update the strategic plan. Your response will help us to improve these services and programs. To keep responses confidential. please do not include your name

Please rank the following programs and services by crrcling a number, one (1) being poor and five (5) being excellent.

SECTION ONE: GENERAL INFORMATION.
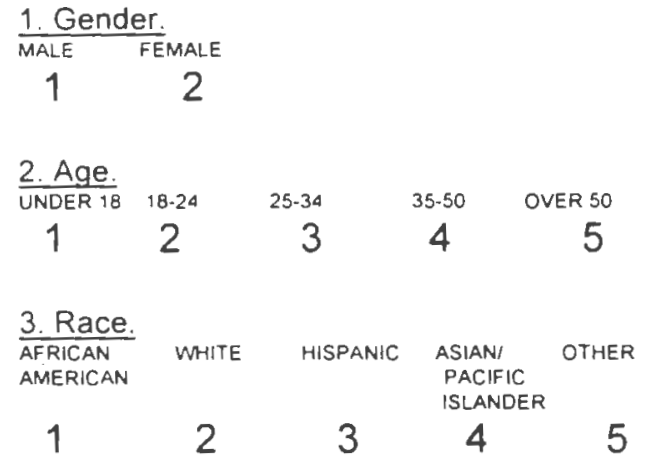

4. How many years have you lived in PHA

\begin{tabular}{|c|c|c|c|c|}
\hline Hussin & & & & \\
\hline $\begin{array}{c}\text { UNDER } 9 \\
\text { YEAR }\end{array}$ & $\begin{array}{l}1.3 \\
\text { YEAR }\end{array}$ & $\begin{array}{r}3+-5 \\
\text { YEAR }\end{array}$ & $\begin{array}{l}5 *-10 \\
\text { YEAR }\end{array}$ & YEAR \\
\hline 1 & 2 & 3 & 4 & 5 \\
\hline
\end{tabular}

\section{SECTION TWO: MANAGEMENT.}

1. Overall level of service by the Management. POOR FAIR GOOD VERY GOOD EXCELLENT

$\begin{array}{lllll}1 & 2 & 3 & 4 & 5\end{array}$

2. Quickness of response to resident problems.

$\begin{array}{ccccc}\text { POOR } & \text { FAIR } & \text { GOOD } & \text { VERY GOOD } & \text { EXCELLENT } \\ 1 & 2 & 3 & 4 & 5\end{array}$

3. Level of follow up for resident concerns.

\begin{tabular}{ccccc}
\hline POOR & FAIR & GOOD & VERY GOOD & EXCELLENT \\
1 & 2 & 3 & 4 & 5
\end{tabular}

4. Level of fairness in rent collections.

\begin{tabular}{cccccc}
\multicolumn{2}{c}{ POOR } & FAIR & GOOO & VERY GOOD & EXCELLENT \\
1 & 2 & 3 & 4 & 5
\end{tabular}

5. Explanations of PHA rules by management.

\begin{tabular}{ccccc}
\hline POOR & FAIR & GOOO & VERY GOOD & EXCELLENT \\
1 & 2 & 3 & 4 & 5
\end{tabular}

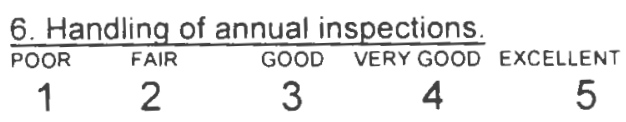

7. Overall concern for residents well being. POOR FAIR GOOD VERYGOOD EXCELLENT

$\begin{array}{lllll}1 & 2 & 3 & 4 & 5\end{array}$

8. Level of communication between management and residents.

$\begin{array}{ccccc}\text { POOR } & \text { FAIR } & \text { GOOD } & \text { VERY GOOD } & \text { EXCELLENT } \\ 1 & 2 & 3 & 4 & 5\end{array}$

SECTION THREE: MAINTENANCE.

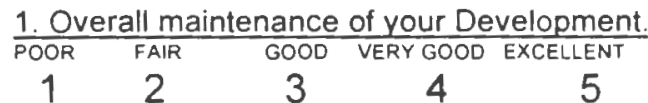

2. Maintenance and upkeep of your building. POOR FAIR $\frac{\text { GOOD }}{1}$ VERY GOOD EXCELLENT

$\begin{array}{lllll}1 & 2 & 3 & 4 & 5\end{array}$

3. Maintenance and upkeep of grounds \begin{tabular}{ccccc}
\hline POOR & FAIR & GOOD & VERY GOOD & EXCELLENT \\
1 & 2 & 3 & 4 & 5
\end{tabular} 4. Maintenance of hallways.

\begin{tabular}{ccccc}
\hline POOR & FAIR & GOOD & VERY GOOD & EXCELLENT \\
1 & 2 & 3 & 4 & 5
\end{tabular}

5. Utilities (heat and electricity).

\begin{tabular}{|c|c|c|c|c|}
\hline POOR & FAIR & GOOD & VERY GOOD & EXCELLENT \\
\hline 1 & 2 & 3 & 4 & 5 \\
\hline \multicolumn{5}{|c|}{ 6. Response to work orders. } \\
\hline$\overline{P O O R}$ & FAIR & $\overline{G O O D}$ & $\overline{V E R Y ~ G O O D ~}$ & EXCELLENT \\
\hline 1 & 2 & 3 & 4 & 5 \\
\hline
\end{tabular}

PLEASE RETURN TO:

Providence Housing Authority Strategic Planning Committee 100 Broad Street Providence Rhode Island 02903 
$\begin{array}{lllll}1 & 2 & 3 & 4 & 5\end{array}$

Section Three: Maintenance. (Continued)

$\begin{array}{ccccc}\text { 8. Pest and rodent control. } & \\ \text { POOR } & \text { FAIR } & \text { GOOD } & \text { VERY GOOD } & \text { EXCELLENT } \\ 1 & 2 & 3 & 4 & 5\end{array}$

$\frac{9 . \text { SnOw removal. }}{\text { POOR GAIR }}$ GOOO VERY GOOD EXCELLENT

$\begin{array}{lllll}1 & 2 & 3 & 4 & 5\end{array}$

10. Graffiti removal and prevention.

$\begin{array}{ccccc}\text { POOR } & \text { FAIR } & \text { GOOD } & \text { VERY GOOD } & \text { EXCELLENT } \\ 1 & 2 & 3 & 4 & 5\end{array}$

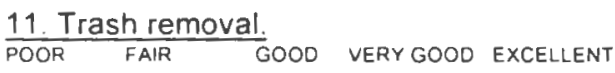

$\begin{array}{lllll}1 & 2 & 3 & 4 & 5\end{array}$

$\frac{\text { 12. Laundry services. }}{\text { POOR FAIR GOOD VERY GOOD EXCELLENT }}$

$\begin{array}{lllll}1 & 2 & 3 & 4 & 5\end{array}$

\begin{tabular}{ccccc} 
13. Up-keep of play areas. & \\
\hline POOR & FAIR & GOOD & VERY GOOD & EXCELLENT \\
1 & 2 & 3 & 4 & 5
\end{tabular}

SECTION FOUR: PHA COMMUNITY SERVICES. (SOCIAL PROGRAMS)

1. Overall level of community services.

\begin{tabular}{ccccc}
1 & FOIR & GOOD & VERY GOOD & EXCELLENT \\
\hline 1 & 2 & 3 & 4 & 5
\end{tabular}

2. Overall community services for aduits. POOR FAIR GOOD VERY GOOD EXCELLENT

$\begin{array}{lllll}1 & 2 & 3 & 4 & 5\end{array}$

3. Overall community service for youths. \begin{tabular}{ccccc}
\hline POOR & FAIR & GOOD & VERY GOOD & EXCELLENT \\
1 & 2 & 3 & 4 & 5
\end{tabular}

$\begin{array}{ccccc}\text { 4. Job training services. } & & & \\ \text { POOR } & \text { FAIR } & \text { GOOD } & \text { VERY GOOD } & \text { EXCELLENT } \\ 1 & 2 & 3 & 4 & 5\end{array}$

5. Education services for adults.

\begin{tabular}{cccccc}
\hline POOR & FAIR & GOOO & VERY GOOD & EXCELLENT \\
1 & 2 & 3 & 4 & 5
\end{tabular}

6. AIDS/STDs education.

\begin{tabular}{ccccc}
\multicolumn{1}{l}{ POOR } & FAIR & GOOD & VERY GOOD & EXCELLENT \\
1 & 2 & 3 & 4 & 5
\end{tabular}

7. Substance abuse prevention programs.

\begin{tabular}{ccccc}
\hline POOR & FAIR & GOOD & VERY GOOD & EXCELLENT \\
1 & 2 & 3 & 4 & 5
\end{tabular}

8. Recreational Activities for adults.

POOR FAIR GOOO VERYGOOD EXCELLENT

$\begin{array}{lllll}1 & 2 & 3 & 4 & 5\end{array}$

9. Recreational activities for youth.

\begin{tabular}{ccccc}
\hline POOR & FAIR & GOOD & VERY GOOD & EXCELLENT \\
1 & 2 & 3 & 4 & 5
\end{tabular}

\begin{tabular}{ccccc} 
10. & Youth sports program. & & \\
\hline POOR & FAIR & GOOD & VERY GOOD & EXCELLENT \\
1 & 2 & 3 & 4 & 5
\end{tabular}

11. Teenage pregnancy prevention program. POOR FAIR GOOD VERY GOOD EXCELLENT

$\begin{array}{lllll}1 & 2 & 3 & 4 & 5\end{array}$

12. Education services for youths

$\frac{\text { 12. Education services for youths. }}{\text { POOR FAIR GOOD VERYGOOD EXCELLENT }}$

$\begin{array}{lllll}1 & 2 & 3 & 4 & 5\end{array}$

SECTION FIVE: SECURITY.

1 Overall security at your development.

\begin{tabular}{ccccc}
\hline POOR & FAIR & GOOD & VERY GOOD & EXCELLENT \\
1 & 2 & 3 & 4 & 5
\end{tabular}

2. Police response time to calls.

$\begin{array}{ccccc}\text { POOR } & \text { FAIR } & \text { GOOD } & \text { VERY GOOD } & \text { EXCELLENT } \\ 1 & 2 & 3 & 4 & 5\end{array}$

3. Level of concern shown by police.

POOR FAIR GOOD VERY GOOD EXCELLENT

$\begin{array}{llllr}1 & 2 & 3 & 4 & 5\end{array}$

SECTION SIX: TENANTS ASSOCIATION

1 The overall effectiveness of your tenants $\frac{\text { association. }}{\text { POOR FAIR }}$

GOOD VERYGOOD EXCELLEN

2 The degree to which your Tenants Association represents your concerns. POOR FAIR GOOD VERY GOOD EXCELLENT

$\begin{array}{lllll}1 & 2 & 3 & 4 & 5\end{array}$

3 The level of communication between you and your tenants association. POOR FAIR GOOD VERY GOOO EXCELLENT

$\begin{array}{lllll}1 & 2 & 3 & 4 & 5\end{array}$

PLEASE RETURN TO:

Providence Housing Authority Strategic Planning Committee 100 Broad Street Providence Rhode island 02903 $751-6400$ ext. 285 